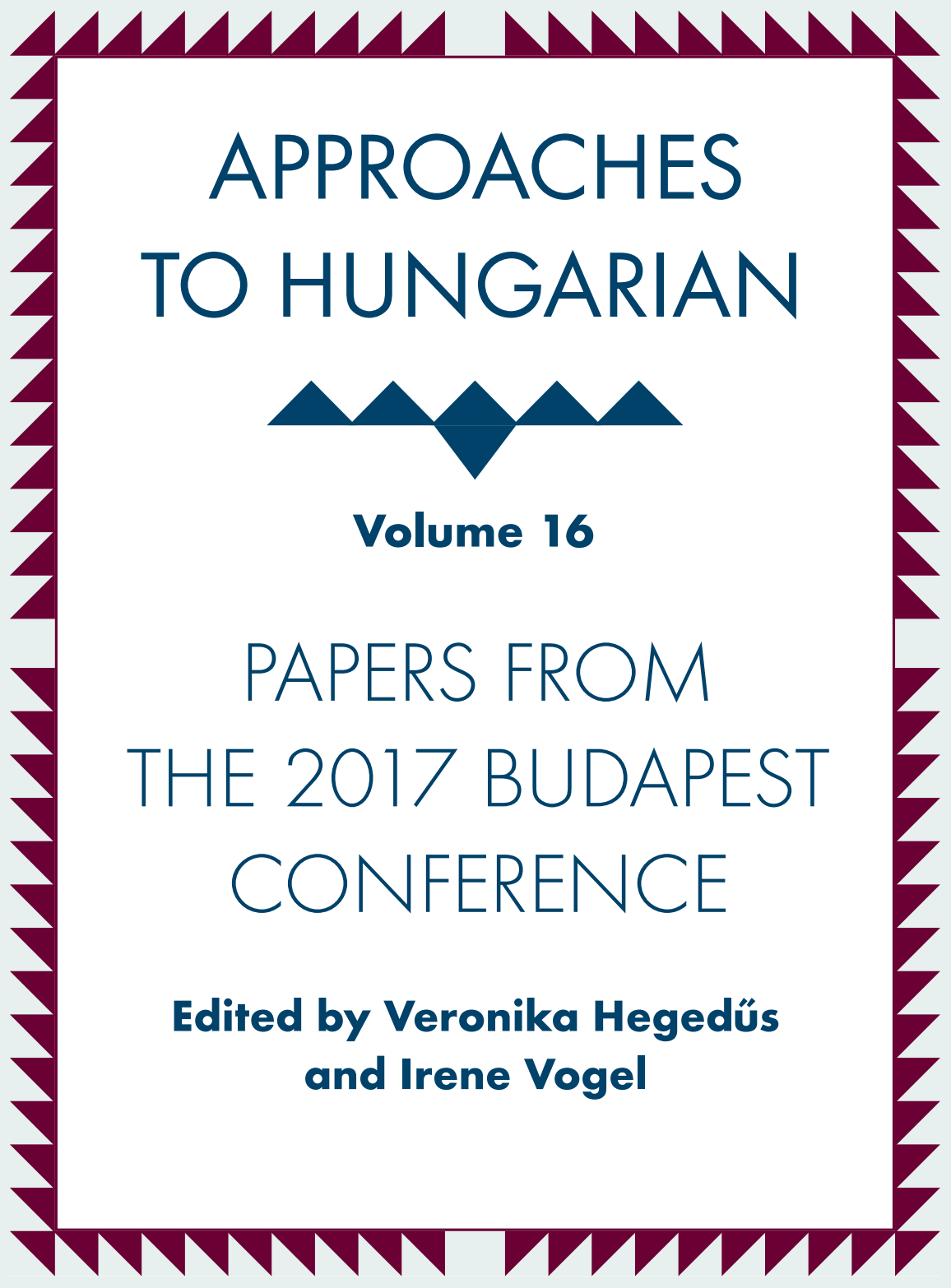

John Benjamins Publishing Company 
Approaches to Hungarian 


\section{Approaches to Hungarian (ATOH)}

Starting with Volume 11, containing papers from the 2007 Conference on the Structure of Hungarian (New York), John Benjamins Publishing Company publishes the volumes from the biennial Conferences on the Structure of Hungarian.

For an overview of all books published in this series, please see benjamins.com/catalog/atoh

Previous volumes were published by the University of Szeged Press (Vols. 1-7) and Akadémiai Kiadó (Vols. 8-10).

\section{Editor}

István Kenesei

Hungarian Academy of Sciences

\section{Volume 16}

Approaches to Hungarian. Volume 16: Papers from the 2017 Budapest Conference Edited by Veronika Hegedüs and Irene Vogel 


\section{Approaches to Hungarian}

Volume 16

Papers from the 2017 Budapest Conference

Edited by

Veronika Hegedüs

Hungarian Academy of Sciences

Irene Vogel

University of Delaware

John Benjamins Publishing Company

Amsterdam/ Philadelphia 
The paper used in this publication meets the minimum requirements of the American National Standard for Information Sciences - Permanence of Paper for Printed Library Materials, ANSI z39.48-1984.

This book was supported by a publication grant to the series editor from the Hungarian Academy of Sciences and by additional funding from the HAS Research Institute for Linguistics for open access publications.

DOI 10.1075/atoh.16

Cataloging-in-Publication Data available from Library of Congress: LCCN 97116531

ISBN 9789027204905 ( $\mathrm{HB})$

ISBN 9789027261601 (Е-BOOK)

(C) 2020 - John Benjamins B.V.

The electronic edition of this book is Open Access under the CC BY-NC-ND 4.o license. https://creativecommons.org/licenses/by-nc-nd/4.o/

This license permits reuse, distribution and reproduction in any medium, provided that the original author(s) and source are credited, for non-commercial purposes only. It does not permit the creation of derivative works without prior permission from the publisher.

This work may contain content reproduced under license from third parties. Permission to reproduce this third-party content must be obtained from these third parties directly.

John Benjamins Publishing Company · www.benjamins.com 


\section{Table of contents}

Introduction

Non-degree equatives and reanalysis: A case study of doubling patterns

in German and Hungarian

Julia Bacskai-Atkari

Anatomy of Hungarian aspectual particles

Aniko Csirmaz \& Benjamin Slade

Intervocalic voicing of Hungarian /h/

Andrea Deme, Márton Bartók, Tekla Etelka Gráczi,

Tamás Gábor Csapó \& Alexandra Markó

Contextual triggers of the Hungarian pre-verbal focus structure:

A guided production study

Tamás Káldi, Levente Madarász \& Anna Babarczy

Testing variability effects in Hungarian vowel harmony

Fanni Patay, Ágnes Benkő, Ágnes Lukács, Péter Rebrus \&

Miklós Törkenczy

With or without the definite article: On the syntax of anaphoric

possessor strategies in Hungarian

György Rákosi

Word order effects of givenness in Hungarian: Syntax or prosody?

Ádám Szalontai \& Balázs Surányi

Object agreement and locality in Hungarian: Infinitival complement clauses, second person objects and accusative adjuncts

Krisztina Szécsényi \& Tibor Szécsényi

Fixed stress as phonological redundancy: Effects on production and perception in Hungarian and other languages

Irene Vogel

(Non-)exhaustivity in focus partitioning across languages

Malte Zimmermann, Joseph P. De Veaugh-Geiss, Swantje Tönnis \& Edgar Onea

Index 



\section{Introduction}

We are pleased to present this volume of papers selected from presentations at the 13th International Conference on the Structure of Hungarian (ICSH13), held in Budapest on June 29-30, 2017. The present selection contains 10 papers, addressing current issues in the syntax, semantics, phonology and phonetics of Hungarian. Due to this variety in topics, the papers are listed alphabetically by author rather than thematically.

In the first paper Non-degree equatives and reanalysis: A case study of doubling patterns in German and Hungarian, Julia Bacskai-Atkari examines equative markers in German and Hungarian from a synchronic and diachronic point of view. The operator field of non-degree equatives is argued to be the starting point of diachronic reanalyses, resulting in changes that may or may not extend to degree equatives. Bacskai-Atkari shows that both languages exhibit doubling patterns that involved categorical reanalysis of an equative element from the matrix clause into the $\mathrm{C}$ head of the embedded clause. The historically and dialectally attested als wie 'lit. as how' in German is such a combination in non-degree equatives, and wie has also taken over as the complementizer of degree equatives. Old Hungarian doubling patterns involving oly 'as' can be attested in a combination such as oly-mint 'so as' in non-degree equatives, however, this was not extended to degree equatives. The reason for this is argued to be a difference in the transparency of the reanalyzed element in the two languages.

In Anatomy of Hungarian aspectual particles, Anikó Csirmaz and Benjamin Slade provide an account of the distribution of various aspectual adverbs in Hungarian and propose a formal semantic characterization of these elements. The central particle covered is még 'still', and the discussion extends to some morphologically related aspectual adverbs. The authors argue that a templatic definition can be given for these, and different specific meanings result from changing some components of the elements involved in the template. Such varying components of the templatic base as proposed here include the scalar argument or the focus set involved. Comparisons are drawn with the English, Hindi and Nepali counterparts of the Hungarian aspectual particles. The generalizations also extend to repetitives, which go back to the same source as még in Hungarian.

The third paper is on Intervocalic voicing of Hungarian / $h$ / by Andrea Deme, Márton Bartók, Tekla Etelka Gráczi, Tamás Gábor Csapó and Alexandra Markó. The authors investigate the amount of voicing and the sound quality (expressed 
in harmonics-to-noise ratio) of $/ \mathrm{h} /$ in syllable onset in Hungarian. They show that intervocalic position is the main factor that triggers its voicing: if /h/ appears between two vowels it is largely realized as voiced. This is in contrast with the base-line post-pausal context, where very little voicing is found. They further show that voicing happens irrespective of word boundary in the sequence and that the phonological condition of including pitch accent on the containing syllable is not a determining factor in the voicing of $/ \mathrm{h} /$. On the other hand, the backness and openness of the flanking vowel(s) play a role, as the exact amount of voicing depends on the horizontal tongue position of the flanking vowel(s) to some extent. The paper contributes to the cross-linguistic observation that intervocalic voicing of $/ \mathrm{h} /$ is a phonetic process.

The paper titled Contextual triggers of the Hungarian pre-verbal focus structure - A guided production study by Tamás Káldi, Levente Madarász and Anna Babarczy presents experimental studies that investigate contextual factors that have been claimed to be involved in the licensing of structural focus in Hungarian. These factors are identification, contrast, the availability of a set on which focus can operate and the explicitness/implicitness of this set. Two guided production studies are reported on in detail. The results of the first experiment show that contexts of identification and those of contrast facilitate the use of preverbal focus; however they also introduce further questions that the second experiment sets out to explore. The results of the second experiment confirm that preverbal focus is produced with a probability that is higher than chance when a set is given, but there is no significant difference between the conditions involving explicit versus implicit sets. The availability of sets is also suggested to be critical in exhaustive interpretations of preverbal focus.

In the paper Testing variability effects in Hungarian vowel harmony, Fanni Patay, Ágnes Benkő, Ágnes Lukács, Péter Rebrus and Miklós Törkenczy take on the task of experimentally testing harmonically mixed stems with respect to the variability they show in vowel harmony when combined with four different (harmonic) suffixes. A sentence completion task was used in the experiment, and this method was expected to overcome previous issues with data sparseness that corpus studies of this variability face. The results confirm that the height and the number of the neutral vowels involved (effects that were previously established in corpus studies), are at work, and they also show that the quality and the order of the neutral vowels also play a role. Furthermore, it is shown that there are differences between the stem types and that the four harmonic suffixes investigated do not behave in a uniform fashion. The results also confirm that native speaker reaction in an experiment matches results of corpus studies, although comparison of data collected with these different methods might not be straightforward. 
The next paper, With or without the definite article: On the syntax of anaphoric possessor strategies in Hungarian by György Rákosi, discusses anaphoric possessor strategies and the distribution of the definite article in these constructions. The paper presents the results of a questionnaire survey that the author conducted to explore the intricacies of the use of the definite article in Hungarian possessive noun phrases involving the primary reflexive maga 'self', the reciprocal anaphor egymás 'each other' and the complex reflexive önmaga 'oneself' as possessors. The main claim based on the results is that the presence or absence of the definite article determines the binding domain in the following way: In the absence of a definite article in the possessive noun phrase, the dependency between the anaphoric possessor and an antecedent that is outside the possessive noun phrase is local, but the presence of the definite article blocks the establishment of a local binding dependency between the possessor and an external antecedent. A phasebased account is proposed to account for the data, and the edge of the DP plays a crucial role.

In the paper Word order effects of givenness in Hungarian: Syntax or prosody?, Ádám Szalontai and Balázs Surányi explore the post-verbal domain of Hungarian sentences, an area that has not been studied in experimental works. The paper presents the results of a forced choice experiment, designed to explore linear placement of textually given topical constituents in the post-verbal domain. The experiment investigates whether givenness plays a role in word order in this domain, and the results show that there is a preferred order, where given phrases precede new phrases. The authors discuss possible syntactic and prosodic accounts and argue for a prosodic interface approach to explain the results. They claim that the observed word order variation is driven by the need to satisfy prosodic requirements associated with givenness. Topical givenness licenses deaccenting and the clause-internal post-verbal position has no prosodic prominence, hence it is preferred to the clause-final, prosodically more prominent position.

Krisztina Szécsényi and Tibor Szécsényi write about Object agreement and locality in Hungarian: Infinitival complement clauses, second person objects and accusative adjuncts in their paper. The paper proposes a distinction between the syntactic operations behind definiteness agreement with object and person agreement in the case of the morpheme -lak/lek (LAK-agreement), which appears with the combination of a first person singular subject and a second person object. As a diagnostic, the authors use infinitival embedded clauses, sometimes with multiple embeddings, in order to identify locality restrictions. They claim that both types of agreement are cyclic in nature but definiteness agreement is more restricted, namely it is blocked by non-object infinitives while LAK-agreement is transmitted. Definiteness agreement is claimed to depend on the availability of a 
position where accusative case can be checked, but there is no such condition on LAK-agreement. The paper also discusses variation among speakers.

In the paper, Fixed stress as phonological redundancy: Effects on production and perception in Hungarian and other languages, Irene Vogel analyzes the acoustic properties of Hungarian word stress in a large, systematically collected, corpus and considers them in relation to issues of redundancy in speech production and in speech perception (stress deafness). The Hungarian findings serve as the basis of comparison for languages with other types of stress systems, analyzed with the same methods: Turkish, Arabic and Spanish. It is demonstrated that stress predictability affects both speech production and perception, and also that its effect may be mitigated by exceptions in otherwise predictable stress languages.

In the last paper, (Non-)exhaustivity in focus partitioning across languages, Malte Zimmermann, Joseph P. De Veaugh-Geiss, Swantje Tönnis and Edgar Onea present an experimental study on exhaustivity inferences with focus partitioning in German, English and Hungarian. They show similarity in the properties of German and English focus-background cleft constructions and Hungarian preverbal focus. It is argued that these constructions use discourse anaphoric devices cross-linguistically and an existence presupposition is involved. The results of the experiment show that exhaustivity inferences are not obligatory in the languages examined, going against some previous claims in the literature, which base exhaustive interpretation on a semantic feature, and as such, are more in line with pragmatic accounts of exhaustivity.

Since the first ICSH, papers from the conferences have appeared in the Approaches to Hungarian series. ICSH1 was held in Bloomington, Indiana in 1992, and papers from that conference were published in Volume 4 of the series. Starting with Volume 11, John Benjamins Publishing Company has published the volumes from the biennial conferences; previous volumes were published by the University of Szeged Press (Vols. 1-7) and Akadémiai Kiadó in Budapest (Vols. 8-10).

ICSH13 was organized by the Research Institute for Linguistics of the Hungarian Academy of Sciences, with financial support from the Hungarian Academy of Sciences. There were 17 talks and 9 poster presentations, out of which 14 papers were submitted for consideration and 10 could be included in this Volume. The abstracts submitted to ICSH13 and the papers submitted for publication underwent a careful peer-review process. We wish to express our gratitude to the external reviewers, as well as to the people involved in the organization and running of the conference. We are also thankful to the Hungarian Academy of Sciences for the financial support, both for the organization of ICSH13 and for the publication of this volume.

The Editors 


\title{
Non-degree equatives and reanalysis
}

\section{A case study of doubling patterns in German and Hungarian}

\author{
Julia Bacskai-Atkari \\ University of Konstanz
}

The article examines reanalysis processes underlying doubling patterns in non-degree equatives in German and Hungarian. In German, the combination als wie (lit. 'as how') is attested historically and in certain present-day dialects. Traditionally, it is assumed to be a mixed pattern involving the earlier canonical equative complementiser als and the later canonical equative complementiser wie; however, more recent proposals suggest that als was in fact reanalysed from the matrix clause. While matrix equative markers and equative complementisers are surface-similar in German historically, these elements are distinct in Hungarian throughout its history. Based on the results of a corpus study on Old Hungarian, the paper argues that reanalysis from the matrix clause is indeed possible and starts in non-degree equatives.

Keywords: comparatives, complementiser, degree, doubling, equatives, German, grammaticalisation, matrix equative marker, reanalysis, similatives

\section{Introduction}

In present-day Standard German, both degree and non-degree equatives (also called similatives; see Haspelmath \& Buchholz 1998) are marked by the element wie:

(1) a. Maria ist so groß wie ihre Mutter. Mary is so tall as her.F mother 'Mary is as tall as her mother.'

b. Maria ist so wie ihre Mutter. Mary is so as her.F mother 'Mary is like her mother.' 
c. Maria ist groß wie ihre Mutter. Mary is tall as her.F mother 'Mary is tall, like her mother.'

The example in (1a) demonstrates degree equatives, while (1b) and (1c) are instances of non-degree equatives. As can be seen, the same complementiser (wie) appears in all the constructions in German; by contrast, English has a difference between as (degree equatives) and like (non-degree equatives), as demonstrated by the translations above.

The element wie is an innovation in German; the original equative complementiser was als ((al)so). This was already present in Old High German equatives, and it came to be replaced by wie during Early New High German (from the second half of the 16th century onwards). (See Jäger 2010). This is illustrated in (2) below:

(2) a. wart aber ie sô werder man geborn ... sô von was.3sg but ever so noble.M man born as from Norwege Gâwân

Norway Gawain

'But was there ever born a man as noble as Gawain from Norway?'

(Parzival 651, 8ff; Eggs 2006: 22-23)

b. waer er sô milt als lanc, er hete tugende be.cond.3sg he so generous as tall he have.cond.3sg virtues vil besezzen

many possess.INF

'If he were as generous as he is tall, he would have had many virtues.'

(Walther von der Vogelweide, Werke Bd. 1, 118f; Eggs 2006: 22)

c. dochn was dâ nieman alsô vrô alsô mîn her Gawein but was.3sg there noone so glad as my lord Gawain 'but noone was as glad there as my Lord Gawain'

(Iwein 2618f; Eggs 2006: 22)

German thus shows a complementiser change in equative constructions, namely from the original als to present-day wie. Interestingly, the combination als wie is attested dialectally and historically (Jäger 2016; see also Eggs 2006; Lipold 1983; Weise 1918). Consider the following:

(3) a. Dei Schweinsbraan schmeggd genau a so fad ais wia your roast.pork tastes exactly PRT so stale as as dei Schbinad you spinach

'Your roast pork tastes just as stale as your spinach'

(Bavarian; Jäger 2016: 260, citing Merkle 1975: 171) 
b. Das es akkerate su als wie bei eich. that.N is accurate so as as by you.PL.DAT 'It is accurate, as is at your place.' $\quad$ (Thuringian; Jäger 2016: 261)

The traditional view (Jäger 2010) is that (3) represents an intermediate stage between (2) and (1), whereby wie is an innovation in a lower (CP) projection alongside the original als (Conj for Jäger 2010 and another C for Bacskai-Atkari 2014a). However, diachronic evidence by Jäger (2016: 291-298) suggests a different process: patterns like (3) appear after the establishment of patterns like (1), and the frequency of patterns like (3) is relatively low, which is unexpected if it constitutes a significant middle stage. Jäger (2016) therefore hypothesises that there is a different reanalysis process underlying (3): namely, the matrix equative element was reanalysed into a subclause headed by wie, resulting in the double heads als wie. Such reanalysis can take place in non-degree equatives, since the presence of the matrix equative element is not necessary (1c). Later, the combination was analogically extended to degree equatives as well.

Since the element als(o) in German is historically and dialectally surfacesimilar in the matrix clause and in the subordinate clause, as in (2), the proposal of Jäger (2016) relies on the time of appearance of als wie patterns and their relative frequency. I examine similar patterns in an unrelated language. There is no surface-similarity between the matrix marker and the equative complementiser in Hungarian, which provides direct evidence for the possibility of reanalysing the matrix equative element into the subclause in non-degree equatives. Further, I argue that surface-similarity was crucial in the spread of als wie in German to degree equatives, which is not attested in Hungarian historically.

The paper is organised as follows. Section 2 describes the basic syntax of equatives in German and Hungarian. Section 3 shows how the model introduced in Section 2 can describe the changes in German. Section 4 discusses the Hungarian data and the results of the corpus study and presents the theoretical conclusions regarding the emergence of doubling patterns.

\section{The syntax of equatives}

As discussed in Section 1, present-day Standard German equatives are marked by the matrix element so and the complementiser wie, as in (1). Hungarian shows a similar distribution:

(4) a. Mari olyan magas, mint az anyja.

Mary so tall as the mother.poss

'Mary is as tall as her mother.' 


\section{b. Mari olyan, mint az anyja.}

Mary so as the mother.poss

'Mary is like her mother'.

c. Mari magas, mint az anyja.

Mary tall as the mother.Poss

'Mary is tall like her mother.'

As can be seen, the equative complementiser is mint 'as' in all cases; the matrix equative marker olyan is available both in degree equatives and in non-degree equatives. Given the similarities between German and Hungarian, it seems reasonable that they should be similar in their syntax.

Let us first consider degree equatives. As the matrix equative element - so in (1a) and olyan in (4a) - imposes selectional restrictions on the comparative standard (the subclause headed by wie and mint), I follow Lechner (2004: 22) in assuming that it takes the subclause as a complement. I also adopt the view that the $\mathrm{AP}$ is in the specifier of the functional projection headed by the matrix equative element (Lechner 2004: 22). This projection is generally referred to as DegP in comparatives (Lechner 2004; Bacskai-Atkari 2018a; see also Corver 1997 for the notion of the DegP); and I will tentatively label it as EquatP (equative phrase) in the present paper, as the projection is not tied to the notion of degree in equatives. There is an additional layer QP, above the DegP (Bacskai-Atkari 2018a: 32, following Lechner 1999: 25). The degree head moves to the $Q$ head, and the specifier of the QP can host degree modifiers; the QP is tied to the notion of degree. ${ }^{1}$ Adopting the view that both wie and mint are complementisers (cf. arguments put forward by Jäger 2010, 2016 for German, and by Bacskai-Atkari 2014a for German and Hungarian), the structure for degree equatives is given in (5a). As there is no gradable adjective in non-degree equatives like (1b) and (4b), I assume that the structure is simpler, as in (5b).

1. Modifiers like extremely, exactly and far show agreement with the particular degree, e.g. far taller is possible but * exactly taller is not. For this reason, such modifiers were already located in [Spec,QP] by Corver (1997: 154-161), albeit the relative position of his QP in the entire degree expression differs from that of Lechner (1999: 25) and Bacskai-Atkari (2018a: 32). Another argument in favour of the QP goes back to Bresnan (1973): the Q head is the locus where a dummy much is inserted, resulting in more in comparatives following the upward movement of -er. In sum, there is independent evidence for the existence of a second functional layer (QP). 
(5) a.

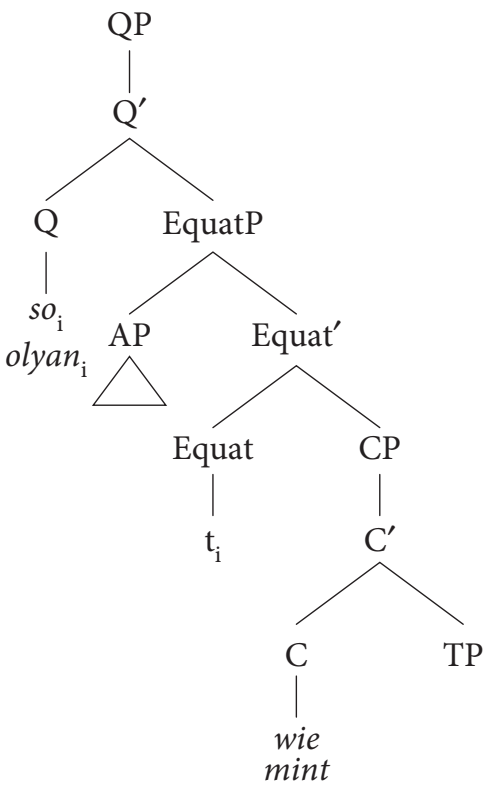

b. EquatP

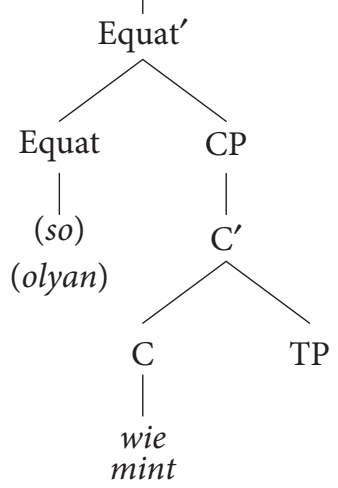

While German and Hungarian are strikingly similar regarding the basic syntactic pattern found in equatives, the doubling patterns differ in the two languages. In Modern Hungarian, mint can be followed by an overt operator (Kenesei 1992; Bacskai-Atkari 2014a, 2014b):

(6) a. Mari olyan magas, mint amilyen (magas) az anyja. Mary so tall as how tall the mother.Poss 'Mary is as tall as her mother.'

b. Mari olyan mint amilyen az anyja.

Mary so as how the mother.poss

'Mary is like her mother.'

The combination mint amilyen 'as how' might at first seem to be strikingly similar to German als wie, in (3) above, but note that while the element amilyen in Hungarian can take a lexical AP in degree equatives, as in (6a), this is not possible with German wie, as shown in (7a):

(7) a. ${ }^{\star}$ Der Tisch ist so lang (als) wie breit das Büro ist. the.mdesk is so long as as wide the.N office is 'The desk is as long as the office is wide.'

b. Der Tisch ist so lang (als) wie das Büro breit ist. the.M desk is so long as as the. $\mathrm{N}$ office wide is 'The desk is as long as the office is wide.' 
The constraint holds regardless of whether als is co-present or not. (7b) shows that the adjective itself is otherwise licensed in its base position, and hence the problem in (7a) stems from the movement of the AP to the left periphery (see BacskaiAtkari 2014a for German comparatives).

The structure for the doubling patterns (leaving out the QP layer) is shown in (8); the AP in the matrix clause appears in degree equatives:

(8)

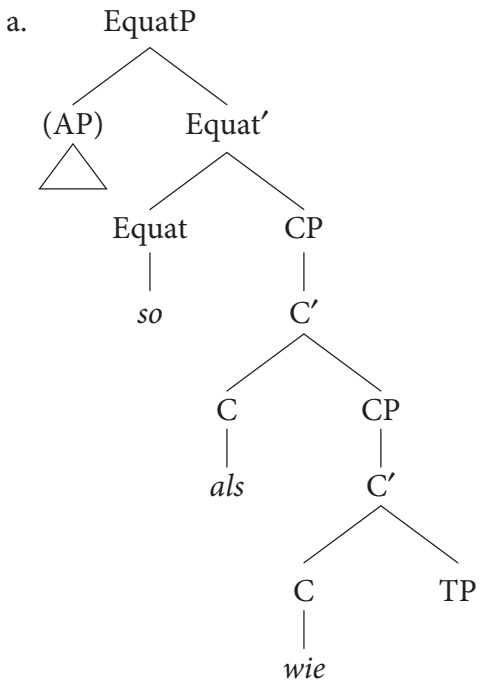

b. EquatP

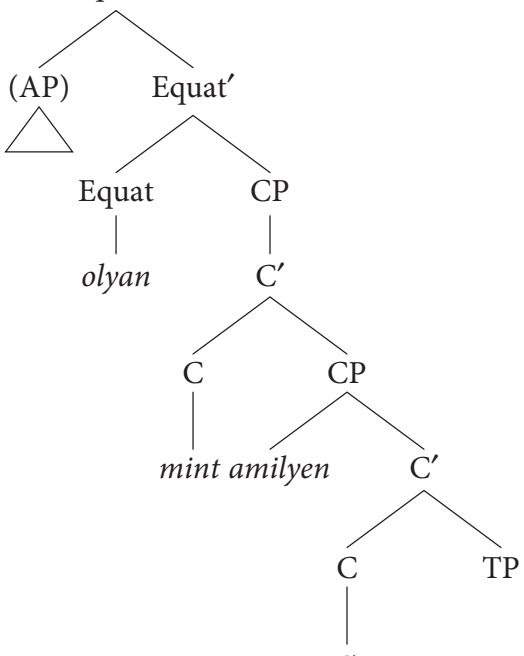

$\varnothing$

There are two CPs, following Bacskai-Atkari (2014a). For German, Jäger (2010) proposed a combination of a ConjP (headed by als) and a CP (headed by wie), but the presence of coordination in comparatives (Lechner 2004) is problematic (Bacskai-Atkari 2018a: 65-70). ${ }^{2}$ There are two major differences between German and Hungarian to mention here. First, the overt element in the lowest projection is a complementiser in German and an operator moving to [Spec,CP] in Hungarian (see above). Semantically, wie can naturally be treated as an operator (Hohaus \& Zimmermann 2014), and in this sense, there is no reason to assume a further

2. Under this non-cartographic view, multiple CPs are possible if there is multiple clausetyping, but otherwise only a minimum of layers is generated. In doubling patterns in comparatives, the lower CP is associated with the relative nature of the clause, while the higher CP marks the clause as comparative. The model crucially differs from cartographic approaches going back to Rizzi (1997), which assume designated projections for each function. Instead, it is closer to the CP-recursion proposed by Vikner (1995) and Vikner, Christensen and Nyvad (2017), which likewise involves multiple CPs with partly similar functions (e.g. a projection hosting a finite complementiser and another projection hosting the fronted finite verb in Scandinavian embedded V2 patterns). 
operator in the specifier. ${ }^{3}$ Second, the canonical equative complementiser is located in different positions.

I suggest that the observed difference follows from different grammaticalisation processes underlying these patterns. In Hungarian, the lower element was introduced as an innovation; in German, the higher element was reanalysed from the subclause (as proposed by Jäger 2016). I show that the latter is attested in nondegree equatives in Hungarian historically, providing cross-linguistic evidence for this kind of change.

\section{Equatives in German}

The original pattern in German equatives (see Section 1) involved the equative complementiser als ((al)so), in (2). This conforms to the regular West-Germanic pattern, whereby the complementiser is as/so in degree and non-degree equatives, and the matrix equative element is as/so. This is partly reflected in the present-day patterns from English, Dutch, and German:

(9) a. Ralph is as tall as Peter.

b. Sophie is zo groot als Lieke. Sophie is so tall as Lieke

'Sophie is as tall as Lieke.'

c. Ralf ist so groß wie Peter.

Ralph is so tall as Peter.

'Ralph is as tall as Peter.'

Regarding the etymology, the following can be established. English as derives from eallswa $($ all + so), and the forms swelce (swilce, such) and so (swa) were also possible historically in as-constructions (Kortmann 1997: 315-317; see also LópezCouso \& Méndez-Naya 2014: 312-314 and references there). Similarly, German als derives from Old High German also (all + so), and various forms of so were possible historically in as-constructions (Jäger 2010). Dutch als is likewise derived from also $(a l+s o)$. Hence, the elements so and as are essentially the same, either as matrix elements or as complementisers, whereby later differentiation and changes are also naturally possible.

3. For this reason, which ultimately follows from economy, the co-occurrence of an operator in the specifier and a head (in the same projection) is generally not attested. As Bacskai-Atkari (2018b: 22-26) argues, this may be possible in free relatives, but they have a syntax different from (8). 
In particular, German wie is an innovation. It is the result of a reanalysis from an operator in the specifier into a grammaticalised $\mathrm{C}$ head, in line with general economy principles. This change was termed the "comparative cycle" by Jäger $(2010,2016)$, based on the "relative cycle" of Van Gelderen (2004; 2009); see also the arguments of Bacskai-Atkari (2014a).

As mentioned in Section 1, there are two possible scenarios regarding the diachronic relation of single als, single wie and the combination als wie in the subclause. These are schematically represented in (10) below. In either case, the change took place in non-degree equatives earlier and later spread to degree equatives (Jäger 2010, Jäger 2016: 294):
a. als $\rightarrow$ als wie $\rightarrow$ wie
b. als $\rightarrow$ wie $\rightarrow$ als wie

The scenario in (10a) is represents the traditional view (which was also adopted by Jäger 2010 and Bacskai-Atkari 2014a), involving als wie as a middle stage. In this case, it is assumed that wie was introduced as a comparative operator in a lower functional projection; once it grammaticalised as a complementiser at a later stage, it eventually came to replace the original complementiser als. This change involves only canonical upward/leftward grammaticalisation, in line with Roberts \& Roussou (2003). The option in (10b) is what Jäger (2016: 291-298) argues for, whereby the combination als wie is a later result, following the establishment of wie as a complementiser and the disappearance of the original als. While this is supported by the observed diachronic order and by the relative frequency of doubling patterns (see Section 1), the element als is surface-ambiguous between the matrix equative element and the original equative complementiser, and it is not clear how such a reanalysis process can take place, as it apparently involves downward reanalysis, seemingly contrary to Roberts \& Roussou (2003). This question remains essentially unaddressed by Jäger (2016).

This paper argues for the change given in (10b). Regarding the emergence of the doubling structure, I assume that the following change took place:

(11)

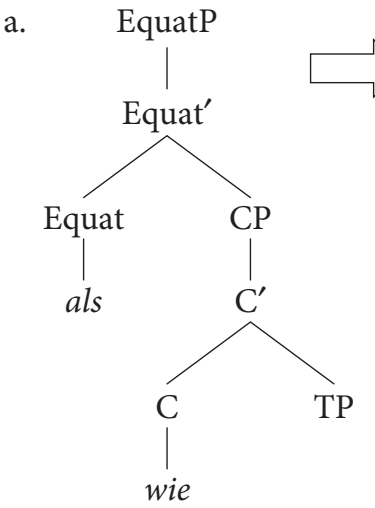

b.

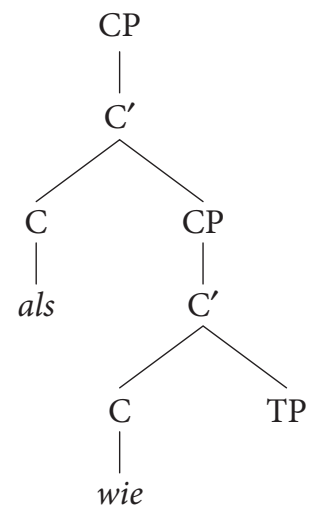


The structure in (11a) represents stage 2 in (10b), where single wie is a complementiser, and the element als is a matrix equative marker. The structure is the same as in Modern Standard German (1b) involving the combination of the matrix equative marker so and the complementiser wie. The change from (11a) to (11b) involves a change in the label but not the reanalysis to a pre-existing lower position and is not contrary to the grammaticalisation scheme of Roberts and Roussou (2003). Indeed, the change in (11) is not an instance of grammaticalisation from a less functional into a more functional element but of relabelling. This is possible because non-degree equatives do not necessarily contain a matrix equative element, see (1c) above. The double CP in (11b) is not embedded under an Equat head but is interpreted as a construction where als is part of the subclause.

There are three important factors to mention here. First, reinterpretation is possible because the element als in (11a) is string-adjacent to wie; unlike in degree equatives, there is no intervening adjective, see (5a) and (5b). Second, in German elements like als (so, also) are surface-ambiguous even in dialects where als in no longer attested as an equative complementiser on its own. This is the case in all dialects except for Low German varieties, where als in equatives is attested even in present-day dialects (Jäger 2016: 262); als is possible as a comparative complementiser in comparatives expressing inequality. Therefore, als is prone to be assigned a different syntactic label. Third, the semantic role of als is to lexicalise the maximality operator, but this semantic function is not tied to the notion of degree and is not associated with a particular syntactic label (Hohaus \& Zimmermann 2014; see also von Stechow 1984 on the role of the two operators). This results in some flexibility in the syntax, restricted to the choice between a matrix equative element and an equative complementiser; and hence the relabelling of als is possible. Naturally, while this can result in two CPs, the number of CPs is restricted. The higher element lexicalises the maximality operator and the lower one lexicalises the comparative operator, which can syntactically be a complementiser head (see Section 2).

Once (11b) was available in non-degree equatives, it could be extended to degree equatives by way of analogy. Degree equatives involve a matrix equative element, which is then present in addition to the double CP in the subclause, as in (8a).

\section{Equatives in Old Hungarian}

Let us now turn to the discussion of the data from Old Hungarian (10th to 15th centuries). As pointed out by Kántor (2013), there are various elements attested in the subclause in similatives in Old Hungarian, but out of these, only mint 
grammaticalised as a $\mathrm{C}$ head. ${ }^{4}$ In order to gain some insight into the distribution of these elements, I carried out a corpus study, using the normalised part of the "Old Hungarian Concordance" corpus (Simon 2014). ${ }^{5}$ The examples given below are from this corpus study. I will first introduce the four individual similative markers, all with a meaning close to 'how', including their etymology. ${ }^{6}$

The element mint stems from the combination of $m i$ 'what' and the modal suffix $-n$ and the locative suffix - $t$. The element miként stems from the combination of $m i$ 'what' and the modal suffix -ként. ${ }^{7}$ Two examples are given from Old Hungarian below:

a. mert vala okèt taneito mikent hatalmas \& ne mikèt
for was they.ACc teaching as great not as
a3 iraftudoc \& a leualtac
the scribes the Levites

'For He taught them as one having authority, and not as the scribes.'

(Munich Codex 36va; Mark 1:22)

b. mert wğ tanoyttya vala hwiket, mynt kynek hatalma for so taught.3sg be.PST they.ACC as who.DAT power.Poss vagyon rea, es nem mykeppen az yrafthwdok is it.subl and not as the scribes

'For He taught them as one having authority, and not as the scribes.'

(Jordánszky Codex 455; Mark 1:22)

The elements miként (in the Munich Codex $)^{8}$ and mint (in the Jordánszky Codex) ${ }^{9}$ appear in the same environment; both correspond to Latin quasi. ${ }^{10}$

The element miképpen stems from mi 'what' and the modal suffix -képpen (this suffix in turn consists of the noun base kép 'picture, likeness' and the modal

4. The reanalysis of mint is a standard reanalysis from specifier into head, in line with economy principles, as in the case of German wie (see Bacskai-Atkari 2014a).

5. The corpus is available at: http://omagyarkorpusz.nytud.hu/en-search.html.

6. The etymological data presented here are based on the following etymological dictionary: Etymologisches Wörterbuch des Ungarischen, edited by Loránd Benkő.

7. The suffix -ként is still productive in Modern Hungarian, e.g. added to the noun tanár 'teacher', it gives tanár-ként 'as a teacher'.

8. The Munich Codex is from 1466 and contains the translation of the 4 gospels.

9. The Jordánszky Codex is from 1516 and 1519 and contains almost the entire New Testament and 7 books of the Old Testament.

10. In addition, miként in the Munich Codex and miképpen in the Jordánszky Codex occur as the equivalents of 18 Latin sicut. 
suffix $-n) .{ }^{11}$ The element monnal is of unclear origin and it is a restricted option (see the discussion below). Two examples are given from Old Hungarian below:

a. mezt latam a żéllètèt lè źallatta meńbọl mōnal for saw.1sG the spirit.ACC down flown.3sg heaven.ELA as galambat \& o raita maradot dove.ACC he upon.him stayed.PTCP 'I saw the Spirit descending from heaven like a dove, and He remained upon Him.'

(Munich Codex 85va; John 1:32)

b. Mert latam yftennek leelkeet le zalwan menyból, for saw.1sg God.DAT spirit.ACC down flying heaven.eLA mykeppen az galamboth, es megh marada hw raytta as the dove.ACC and PRT stayed.3sg he upon.him 'I saw the Spirit descending from heaven like a dove, and He remained upon Him.'

(Jordánszky Codex 625; John 1:32)

Again, the elements miképpen and monnal appear in exactly the same environment (the Latin original contains again quasi) in the two different translations, and they can be treated as synonymous in non-degree equatives.

As mentioned above, out of the four similative elements, only mint grammaticalised as a complementiser in degree equatives. The question arises why this was the case. Kántor (2013) suggests that this element was more frequent while the other elements gradually disappeared or became marginal. My corpus search based on the "Old Hungarian Concordance" corpus mentioned above gave the number of hits summarised in Table (as of 29th September 2018). The corpus contains results for Old Hungarian ${ }^{12}$ and also for selected texts from Middle Hungarian (16th to 18 th centuries). ${ }^{13}$

11. It appears that the suffix -képpen is also still productive in Modern Hungarian, e.g. added to the noun büntetés 'punishment', it gives büntetés-képpen 'as a punishment'.

12. This includes various Old Hungarian codices and some minor texts; as of 29th September 2018, this normalised part of the corpus amounts to about 450000 tokens, counting the normalised versions without punctuation marks.

13. As of 29th September 2018, the normalised part of the corpus includes two Bible translations from Middle Hungarian: the translation of Gáspár Károli from 1590 (the translation is available for the whole Bible but the corpus contains only the books of the New Testament) and the translation of János Sylvester from 1541 (this translation includes the New Testament only). This normalised part of the corpus amounts to about 319402 tokens, counting the normalised versions without punctuation marks. 
Table 1. Similative markers in the Old Hungarian Concordance corpus

\begin{tabular}{lllr}
\hline & Old Hungarian & Middle Hungarian & Total \\
\hline mint & 542 & 842 & 1384 \\
miképpen & 738 & 492 & 1230 \\
miként & 478 & 7 & 485 \\
monnal & 189 & - & 189 \\
\hline
\end{tabular}

Considering the total number of occurrences, one might at first indeed attribute the grammaticalisation of mint to its higher frequency, though miképpen is almost as frequent as mint. Note, however, that the hits for mint also include degree equatives and comparatives expressing inequality, hence the number of non-degree equatives with mint is actually lower. Importantly, when considering its distribution in Old Hungarian, mint is not even the most frequently occurring element of the four similatives. Its frequency increases in Middle Hungarian, while the relative frequency of the other elements decreases. In other words, it seems that mint very probably did not come to be the canonical equative complementiser simply due to its high frequency, as its frequency was not the highest of the similative elements; rather, it came to be the most frequent similative element because it was the only one that grammaticalised as the canonical equative complementiser.

One factor to take into consideration is that mint is less transparent than miképpen and miként, and therefore more suitable for grammaticalisation, especially in degree equatives. The role of transparency can also be detected in English regarding the difference between as (non-transparent) occurring in degree equatives and like (transparent) occurring in non-degree equatives. Regarding the entire picture, it is also important to mention that monnal was restricted in its occurrence; it occurs only in the Munich Codex and in the Vienna Codex (middle of the 15th century) in the normalised part of the corpus. The two codices are related, and they are both parts of the "Hussite Bible", which also includes the Apor Codex (end of the 15th century - beginning of the 16th century). ${ }^{14}$ It seems that the form monnal is restricted to this group. ${ }^{15}$

To achieve comparable results, I examined two Bible translations in detail, comparing the same loci in the gospels. The first one is the Munich Codex from 1466, which contains the translation of the 4 gospels. The second one is the

14. A search in the Apor Codex (not yet normalised) gives 8 hits for the form monnnal (note that this is the original spelling, and other orthographic variants may occur in the text, too).

15. According to Adrienne Dömötör (p.c.), monnal is not attested in other Old (or Middle) Hungarian texts than the three codices belonging to the Hussite Bible. 
Jordánszky Codex from 1516 and 1519, which contains almost the entire New Testament and 7 books of the Old Testament. I searched for the equivalents of the Latin non-degree equative markers quasi and tamquam. The element quasi derives from quam si 'as if' but it was no longer transparent in late classical Latin either (see Tarriño 2011). The element tamquam derives from tam 'so' and quam 'as'.

The search results for the Munich Codex and the Jordánszky Codex are given in Table 2: ${ }^{16}$

Table 2. Non-degree equative markers in the Munich Codex and the Jordánszky Codex

\begin{tabular}{lccc}
\hline & Munich Codex & Jordánszky Codex & Total \\
\hline monnal & 21 & - & 21 \\
miként & 4 & - & 4 \\
miképpen & - & 7 & 7 \\
mint & 2 & 5 & 7 \\
oly-mint & - & 16 & 16 \\
ugy-mint & - & 1 & 1 \\
\hline
\end{tabular}

There are very few instances of mint in the Munich Codex; the most prominent equivalent is monnal. The proportion of mint is higher in the Jordánszky Codex, where it appears on its own and in combination with oly 'so' and ugy 'so.ADV'. An example for oly-mint is shown in (14): ${ }^{17}$

(14) lataa a' menyorzagot nythvan lenny, es y tennek zent saw.3sg the heaven.ACC open.PTCP be.INF and god.DAT sacred lelkeet oly mynth galamb kepeben le zallany spirit.ACC so as dove picture.POss.INE down descend.INF 'He saw the heavens parting and the Spirit descending upon Him like a dove.'

(Jordánszky Codex 454; Mark 1:10)

16. There is apparently no one-to-one correspondence between a Latin element (quasi/tamquam) and its Hungarian translation. Note that the total number of occurrences differs in the two texts. This is because a similative meaning can be expressed in other ways (such as coordination), which cannot be considered as proper similatives.

17. The Latin original contains tamquam. Note that the combinations oly-mint and ugy-mint are not calques based on Latin: most occurrences have quam in the original. There are also independent examples in the Kazinczy Codex (from between 1526 and 1541), which is not a translation. 
Table 3 shows the results for oly-mint ${ }^{18}$ in the normalised corpus (as of 29th September 2018).

Table 3. The occurrences of oly-mint in the Old Hungarian Concordance corpus

\begin{tabular}{ll}
\hline & Number of occurrences \\
\hline Old Hungarian & $\sum 64$ \\
Booklet (1521) & 1 \\
Kazinczy Codex (between 1526 and 1541) & 9 \\
Jordánszky Codex (1516 and 1519) & 54 \\
Middle Hungarian & $\sum 17$ \\
Sylvester's Bible translation (1541) & 17 \\
Total & $\mathbf{8 1}$ \\
\hline
\end{tabular}

The number of occurrences, especially compared to Table 1 , is rather low and restricted to just a handful of texts from the first half of the 16th century. The difference is also reflected between the Munich Codex and the Jordánszky Codex (Table 2). This suggests that oly-mint emerged quite late in Old Hungarian and did not come to be a dominant pattern in Middle Hungarian either. This is reminiscent of the emergence of als wie in German. It appeared only after wie was established as an equative marker, but it did not emerge as a dominant pattern in any German dialect (Jäger 2016: 266-269). The question is what the status of the combination oly-mint is. Since the matrix equative marker in Hungarian is generally oly(an), one might think that instances of oly-mint also include a matrix equative marker and a complementiser. After all, oly was clearly available as a matrix equative marker in Old Hungarian, as shown in (15): ${ }^{19}$

18. Table 3 does not include results for $u g y$-mint. The corpus search (as of 29th September 2018) gives only 6 hits for ugy-mint for Old Hungarian: 5 instances from the Jordánszky Codex and 1 instance from the Czech Codex (from 1513). This seems to have been a very restricted pattern; all the 6 examples are essentially the adverbial counterparts of oly-mint as in (14). In other words, the reanalysis affecting oly (see below) apparently affected ugy only to a limited degree and turned out not to be productive. The Middle Hungarian part of the corpus contains 82 instances of $u g y$-mint, all from Károli’s Bible translation (see above), but in these cases ugy-mint is used in the sense of 'about, approximately', as in (i). This suggest that ugy-mint may have undergone quite different reinterpretation processes, which are different from the ones affecting oly-mint and are hence not relevant here.
(i) v'gy mint egy óra múluan so.ADV as one hour elapsing 'about an hour later' (Károli 76v)

19. The Czech Codex is from 1513 and the Jókai Codex is from around 1440. 
(15)

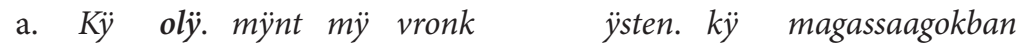
who so as our lord.Poss.1PL God who heights.INE

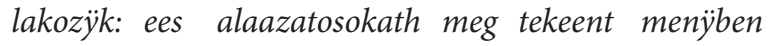
lives and meek.PL.ACC PRT regards heaven.INE ees foldon and eart.sup

'Who is like our Lord the God, who lives in heaven and regards the meek in heaven and on earth.'

(Czech Codex 140)

b. Mert banya uala mÿkoron valamely egÿhazat nem lewl for regrets be.PsT when some church.ACC not finds uala oly tÿztan ment ew akarya vala be.PST so clean.ADV as he wants be.PST

'For he was sorry when he did not find a church as clean as he wanted it to be.'

(Jókai Codex 97)

In (15a), oly is a predicate in the matrix clause. It cannot be part of the subclause; this structure is analogous to (4b) and German (1b). In (15b), there is a gradable adverb intervening between oly and the subclause, again making it impossible for oly to be part of the subclause. This is a structure analogous to (4a) and German (1a).

However, (14) is different. The element oly is an adjectival equative marker, which, in non-degree equatives, is possible as a predicate, as in (15a), or as an attribute, but not as a verbal modifier. In (14), the similative clause is adverbial (it specifies the manner of flying), and hence oly is located in the subclause. As there are several other occurrences of this type in Old (and Middle) Hungarian (Table 3 ), it can be concluded that the reanalysis of oly into the subclause was complete in the relevant grammar. Reanalysis involves a categorical change in the syntactic structure, as in German, involving a change from Equat to C, illustrated in (16):

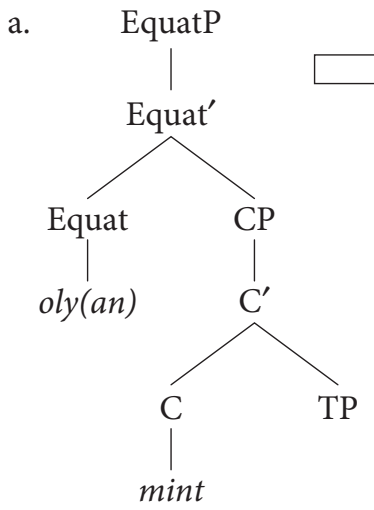

a. b.

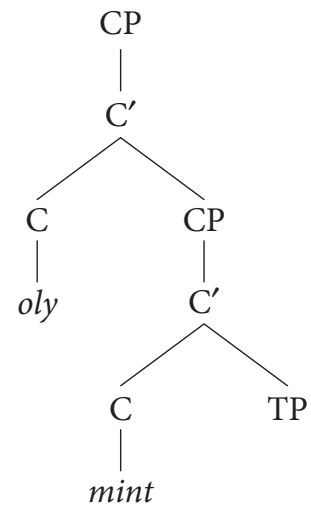

Reanalysis is possible because the two elements are adjacent in non-degree equatives initially as well, and there is no movement to a $\mathrm{Q}$ head, as indicated in (5b) 
above. In Old Hungarian, reanalysis involved only the shorter form oly but not the strong form olyan (the latter is not a clitic). Note that the form oly was much more frequent in Old Hungarian than olyan: as of 29th September 2018, a corpus search on the normalised part of the "Old Hungarian Concordance" corpus gave 179 hits for oly $(79,56 \%)$ and 46 hits for olyan (20,44\%). The Middle Hungarian part of the corpus (containing the two Bible translations mentioned before) gave 144 hits for oly $(42,40 \%)$ and 106 hits for olyan (57,60\%), indicating a change in the relative frequency of these elements.

The syntactic development is similar to German, see (11), but oly-mint (and ugy-mint) was not extended to degree equatives, unlike German als wie. It is certainly possible that the combination was not well-spread enough in the relevant dialects. In addition, there are certain factors that might have hindered a development similar to German. One factor is the lack of ambiguity regarding the status of oly outside constructions like (14). Contrary to German als, which is attested in subclauses in other constructions, oly occurs otherwise in main clauses only. In degree equatives, a matrix equative marker is necessary, taking the gradable predicate as an argument: oly(an) in Hungarian, which is surface-similar to oly-appearing in oly-mint. This configuration would have been exceptional in the Hungarian syntactic paradigm, since in Hungarian, unlike in West Germanic, matrix equative markers differ from equative complementisers. ${ }^{20}$

In addition, the comparative operators of the form amilyen, (6), started to appear in Middle Hungarian (Bacskai-Atkari 2014a), and these appear in a double $\mathrm{CP}$ where mint is the higher head, lexicalising the maximality operator. The relative position and function of mint is thus in conflict with doubling patterns involving oly-mint, where mint is the lower $\mathrm{C}$ head (and oly lexicalises the maximality operator). ${ }^{21}$

While oly-mint had no continuation in later periods, the fact that it existed has important repercussions for syntactic theory and diachronic syntax. It is evident

20. A triple combination of this form is possible in German, (3), indicating that while a triple combination involves a certain degree of redundancy, it is not excluded in the grammar. Still, as mentioned above, als wie is not the predominant pattern in any German dialect, and it may be the case that redundancy also matters in this respect.

21. As discussed in Section 2, the co-occurrence of an overt comparative operator with a complementiser in the same projection (similarly to a Doubly Filled COMP effect) is not possible, rendering a sequence like *oly amilyen mint 'so how as' impossible. Further, a triple combination like ${ }^{\star}$ oly mint amilyen, involving three CPs, is not attested and is in fact not expected on theoretical grounds either: as mentioned in Section 2, in case there is a double CP, one projection lexicalises the maximality operator and another one the comparative operator, rendering a third CP unmotivated: this is a natural restriction on the number of CPs. 
that the combination oly-mint involves reanalysis from the matrix equative element into a complementiser and not the simultaneous usage of two already established complementisers, as was traditionally claimed to be the case for German als wie. This process involves a change in the syntactic label but no downward grammaticalisation, and is hence congruent with the hypothesis formulated by Roberts \& Roussou (2003). In German, the element als is ambiguous between a matrix equative marker and a complementiser, while this is clearly not the case for Hungarian. The Old Hungarian data thus provide additional evidence for the label change proposed for German.

\section{Conclusion}

This article examined equative markers in German and Hungarian, concentrating on doubling patterns synchronically and diachronically. Non-degree equatives are less restrictive than degree equatives in terms of operators in the subclause, and changes/innovations by default start from non-degree equatives and may or may not spread to degree equatives. In Old Hungarian, this resulted in the availability of more operator elements in non-degree equatives, which were also more transparent with respect to their similative meaning. In German, the difference can be detected in the diachronic development: wie takes over in non-degree equatives earlier than in degree equatives. In both languages, doubling patterns can involve the reanalysis of the matrix equative element into a $\mathrm{C}$ head. This is an instance of categorial change, and is attested in German (als wie) and in Old Hungarian. The patterns may or may not be extended analogically to degree equatives. This is related to transparency. In German, the reanalysed als is identical to the previous canonical equative complementiser, while in Old Hungarian the reanalysed oly was idiosyncratic as an equative complementiser and still transparent as a matrix equative element, which hindered its analogical extension to degree equatives. The differences between the two languages can thus be drawn back to more general properties.

\section{Acknowledgements}

This research was funded by the German Research Fund (DFG), as part of my project "The syntax of functional left peripheries and its relation to information structure" (BA 5201/1-1), carried out at the University of Potsdam. I owe many thanks to Malte Zimmermann and to Agnes Jäger for various discussions on equatives constructions, as well as to Marcel den Dikken and Adrienne Dömötör for their helpful questions and suggestions at the conference. 


\section{References}

Bacskai-Atkari, Julia. 2014a. Cyclical change in Hungarian comparatives. Diachronica 31(6). 465-505. https://doi.org/10.1075/dia.31.4.01bac

Bacskai-Atkari, Julia. 2014b. The syntax of comparative constructions: Operators, ellipsis phenomena and functional left peripheries. Potsdam: Universitätsverlag Potsdam.

Bacskai-Atkari, Julia. 2018a. Deletion phenomena in comparative constructions: English comparatives in a cross-linguistic perspective. Berlin: Language Science Press.

Bacskai-Atkari, Julia. 2018b. Deutsche Dialekte und ein anti-kartografischer Ansatz zur CPDomäne. In Augustin Speyer \& Philipp Rauth (eds.), Syntax aus Saarbrücker Sicht 2: Beiträge der SaRDiS-Tagung zur Dialektsyntax, 9-29. Stuttgart: Steiner.

Bresnan, Joan. 1973. The syntax of the comparative clause construction in English. Linguistic Inquiry 4(3). 275-343.

Corver, Norbert. 1997. Much-support as a last resort. Linguistic Inquiry 28(1). 119-164.

Eggs, Frederike. 2006. Die Grammatik von als und wie. Tübingen: Narr.

Gelderen, Elly van. 2004. Grammaticalization as economy. Amsterdam: John Benjamins. https://doi.org/10.1075/la.71

Gelderen, Elly van. 2009. Renewal in the left periphery: Economy and the complementiser layer. Transactions of the Philological Society 107(4). 131-195.

https://doi.org/10.1111/j.1467-968X.2009.01216.x

Haspelmath, Martin \& Oda Buchholz. 1998. Equative and similative constructions in the languages of Europe. In Johan van der Auwera \& Dónall Ó Baoill (eds.), Adverbial constructions in the languages of Europe, 277-334. Berlin: Mouton de Gruyter.

https://doi.org/10.1515/9783110802610.277

Hohaus, Vera \& Malte Zimmermann. 2014. Equatives outside the domain of degree constructions. Paper presented at: Linguistic Evidence 2014, Tübingen, Universität Tübingen, 13-15 February 2014.

Jäger, Agnes. 2010. Der Komparativzyklus und die Position der Vergleichspartikeln. Linguistische Berichte 224. 467-493.

Jäger, Agnes. 2016. Vergleichskonstruktionen im Deutschen: Diachroner Wandel und synchrone Variation. Universität zu Köln habilitation.

Kántor, Gergely. 2013. Hungarian mint as Conj0. Talk delivered at: 11th International Conference on the Structure of Hungarian (ICSH11), Piliscsaba, Pázmány Péter Catholic University \& Research Institute for Linguistics of the Hungarian Academy of Sciences, 29-31 August 2013.

Kenesei, István. 1992. On Hungarian complementisers. In István Kenesei \& Csaba Pléh (eds.), Approaches to Hungarian 4, 37-50. Szeged: JATE.

Kortmann, Bernd. 1997. Adverbial subordination: A typology and history of adverbial subordinators based on European languages. Berlin: Walter de Gruyter. https://doi.org/10.1515/9783110812428

Lechner, Winfried. 1999. Comparatives and DP-structures. University of Massachusetts Amherst dissertation.

Lechner, Winfried. 2004. Ellipsis in comparatives. Berlin: Mouton de Gruyter. https://doi.org/10.1515/9783110197402

Lipold, Günter. 1983. Möglichkeiten der Komparation in den deutschen Dialekten. In Werner Besch, et al (eds.), Dialektologie: Ein Handbuch zur deutschen und allgemeinen Dialektforschung, 1232-1241. Berlin: Mouton de Gruyter. 
López-Couso, María José \& Belén Méndez-Naya. 2014. On comparative complementizers in English: Evidence from historical corpora. In Nila Méndez-Naya Vazques (ed.), Creation and use of historical English corpora in Spain, 311-333. Newcastle upon Tyne: Cambridge Scholars Publishing.

Merkle, Ludwig. 1975. Bairische Grammatik. München: Heimeran.

Rizzi, Luigi. 1997. The fine structure of the left periphery. In Liliane Haegeman (ed.), Elements of grammar, 281-337. Dordrecht: Kluwer. https://doi.org/10.1007/978-94-011-5420-8_7

Roberts, Ian \& Anna Roussou. 2003. Syntactic change. A Minimalist approach to grammaticalization. Cambridge: Cambridge University Press. https://doi.org/10.1017/CBO9780511486326

Simon, Eszter. 2014. Corpus building from Old Hungarian codices. In Katalin É. Kiss (ed.), The evolution of functional left peripheries in Hungarian syntax, 224-236. Oxford: Oxford University Press.

von Stechow, Arnim. 1984. Comparing semantic theories of comparison. Journal of Semantics 3. 1-77. https://doi.org/10.1093/jos/3.1-2.1

Tarriño, Eusebia. 2011. Comparative clauses. In Philip Bardi (ed.), Complex sentences, grammaticalization, typology, 373-426. Berlin: Walter de Gruyter. https://doi.org/10.1515/9783110253412.373

Vikner, Sten. 1995. Verb movement and expletive subjects in the Germanic languages. Oxford: Oxford University Press.

Vikner, Sten, Ken Ramshøj Christensen \& Anne Mette Nyvad. 2017. V2 and cP/CP. In Laura R. Bailey \& Michelle Sheehan (eds.), Order and structure in syntax I: Word order and syntactic structure, 313-324. Berlin: Language Science Press.

Weise, Oskar. 1918. Die vergleichenden Konjunktionen in den deutschen Mundarten. Zeitschrift für deutsche Mundarten 13. 169-181. 



\title{
Anatomy of Hungarian aspectual particles
}

\author{
Aniko Csirmaz \& Benjamin Slade \\ University of Utah
}

\begin{abstract}
The paper explores a common core of meaning that various aspectual adverbials in Hungarian (including megint, ismét 'again', még 'still') share. It is proposed that there is a general definition for various aspectual elements related to times and events. We suggest that some components of those elements, including the scalar argument and the focus set, can vary - and this results in the different specific meanings. We assume that meaning is compositional and also address the complex form mégis '(concessive) still' and other elements that appear to be synonymous with mégis.
\end{abstract}

Keywords: aspectual adverbials, focus, repetitives, additive particles, semantics, Hungarian, Hindi, Nepali

\section{Overview}

In this paper we provide a descriptive account of the distribution of selected aspectual adverbials in Hungarian with comparison to English, Hindi, and Nepali together with a proposal for a general approach to a formal semantic characterisation of these elements which captures connections suggested by the morphological shapes of these elements crosslinguistically.

This paper is structured as follows. First, we discuss the various meanings of még 'still' and then we propose a templatic definition that these meanings share. Then we discuss how mégis 'still' and még ... is 'even' are related to még. Next, we discuss how the repetitive adverbs megint and ismét are related to még. We then propose revisions to some earlier descriptions and treatments of crosslinguistic equivalents of még, including English still and German noch. A summary concludes the paper and notes some outstanding questions. 


\section{Még}

Hungarian még has several interpretations that are also shared by English still. In addition, there are a variety of other aspectual elements that are related to még morphologically, etymologically, and/or semantically. In enumerating the various senses we rely on a number of earlier treatments of crosslinguistic equivalents of még, notably Michaelis (1993), Ippolito (2007), and Beck (2016).

In the first table, we show that még has the temporal/continuity and marginality readings of still (examples illustrating these and other meanings appear below). In addition, it can also function as an additive. The form of még can also be found in mégis, the concessive/adversative particle, as well as the repetitive adverbs megint and ismét. The repetitives and their specific relation to még will be addressed in Section 6. In addition, még appears along with the additive particle is in the scalar particle counterpart of even. The additive particle is and - the equivalent of deictic then - akkor are also shown below. When akkor appears with is, the resulting combination akkor is has a concessive interpretation.

Table 1. Selected aspectual adverbs and component pieces in Hungarian

\begin{tabular}{ll}
\hline Hungarian & Meaning \\
\hline akkor & "then (at that time)"* \\
\hline $\begin{array}{l}\text { megint } \\
\text { ismét } \\
\text { újra } \\
\ldots\end{array}$ & $\begin{array}{l}\text { repetitive "again", } \\
\text { restituitive "again" }\end{array}$ \\
\hline még (mindig) & temporal/continuity "still" \\
\hline még & marginality "still" \\
\hline mégis & $\begin{array}{l}\text { concessive/adversative "still", } \\
\text { "(and) yet" }\end{array}$ \\
\hline még & additive/subconstituent \\
\hline még & comparative \\
\hline még ... is & $\begin{array}{l}\text { scalar(-additive) } \\
\text { particle "even" }\end{array}$ \\
\hline is & additive particle "also" \\
\hline
\end{tabular}

*Akkor also appears in the apodosis of conditional "if...then" construction, roughly equivalent to the role of English then in such constructions. Potential differences between mégis and akkor is fall outside of the scope of this paper.

Once again, the goal of this paper is to explore the relations between the elements shown above, by relying on a generalized, templatic definition. Various substantiations of that definition - involving differences in the scale, ordering 
relation, focus, etc. - will yield the meanings of még as well as those of other aspectual elements.

Before proceeding to the specific definitions, we offer some examples that illustrate the aspectual particles in Table 1.

(1) Deictic akkor

János akkor itta meg a sört.

János.NOM then drank perfective the beer.ACC

János drank the beer then / at that time.'

(2) Repetitive (\& restitutive) megint/ismét

Feri megint / ismét ivott egy pálinkát.

Feri.nom again / again drank one palinka.ACC

'Feri drank a palinka again.'

(3) Temporal/continuity még

János még (mindig) olvas.

János.NOM still always reads

'János is still reading.' (optional mindig 'always' ignored here)

(4) Marginality még

$A z$ Octavia még biztonságos (az annál kisebb autók

the Octavia.Nom still safe the than-that smaller cars.Nom

veszélyesek lehetnek).

dangerous.PL are.COND

'Octavias are safe (cars smaller than that can be dangerous).'

(5) Concessive/adversative mégis/akkor is

Bár fogyókúrázott, Feri mégis / akkor is

though dieted Feri.Nom still / then too

evett zsíros-kenyeret.

ate lard.ADJ-bread.ACC

'Even though he was on a diet, Feri ate some bread with lard.'

(6) Additive még

János ivott egy sört. (És) ivott még egy kólát /

János.NOM drank one beer.ACC and drank still one coke.ACC /

evett még egy perecet.

ate still one pretzel.ACC

'János drank a beer. And he drank a coke / ate a pretzel (as well).'

(additive, no temporal ordering)

(7) Comparative még

Ez egy nagy labda. (Az nagyobb.) És az még nagyobb.

this one big ball that bigger and that still bigger

'This is a big ball. (That one is bigger.) And that one is still bigger.' 
(8) Scalar additive még ... is

$\begin{array}{lll}\text { Mindenki Még Feri } & { }^{*}(\text { is }) \\ \text { everyone.NOM } & \text { still } & \text { Feri.NOM }{ }^{*} \text { (too) } \\ \text { zsíros-kenyeret } & \text { kért. } \\ \text { lard.ADJ-bread.ACC } & \text { asked }\end{array}$

'Everyone asked for some bread with lard. Even Feri asked for some bread with lard'

(9) Additive is

Feri is evett zsíros-kenyeret

Feri.NOM too ate lard.ADJ-bread.ACC

'Feri ate some bread with lard too'

\subsection{Temporal még}

We start with a discussion of temporal/continuity még. This kind of aspectual particle has been discussed in detail in a number of works earlier, mostly focusing on English and German (Michaelis 1993; Ippolito 2007; Beck 2016; Klein 2007). Here we adopt a rather straightforward definition and we address some differences with earlier definitions in Section 5.

First we offer an initial characterization of the meaning of temporal még. This will be subsequently revised to allow a more general, templatic definition. (Here and throughout, material in square brackets specifies presuppositional content.)

In the first definition, még combines with an ordered scale of times $T$, a time interval $t$, an eventuality $e$, and a saturated predicate $\mathcal{P}$ (with all arguments except for those indicated already saturated before combining with the adverb). It asserts that there is an eventuality $e$ of type $\mathcal{P}$ at time $t$. Essentially, temporal még presupposes the existence of a time and an event, such that the presupposed event $e^{*}$ is of type $\mathcal{P}$ and its event time is $t^{*}$. In addition, $t^{*}$ (left-)abuts ${ }^{1}$ the time of the event argument $e .^{2}$

(10) 'temporal' még, first version:

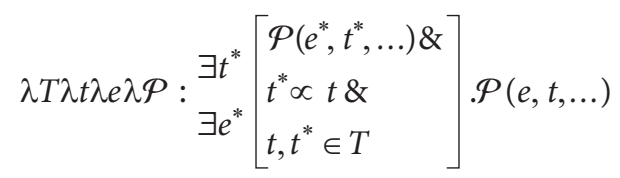

1. The notation $\propto$ follows Krifka (2000) and others. We note that $\propto$ (and its counterpart $\infty$ ) have the virtue of distinguishing between left- and right-abutment (respectively), which is crucial for the definition proposed.

2. $\mathrm{T}$ is the temporal scale in its entirety. For present purposes we assume that there is a covert argument $T$ that the adverb takes, and $T$ determines the scale of which $t, t^{*}$ are degrees. 
As the first step in revising the definition above, we suggest that még (as well as still) is focus sensitive. ${ }^{3}$ It is the time argument that is focused, so elements of the set of focus alternatives contain times distinct from $t$ (see Rooth 1985, 1992). ${ }^{4}$ As before, the arguments of temporal még are the ordered scale of times $T$, time $t$, event $e$, and saturated predicate $\mathcal{P}$. The assertion is that $e$ is an event of type $\mathcal{P}$ at $t$. Also as before, the presupposition is that there is an event $e^{*}$ of type $Q$ and event time $t^{*}$ such that $t^{*}$ left abuts $t$. Since time is focused, any element of the set of focus alternatives $Q\left(e^{*}, t^{*}\right)$ is identical to $\mathcal{P}(e, t)$ except for the identity of the time argument. $^{5}$

(11) 'temporal' még, revised:

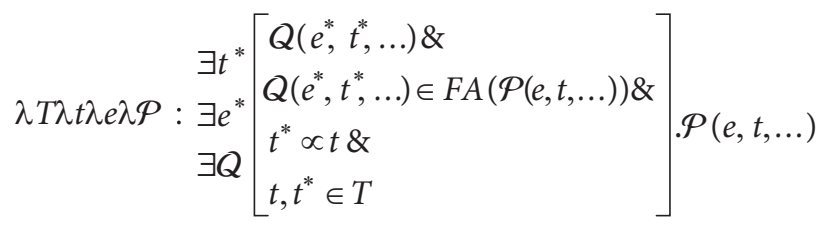

In the following subsections we examine other uses of még. The revised definition above in (11) is representative of the basic form of the definitions that will be given for the other uses of még, which differ from one another in a parametric fashion; that is, differing in terms of the identity of the scalar elements, the ordering relation, and the focus (and thus the set of focus alternatives).

\subsection{Comparative még}

The comparative use of the German counterpart of még was independently mentioned in Klein (2007) and Umbach (2009). The variable arguments of $\mathcal{P}(e, t)$ differ according to the type of predicate. If $\mathcal{P}$ is an individual-level predicate, then one of the individual arguments will differ (12) between the assertion and the

3. A reviewer wonders why még would not be sensitive to the full range of focus in Hungarian, such as material in the special preverbal focus position. However, the preverbal position is associated with exhaustive interpretation, suggesting that it is not available to be associated with other focus-sensitive operators. The type of focused material relevant to még and other particles appears to be focus that involves the position of nuclear stress rather than stress and a designated syntactic position.

4. We assume that it is $t, t^{*}$ that are focused and ordered (cp. Ippolito 2007). As a consequence there will be distinct eventualities that have the corresponding event times.

5. Temporal még does in fact receive an obligatory imperfective reading (cp., for instance, the discussion in Ippolito 2007 of English temporal still). We do not explore this fact in the current paper due to lack of space, but it could relate to morphosyntactic restrictions on the attachment site of temporal még. 
presupposition. ${ }^{6}$ If $\mathcal{P}$ is a stage-level predicate, then the time argument can also differ $(13,14) .^{7}$

(12) Ez egy nagy labda. (Az nagyobb.) És az még nagyobb. this one big ball that bigger and that still bigger 'This is a big ball. (That one is bigger.) And that one is still bigger.'

(13) A víz meleg. Most még melegebb. the water.NOM warm now still warmer 'The water is warm. Now it's even warmer.'

(14) Ez a csésze kávé meleg. Az a csésze tea this the cup coffee.Nom warm that the cup tea.Nom még melegebb.

still warmer

'This cup of coffee is warm. That cup of tea is warmer'.

For the definition of comparative még, we propose the following entry: ${ }^{8}$

$$
\left.\begin{array}{rl}
\exists d^{*} & \mathbb{Q}\left(e^{*}, d^{*}, t^{*}, \ldots\right) \& \\
\exists D \lambda d \lambda e \lambda t \lambda \mathcal{P}: & \exists e^{*} \\
\exists t^{*} & Q\left(e^{*}, d^{*}, t^{*}, \ldots\right) \in F A(\mathcal{P}(e, d, t, \ldots)) \& \\
& d^{*}<d \& \\
d, d^{*} \in D
\end{array}\right] . \mathcal{P}(e, d, t, \ldots)
$$

In all cases of comparative még, the predicates $\mathcal{P} / Q$ are comparative adjectives. $d$ is a degree along the adjectival scale. As noted before, the elements of the set of focus alternatives can differ in either the individual argument $\left(e \neq e^{*}\right)$ or the time $(t$ $\left.\neq t^{*}\right)$, and naturally in the degree $\left(d \neq d^{*}\right)$. In all other respects, the presupposition

6. We assume focus alternatives are generated as per Rooth $(1985,1992)$.

7. A reviewer notes that s/he finds még in (12-14) acceptable (only) if még has focus stress. We find that comparative még does not differ from temporal még, for example, so the difference may represent speaker-variation. At this time we have no account of this effect or of the contrast.

8. A reviewer asks about interaction of this type of még with a wider variety of adjectives, including distinctions between graded/non-gradable. While Hungarian examples like még üresebb are marginally possible, as are their English counterparts like still emptier, the acceptability of these has more to do with the fact that these do not actually require the absolute endpoint to have been reached (e.g. a bottle with a few drops of water in the bottom is in most situations reasonably described as empty), and so gradable-like comparisons with such adjectives are often still possible. However, this seems like an issue rather separate from what this paper addresses. 
and the assertion are identical, as in the case of the other aspectual adverbials discussed.

Note that in the examples given above, the adjectival predicate is not comparative, thus there is another difference between $\mathcal{P}$ and $\mathcal{Q}$. First of all, it is not necessary that this adjective appear in the base form, but it can also be comparative, identical to $\mathcal{P}$ :
Ez a csésze kávé már melegebb. Az a csésze kávé this the cup coffee.NOM already warmer. that the coffee cup.NOM még melegebb
still warmer
'This cup of coffee is already warmer. That cup of coffee is still warmer.'

For present purposes, we assume that both the comparative and base form have a second degree argument. In the case of the base form, that is the contextual standard, and in the case of the comparative, it is the degree supplied by the entity that serves as comparison (see Heim 2001).

\subsection{Marginality még}

For the marginality meaning, let us start with Example (17), which is based on Michaelis (1993). Marginality még expresses that the predicate $\mathcal{P}$ holds for the individual $e$. Given a scale of individuals ranked according to property $\mathcal{P}, e$ is close to the standard (such that individuals below/above the standard, depending on the specific predicate, are not $\mathcal{P}$-individuals). ${ }^{9}$

\section{Az Octavia} még biztonságos the Octavia.NOM still safe (az annál kisebb autók veszélyesek lehetnek). dangerous.PL are.COND 'Octavias are safe (cars smaller than that can be dangerous).'

We suggest that in reality (17) involves two kinds of issues: some kind of comparison and a standard. The difference between the two kinds of marginality readings are illustrated below. Giving English examples will be justified momentarily.
a. Sopron is still in Hungary.
b. This dress is expensive. That dress is still expensive.
(simple marginality)

(comparative marginality)

9. A reviewer notes that s/he finds that (17), (19a) and (20) are acceptable if (presumably only if) még is stressed. See further fn. 7 above on apparent variation between speakers regarding stress on még. 
Example (18a) shows simple or true marginality. Given a ranking of settlements of Hungary according to their distance from the border (where a settlement on or on the other side of the border is not in Hungary), it asserts that Sopron, a city located close to the western border of the country, is low on the scale. We label this as the 'simple' or S-marginality. In (18b) the degree to which a dress is expensive is compared to the degree of another dress. Note that unlike with comparative még/still, the degree to which the second dress is expensive is smaller than the degree in the presupposition - that is, the second dress is cheaper, but still expensive. This interpretation will be referred to as 'comparative' or C-marginality.

Unlike comparative még discussed above in Section 2.2, C-marginality does not involve a comparative predicate. In addition, the individual in the assertion is associated with a degree that is closer to the standard that the degree in the presupposition. With comparative még, the relation was the opposite: the degree in the presupposition was closer to the standard than the degree in the assertion. Thus the two readings are distinct.

Distinguishing these two subtypes of marginality still is also required by the fact that Hungarian only has the S-marginality reading for simplex még. In the C-marginality example, equivalent to (18b), only a temporal interpretation is available.
a. Sopron
még Magyarország-on
Sopron-NOM still Hungary-on
van.
'Sopron is still in Hungary'.

(S-marginality)

b. Ez a ruha drága. Az a ruha is / \#még drága. this the dress expensive that the dress too / still expensive 'This dress is expensive. That dress is expensive too / still expensive.'

(C-marginality, only ok if temporal még)

We note that it appears that még mindig (which also has a temporal interpretation equivalent to még) permits the C-marginality reading, lacking the obligatory temporal interpretation of (19b). At this point we only note this fact and leave a discussion of the possible contribution of mindig 'always' for the future.

(20) Ez a ruha drága. Az a ruha még mindig drága. this the dress expensive that the dress still always expensive 'This dress is expensive. That dress is still expensive.'

Crucially with C-marginality, as in (18b) (and (20)), no marginal degree is necessary. The second dress does not need to be marginally expensive. This also holds for the following example (Michaelis 1993: 223, also Ippolito 2007):

(21) Compact cars are still fairly safe. Subcompacts start to get dangerous. 
We offer the following definition for C-marginality:

$$
\lambda D \lambda d \lambda e \lambda \mathcal{P}: \begin{array}{ll}
\exists d^{*} & \exists e^{*} \\
\exists Q
\end{array}\left[\begin{array}{l}
Q\left(e^{*}, d^{*}, \ldots\right) \& \\
Q\left(e^{*}, d^{*}, \ldots\right) \in F A(\mathcal{P}(e, d, \ldots)) \& \\
d^{*}>d \& \\
d, d^{*} \in D
\end{array}\right] \mathscr{P}(e, d, \ldots)
$$

Once again, $\mathcal{P} / Q$ is a gradeable adjective or some predicate with a scalar argument (for example, with the spatial ordering described for (18a) and (19a)). The C-marginal still combines with an ordered scale of degrees $D$, a degree $d$, an event $e$ and a saturated predicate $\mathcal{P}$. This flavour of still presupposes that there is an eventuality $e^{*}$, degree $d^{*}$ and predicate $Q$. The predicates $\mathcal{P}$ and $Q$ are identical, but $d^{*}$ is greater than $d$. With C-marginal still, one of the additional arguments of $\mathcal{P}$ is focused. In (18b) it is the individual that dress which is focused. In the presupposition, the corresponding argument of $Q$ will differ, yielding a set of focus alternatives that includes This dress is d-expensive.

Simple marginality is the interpretation that is available for még as well as still. In this case the comparison is with the standard rather than another individual. $\mathrm{S}$-marginals also induce an implicature that the degree in the assertion is close to the standard, hence the marginal interpretation. We propose the following definition for this interpretation of még:

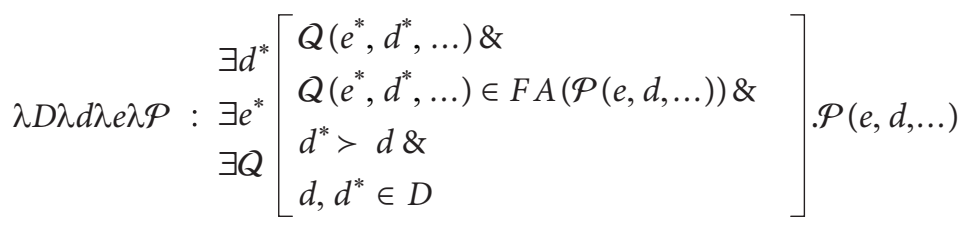

Here $Q$ invokes a standard, inducing a contextually-restricted domain widening of focus alternative to a standards (see also the discussion of comparative még, and either comparative or base adjectives in the presupposition above). The standard is defined as the area of maximal overlap for all alternatives along the scale. For example, this coffee is still warm might involve comparing hot beverages in Europe and finding the maximal overlap. ${ }^{10}$

10. A reviewer points out that there remain complexities in defining the standard along these lines. The precise definition of a standard is not crucial for the definition of S-marginality we propose here, as it really just requires some way of establishing a standard, but nothing crucial in the analysis hinges on the details of that definition. 


\subsection{Additive még}

In the meanings of még discussed above, there was a scalar component. Additive még could be described as lacking such a scalar element. First, we suggest that if the predicates are identical, then the resulting meaning is not purely additive, but there is a temporal component as well, which establishes a temporal ordering (see (24)). If the predicates are distinct, as in (25), then the resulting meaning is purely additive and there is no temporal ordering imposed on the asserted and presupposed events. ${ }^{11}$

$$
\begin{array}{lllll}
\text { János } & \text { ivott } & \text { egy sört. } & (\hat{E} s) \text { ivott még egyet. } \\
\text { János.NOM drank one beer.ACC and drank still one.ACC }
\end{array}
$$
'János drank a beer. And he drank another one.'

(temporal ordering, 'additive' (Beck 2016, Klein 2007, Umbach 2009))
(25) János ivott egy sört. (És) ivott még egy kólát / János.Nom drank one beer.ACC and drank still one coke.ACC / evett még egy perecet. ate still one pretzel.ACC
'János drank a beer. And he drank a coke / ate a pretzel (as well)'.

(additive, no temporal ordering)

For the 'temporal additive még' we propose the definition below. Similarly to temporal még (see (11)), the time of the asserted event $e$ follows the time of the presupposed event $e^{*}$. Elements of the set of focus alternatives differ from the asserted proposition in the time variable. The only difference between temporal

11. Beck (2016), Umbach (2009), Klein (2007) note that German noch is ambiguous depending on the focus in the sentence. Depending on focus placement, noch can either have an additive or a further-to interpretation. Here we suggest that at least for Hungarian, the nature of the predicates is also relevant in determining whether a truly additive reading is possible.

A reviewer asks about similar issues of focused vs. unfocused még in Hungarian, but in the Hungarian variety of the first author it is unclear whether there is clear parallel to the German facts.

Another reviewer asks about the evidence against temporal ordering in (25). Note that both the alternatives below are possible:

(i) János ivott egy sört ... és evett elötte még egy

J-NOM drank one beer-ACC $\ldots$ and ate before.poss still one

perecet. I és evett utána még egy perecet

pretzel-ACC / and ate after.Poss still one pretzel-ACC

'John drank a beer ....and ate a pretzel before that / and ate a pretzel after that' 
még and the 'temporal' additive még is that the required relation is precedence by the presupposed event rather than abutment.

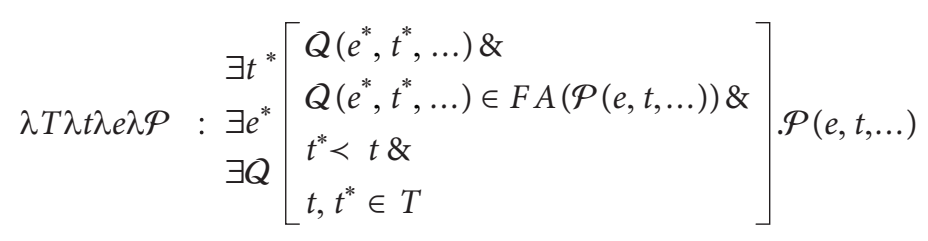

The non-temporal additive appears to be synonymous with the additive particle is 'too'. If this was so, it would be puzzling, because so far we have identified a scalar argument in all senses of még. Here we follow Beck (2016) and Umbach (2009), who suggest that with non-temporal additives, the relevant scale is order of mention.

Thus, for non-temporal additives, we posit the following:

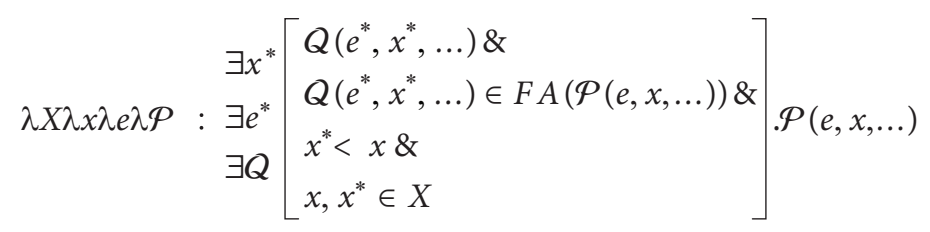

Where $x, x^{\star}$ are individuals, and $X$ is an ordering of individuals. Here $<$ is an order of mention relation which holds between $x^{*}, x$ iff $x^{*}$ was introduced into the discourse earlier than $x$.

\section{Templatic meaning}

The previous section presented a number of meanings for még and specific definitions for those meanings. In this section we describe a general, templatic meaning which captures all of the meanings above.

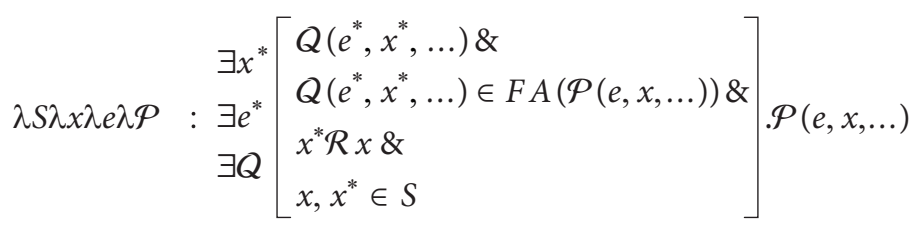

As before, $\mathcal{P}, Q$ are saturated predicates, except for the arguments indicated. The arguments $e$ and $e^{*}$ are event variables. Specific to the template, $x$ and $x^{*}$ are scalar entities (times, degrees, etc); $\mathcal{R}$ is a relation (for example, $<,>,<$, or $\propto$ ) and $S$ is a scale. As seen above, $F A$ is a set of focus alternatives to $\mathcal{P}(e, x)$ which differ in 
terms of variation of elements under focus, which may include times, degrees, or subconstituents (assuming 'transparency' of the event variable).

Given variability in the specific type of scale, scalar relations/entities and focus alternatives, the meanings shown above can be derived by selecting the focused element and the ordering relation, as discussed above.

One of the salient meanings that we have not addressed so far is concessive still. The Hungarian equivalent, mégis, contains the additive particle is 'too' in addition to még. The meaning and the contribution of the additive particle are discussed in the next section. ${ }^{12}$

\section{Concessive mégis and additives}

The concessive meaning is absent for még. Notably, the Hungarian concessive element contains még and the additive particle is: ${ }^{13}$

(29) Bár fogyókúrázott, Feri *még / mégis

though diet.PAst.3sg Feri.NOM still / still

evett zsiros-kenyeret.

ate lard.ADJ-bread.ACC

'Even though he was on a diet, Feri still ate some bread with lard.'

The definition we propose for concessive mégis is given below. Note that it differs significantly from the templatic version proposed above. This is not surprising, since mégis contains the additive particle in addition to még and so we would predict the meaning to also contain additional elements.

$\begin{aligned} \exists e^{*} & \exists Q \\ \lambda S \lambda w \lambda e \lambda P: & \exists e^{\prime} \\ & \exists \mathcal{R} \\ & \exists W^{c g} \subseteq W\end{aligned}\left[\begin{array}{l}\mathcal{R}\left(e^{\prime}, w, \ldots\right) \& \\ Q\left(e^{*}, \ldots\right) \in F A(\mathcal{P}(e, \ldots)) \& \\ \sum\left(\left\{\Lambda\left(w^{\prime}\right) \mid \mathcal{R}\left(e^{*}, w^{\prime}\right) \wedge \mathcal{P}\left(e, w^{\prime}\right) \wedge w^{\prime} \in W^{c g}\right\}\right)< \\ \sum\left(\left\{\Lambda\left(w^{\prime \prime}\right) \mid \mathcal{R}\left(e^{*}, w^{\prime \prime}\right) \wedge Q\left(e, w^{\prime \prime}\right) \wedge w^{\prime \prime} \in W^{c g}\right\}\right) \\ \sum\left(\left\{\Lambda\left(w^{\prime}\right) \mid \mathcal{R}\left(e^{*}, w^{\prime}\right) \wedge \mathcal{P}\left(e, w^{\prime}\right) \wedge w^{\prime} \in W^{c g}\right\}\right), \\ \sum\left(\left\{\Lambda\left(w^{\prime \prime}\right) \mid \mathcal{R}\left(e^{*}, w^{\prime \prime}\right) \wedge Q\left(e, w^{\prime \prime}\right) \wedge w^{\prime \prime} \in W^{c g}\right\}\right) \in S\end{array}\right] \mathcal{P}(e, w, \ldots)$

12. A reviewer points out that in Hungarian is on its own can also have a scalar meaning ('even'). However, a similar observation holds for English, as in Don't feel bad, this problem would be difficult for Einstein too, even though English too is uncontroversially a plain additive. We note that for both English and Hungarian, this scalar reading of is/too requires a special rise-fall intonation. Given the role of prosody, we assert that it is possible to maintain that these elements are not inherently scalar, and marked prosody (or whatever contributes marked prosody) yields the scalar meaning (which may actually derive from a conversation implicature).

13. The concessive meaning is also available for akkor is 'then too', a fact that we do not address here. 
In (30), $W^{g g}$ is the set of worlds consistent with the common ground. Assuming such examples involve verum focus, the set of Focus Alternatives contains $\mathcal{P}(e)$ and $\neg \mathscr{P}(e) . \Lambda\left(w^{\prime}\right)$ is the likelihood of $w^{\prime}$. Building on that, $\Sigma\left(\left\{\Lambda\left(w^{\prime}\right) \mid \ldots\right\}\right)$ is the sum of the likelihood of every world in a particular set. Thus both the number of worlds in the set and the individual likelihood of each particular world affects the result. Finally, $S$ is an ordering of real numbers. In sum, the overall likeliness of the worlds in which both the presupposed 'frame-setting' eventuality (Even though he was on a diet in (29)) and the eventuality in question both occur is lower than the overall likeliness of the worlds in which the 'frame-setting' eventuality occurs but the eventuality in question does not (given the speaker's background knowledge / assumptions).

In general, the presence of the additive is seems to correlate with the additional presupposition of a 'framing' eventuality. The scalar elements, which involve summation of likelihood over sets of worlds, is also more complex than in the examples seen before.

Hungarian is not unique in invoking the additive particle for concessives. Hindi and Nepali also combine an additive element with a temporal adverb for the concessive meaning, as discussed in more detail in Section 6.2.

The table below summarizes the relations between the relevant temporal adverbials. Note that Hindi and Nepali combine the additive element with an adverb which can mean "again" or "then (= after that)". As shown in Section 6.1 below, the még element in Hungarian is etymologically connected to meg, which in Old Hungarian was used with a counter-directional sense (Benkő 1970), a sense which is closely connected with repetitives (cp. English again, originally used in the sense "against; back"). If morphology reflects semantic structure, this is not surprising, given the differences between the templatic definition of (28) and the concessive adverb.

Table 2. Crosslinguistic comparison of aspectual adverbs

\begin{tabular}{llll}
\hline Hungarian & Hindi & Nepali & Meaning \\
\hline $\begin{array}{l}\text { megint } \\
\text { ismét }\end{array}$ & $\begin{array}{l}\text { phir } \\
\text { phir se }\end{array}$ & pheri & $\begin{array}{l}\text { repetitive, } \\
\text { restituitive "again" }\end{array}$ \\
\hline még (mindig) & $\begin{array}{l}\text { abhī bhī } \\
\text { ab tak }\end{array}$ & $\begin{array}{l}\text { aile samma } \\
\text { ajha(i) (pani) } \\
\text { aile pani }\end{array}$ & $\begin{array}{l}\text { temporal/continuity } \\
\text { "still" }\end{array}$ \\
\hline még & abhī (?) & ? & marginality "still" \\
\hline $\begin{array}{l}\text { mégis } \\
\text { akkor is }\end{array}$ & phir bhī & $\begin{array}{l}\text { pheri pani } \\
\text { tai pani }\end{array}$ & $\begin{array}{l}\text { concessive/adversative } \\
\text { "still" }\end{array}$ \\
\hline is & bhī & pani & $\begin{array}{l}\text { additive particle "also", } \\
\text { conjunction (Hungarian) }\end{array}$ \\
\hline
\end{tabular}


Let us briefly address the scalar additive element, which also contains both még and is. Unlike concessive mégis, it is a complex disjoint element:
Mindenki
zsiros-kenyeret
kért. Még Feri
*(is)
everyone.NOM lard.ADJ-bread.ACC asked still Feri.NOM too
zsíros-kenyeret kért.
lard.ADJ-bread.ACC asked
'Everyone asked for some bread with lard. Even Feri asked for some bread with lard.'

We propose that here még contributes the scalar component, while the additive is functions as a plain additive. ${ }^{14}$

The previous sections outlined a general templatic approach to még and noted that the presence of the additive element in the concessive mégis may not be an accident. The next two sections focus on previous accounts, noting some basic differences between the current and earlier proposals. Section (6) presents some historical facts and comments on their relevance for the pattern of aspectual particles.

\section{Other accounts}

A number of papers discuss various senses of still or the German equivalent noch; these include Michaelis (1993), Ippolito (2007) and Beck (2016). These papers focus on the semantic properties and - in some cases - aspectual constraints of aspectual particles. The role of morphology or the positing of a unique, general definition is generally not a concern, unlike in the present approach. Beck (2016:3) explicitly assumes a general definition of the various senses of noch. However, we note that there are some issues with the general approach. First of all, she assumes abutment for all senses (see below); and the implicature of noch, also discussed below, is also problematic. In addition, she is not concerned with complex forms of the sort that contain the equivalent of still and some other element, such as the additive we noted for the concessive and the scalar additive.

Without presenting and discussing the earlier proposals in great detail, we point out some differences between the current proposal and other treatments.

\footnotetext{
14. As noted above in fn. 12 , a reviewer points out that még is not required for a concessive interpretation. Furthermore, s/he cites L. Varga (p.c.) who notes that the concessive reading is possible even in absence of both még and is. We note that such examples require a marked, rise-fall intonation (absent if both elements are overt) and assume that some covert element (perhaps a covert még) contributes the marked prosody.
} 
The first general issue is abutment. Recall that in the temporal reading the presupposed event left-abuts the asserted event. For the earlier approaches, abutment is assumed to survive in other interpretations - notably, in the marginality sense, where the degree in the assertion is assumed to abut the standard (e.g. the standard of safety). We have argued that abutment is not necessary; it is certainly absent in the comparative and comparative marginality senses. We suggested that even in the case of simple marginality, it may be an implicature.

The other salient issue concerns the relevance of temporal still for the future. For example, Beck (2016) explicitly proposes that temporal still implicates that the event will not hold at a time that follows the time of the asserted event. For example, for Beck, It's still raining implicates that it won't be raining in the future. This implicature is also held responsible for the oddity of temporal still in John is still dead. We suggest that in fact there is no future implicature. Consider the sentence This dress is still expensive, which may be uttered by someone who keeps checking the price of a particular dress, hoping to purchase it if it is on sale. In this case, there is no necessary entailment, implicature or presupposition that the dress will be cheaper at a later time. Rather, we propose that there must be salient worlds in which at the time of the assertion the eventuality is not true - that the speaker considered the dress no longer being expensive a salient possible alternative to the current actual state of affairs.

So, likewise, the proposition It is still raining is licit or felicitous only if there are salient worlds where It is not raining is true (e.g. where the speaker had some reason to believe that it might not be raining). The oddity of examples like John is still dead, also discussed by Beck (2016), then arises because if the proposition John was dead $\left(a t t^{*}\right)$ is part of the conversational background, then there will not be likely to be salient worlds where John is not dead now/ $t$ ( $t$ following $\left.t^{*}\right)$ is true (i.e. if a speaker believes that John was dead at some earlier time $t^{*}$ they are unlikely to entertain beliefs about John not being dead at a later time $t$ under ordinary circumstances).

Ippolito (2007) focuses on English still and already. She discusses aspectual/ temporal properties and temporal, marginality and concessive uses. She also relates these uses to additive, scalar and exclusive particles. In addition, she also mentions the repetitive again. One of her key observations (from our perspective) is the claim that temporal still and again focus the time variable, similarly to what we have proposed above. We note that some definitions she offers seem to be erroneous. For example, Ippolito argues that the concessive involves the presupposition that the set of worlds in which the framing proposition (John studied all night) and the proposition at issue ((still) he failed the exam) are both true are less likely than the worlds in which the framing proposition is not true, but the proposition at issue is true. This seems incorrect. The comparison which seems to the relevant 
one is where the framing proposition is true but the proposition at issue is not. I.e., where John studied all night and failed is held as less likely than John studying all night and not failing.

Furthermore, in the discussion of concessive still, Ippolito argues that the worlds considered must be maximally similar to the evaluation world. We suggest that this not a necessary assumption. The sum of likelihood and the requirement that the (sets of) worlds under consideration include only those worlds where the frame setting proposition is true restricts the set of worlds in the appropriate manner. ${ }^{15}$

\section{Extensions and summary}

\subsection{Repetitives}

Historical considerations shed light on some relations among aspectual particles. In connection with Hindi and Nepali, we noted earlier that repetitives are related to concessive adverbs. In fact, repetitives and temporal still are very similar in meaning. While temporal still requires the asserted and presupposed events to abut, repetitives only require precedence. Thus repetitives also fit with the templatic definition proposed for still.

In addition to the similarity in meaning, morphology also reveals a connection between repetitives and még in Hungarian. Some repetitives, megint and ismét are superficially similar to még:

15. Zimmermann (2017) does not discuss aspectual still, but he does examine particles in Vietnamese which bear on some aspects of the present study. His observation concerning scalar additives is identical to what we have suggested above: that the scalar and additive components are introduced by different elements. He discussed structures of the sort illustrated below, where thậm chí... cũng is reminiscent of the scalar additive még... is of Hungarian.

\footnotetext{
(ii) Tân thì thậm chí $1.7 m$ cũng nhayqua

Tan.TOP,1 PRT SCAL $1.7 \mathrm{~m}$ ADD jump

'Tan can even jump 1.7m.'
}

[Zimmermann 2017: 141]

Zimmermann argues at length that thậm chí is a scalar(-additive) particle and cũng is an additive. However, there are some differences between Vietnamese and the Hungarian facts considered here. First, thi is a topic marker (Zimmermann 2017: 141); this holds for neither element in Hungarian. Second, Zimmermann (2017: 140) notes that cũng sometimes also appears to bear a scalar reading even without the scalar thậm chí. As noted in footnote 13, such a scalar reading is also available in Hungarian in the presence of marked prosody. 


\section{(32)}

Feri megint / ismét ivott egy pálinkát.

Feri.NOM again / again drank one palinka.ACC

'Feri drank a palinka again.'

In fact, both megint and ismét are derived from meg, which is the perfective particle in present-day Hungarian. In addition, még also ultimately derives from meg 'again', 'and, in addition' (Benkő 1970).

The original interpretation of meg was 'back' (crosslinguistically repetitives often derive from a word meaning 'back'; this is also true for such elements in other languages including, among others, English again). ${ }^{16}$

As noted above, the relation between the asserted and presupposed events is one of precedence with repetitives. As with temporal még, the elements of the set of Focus Alternatives differ from the asserted event in terms of temporal specification: ${ }^{17}$

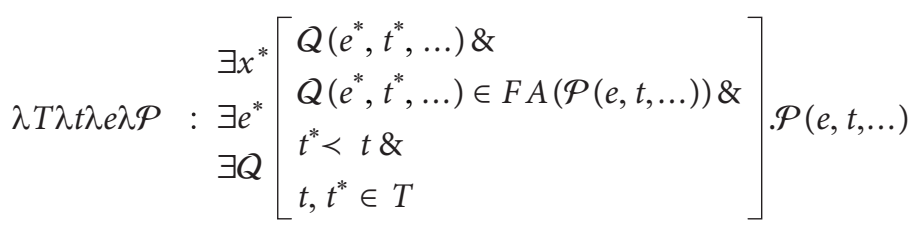

\subsection{Crosslinguistic patterns}

The allosemy of certain aspectual adverbs is a property found in aspectual adverbs in other languages as well. English still and German noch are well known. As well, in Indo-Aryan languages like Hindi and Nepali we find adverbial elements which recur with distinct but related functions in a variety of contexts, see the ambiguous examples below, where Hindi phir, Nepali pheri can mean either "again" or "then" (in the sense of "after that"):

(34) Rām phir so gayā.
Ram then/again sleep went
"Ram slept then/again."

[Hindi]

16. A reviewer suggests that ismét itself can be traced back to an intermediate form which appears in Old Hungarian codices as és még lit. "and/too still", connecting to még "still". However, Benkő (1970) allows ismét could have derived either from még or else from meg an element which at an earlier point could mean "back".

17. A reviewer points out that (33) does not taken into account restitutive readings. However, the point of defining the predicates of eventualities in the fashion that we have is to allow them to attach at various levels of structure, which will have the result that repetitive and restitutive readings will naturally follow from their attachment positions (cf. von Stechow 1996). 
(35) Birendra pheri sutyo.

Birendra then/again slept

"Birendra slept then/again."

[Nepali]

Similarly, just as Hungarian még occurs in a collocation with an additive particle (Hungarian is) with semantics akin to that of English concessive/adversative still, both Hindi phir and Nepali pheri also occur in collocations with an additive particle (Hindi $b h \bar{i}$, Nepali pani) with the same adversative sense:

(36) Shyām guṇ̣̂ā hai; phir bhī merā dost hai.

Shyam villain is, then/again too my friend is

"Shyam's a villain; still ${ }_{\text {conc }}$ he's my friend."

[Hindi]

(37) Pheri pani timro tasbir äkha-mā àe-rahancha.

then/again too your image eye-in come-continues

"Still your image keeps coming into my eyes."

[Nepali]

For more detailed discussion of aspectual adverbs in Indo-Aryan, see Slade \& Csirmaz (under review).

Table 3 provides relevant correspondences between Hungarian, Hindi, Nepali, and German.

Interestingly, though Hungarian még does not bear the same sort of temporal ordering as Hindi phir or Nepali pheri which can mean "after that", it can bear a sense which is nearly identical but where the ordering relation is reversed:
Még épitett egy házat
(mielött meg halt)
still built one house.ACC before PERF died
'He built a house (before he died)'

The denotation for this sense of még is provided below in (39): ${ }^{18}$

(39) még "(inverse) then; before that":

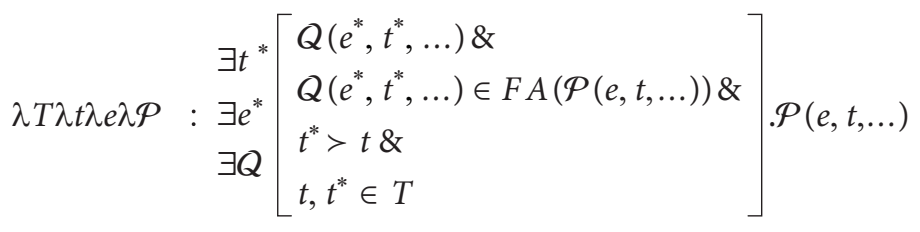

Here, as in other cases where the syntactic predicate is part of the focus, the predicate of eventualities can be different in the presupposition and the assertion (as per

18. Note that the "then; after that" denotation for Hindi phir, Nepali pheri would be identical but for the reversal of the ordering, i.e. $t^{*}<t$. 
Table 3. Comparison of Hungarian, Hindi, Nepali, \& German

\begin{tabular}{|c|c|c|c|c|}
\hline Hungarian & Hindi & Nepali & German & Meaning \\
\hline akkor & $\mathrm{tab}$ & $\begin{array}{l}\operatorname{tab}(a) \\
\text { taile }\end{array}$ & da & "then (at that time)" \\
\hline az (u)tán & phir & $\begin{array}{l}\text { pheri } \\
\text { tab(a) pachi }\end{array}$ & dann & "then (after that)" \\
\hline még & - & - & - & "before that" \\
\hline $\begin{array}{l}\text { megint } \\
\text { ismét } \\
\text { újra }\end{array}$ & $\begin{array}{l}\text { phir } \\
\text { phir se } \\
\text { (dobr) }\end{array}$ & pheri & wieder & repetitive, restituitive \\
\hline \multicolumn{5}{|l|}{$\cdots$} \\
\hline még (mindig) & $\begin{array}{l}\text { abhī bhī } \\
\text { ab tak }\end{array}$ & $\begin{array}{l}\text { aile samma } \\
\text { ajha(i) (pani) } \\
\text { aile pani }\end{array}$ & noch & temporal/continuity "still" \\
\hline $\begin{array}{l}\text { mégis } \\
\text { akkor is }\end{array}$ & phir bhī & $\begin{array}{l}\text { pheri pani } \\
\text { tai pani } \\
\text { tarai pani } \\
\text { ra pani }\end{array}$ & dennoch & $\begin{array}{l}\text { concessive/adversative } \\
\text { "still" }\end{array}$ \\
\hline még ... is & bhī & pani & sogar & scalar(-additive) \\
\hline is & bhī & pani & auch & additive particle "also" \\
\hline
\end{tabular}

the normal calculation of focus alternatives), so for example in (38), halt "died" is one of the focus alternatives to épitett egy házat "built a house". ${ }^{19}$

19. In Hungarian, még also occurs in idiomatic expressions used to express speaker evaluation of an action or wish (on the part of someone other than the speaker, i.e. it cannot be self-evaluative) as very inappropriate or undesirable.
(iii)
a. Még mit nem!
still what.ACC not
'God forbid!'
b. Még csak az kéne!
still only that.ACC is.COND
'God forbid!/ That's just what we need!'

At this point, we cannot offer a more specific description of the role of még in these examples. We note, however, that it appears that még in these examples seems to require a scale of desirability, and it indicates that the salient event is ranked very low on this scale - in general a semantic contribution in line with that we have seen associated with még in other contexts as described above. 


\subsection{Summary}

In sum, we explored the meaning of a variety of aspectual elements which appear as or contain még in Hungarian. In several cases, we proposed changes to earlier definitions offered for its English or German equivalents, still or noch. Most importantly, we argued that it is possible to give a templatic definition - which differs from the one adopted by Beck (2016) - and by allowing for the variation of some arguments, the nature of the scale, the ordering relation and the focused element, we obtain the meanings discussed from the templatic base. In addition, the generalization extends to repetitives, which share a source with még and are, in some cases, superficially similar to it.

Table 4 below summarizes the meanings discussed and accounts proposed, in terms of how each of the different senses assigns specifications to the properties of the templatic base. ${ }^{20}$

Table 4. Summary of aspectual elements

\begin{tabular}{lllll}
\hline Item & Scale & Relation & Focus & $\begin{array}{l}\text { Identity of scale/ } \\
\text { focus }\end{array}$ \\
\hline "temporal" still & time & $\propto$ & time & yes \\
"temporal additive" & time & $\prec$ & time & yes \\
STILL & & & individuals & no \\
"marginality" sTILL & degrees & $>$ & verum & no \\
"Concessive" sTILL & likelihood & $<$ & time & yes \\
AGAIN & time & $<$ & non-time element & no \\
THEN" & time & $<$ & &
\end{tabular}

*English ordering "then" behaves as a relational inverse of the Hungarian use of még described in (39). That it requires part of the clause to be focused (rather than the time variable) is clear from the infelicity of examples like (iv) in contrast to (v):

(iv) John built a house. \# Then MARY planted a flower garden.

(v) John built a house. Then he PLANTED A FLOWER GARDEN.

Naturally, a number of questions remain. These include morphological and semantic connections in other languages, including the Hindi and Nepali facts discussed briefly above. Crosslinguistic variation and the role of the additive particle are also issues that remain to be discussed in the future.

20. Where $\propto=$ left-abuts; $<=$ precedes; $>=$ follows; $<=$ is less than. 


\section{Acknowledgements}

We acknowledge the help of Éva Dékány and comments by reviewers for ICSH 13. We are indebted to the organizers of the conference, especially to Veronika Hegedüs, for assistance.

\section{References}

Beck, Sigrid. 2016. Discourse related readings of scalar particles. Proceedings of SALT 26, $142-$ 165. https://doi.org/10.3765/salt.v26io.3783

Benkő, Lóránd (ed.). 1970. A magyar nyelv törtnéti-etimológiai szótára [A historical-etymological dictionary of Hungarian], vol 2. Budapest: Akadémiai Kiadó.

Heim, Irene. 2001. Degree operators and scope. In Caroline Féry \& Wolfgang Sternefeld (eds.), Audiatur Vox Sapientiae. A Festschrift for Arnim von Stechow, 214-239. Berlin: Akademie Verlag.

Ippolito, Michela. 2007. On the meaning of some focus-sensitive particles. Natural Language Semantics 15(1). 1-34. https://doi.org/10.1007/s11050-007-9004-o

Klein, Wolfgang. 2007. About the German particles schon and noch. Ms, Max Planck Institute for Psycholinguistics. Published in Klein, Wolfgang. 2018. Looking at Language, 283-323. Berlin: De Gruyter.

Krifka, Manfred. 2000. Alternatives for aspectual particles: Semantics of still and already. Annual Meeting of the Berkeley Linguistics Society 26(1). 401-412. https://doi.org/10.3765/bls.v26i1.1125

Michaelis, Laura A. 1993. 'Continuity' within three scalar models: The polysemy of adverbial still. Journal of Semantics 10. 193-237. https://doi.org/10.1093/jos/10.3.193

Rooth, Mats. 1985. Association with Focus. Amherst, MA: University of Massachusetts dissertation.

Rooth, Mats. 1992. Theory of focus interpretation. Natural Language Semantics 1(1). 75116. https://doi.org/10.1007/BF02342617

Slade, Benjamin \& Aniko Csirmaz. under review. Pieces of Indo-Aryan and Hungarian adverbs. In Moreno Mitrović (ed.), Logical Vocabulary, Logical Change. Amsterdam: John Benjamins.

von Stechow, Arnim. 1996. The different readings of wieder "again": A structural account. Journal of Semantics 13. 87-138. https://doi.org/10.1093/jos/13.2.87

Umbach, Carla. 2009. Another additive particle under stress: German additive noch. Symposium on Logic and Language (LoLa) 10, 149-156. Budapest: HAS.

Zimmermann, Malte. 2017. Scalar particles and contrastive topics in English and Vietnamese. In E. A. Bar-Asher Siegal (ed.), Proceedings of IATL 2015, 123-152. Cambridge, MA: MITWPL. 



\title{
Intervocalic voicing of Hungarian /h/
}

\author{
Andrea Deme ${ }^{1,2}$, Márton Bartók ${ }^{1,2}$, Tekla Etelka Gráczi ${ }^{4,2}$, \\ Tamás Gábor Csapó ${ }^{3,2}$ \& Alexandra Markó ${ }^{1,2}$ \\ ${ }^{1}$ Eötvös Loránd University / ${ }^{2}$ MTA-ELTE “Lendület” Lingual Articulation \\ Research Group / ${ }^{3}$ Budapest University of Technology and Economics / \\ ${ }^{4}$ Research Institute for Linguistics, Hungarian Academy of Sciences
}

In this study, we investigated whether the amount of voicing, and the sound quality (expressed in HNR) of / $\mathrm{h} /$ in syllable onset are affected by intervocalic context (vs. post-pausal context), by backness and openness of the flanking vowels, and by a phonological conditioner, pitch-accent. We showed that both measures were similarly high in all intervocalic positions (irrespective of the presence of word-boundary and pitch-accent), while after a pause they were substantially lower, meaning that $/ \mathrm{h} /$ was voiced, and more modally voiced intervocalically, than after a pause. Further, interaction of this effect with that of vowel features led us to conclude that open, close, back, and front vowel groups should be considered internally heterogeneous with respect to their effect on $/ \mathrm{h} /$ voicing.

Keywords: phonetic analysis, fricative voicing, glottal fricative, laryngeal fricative, fraction of voiced frames, HNR, voice leak, intervocalic voicing, breathy voice

\section{Introduction}

In the Hungarian consonant inventory, all but one of the obstruents occur in voiced and voiceless pairs. The only exceptional obstruent is the laryngeal fricative $/ \mathrm{h} /$, which has no voiced counterpart in the system, but may be phonetically realized as a non-contrastive voiced [ $\mathrm{h}$ ] segment (Siptár 2001; Siptár \& Törkenczy 2007). ${ }^{1}$ In our research, we aim to examine this allophonic alternation of the laryngeal fricative from a phonetic point of view, in an attempt to shed more light on the phonetic and phonological factors that may facilitate or restrain the occurrence of [ $\mathrm{h}]$

1. Note that while the phoneme corresponding to the segment(s) at hand is referred to as a voiceless velar fricative / $\mathrm{x} /$ in current phonological descriptions (see Siptár \& Törkenczy 2007), it is described as a laryngeal fricative /h/ in the phonetic literature (see Bolla 1995; Gósy 2004; Kassai 2005). Merely for the sake of simplicity and since the authors of the present paper come from the field of phonetics, the latter practice is adhered to in the present paper. 
in Hungarian, and thus to test previous claims made both in the field of phonology and phonetics on this issue. As a first step in this process, the present study investigates the effect of intervocalic context (vs. post-pausal word-initial position), two vowel quality features, viz. vowel backness and openness, and a phonological conditioner, pitch-accent, on the ratio of voicing that occurs in $/ \mathrm{h} /$ in syllable-onset in laboratory speech. As a second aim, we also investigate the general sound (but not necessarily voice) quality of / $\mathrm{h} /$ tokens with respect to their periodicity, and as a function of the openness and backness of the context vowels. For this purpose, we analyze an additional acoustic parameter, harmonics-to-noise ratio (HNR), which is traditionally assumed to reliably and informatively quantify the amount of voicing and turbulent noise in fricatives, and can account for subtle differences of modally voiced, breathy voiced, and voiceless realizations on a continuous scale.

\subsection{Background}

To Hungarian phonology, the asymmetric behavior of /h/ in voicing assimilation seems to be of the greatest concern, as /h/ triggers regressive devoicing, but does not undergo voicing before voiced obstruents (see e.g., Siptár 2001; Siptár \& Törkenczy 2007). Its allophonic voiceless-voiced alternation, on the other hand, is assumed to be clear-cut: /h/ is taken to occur (almost) invariably as [h] in intervocalic positions (Siptár 2001; Siptár \& Törkenczy 2007) (hereafter, in VhV) as well as in sonorant- $h$-vowel positions (hereafter, son $h V$ ) (Siptár 1994/2016) due to what is often considered a purely phonetic process (Szigetvári 1998). Despite the prevalent view that emphasizes the phonetic nature of the intervocalic voicing of $/ \mathrm{h} /$, in some sources we also find suggestions that the occurrence of [ $\mathrm{h}]$ is to some extent also conditioned phonologically. According to Siptár (1994/2016), in formal or slower speech styles $/ \mathrm{h} /$ may be realized as [ $\mathrm{h}$ ] only in intervocalic contexts where $/ \mathrm{h} /$ is followed by an unaccented vowel, as in tehén [tzhe:n] 'cow'. In these cases, additionally to voicing, / $\mathrm{h} /$ may also be phonetically unrealized, resulting in such surface forms as [tee:n]. If, however, /h/ is followed by an accented vowel, as in $a$ hir [ $v$ 'hirr] 'the news', /h/ may not be voiced and cannot be deleted either (i.e., no ${ }^{*}\left[v^{\prime}\right.$ irr $]$ may occur), or at least not in the speech style mentioned above. By contrast, as Siptár (1994/2016: 265) claims, in fast/casual speech, /h/ may be realized as voiced also in the a hír [ $v^{\prime}$ hirr] context, as in this speech style the rule governing the voicing of $/ \mathrm{h} /$ does not block voicing in the onset $/ \mathrm{h} /$ of an accented syllable.

To summarize the above phonological description of the behavior of Hungarian $/ \mathrm{h} /$ in syllable onset, we highlight three major claims: the realization of $/ \mathrm{h} / \mathrm{as}$ a voiced [h] segment is facilitated by (i) intervocalic context, (ii) sonorant-vowel context, and (iii) the absence of prominence on the syllable starting with $/ \mathrm{h} /$. Such 
claims could easily be supported or falsified by objective empirical data, and thus one might expect that we find such data in the literature. However, as our review of empirical phonetic research will show, this is not the case. The effect of the first two factors, i.e., intervocalic and sonorant-vowel contexts, has not yet been tested under strictly controlled experimental conditions, while the effect of the third one, namely the effect of prominence, has not yet been addressed in any kind of structured empirical studies at all.

Before we review the moderate amount of empirical evidence on the voicing of /h/ in Hungarian, we make a brief note here on how the very same phenomenon is treated in other languages. Voicing of /h/-like segments in intervocalic position, or in a voiced environment in general is claimed to be present in many languages: British English (Ladefoged \& Johnson 2011: 157), Amharic (IPA Handbook 1999: 48), Czech (IPA Handbook 1999: 70), Hebrew (IPA Handbook 1999: 98), and Korean (IPA Handbook 1999: 112), to name a few. However, to the authors' knowledge, to date there are only two studies by Mitterer (2018) and by Teras (2018) which provided some quantitative data on the amount of voicing found in intervocalic $/ \mathrm{h} /$ or on the ratio of voiced variants among intervocalic tokens. However, these studies provide no data on $/ \mathrm{h} /$ tokens in other than intervocalic (e.g., post-pausal) positions, or on the acoustic characteristics of breathy voice in /h/ tokens, which could have served as reference for our present analysis.

While investigating acoustic correlates of the singleton-geminate opposition in Maltese, Mitterer (2018) incidentally found that intervocalically, more than $80 \%$ of the analyzed Maltese singleton /h/ tokens were "fully voiced" (i.e., voiced throughout the whole segment), while the remaining $20 \%$ showed "a relatively uniform distribution of voicing leaks from $10 \%$ to $80 \%$ " (2018: 35). From the data presented on figures we can also infer that while the average duration of singleton $/ \mathrm{h} /$ tokens was $150 \mathrm{~ms}$, the average duration of voice leak was approximately $70 \mathrm{~ms}$, resulting in a ratio of $47 \%$ of voicing in intervocalic $/ \mathrm{h} /$ on average. Teras (2018) studied pronunciation variants of the short intervocalic/h/in Estonian, and labelled $/ \mathrm{h} /$ tokens manually in a binary manner (voiced vs. voiceless). She found that $70 \%$ of the intervocalically positioned $/ \mathrm{h} /$ tokens were realized as voiced, while an additional 6\% percent labelled as unvoiced were also "partly voiced" (2018: 84). Although these results do not lend themselves to direct comparison with ours, since Mitterer presents only absolute voicing durations (besides the gross ratios of "voiced" tokens presented by both Mitterer and Teras), both studies are important for our present analysis, mainly for two reasons. First, these data provide evidence that intervocalic/h/-voicing occurs in several languages. Second, they also further establish the relevance of our present analysis by showing how limited the amount of available data is on the extent of voicing observable in the laryngeal fricative, not to mention the quality of voicing it exhibits. 
In Hungarian phonetics, the status, place of articulation, and voicing characteristics of $/ \mathrm{h} /$ have long been a matter of debate. By now, the status of $/ \mathrm{h} / \mathrm{as}$ a consonant has been clearly established in Hungarian phonetics (see Laziczius 1937, 1963/1979; Bolla 1995; Gósy 2004; Kassai 2005). As far as the allophones of $/ \mathrm{h} /$ are concerned, more specifically the place of articulation of these, and the contexts that facilitate the occurrence of each allophone, the phonetic handbooks of Hungarian show a diverse picture. Since the present study focuses on the voicing characteristics of $/ \mathrm{h} /$ in Hungarian, we do not detail the various allophones enumerated in these handbooks, rather we focus on the relevant ones: [h] and [6]. All of the recent phonetic textbook authors (Bolla 1995; Gósy 2004; Kassai 2005) link voiced fricative [h] to intervocalic contexts. Bolla (1995), on the basis of $\mathrm{X}$-ray images taken from one male and one female speaker, considers these speech sounds pharyngeal, even though he uses the IPA symbols of voiceless and voiced laryngeal fricatives. With the exception of Bolla, [h] is undisputedly assumed to bear a glottal place of articulation by all of the cited sources. (Note, however, that due to strong coarticulation expected between $/ \mathrm{h} /$ and the neighboring vowels, the accompanying secondary oral gestures in / $\mathrm{h} /$ warrant further discussion, see Section 1.3.) To summarize these views on the voicing feature of the above mentioned allophones, (i) /h/ is unanimously claimed to be voiceless in post-pausal syllable onset, and (ii) it is unanimously claimed to be voiced in syllable onset intervocalically. These observations lead us to the last but, with respect to the present study, most important point in our summary, the issue of voicing in Hungarian /h/.

In the first empirical studies which dealt with $/ \mathrm{h} /$ in Hungarian, with regard to its voicing, two important questions were formulated: (i) if the laryngeal fricative sounds may be voiced, and (ii) how one should interpret their uncommon voicing patterns, which combine two articulatory gestures: the incomplete adduction and the clearly observable undulation of the vocal folds. As Laziczius (1937) points out citing Meyer and Gombocz (1909), voiced [6] was observed instrumentally already in the early 1900's between vowels (or between voiced sounds in general, as first formulated by Meyer, according to Laziczius) in 20 tokens using a kymograph (Meyer and Gombocz 1909, see Laziczius 1937). That is, there was evidence available to formulate the tentative conclusion that a voiced laryngeal fricative exists and occurs allophonically in intervocalic positions in Hungarian. Along with this finding, according to Laziczius (1937), the most intriguing questions the existence of this voiced allophone raised were (i) if [h] should really be considered an allophone of the laryngeal voiceless fricative, as the constriction and frication produced in [ $\mathrm{h}]$ is fundamentally different from that observable in its voiceless counterpart [h], and (ii) if [h] should be simply considered "voiced", as its voicing without complete vocal fold contact is clearly different from the voicing of vowels or other obstruents. Regarding the first question, Laziczius (1937) implicitly seems 
to suggest that despite the apparent differences between the fricative gestures in $[\mathrm{h}]$ and [ $\mathrm{h}]$, these sounds are not to be distinguished more than as allophonic variants, as they do not reflect a linguistically relevant opposition in Hungarian. ${ }^{2}$ As one might expect, today's mainstream phonetic and phonological description of Hungarian follows this tradition. As to the latter question, he suggests that instead of voicing, the term (glottal) murmur should be used which encompasses both the fricative gesture and the voicing gesture in the glottis, and distinguishes the voicing of [ $\mathrm{h}$ ] from the full voice observable in voiced obstruents and vowels (Laziczius 1937). Nowadays, additionally to glottal murmur, the term breathy voice (see also e.g., Maddieson 1984; Stevens 1999) and whispery voice (Laver 1994) are also used for the unique voicing patterns / $\mathrm{h} /$ sounds exhibit. However, not only the terminology but also the articulatory and acoustic parameters assigned to these terms may also vary with authors. ${ }^{3}$ (For an illustration of differences in the articulation of [h] and [h], see Esling 2005.)

In sum, studies in Hungarian phonetics from the first half of the 20th century already claimed that there is evidence to assume the existence of a voiced laryngeal fricative in Hungarian, and they also realized the peculiarity of the voice quality it displays. However, the systematic exposure of the factors that facilitates the occurrence of [ $\mathrm{h}]$, and the acoustic description of its voicing characteristics were at that time, and as we will see below, are still, missing from the literature.

As we already briefly discussed, in the phonetic textbooks published in the last decades, a very strong agreement is reached with respect to the occurrence of breathy voiced $/ \mathrm{h} /$, irrespective of its place of articulation. According to this consensus, and in line with phonology, Hungarian /h/ is (breathy) voiced in all VhV contexts (Laziczius 1963/1979; Bolla 1995; Kassai 2005), as well as in all Son $h$ V contexts (Laziczius 1963/1979; Kassai 2005). But interestingly, these prevalent assumptions are treated as trivial, despite the fact that ever since the study of Meyer and Gombocz (1909) who observed the breathy voiced [ 6 ] in only 20 intervocalic tokens of $/ \mathrm{h} /$ in unsystematically varying contexts, there has been only one experimental attempt to gather some more evidence for it, by the use of modern, and (at least in some sense) more reliable techniques, in more speakers, and via the analysis of more than 20 data points (Gósy 2005, see below). Moreover, the

2. Actually, the phonemic distinction between $[\mathrm{h}]$ and [h] is generally very rare, as it is attested only in two of the 317 languages included in the UCLA Phonological Segment Inventory Database (Maddieson 1984).

3. Breathy voice and whispery voice are compound phonatory modes involving two particular types of voiceless airflow, whisper and breath, and a voicing gesture (for further discussion see Laver 1994; Gobl \& Ní Chasaide 1995). 
hypothesis that Son $h \mathrm{~V}$ contexts also facilitate the voicing of /h/ to the same extent as $\mathrm{VhV}$ contexts, has never been addressed and corroborated experimentally. The same also applies to Siptár's (1994/2016) suggestion that prominence may play a role as a governing factor in the $[\mathrm{h}] \sim[\mathrm{h}]$ alternation.

As the first, and to date the only follower of the path Meyer and Gombocz had set for research, Gósy (2005) analyzed 50 intervocalic realizations of $/ \mathrm{h} /$, by the use of visual inspection of the spectrogram and the oscillogram, and a categorical analysis that differentiated only between voiced and voiceless realizations (the criterion for $/ \mathrm{h} /$ to be classified as voiced was whether it showed low-frequency periodicity for minimally two thirds of its length). The material consisted of a number of different Hungarian vowel qualities serving as VhV contexts in Hungarian words. As the aim of the study was an initial exploration of the occurrence of the voiced allophone of /h/, these VhV contexts varied unsystematically: some contexts were symmetrical, some asymmetrical, some occurred word-medially, while others at word boundaries. The vowel opening and backness features were also not systematically controlled factors, or at least their variation did not result in a numerically well-balanced design, and neither were these features tested in otherwise completely well-matched comparisons (e.g., vowels were not matched for the backness feature, when the effect of openness was evaluated). In the final analysis, Gósy (2005) concluded that /h/ is likely to undergo voicing (i) if the speech rate is fast, ${ }^{4}$ and the duration of the consonant is reduced accordingly, and (ii) if the $/ \mathrm{h} /$ sound is produced in the symmetric context of front vowels (as opposed to back vowels). More specifically, among all front contexts approx. $75 \%$ of $/ \mathrm{h} /$ tokens were realized with 100\% voicing, while among back contexts, only approx. 38-39\% (Gósy 2005: Figure 13).

Even though it may be claimed that due to the unbalanced speech material, the cited conclusions should be regarded as only tentative, they point to a very important question, namely, if the features of the vowels that serve as context for $/ \mathrm{h} /$ may play a role in facilitating the intervocalic voicing of $/ \mathrm{h} /$. More specifically, on the basis of the results of Gósy (2005), we may propose that both backness and openness should be tested as potential factors affecting the voicing of intervocalic $/ \mathrm{h} /$. The reason to include also openness in the analysis is basically the same as the rationale behind measuring the effect of backness, i.e., the interaction between the tongue position and the laryngeal settings that is exerted via a complex system of physiological and aerodynamical linkages between the tongue and the larynx structures.

4. Gósy (2005) provides no specific measure of 'fast' speech. 
As articulatory studies tend to suggest, front close unrounded vowels (e.g., /i/ /e/) (and according to some sources, even the open front/a/, see Demolin et al. 2002) have a higher larynx position than back close, close-mid or open rounded vowels (as e.g., /u/ /o/) (Painter 1976; Hess 1998; Hoole \& Kroos 1998; Demolin et al. 2002). ${ }^{5}$ Although the results are somewhat inconclusive for the effect of the backness feature alone (while Painter 1976 found implications of the backness effect via electromyography, Hoole and Kroos (1998) showed no clear support for it but found high interspeaker variability via digital video filming of the thyroid prominence), and are not really explicit about the effect of vowel openness alone (see e.g., Demolin et al. 2002), we may tentatively claim that front vowels display a higher position of the larynx than back vowels, while to a smaller extent, close vowels are also differentiated by higher positions of the larynx from low vowels. Moreover, larynx position also affects the production of voicing, since lower positions of the larynx induce a greater abduction of the vocal folds (Zenker \& Zenker 1960; Pabst \& Sundberg 1992), while higher positions increase adduction, and thus tension in the vocal folds (Sundberg \& Askenfeld 1981; Honda et al. 1999). As a result, a higher position of the larynx also decreases the possibility of creating a glottal chink needed for the production of breathy voice or voicelessness.

Now, as a result of such governing forces of articulation as 'articulatory economy', i.e., the (maximal) reduction of metabolic costs of speech production (see e.g., Lindblom 1990 for further details), we may assume that the vertical position of the larynx may be lower in / $\mathrm{h} /$ if it is flanked by back/open vowels symmetrically (rather than by front/close vowels), since back/open vowels also induce lower position of the larynx. This interrelation may be regarded as 'secondary' coarticulation, as coarticulation in this case affects articulatory gestures which are not traditionally considered to be primary gestures in the production of speech sounds, such as vertical larynx position. Consequently, we may also expect that the maintenance and/or the quality of voicing in / $\mathrm{h} /$ varies as a function of vowel quality, especially vowel backness and openness. On this basis, we argue that the vocalic features openness and backness, affecting the vertical position of the larynx both in the vowel and possibly in the enclosed consonant due to coarticulation, should both be tested as potential factors that may also affect the control and the quality of voicing in the enclosed laryngeal fricative.

5. Actually, this interrelation is only true for languages that do not use the advanced tongue root [ATR] feature, since in the [ATR] languages the opposite relationship was observed empirically between vowel openness and larynx height, as reviewed and pointed out by Hess (1998). 


\subsection{Aims}

Before discussing the aims of the present study, let us briefly recapitulate the claims made in the literature whose validity is at issue. First, it is claimed without firm empirical evidence that Hungarian /h/ in syllable onset is (breathy) voiced in all VhV contexts (Laziczius 1963/1979; Bolla 1995; Siptár 2001; Siptár \& Törkenczy 2007; Kassai 2005), as well as in all SonhV contexts (Laziczius 1963/1979; Siptár 1994/2016; Kassai 2005). The most reliable experimental attempt addressing the effect of $\mathrm{VhV}$ context so far concluded that / $\mathrm{h} /$ is likely to undergo voicing if it is produced in the symmetric context of front vowels (rather than back vowels) (Gósy 2005). However, the evidence supporting this conclusion was obtained in a study where the analyzed contexts were most probably not well-controlled for all features of interest, and thus the conclusions need further support and clarification. Moreover, on the basis of the findings of Gósy (2005), and the complex interlinks between lingual and glottal articulatory structures, we also propose that the effect of vowel openness should also be tested as a potential conditioner of $/ \mathrm{h} /$ voicing. Second, it is also claimed without objectively gathered empirical data that $/ \mathrm{h} /$ may be realized as [h] only in intervocalic contexts where $/ \mathrm{h} /$ is followed by an unaccented vowel (Siptár 1994/2016). For this claim we find no objective evidence in the literature.

In the present study, we aim at gathering empirical evidence for all but one of these claims and proposals. Our primary goal is to test four effects that may potentially affect the voicing characteristics of intervocalic /h/: (i) intervocalic context (vs. post-pausal word-initial position), two vowel quality features of the flanking vowels, (ii) backness, and (iii) openness, and (iv) a phonological conditioner, prominence. ${ }^{6}$ In the present study we test these effects in syllable-onset (i.e., the position of $/ \mathrm{h} /$ in the syllable is a controlled factor in the analysis), since in this position, the place of articulation of / $\mathrm{h} /$ is undisputedly laryngeal (with accompanying secondary oral gestures due to lingual coarticulation; for more details, see Section 1.3).

On the basis of the findings of Meyer and Gombocz (1909), and Gósy (2005), and the previous professional experience of the authors with the segment at hand,

6. Note that due to reasons of space, this study is only concerned with intervocalic context, and symmetrical vowel contexts specifically. The latter decision is further motivated by the fact that the predictions are much clearer for symmetric contexts than for asymmetric contexts (see Gósy 2005), where further movements of the larynx are also expected during the production of $/ \mathrm{h} /$, i.e., a dynamic instead of a static production is expected, with less clearly predictable effects on phonation. However, we already started to gather and analyze data on the effect of the son $h \mathrm{~V}$ context, on which preliminary results were already presented elsewhere (Deme et al. 2018). 
we hypothesized that intervocalic contexts invariantly elicit the voicing of $/ \mathrm{h} /$ in syllable onset, irrespective of the presence or absence of a word boundary and a corresponding sentence level prominence. However, in accordance with the findings of Gósy (2005), the phonetic characteristics of breathy voice, and the above outlined interaction of articulatory structures, we also expected that front and close vowels facilitate the maintenance of voicing in $/ \mathrm{h} /$ more (i.e., throughout the whole segment).

As a second aim, we also intended to give an initial, exploratory description of the quality of breathy voice Hungarian /h/ is claimed to exhibit, or to put it more precisely, to describe the quality of the sound (but not necessarily just the quality of the voice or voiced fraction of the sound) produced during the production of $/ \mathrm{h} /$ in intervocalic positions as opposed to the sound quality (may it be voiced, unvoiced, or partially voiced) it exhibits in a baseline post-pausal position. To grasp this general "sound quality" or signal characteristic difference between realizations, we measured and analyzed harmonics to noise ratio (HNR) as a function of the quality of the flanking vowels, with special attention paid to backness and openness. This acoustic parameter is briefly introduced in the next section, along with the acoustics of breathy voice known from the literature. As far as the quality of the produced sound, i.e., signal noisiness/periodicity of $/ \mathrm{h} /$ is concerned, we predict that higher and more fronted positions of the tongue (and the larynx) facilitate the increased adduction of the vocal folds, and thus reduce the breathiness, i.e., the amount of noise in $/ \mathrm{h} /$.

We find it important to emphasize here that to reliably test our hypotheses, the most fruitful approach is to use a phonetically well-controlled and numerically also well-balanced speech material, and a fine-grained phonetic analysis, which could account for voicing (and the quality of the signal in $/ \mathrm{h} /$ tokens in general) in a gradual way by quantifying these features on a continuous scale. In order to fulfill these expectations, in our experiment we used read laboratory speech, and measured the ratio of the voiced part (RVP) to express the amount of voicing, and harmonics-to-noise ratio (HNR) to express the quality of voicing in the segment at hand. Our approach in all of these respects constitutes novelty both in the topics of fricative voicing (especially in the laryngeal fricative) and the quality of breathy voice in general.

\subsection{The acoustics of breathy voice, and acoustic parameters that quantify voice quality in fricatives}

As discussed in the previous sections, the intervocalic allophone of Hungarian $/ \mathrm{h} /$ in syllable onset is claimed to be a voiced laryngeal fricative [h]; however, as we have also seen in detailed phonetic argumentations, the voicing of $/ \mathrm{h} /$ is 
a very special type of phonation, namely breathy voice. Therefore, to reveal if intervocalic /h/ is really "voiced", we must somehow grasp the (subtle) acoustic difference between the voiceless (or, applying Laver 1994's terms, the breath phonated) [h] and the breathy voiced [h] variant of the laryngeal fricative. Based on the acoustic and articulatory features associated with breathy voice (and summarized briefly below), we opted for the harmonics to noise ratio (HNR) parameter to operationalize this difference, which expresses the harmonicity/noisiness of the voice source.

In the production of breathy voice, the vocal folds vibrate very inefficiently, and they never come fully together during the "closed" phase. As a result, a substantial amount of air is constantly escaping through the glottis during the whole phonatory cycle in the form of a turbulent air stream, causing a clearly audible frication noise characterizing this special voice quality (see e.g., Laver 1994; Gobl \& Ní Chasaide 1995; Stevens 1999). In accordance with this, and according to Gobl and Ní Chasaide (1995), an important acoustic cue that differentiates breathy voice from other "noisier" types of phonation, including voicelessness, is a dominant periodic component relative to the noise component. Consequently, we propose that HNR, a measure of signal harmonicity is appropriate to quantify the fine-grained phonetic difference between breathy voiced and voiceless realizations of $/ \mathrm{h} /$, and it may also reliably reflect the dominance of noise/periodic components within the groups of phonated variants. As its name suggests, HNR expresses the relation between periodicity and noise in a signal, and so it can be a measure of both degree of voicing and "noisiness", i.e., how periodic (as opposed to aperiodic) a sound is (Gradoville 2011; G. Kiss 2013). A HNR of $20 \mathrm{~dB}$ means that $99 \%$ of the energy of the signal is in the periodic part, and 1\% is noise; in other words, HNR approximating to $20 \mathrm{~dB}$ indicates a modally voiced (e.g., a vowel) segment, while a $\mathrm{HNR}$ of $0 \mathrm{~dB}$ means that there is equal energy in the harmonics and in the noise (see the Praat manual) (for details of calculation, see Boersma 1993). We argue that for the purposes of the present study, HNR is the most suitable parameter, since unlike other source parameters (e.g., spectral tilt or formant bandwidth based parameters, see Garellek to appear), it can be measured both in (partially) voiced and voiceless realizations, and can thus quantify the differences between these qualities on one single dimension. We must also emphasize here again, however, that there are no formerly established HNR values for the possible realization of the laryngeal fricative which could be used as a reference in the present analysis.

As a second important feature of the laryngeal fricative, we must also briefly mention here its susceptibility to coarticulation, which is also a reason why e.g., measures of spectral balance (e.g., center of gravity, COG) were not used here as a measure of voicing, despite its widely accepted use for this purpose in 
fricatives (see e.g., Gradoville 2011; G. Kiss 2013). Since the laryngeal fricative is specified only for a constriction in the glottis and is underspecified for oral configuration (see Keating 1988: 282-283; Beckman 1995: 212), it can essentially be produced with any kind of anticipating or perseverating supraglottal (co)articulatory maneuvers that the economical production of the following or the preceding vowels may demand. Therefore, even in cases where the main place of articulation of $/ \mathrm{h} /$ is in the larynx (as is expected in the case of $/ \mathrm{h} /$ in syllable onset in Hungarian), there is most probably a secondary constriction also in the oral cavity when $/ \mathrm{h} /$ is preceded, followed, or enclosed by vowels. And this constriction inevitably shifts the center of gravity of the spectrum to a certain extent.

\section{Methods}

\subsection{Participants}

We recorded 19 speakers (11 male, 8 female) aged between 22 and 38 (average: 30). The speakers were monolingual native speakers of Hungarian with no speech or hearing disorders reported. Informed consents were collected from each participant before the recordings.

\subsection{Material}

We analyzed / $\mathrm{h} /$ realizations in syllable onsets of Hungarian words embedded in meaningful sentences which we recorded as part of a bigger set of linguistic material. Tokens of $/ \mathrm{h} /$ were recorded in three conditions which varied in vowels as contexts, in the position of $/ \mathrm{h} /$ in the word, and in the syllable having or not having pitch-accent. ${ }^{7}$ The three conditions were the following. (i) Word-medial $/ \mathrm{h} /$ as the onset of an unaccented syllable (referred to as $\mathrm{VhV}$ in the analysis), e.g., Teher / teher/ nyomta a vállát, nem a semittevés könnyüsége 'it was burden that she carried on her shoulders, not the unbearable lightness of doing nothing. (ii) Word-initial $/ \mathrm{h} /$ in a pitch-accented word (the pitch-accent was elicited by pre-verbal focus position) as the onset of the accented syllable (referred to as $\mathrm{V} \# h \mathrm{~V}$ in the analysis),

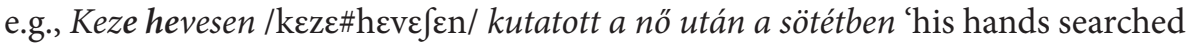

7. In Siptár (1994/2016) it is not specified if the effect of 'prominence' should be regarded as an effect of lexical stress or sentential prominence, i.e., pitch-accent. Therefore, in the present study we opted for testing the stronger prosodic phrase boundary marker, pitch-accent, which thus should also exert the strongest effect (if prominence does play a role in the issue at hand). 
for her vehemently in the dark' (iii) Word-initial utterance-initial (post-pausal) $/ \mathrm{h} /$ as the onset of the pitch-accented syllable (referred to as $\# h \mathrm{~V}$ in the analysis), e.g., Herendi /herendi/ 'from Herend (name of a city)'. (Note that items in the $\# h \mathrm{~V}$ condition were one-word sentences, and while reading these sentences, participants were repeatedly reminded to read each item as an individual sentence.) Target items were collected by means of the 'szószablya' webcorpus (Halácsy et al. 2003). In this setting, condition (iii) served as a baseline, since in this condition $/ \mathrm{h} /$ is predicted to exhibit no voicing both by phonetic and phonological studies. As mentioned above, to reduce the number of variables, but still provide a representative and well-balanced set of vowels for the investigation of the effect of backness and openness, in the present study, we limited the analysis to symmetric $\mathrm{V}$-contexts, where we used / $\mathrm{u} v \mathrm{i} \varepsilon /$ in all conditions systematically. In other words, we compared $/ \mathrm{h} /$ realizations in $/ \mathrm{uhu} /, / \mathrm{vh} \mathrm{v} /$, /ihi/ and / $\mathrm{eh} \varepsilon /$ sequences, to test the effect of vowel backness (back/uhu/ and / phv/ vs. front /ihi/ and / $/ \mathrm{ch} /$ ) and vowel openness (close /uhu/ and /ihi/ vs. open / $\mathrm{hh} v /$ and $/ \varepsilon h \varepsilon /$ ). Note that the feature of lip rounding covaried with backness (front vowels were both unrounded, while back vowels were both rounded), and showed a 50-50\% distribution both in the open and the close groups (one rounded and one unrounded in each group). Since there is no open rounded front vowel in the Hungarian vowel inventory, this solution was the only one that could efficiently control for the effect of lip rounding (or at least balance it among the conditions). However, we are also aware that it potentially also exaggerated the effect that vowel backness may have exhibited, as lip rounding further lowers the position of the larynx (see Hoole \& Kroos 1998).

To reduce the overall duration of recording sessions, we recorded 3 repetitions from each stimulus. Recordings were made in a sound-attenuated room with an omnidirectional microphone and an external sound card. The items were presented on a computer screen in a randomized order; the recording sessions were administered by the SpeechRecorder software (Draxler \& Jänsch, 2004). After the exclusion of mispronounced tokens, a total of 1446 stimuli were analyzed.

\subsection{Measurements}

\subsubsection{Estimation of the voiced part}

As already mentioned, to quantify the extent to which $/ \mathrm{h} /$ was realized as voiced on a ratio scale (instead of using the categorical 'voiced' vs. 'voiceless' labels), we used the ratio of the voiced part to the total duration measure (RVP). For this purpose, we measured the total segment duration and the duration of voicing (more specifically, the fraction of locally unvoiced frames) in it. To find the optimal way for the detection of voicing, and thus the estimation of RVP in the target segments, we ran a pre-test on three speakers' data, i.e., on 450 stimuli. First, two authors of the 
study segmented and labelled the target VCV and target CV segments, and they also annotated the voiced fraction of the $/ \mathrm{h} /$ realizations manually by the use of acoustic cues in the low-pass filtered acoustic signal (upper limit of the filter: $500 \mathrm{~Hz}$ ). After the extraction of RVP in both annotations, we compared the data from the two annotators, and found close agreement between them $(\rho=0.9, p<0.001)$. Then, we also extracted the RVP by the use of the voice report function in Praat (Boersma \& Weenink 2017) using the settings suggested by Eager (2015): we used genderspecific $\mathrm{f}_{0}$-ranges of $70-250 \mathrm{~Hz}$ for males and $100-300 \mathrm{~Hz}$ for females. Finally, we compared the data of the second annotator and the RVP extracted by Praat. The comparison showed a very close agreement between the data extracted manually and automatically $(\rho=0.7, p<0.001)$. On this basis, and based upon other independent sources which concluded that the voice report function in Praat may be regarded as statistically equivalent to manual annotation (see Eager 2015), we finally opted for manual annotation of the target segments but the use of automatic voice detection (i.e., Praat's voice report) for the estimation of RVP in all participants. Typical examples of $/ \mathrm{h} /$ tokens in $\# h \mathrm{~V}, \mathrm{~V} \# h \mathrm{~V}$, and $\mathrm{V} h \mathrm{~V}$ conditions, and one atypical (i.e., almost voiceless) example of $/ \mathrm{h} /$ in $\mathrm{VhV}$ condition are illustrated in Figure 1 by the recorded audio waveform, spectrogram, and their corresponding manual segmentation. RVP data were also analyzed in interrelation with total token duration.
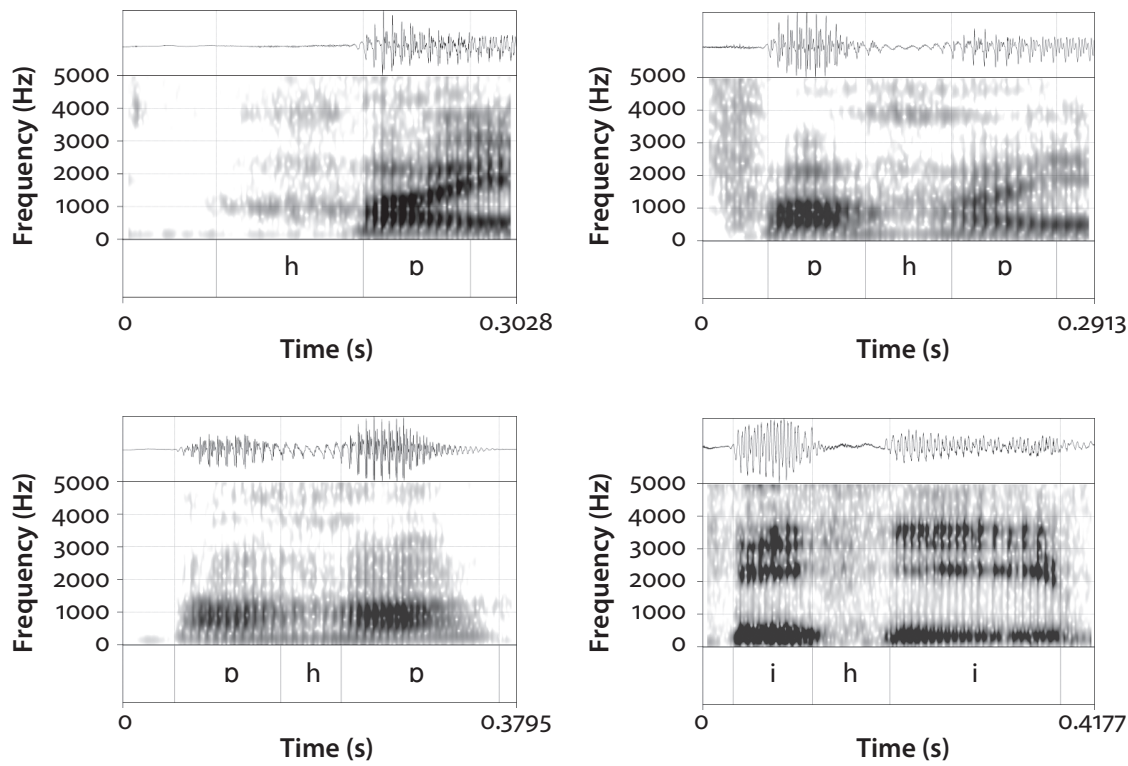

Figure 1. Upper row: typical examples of /h/ tokens in the \#hV (left, voiced in $18 \%$ ), and $\mathrm{V} \# h \mathrm{~V}$ (right, voiced in 100\%) conditions; bottom row: typical (left, voiced in 100\%) and atypical (right, voiced in 25\%) examples of /h/ tokens in the $\mathrm{VhV}$ condition 


\subsubsection{Acoustic measure of signal characteristics}

Our second aim was to also investigate how intervocalic (vs. post-pausal) position affects the sound quality, or more specifically, the periodicity/noisiness of $/ \mathrm{h} /$. Moreover, we also intended to test if this feature of the $/ \mathrm{h} /$ realizations is also affected by the backness and openness of the neighboring vowels. For this purpose, we measured HNR, an acoustic parameter (which we also briefly introduced in Section 1.3) in Praat: we measured the mean HNR within the whole /h/ segment (HNR averaged over all frames, may it be voiced or voiceless), with the minimum pitch set to $100 \mathrm{~Hz}$ for women and $70 \mathrm{~Hz}$ for men (on the basis of Eager 2015), and the values of silence threshold, time step, and periods per second set to Praat's standard values. Note that HNR averaged for the whole segment is affected both by the amount of voicing present in the segment, and the intensity of the noise components. Therefore, this method has the advantage of encompassing both features of interest in one simple dimension, while it also has the disadvantage that it puts limits to the interpretation of the parameter at hand, as it does not simply reflect the quality of voicing in the voiced fraction of the sound, but rather an overall quality of the whole segment.

\subsubsection{Statistical analyses}

We used the lme4 package (Bates et al. 2015) in R ( $\mathrm{R}$ Core Team 2017) to perform a linear mixed effects analysis of the effect of vowel backness, vowel openness and condition (as fixed effects) on RVP and HNR values. In these models, we also included random intercepts for subjects, and random slopes by subject for all fixed effects. Assumptions of homoscedasticity and normality were tested by visual inspection of residual plots. $P$-values were obtained via the Satterthwaite approximation available in the lmerTest package (Kuznetsova et al. 2017). Pairwise comparisons were carried out with Tukey's post hoc tests available in the lsmeans package (Russell 2016). For graphical representation, we summarized the data with adjustment of the confidence intervals by removing inter-subject variability using the method proposed by Morey (2008). Correlation analyses were performed by Spearman's test.

\section{Results}

In general, $32 \%$ of $/ \mathrm{h} /$ tokens were realized with $100 \% \mathrm{RVP}$ in all conditions, among which $97 \%$ were found in the two types of intervocalic conditions. Among tokens of intervocalic positions, $81 \%$ were realized as fully voiced. Among all $/ \mathrm{h} /$ tokens between front vowels $87 \%$ were realized as fully voiced (i.e., RVP $=100 \%$ ), while among all tokens between back vowels, 75\%. Overall RVP data (Figure 2, upper 
left) shows that all the intervocalic conditions pattern together and are clearly distinguished from the baseline condition with a relatively high ratio of voicing. The group means and their standard deviations were as follows: \#hV: $35 \pm 21 \%$, V\#hV: $88 \pm 23 \%$, VhV: $96 \pm 13 \%$. Figure 2 also shows the data broken down by vowel quality (upper right panel). Generally speaking, the tendencies in terms of all vowel qualities are highly similar to what is observable in the pooled data, that is, on this basis no notable vowel quality effect may be suspected. However, we also see that in the word-initial pitch-accented $(\mathrm{V} \# h \mathrm{~V})$ condition, the extent of voicing in the back $/ \mathfrak{v} /(78 \pm 27 \%)$ and $/ \mathrm{u} /$ contexts $(87 \pm 24 \%)$ is slightly lower than in the front vowel contexts $(94 \pm 18 \%$ for both $/ \varepsilon /$ and $/ \mathrm{i} /$ ), while in the post-pausal syllable onset $(\# h \mathrm{~V})$, the front /i/ $(29 \pm 19 \%)$ and / $/$ / $(34 \pm 20 \%)$ elicited a lower ratio of voicing in $/ \mathrm{h} /$ as opposed to the back /u/ $(37 \pm 22 \%)$ and $/ \mathfrak{v} /(39 \pm 20 \%)$.
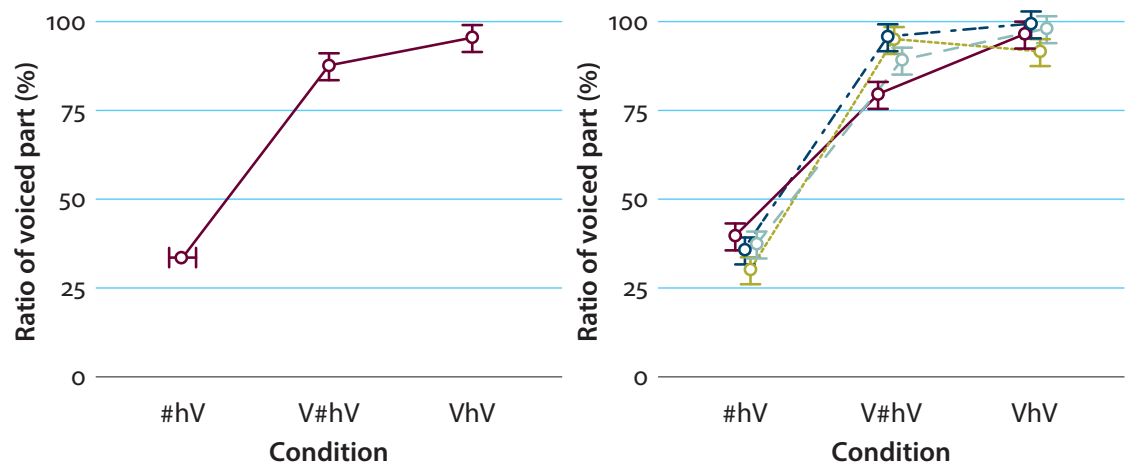

\section{Vowel}
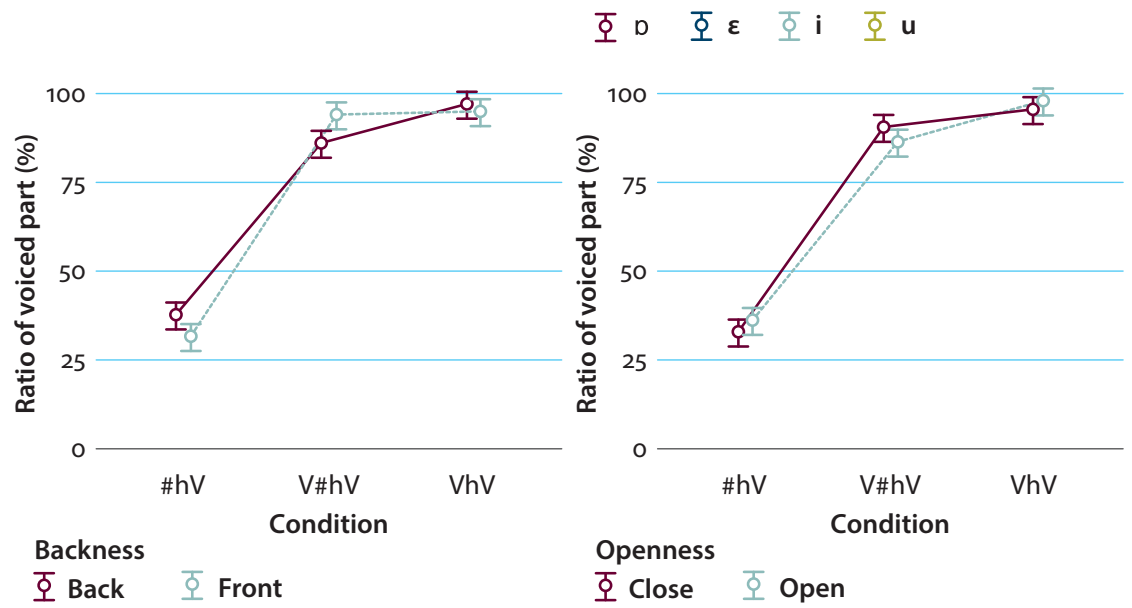

Figure 2. RVP in all /h/ segments pooled (upper left), and as a function of the right vowel's quality (upper right; / $/$ /: black solid line; / $/$ /: black dotted-dashed line, /i/: grey dashed line, /u/: gray dotted line), vowel backness (bottom left), and vowel openness (bottom right) (mean $\pm 95 \%$ confidence interval, adjusted for inter-speaker variability) 
The above observations were partially corroborated by statistical analysis: according to a linear mixed model including the fixed factors openness, backness, and condition, and speaker as random effect, there was a significant interaction effect between backness and condition $(F(2,1042.50)=18.13, p<0.001)$ (Figure 2, bottom left), between openness and condition $(F(2,1041.47)=3.92, p$ $=0.02)$, and between openness and backness $(F(1,1113.64)=8.79, p=0.03)$ on RVP (Figure 3).

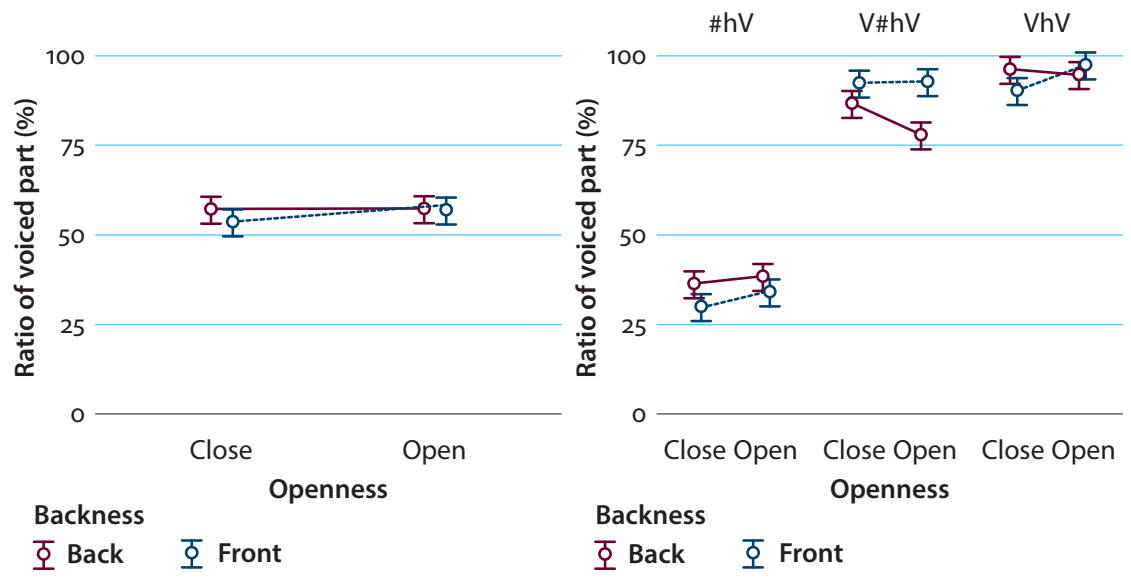

Figure 3. RVP as a function of vowel openness, backness, and condition (mean $\pm 95 \%$ confidence interval, adjusted for inter-speaker variability) comparing RVP in the three conditions within vowel groups

The first interaction is due to a difference between the front and back vowel groups in the $\mathrm{V} \# h \mathrm{~V}$ context (where back vowels exhibited a slightly lower ratio of voicing in $/ \mathrm{h} / \mathrm{RVP}=94 \pm 18 \%$ for front, and $83 \pm 26 \%$ for back vowels), and a somewhat smaller difference observable in the $\# h \mathrm{~V}$ context in the opposite direction (where back vowels exhibited a slightly higher ratio of voicing, RVP $=38 \pm 21 \%$ for back and $32 \pm 20 \%$ for front vowels). The interactions show that the clearly visible effect of condition is to some extent different in the front and back vowel groups (as contexts), while the effect of backness is also to some extent different in the open and close vowels, i.e., neither the back and front vowels, nor the open and close vowels behave as homogenous groups (as contexts) with respect to the RVP in /h/. Despite the interactions, Tukey's post hoc test revealed that all tokens differed in the $\# h \mathrm{~V}$ vs. $\mathrm{V} \# h \mathrm{~V}$ ( $p<0.0001$ in all pairs), and in the $\# h \mathrm{~V}$ vs. $\mathrm{VhV}(p<0.0001$ in all pairs) comparisons, but not in the $\mathrm{V} \# h \mathrm{~V}$ vs. $\mathrm{VhV}$ comparisons, where vocalic features were held constant. 
We also analyzed the duration of $/ \mathrm{h} /$ as a function of conditions (fixed factor: condition) to see if token durations varied systematically in the three conditions. The model revealed that the absolute duration of $/ \mathrm{h} /$ is indeed affected by the condition $(F(2,18.76)=11.86, p<0.001)$, but according to pairwise comparisons, only the $\# h \mathrm{~V}$ condition $(M=79.89 \mathrm{~ms}, S D=25.46)$ differs from $\mathrm{VhV}(M=67.78$ $\mathrm{ms}, S D=18.37)$ significantly $(p=0.006)$, while $\mathrm{V} \# h \mathrm{~V}(M=75.70 \mathrm{~ms}, S D=28.20)$ does not differ from any of the conditions. Correlation analysis of token durations and RVP additionally showed that the difference between conditions also lies in the interrelation between /h/ duration and the amount of voicing: while /h/ duration was in strong negative correlation with RVP in both types of intervocalic positions (V\#hV: $\rho=-0.57, p<0.0001$; VhV: $\rho=-0.41, p<0.0001$ ), it showed only a very weak significant negative correlation in $\# h \mathrm{~V}(\rho=-0.09, p=0.02)$. This result suggests that the duration of the voice leak in $/ \mathrm{h} /$ from the right vowel is almost independent of the total duration of the segment post-pausally, but longer segments tend to have less voicing intervocalically (Figure 4).

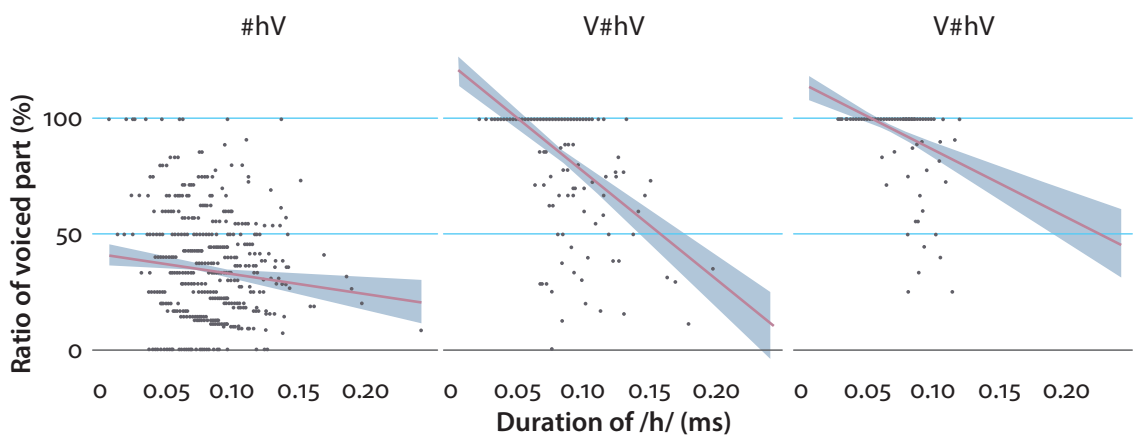

Figure 4. Correlations of segment duration and ratio of voiced part

Lastly, we turn to the measure of harmonicity. Visual observation of the overall HNR data reveal a very similar trend to what we observed in the RVP data, namely that the intervocalic and post-pausal onset conditions differ remarkably, while the two intervocalic conditions pattern together (this observation is also supported by post hoc tests of the linear mixed effects model: for $\# h \mathrm{~V} v$ v. $\mathrm{V} \# h \mathrm{~V} p<0.029$; for $\# h \mathrm{~V}$ vs. $\mathrm{V} h \mathrm{~V} p<0.0001)$. $/ \mathrm{h} /$ realizations in $\# h \mathrm{~V}$ showed dominance of aperiodic (noise) components over periodic components (lower HNR values), while /h/ tokens in $\mathrm{V} \# h \mathrm{~V}$ and $\mathrm{VhV}$ appeared to be more periodic (higher HNR values) (Figure 5, upper left). According to the data sorted by the vowel quality feature (Figure 5, upper right), $/ \mathrm{h} /$ tokens were the least periodic in $/ \mathrm{v} /$ context in all but the $\# h \mathrm{~V}$ 
condition, while tokens in /i/ context and in $\mathrm{V} \# h \mathrm{~V}$ condition were the most periodic. On the basis of HNR values, the following harmonicity order of $/ \mathrm{h} / \mathrm{realiza}$ tions emerged in the two intervocalic contexts, in terms of the context vowel: $/ v /<$ $\mid \varepsilon /</ \mathrm{u} /</ \mathrm{i} /$, and the following grouping was established in VhV context: $/ \mathfrak{v} / \mathrm{vs}$. $/ \varepsilon$ $\mathrm{u}$ i/ (where the latter group displayed less noisy /h/ tokens) (Figure 5, upper right).
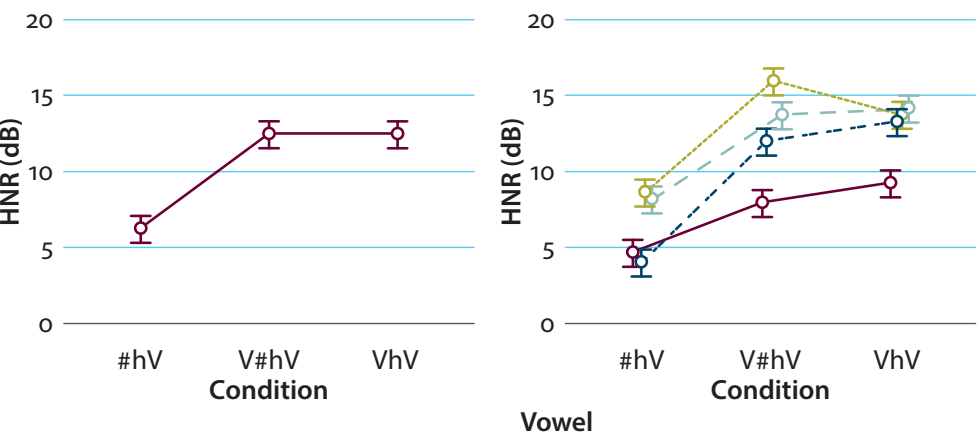

$$
20
$$$$
\text { 호 } \mathrm{D} \text { 오 } \varepsilon \text { 호 } \mathrm{i} \text { 오 } \mathrm{u}
$$
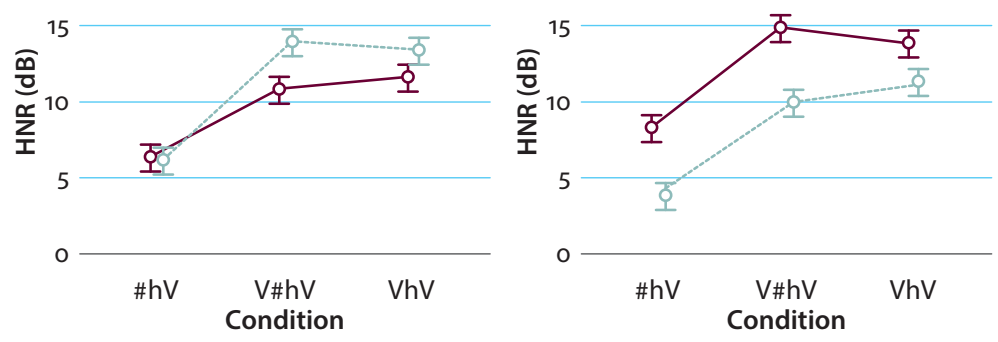

Backness

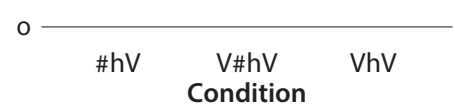

호 Back 호 Front

\section{Openness}

호 Close 호 Open

Figure 5. HNR in all /h/ segments pooled (upper left), and as a function of the right vowel's quality (upper right; / $/$ /: black solid line; / $\varepsilon /$ : black dotted-dashed line, /i/: grey dashed line, $/ \mathrm{u} /$ : gray dotted line), vowel backness (bottom left), and vowel openness (bottom right) (mean $\pm 95 \%$ confidence interval, adjusted for inter-speaker variability)

On the HNR data, a linear mixed model revealed a significant 3-way interaction effect of backness, openness and condition $(F(2,995.74)=13.3670, p<0.001)$, which is to be interpreted as a condition by openness, or a condition by backness interaction, that varies across the levels of the third variable. Therefore, in the present design this result is basically equivalent to a condition by vowel quality interaction, which reflects again that the open, close, back, and front vowel groups do not behave as homogenous groups with respect to their role in facilitating /h/ voicing. 
According to Tukey's post hoc tests, $\# h \mathrm{~V}$ vs. $\mathrm{V} \# h \mathrm{~V}$, and $\# h \mathrm{~V}$ vs. $\mathrm{V} h \mathrm{~V}$ contexts differ in all vowel groups significantly $(p<0.05)$, but the two intervocalic conditions do not. The differences of group means show that the acoustic signal exhibited more dominant periodic components in all conditions in close vowels' context (Figure 5, bottom right), and that a similar trend was true for $/ \mathrm{h} /$ tokens in back vowels' context in all but the $\# h \mathrm{~V}$ condition (Figure 5, bottom left).

We also tested if signal harmonicity in /h/ is correlated with RVP, to see to what extent the value of HNR was affected by the length of the periodic signal fragment. We found a strong/moderate positive correlation in both intervocalic contexts (V\#hV: $\rho=0.59, p<0.001 ; \mathrm{VhV}: \rho=0.32, p<0.001$ ), but no correlation in $\# h \mathrm{~V}$ (Figure 6).

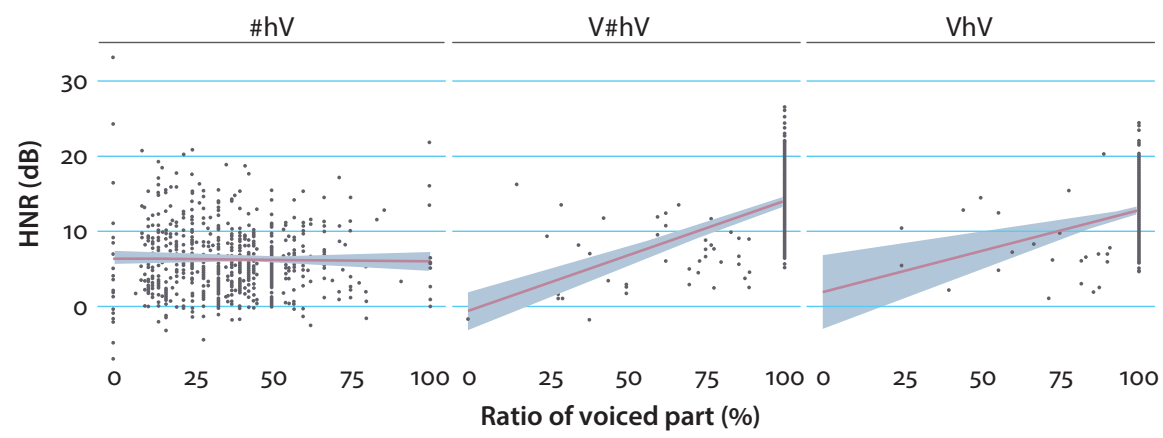

Figure 6. Correlations of HNR and ratio of voiced part

This reflects that the differences we found in HNR values between the intervocalic and post-pausal conditions are linked to the amount of voicing: although an increase in overall signal periodicity is indeed in correspondence with an increased ratio of voiced frames intervocalically, it is not so if the segment is uttered after a pause. In other words, the noisy quality of $/ \mathrm{h} /$ tokens in post-pausal position cannot simply be interpreted as a result of shorter relative durations of the voice leak from the neighboring vowel; rather, it is a generally noisier sound quality.

\section{Discussion and conclusions}

The acoustic analysis of the Hungarian /h/ has shown that the main factor triggering its voicing in syllable onset is the intervocalic position: if the $/ \mathrm{h} /$ occurs between two vowels, it is realized as voiced (in roughly $80 \%$ of its total duration), 
irrespective of the word boundary in the sequence or the presence of pitch-accent on the containing syllable, while in a post-pausal context (regarded as a baseline in the analysis) a very low amount (approx. 30\%) of voicing is found. However, vowel backness also has an effect in interaction with this condition. Thus, although in a binary categorization we are safe to categorize /h/ as voiced intervocalically, the exact amount of its voicing is to some extent dependent on the horizontal tongue position of the flanking vowel(s). On a word boundary, and between front vowels, $/ \mathrm{h} /$ appears to contain more voicing than between back vowels, but the tendency is reversed when the onset / $\mathrm{h} /$ is uttered after a pause.

The ratio of fully voiced tokens we found in intervocalic positions was highly in line with Mitterer (2018), and roughly in line with the results of Teras (2018). Similarly to Mitterer, we found that $81 \%$ of tokens were realized with $100 \%$ voicing, while Teras had found this ratio to be $70 \%$. As far as the ratio of voiced variants in intervocalic front and back contexts is concerned, to some extent, our results are close to Gósy (2005), since both studies conclude that front vowels favor / $\mathrm{h} /$ voicing. However, there is a striking difference with regard to the disfavored back vowel context. To recall, Gósy (2005) put the ratio of voiced variants at $75 \%$ between front vowels, and 38-39\% between back vowels, compared to the present study's findings of $87 \%$ between front vowels and $75 \%$ between back vowels. We are tempted to put down this divergence in the results to major differences in methodology and speech material applied in the two studies, and conclude that by and large, our results are in accord with Gósy (2005) as well. On the basis of the above, we claim that our first hypothesis is partially corroborated, as the position of the $/ \mathrm{h} /$ and the presence of pitch-accent did not show an effect on the amount of voicing in $/ \mathrm{h} /$, but the effect of openness is more complex than hypothesized. This effect of vowel quality will receive further comment as we discuss our findings on HNR.

The durational analysis revealed that there are further differences between $/ \mathrm{h} /$ variants and the phonetic processes that are responsible for $/ \mathrm{h} /$ voicing in the intervocalic and post-pausal positions. The results show that $/ \mathrm{h} /$ tokens are the longest if they are produced word-initially and after a pause, and that duration and amount of voicing are in closer correspondence if $/ \mathrm{h} /$ is positioned intervocalically rather than post-pausally. While /h/ tends to have less voicing if its total duration increases intervocalically, the amount of voice leak from the neighboring vowel is much more independent of the total duration of the token if it is preceded by a pause.

Our results suggest that the voiced realization of $/ \mathrm{h} /$, i.e., [h], is voiced in approximately $80 \%$ of its total duration, while its voiceless counterpart [h] contains vocal fold vibration in about one third (approx. 30\%) of its total duration. As these values were established on the basis of a great number of observations, 
they may be also treated as gross reference values in future binary-classificationbased analyses.

We also intended to give an initial, exploratory description of the quality of breathy voice Hungarian /h/ is claimed to exhibit. To put it more precisely, we aimed to describe the quality of the sound (but not necessarily just the quality of voice or the voiced fraction) produced during the production of $/ \mathrm{h} /$ in intervocalic positions as opposed to the sound quality (may it be voiced, unvoiced, or partially voiced) it exhibits in a baseline post-pausal position. To grasp this general "sound quality" or signal characteristic difference between realizations, we measured and analyzed the harmonics-to-noise ratio as a function of the quality of the flanking vowels, with special attention paid to backness and openness again. We predicted that higher and more fronted positions of the tongue (and the larynx) facilitate the increased adduction of the vocal folds, and thus reduce breathiness, i.e., the amount of noise in $/ \mathrm{h} /$. This hypothesis was again partially corroborated by our results, as we found that front vowels and close vowels did indeed facilitate more periodic (less breathy/less noisy) $/ \mathrm{h} /$ realizations, but these tendencies were found so clearly only in intervocalic contexts. After a pause, /h/ variants were not distinguished by HNR along the neighboring vowels' backness feature, while the distinction was still present, only at a generally lower mean value along the openness dimension. HNR data were also in line with RVP (which we used to quantify the amount of voicing), as both of these measures reflected that $/ \mathrm{h} /$ tokens are more likely to be voiced (or they contain more prominent periodic components) intervocalically than after a pause. Furthermore, we also showed that the difference we found between the two positions reflected actual dissimilarities of the laryngeal settings the /h/ tokens were produced with, and not only the fact that post-pausal $/ \mathrm{h} /$ tokens generally contained a lower ratio of voiced part. In the statistical analysis, however, we found a three-way interaction of the factors, indicating that the vowel quality features openness and backness, which are claimed to distinguish and cluster the tested vowels, do not seem to be relevant, or homogenous categories with respect to their behavior as facilitating contexts for intervocalic /h/ voicing. That is, in this respect, $/ \mathcal{E} /$ differs from $/ \mathfrak{v} /$ in other aspects than $/ \mathrm{i} /$ differs from $/ \mathrm{u} /$. We can further note that on the basis of the HNR values measured in intervocalic $/ \mathrm{h} /$ realizations, two (more or less distinct) vowel groups seemed to emerge: $/ \mathfrak{v} /$ vs. /i u $\varepsilon /$. Before turning to the explanation of this result, we take a short detour into the underlying articulatory mechanisms of these vowels and their traditional featural description (that we also applied in the present study).

Traditionally, vowel qualities are defined and described on the basis of articulatory and perceptual-acoustic features in a mixed manner as follows (see IPA Handbook 1999). The first feature is jaw opening and/or tongue height, i.e., the 
vertical position of the highest point of the tongue or the position of the tongue body as a whole. In this dimension we distinguish 'close', and 'open' vowels, and two in-between categories defined on a perceptual basis: 'close-mid', and 'openmid'. The second feature is tongue backness, i.e., the horizontal position of the highest point of the tongue or the position of the tongue body as a whole. In this dimension we define 'front', 'back', and 'central' vowels. The third feature is lip rounding. In this dimension we have 'rounded', and 'unrounded' vowels. (To these features, the additional feature of phonological length is also added, if relevant.) Although these features seem to be rather straightforward, and are thus widely used, if we take into account the actual articulatory maneuvers the vowels are produced by, this 'lingual oral model' of classification (Esling 2005: 15) seems to be highly oversimplifying.

In a series of studies done by electromyography and via the computational modelling of the tongue muscles, Honda (1996) analyzed the coordination of the lingual muscles, with special attention paid to vowel articulation. Based on his findings, Honda (1996) proposed that the main four muscles of the tongue are assigned to the production of the anchor vowels of the cardinal vowel system in pairs, as follows: the genioglossus posterior and genioglossus anterior are involved in the production of / $\mathrm{i} /$, the genioglossus anterior and the hyoglossus are employed in the production of /æ/, the genioglossus posterior and the styloglossus are patterning together in the production of $/ \mathrm{u} /$, and the hyoglossus and the styloglossus are engaged in the production of $/ a /$. That is, from an articulatory perspective, the difference between "openness" categories is indeed fundamentally different in "front" and in "back" vowels: in "front" vowels (/i/ vs. /æ/) it is indeed the difference in jaw opening, while in "back" vowels $(/ \mathrm{u} / \mathrm{vs}$. /a/) it is raising, and retraction of the tongue in the case of "close" and "open" vowels, respectively (see Esling 2005: 23). What is more, due to the connections of these muscles to other speech organs, these findings also imply that it is the "back open" $/ \mathfrak{v} /$-like vowels which exhibit the strongest connection to (and the greatest effect on) the laryngeal settings via the direct link of the hyoid bone. In conclusion, it may as well be argued that the coarticulatory effects of $/ \mathfrak{v}$ /-like sounds on the vertical position of the larynx in the flanking speech sounds and thus on the quality of voicing may also be fundamentally different from that of the rest of the "vowel regions" in the vowel space. Therefore, we may now draw the conclusion that our results, which show the two "natural classes" of vowels / $/$ / vs. /i u $\varepsilon /$ emerging as separate categories, are wellestablished in the articulatory implementation of the studied vowel categories.

To conclude, the present study has contributed to the observation that the intervocalic voicing of $/ \mathrm{h} /$ is a phonetic process that generalizes across languages. It has also shown that such phonological conditioners as pitch-accent do not play 
a role in this process, but the openness of the flanking vowels as a vocalic feature does, via coarticulation. Our fine-grained phonetic analysis has further demonstrated that the sound quality of the fricative is also affected by the openness and backness of the flanking vowels. Our proposed explanation for this finding is informed by a less simplified explanation of vowel articulation, and the complex interactions between the tongue and the larynx structures.

\section{Acknowledgements}

The authors are very grateful to the two anonymous reviewers for their insightful comments. Help by Gergely Varjasi in gathering experimental data is gratefully acknowledged.

\section{References}

Bates, Douglas, Martin Mächler, Ben Bolker \& Steve Walker. 2015. Fitting linear mixed-effects models using lme4. Journal of Statistical Software Volume 67(1). 1-48.

Beckman, Mary. 1995. Implications for phonological theory. In William Hardcastle \& John Laver (eds.), The handbook of phonetic sciences, 199-225. Cambridge, MA: Blackwell,

Boersma, Paul. 1993. Accurate short-term analysis of the fundamental frequency and the harmonics-to-noise ratio of a sampled sound. IFA Proceedings 17. 97-110.

Boersma, Paul \& David Weenink. 2017. Praat: doing phonetics by computer [Computer program]. Version 6.0, retrieved 15 July 2017 from http://www.praat.org/

Bolla, Kálmán. 1995. Magyar fonetikai atlasz. A szegmentális hangszerkezet elemei. Budapest: Nemzeti Tankönyvkiadó.

Deme, Andrea, Márton Bartók, Tekla Etelka Gráczi, Tamás Gábor Csapó \& Alexandra Markó. 2018. Context dependent voicing characteristics of the Hungarian /h/. Talk on Hanyang International Symposium on Phonetics and Cognitive Sciences of Language 2018. Hanyang, South Korea, 18-19 May 2018.

Demolin, Didier, Sergio Hassid, Thierry Metens \& Alain Soquet. 2002. Real-time MRI and articulatory coordination in speech. Comptes Rendus - Biologies 325(4). 547-556. https://doi.org/10.1016/S1631-0691(02)01458-o

Draxler, Christoph \& Klaus Jänsch. 2004. SpeechRecorder - A universal platform independent multi-channel audio recording software. In Proceedings of 4th International Conference on Language Resources and Evaluation, 559-562. Lisbon. http://citeseerx.ist.psu.edu/viewdoc/ download?doi=10.1.1.58.5793\&rep=rep1\&type $=$ pdf

Eager, Christopher D. 2015. Automated voicing analysis in Praat: Statistically equivalent to manual segmentation. In Proceedings of ICPhS. Glasgow, UK: University of Glasgow. https://www.internationalphoneticassociation.org/icphs-proceedings/ICPhS2015/Papers/ ICPHS0083.pdf

Esling, John H. 2005. There are no back vowels: The laryngeal articulator model. Canadian Journal of Linguistics 50. 13-44. 
G. Kiss, Zoltán. 2013. Measuring acoustic correlates of voicing in stops and fricatives. In Péter Szigetvári (ed.), VLLXX: Papers Presented to László Varga on his 70th Birthday, 289-311. Budapest: Tinta Könyvkiadó.

Garellek, Mark. to appear. The phonetics of voice. In William Katz \& Peter Assmann (eds.), The Routledge Handbook of Phonetics. http://idiom.ucsd.edu/ mgarellek/files/Garellek_Phonetics_of_Voice_Handbook_final.pdf

Gobl, Christer \& Ailbhe Ní Chasaide. 1995. Voice source variation. In William Hardcastle \& John Laver (eds.), The handbook of phonetic sciences, 427-461. Cambridge, MA: Blackwell.

Gósy, Mária. 2004. Fonetika, a beszéd tudománya. Budapest: Osiris Kiadó.

Gósy, Mária. 2005. A /h/ zöngésedése két magánhangzó között. Beszédkutatás 5-20.

Gradoville, Michael Stephen. 2011. Validity in measurements of fricative voicing: Evidence from Argentine Spanish. In Scott M. Alvord (ed.), Selected Proceedings of the 5th Conference on Laboratory Approaches to Romance Phonology, 59-74. Somerville, MA: Cascadilla Proceedings Project. http://www.lingref.com/cpp/larp/5/paper2635.pdf

Halácsy, Péter, András Kornai, László Németh, András Rung, István Szakadát \& Viktor Trón. 2003. A szószablya projekt. In Alexin Zoltán \& Dóra Csendes (eds.), I. Magyar Számítógépes Nyelvészeti Konferencia elöadásai (MSZNY 2003), 299. http://eprints.sztaki.hu/7886/1/ Kornai_1773394_ny.pdf

Hess, Susan A. 1998. Pharyngeal articulations. Ph.D. dissertation. Los Angeles: University of California. http://phonetics.linguistics.ucla.edu/research/Hess_diss.pdf

Honda, Kiyoshi. 1996. Organization of tongue articulation for vowels. Journal of Phonetics 24. 39-52. https://doi.org/10.1006/jpho.1996.0004

Honda, Kiyoshi, Hiroyuki Hirai, Shinobu Masaki \& Yasuhiro Shimada. 1999. Role of vertical larynx movement and cervical lordosis in f0 control. Language and Speech 42. 401411. https://doi.org/10.1177/00238309990420040301

Hoole, Philip \& Christian Kroos. 1998. Control of larynx height in vowel production. In Proceedings of the 5th Conference on Language Processing (ICSLP) 2, 531-534. Sydney. https:// www.isca-speech.org/archive/archive_papers/icslp_1998/i98_1097.pdf

IPA Handbook = International Phonetic Association. 1999. Handbook of the International Phonetic Association: A guide to the use of the International Phonetic Alphabet. Cambridge: Cambridge University.

Kassai, Ilona. 2005. Fonetika. Budapest: Nemzeti Tankönyvkiadó.

Keating, Patricia A. 1988. Underspecification in phonology. Phonology 5/2. 275-292. https://doi.org/10.1017/S095267570000230X

Kuznetsova, Alexandra,Per B. Brockhoff \& Rune H. B. Christensen . 2017. lmerTest package: Tests in linear mixed effects models. Journal of Statistical Software 82(13). 1-26. https://doi.org/10.18637/jss.v082.i13

Laver, John. 1994. Principles of phonetics. Cambridge: Cambridge University Press. https://doi.org/10.1017/CBO9781139166621

Laziczius Gyula. 1937. A zöngés h kérdése. Magyar Nyelv 33. 305-310.

Laziczius Gyula. 1963/1979. Fonetika. Budapest: Nemzeti Tankönyvkiadó.

Ladefoged, Peter \& Keith Johnson. 2011. A course in phonetics (6th ed.). Boston: Wadsworth, Cengage Learning.

Lindblom, Björn. 1990. Explaining phonetic variation: A sketch of the H\&H theory. In William Hardcastle \& Alain Marchal (eds.), Speech production and speech modeling, 403-439. Dordrecht: Kluwer. https://doi.org/10.1007/978-94-009-2037-8_16 
Maddieson, Ian. 1984. Patterns of sounds. Cambridge: Cambridge University Press. https://doi.org/10.1017/CBO9780511753459

Meyer, E. A. \& Zoltán Gombocz. 1909. Zur Phonetic der Ungarischen Sprache. Upsala: Edvard Berlings Buchdruckerei.

Mitterer, Holger. 2018. Not all geminates are created equal: Evidence from Maltese glottal consonants. Journal of Phonetics 66. 28-66. https://doi.org/10.1016/j.wocn.2017.09.003

Morey, Richard D. 2008. Confidence intervals from normalized data: A correction to Cousineau (2005). Tutorial in Quantitative Methods for Psychology 4(2). 61-64. https://doi.org/10.20982/tqmp.04.2.po61

Pabst, Friedemann \& Johan Sundberg. 1992. Tracking multi-channel electroglottograph measurement of larynx height in singers. Speech Transmission Laboratory Quarterly Progress and Status Report (STL-QPSR) 33(2-3). 67-78.

Painter, Colin. 1976. Pitch control and pharynx width in Twi: An electromyographic study. Phonetica 33. 334-352. https://doi.org/10.1159/000259781

R Core Team. 2017. R: A language and environment for statistical computing. Vienna, Austria: $\mathrm{R}$ Foundation for Statistical Computing. https://www.R-project.org/

Russell, V. Lenth. 2016. Least-squares means: The R package lsmeans. Journal of Statistical Software 69(1). 1-33.

Siptár, Péter. 1994/2016. A mássalhangzók. In Ferenc Kiefer (ed.), Strukturális magyar nyelvtan 2. Fonológia, 183-272. Budapest: Akadémiai Kiadó. Digital edition: 2016.

Siptár. Péter. 2001. Három felemás magyar mássalhangzó. Magyar Nyelv 97. 385-404.

Siptár, Péter \& Miklós Törkenczy. 2007. The Phonology of Hungarian. New York: Oxford University Press.

Sundberg, Johan \& Anders Askenfelt. 1981. Larynx height and voice source. A relationship? Speech Transmission Laboratory Quarterly Progress and Status Report (STL-QPSR) 22(2-3). 23-36.

Stevens, Kenneth N. 1999. Acoustic phonetics. Cambridge, MA: MIT Press.

Szigetvári, Péter 1998. Miért nem zöngésedik a [h]? (draft). In László Büky \& Márta Maleczki (eds.), A mai magyar nyelv leírásának újabb módszerei III, 169-181. Szeged: JATE. http:// seas3.elte.hu/szigetva/papers/miert_h.pdf

Teras, Pire. 2018. The phonetic variation of short intervocalic/h/ in Estonian. In Katarzyna Klessa, Jolanta Bachan, Agnieszka Wagner, Maciej Karpiński \& Daniel Śledziński (eds.), Proceedings of the 9th International Conference of Speech Prosody, 883-887. Poznań: Adam Mickiewicz University. https://www.isca-speech.org/archive/SpeechProsody_2018/ pdfs/158.pdf

Zenker, Wolfgang \& Adolf Zenker 1960. Über die Regelung der Simmelippenspannung durch von aussen eingreifende Mechanismen. Folia Phoniatrica 12(1). 1-36.

https://doi.org/10.1159/000262846 



\title{
Contextual triggers of the Hungarian pre-verbal focus structure
}

\section{A guided production study}

\author{
Tamás Káldi ${ }^{1,2}$, Levente Madarász ${ }^{1}$ \& Anna Babarczy ${ }^{1,2}$ \\ ${ }^{1}$ Research Institute for Linguistics, Hungarian Academy of Sciences \\ ${ }^{2}$ Department of Cognitive Sciences, Budapest University of Technology and \\ Economics
}

The study uses a novel experimental method to investigate contextual factors claimed in the theoretical literature to license the use of Hungarian pre-verbal focus. These factors are: (i) identification, (ii) contrast, (iii) availability of a set on which the focus operates and (iv) whether this set is explicit or implicit. We tested the effects of these factors using online surveys in which respondents read short texts describing a context and saw a cloud of randomly arranged words. The experimental task was to create sentences that naturally fit the context by clicking the words in the cloud. Results show that narrow identification and contrast reliably predict the use of pre-verbal focus as does the availability of a set regardless of explicitness.

Keywords: Hungarian focus, word order, identification, contrast, contextual factors, production experiment, information packaging

\section{Introduction}

1.1 Hungarian: A free word-order language

Hungarian is a free word order language; almost any order of constituents will make up a grammatical structure. Consider the (incomplete) list of word order variations in (1): any one of the examples is a grammatical Hungarian sentence. 
(1) a. Meg-harapta ${ }^{1}$ a kutya a postást.

$\mathrm{VM}^{2}$-bite-PST.3SG the dog-NOM-SG the postman-SG-ACC

'The dog bit the postman.'

b. Meg-harapta a postást a kutya.

c. A kutya meg-harapta a postást.

d. A postást meg-harapta a kutya.

e. A kutya a postást meg-harapta.

f. A postást a kutya meg-harapta.

g. A postást a kutya harapta meg.

h. A kutya a postást harapta meg.

i. A postást harapta meg a kutya.

j. A kutya harapta meg a postást.

As it is a generally valid assumption that nothing is without a cause, a question regarding the observation in (1) promptly presents itself: what causes speakers of Hungarian to opt for one of the above word order variations in one particular instance, and why are they using another one in another instance? This is the question that the current study attempts to at least partially answer with respect to two sentence types in (1): what factors contribute to the use of (1c), which will be referred to by the well-established term "neutral" sentence (see e.g. Kálmán 1985), and (1h), which we shall label "pre-verbal focus" sentence. We will argue that two of the most crucial factors are identification and contrast; and we will propose that both of these can be captured in terms of the availability of sets, whether explicit, implicit or evoked in the context. Before elaborating on these factors, first we provide a short introduction to the basic notions of sentential focus and related aspects in the following sections.

\subsection{Accounts of word order: Discourse configurationality}

The question formulated above was first raised and meticulously studied by Sámuel Brassai $(1852,1860)$ who divided the sentence into two parts: the inchoativum and the bulk ('zöm'). In Brassai's account, the former contains elements that "practically lay a basis for the meaning of the sentence in the listener's mind, i.e., they are calling attention, and pointing forward, connecting the mental activity of

1. According to the Hungarian orthographic conventions, the verbal modifier (VM) and the verb are written as one word. In the current study hyphenated forms are used for illustrative purposes.

2. The abbreviation VM will be used for Verbal Modifier. 
the listener with that of the speaker"3 (1860:351). As far as the bulk is concerned, its function is "the communication of an action or a circumstance of an action that the speaker supposes to be unknown to the listener" (1860: 72). Although in certain cases the bulk may contain old information, it can be argued that it is the more informative part of the sentence. For this reason, as Brassai also points out, the inchoativum is optional, while the bulk is obligatory. In another study, Brassai mentions that sentences should not be studied only in isolation, since they serve the role of building blocks in texts. That is, "speech never serves to express merely single thoughts, but sequences of them, and just as every word, every form has a certain word order value, every sentence, every structure of thought has a given sentence order value" (Brassai 1885: 30-31).

The passages from Brassai's works cited above clearly outline a framework in which the use of the different word order variations exemplified in (1) can be accounted for. There are two closely related considerations: one of these is the information status of a particular element (given or new, emphatic or backgrounded), while the second is text coherence. Although at first sight it may seem redundant to differentiate the two aspects, in our opinion, the distinction is justifiable. If a text is to be coherent, then the information in the sentences it is comprised of must be structured with respect to their status, as required by the text. However, different word order variations of a sentence can appear in the same text depending on what is emphasized without compromising coherence. Also, isolated sentences can express the information status of their constituents via particular word order variations. Therefore, it is not only coherence that determines word order, but also, and perhaps more importantly, the information status of the elements. For this reason, Brassai's findings bear special relevance to our investigation, since it is his work that first meticulously studied the interrelations between context, the psychological state of the interlocutors and the use of different word order patterns in Hungarian.

The issue of the relationship between information status and word order (in Hungarian and also in other languages) was taken up in the generative tradition by É. Kiss (1995). By this time, the terms Topic and Focus had been introduced in the literature, ${ }^{4}$ therefore É. Kiss (1995) could formulate her linguistic typological account using these terms. On the one hand, it has been observed that in certain languages "the structural relation [NP, S] can be used to express not only the

3. Translations of Brassai's text were borrowed from É. Kiss (2008: 28, 30).

4. The functional notions were first defined by linguists of the Prague School. However, these functions were not yet given the names Topic and Focus. For more on these issues see e.g. Aronoff and Rees-Miller (2017) 
function 'grammatical subject', associated with the most prominent theta role, but, alternatively, the discourse-semantic function 'topic', as well”' (É. Kiss 1995: 3). On the other hand, "many languages have a designated structural position for focus, akin to the WH-position of the English sentence" (É. Kiss 1995: 4). In order to capture these cross-linguistic observations, the term discourse configurationality was coined. A language is discourse configurational if either one or both of the following two independent descriptions are valid for the given language: (i) the function Topic "is expressed through a particular structural relation", (ii) the function Focus "is expressed through a particular structural relation" (É. Kiss 1995: 6). Since the current study concentrates on Focus, this notion and the corresponding "structural relation" will be discussed in the following section in more detail.

\subsection{The structures investigated in the present study}

The two structures investigated in the present paper are (1c) and (1h) repeated as (2a) and (2b), respectively, for convenience.
(2)
a. A kutya meg-harapta a postást. the dog-NOM-SG VM-bite-PST.3SG the postman-SG-ACC 'The dog bit the postman.'
b. A kutya a postást harapta meg.
'It was the postman that was bitten by the dog.'

The most crucial difference between the two structures is the element that appears immediately pre-verbally.

In (2a) it is the VM, meg, that sits in the pre-verbal position, and it is incorporated into the verb (V) forming a phonological word with it (É. Kiss 2002). The Noun Phrase (NP), a kutya, preceding the VM-V compound functions as a Topic, while the post-verbal NP, a postást, is commonly referred to as information focus (see e.g. É. Kiss 1998) or post-verbal focus (see e.g. Surányi 2011). The different terms in the literature denoting this word order variant are all indicative of the aspect central to the given analysis. In order to remain theory-neutral, the term 'neutral sentence' will be used in the present study to refer to structures exemplified in (2a).

In (2b) the VM-V order is reversed, and the NP which is post-verbal in (2a) occupies the immediately pre-verbal position. Accordingly, its status is changed: the immediately pre-verbal NP functions as a Focus. A number of different terms have been used to denote this sentence type, as well (e.g. identification focus in É. Kiss 1998, contrastive focus in Kenesei 2006), but, in the current study the

5. PreVf sentences are translated into English as clefts based on É. Kiss (1998). 
theory-neutral 'pre-verbal focus' (henceforth preVf) will be used. Since the current paper aims to investigate the contextual factors that potentially contribute to the use of preVf and neutral sentences, we first review some of the definitions of Focus presented in previous literature, and then we enumerate the contextual requirements for preVf as suggested by theoretical accounts.

\subsection{What is Focus?}

In modern linguistics, the term Focus has been defined in a number of ways. One of the most often cited earliest definitions is given by Halliday (1967). Halliday (1967: 204) claims that "focus reflects the speaker's decision as to where the main burden of the message lies." It is associated with "prominence" and it is a kind of emphasis that helps the speaker mark the most informative part of their message. Halliday adds that "what is focal is 'new' information; not in the sense that it cannot have been previously mentioned, [...], but in the sense that the speaker presents it as not being recoverable from the preceding context." Clearly, Halliday's approach is a directly functional one: the author identifies functions of focusing which he claims to be the most important. Nevertheless, it must be noted, that Halliday's treatment is strictly specific to the English language.

Rooth $(1985,1992)$, and Krifka (2008) using the Alternative Semantics framework and the notion of sets take a more general stance, and as we will see, create a theoretical framework that can be applied cross-linguistically: "Focus indicates the presence of alternatives that are relevant for the interpretation of linguistic expressions" (Krifka 2008: 247). The novelty of the Alternative Semantics approach lies in the fact that it attempts to formulate the most central and cross-linguistically valid function of Focus. To achieve this, the theory has three additional tenets. First, the description does not specify what form a Focus containing construction has to take. It only indicates that focus has to be marked somehow. Consequently, it allows for the variety of different focus marking strategies observed in different languages. ${ }^{6}$ Second, the description does not specify the type of linguistic expression $^{7}$ that can be focused. Third, it does not specify how "different ways of focus marking signal different ways of how alternatives are exploited" (Krifka 2008: 248). That is, the indication of the presence of alternatives can be used to express different aspects of propositional content within or across languages. ${ }^{8}$ In

6. The most typical Focus marking strategies are marking through intonation, word order, particles, clitics etc. (see e.g. Miller 2006).

7. E.g. phrase, sentence, suffix etc.

8. For an explanation see Example (3) and (4) and the corresponding discussion. 
sum, the alternative semantics approach "allows for languages to differ in the ways they mark focus and in the specific interpretational effects of focus" (Krifka 2008: 248). In the present study, Rooth's and Krifka's approach is adopted. Therefore, we take it that preVf indicates the presence of alternatives. The ways the alternatives indicated by Hungarian preVf are "exploited" will be discussed in the forthcoming sections.

\subsection{Contextual factors commonly associated with preVf and neutral sentences}

According to theorists, there are two main ways in which the indication of the presence of alternatives is exploited in Hungarian: preVf may express identification or contrast. These two functions will be discussed in the following two subsections.

\subsubsection{Identification}

É. Kiss (1998) defined preVf as "identificational focus" claiming that its function is to represent "a subset of the set of contextually or situationally given elements for which the predicate phrase can potentially hold; it is identified as the exhaustive ${ }^{9}$ subset of this set for which the predicate phrase actually holds" (p. 245). The identificational function of the immediately pre-verbal slot was already recognized by Brassai (1860), who claimed that the very first element in the bulk (i.e. the part following the optional inchoativum) is the most prominent, most emphatic one "which we assume the speaker or listener would ask about" (translation by É. Kiss 2008: 33). Recall, that Brassai (1860) put forward the idea that sentences serve as building blocks of texts or dialogues. With respect to dialogues, it is reasonable to assume that answers given to wh-questions will be felicitous if they identify the entity which corresponds to the wh-element in the question. This identification is achieved through focusing the expression which denotes the entity at hand. Indeed, question - answer congruence has been a test for Focus not only for Hungarian but cross-linguistically, as well (Rooth 1992, Krifka 2001). Rooth (1992), for example claims that "there is a correlation between questions and the position of focus in answers" (p. 9). Consider the sentence pairs in (3) and (4).

(3) a. Who owns a gorilla?

[x owns a gorilla]

b. $\quad[\mathrm{John}]_{\mathrm{F}}$ owns a gorilla.

c. ${ }^{\star}$ John owns a [gorilla $]_{\mathrm{F}}$.

9. Although exhaustive interpretation is an important aspect of preVf well studied both in the theoretical and experimental literature, this issue will not be directly addressed in the present paper. The question of exhaustive interpretation will be addressed in Section 3. 
(4) a. What does John own?

[John owns $\mathrm{x}$ ]

b. ${ }^{\star}[\mathrm{John}]_{\mathrm{F}}$ owns a gorilla.

c. John owns a [gorilla $_{\mathrm{F}}$.

As illustrated by (3a) and (4a), a question introduces a set of alternatives which are related to the potential answers that can be given to them (Hamblin 1973, Rooth 1992, Roberts 1996). (3a) introduces a set of people as potential owners (e.g. [John, Mary, Carl, Susan]), whereas (4a) introduces a set of entities that can be owned (e.g. [a gorilla, a car, a cat, a house]). Focus serves to identify one or more elements of the introduced sets to which the rest of the sentence holds. For this reason, (3c) is an infelicitous answer to (3a), since [gorilla] is not a subset of the set introduced by (3a), and likewise, (4b) is an infelicitous answer to (4a), as [John] is not a subset of the set introduced by (4a). On the contrary, (3b) and (4c) are appropriate answers to their respective questions.

Interestingly, É. Kiss (1998) claims that wh-questions "can be answered not only by an identificational focus (i.e. preVf) but - less commonly - by a mere information focus (i.e. neutral sentence), depending on whether the answer is intended to be exhaustive" (p. 249). ${ }^{10}$ The author reasons that focusing does not take place if the only role of the constituents at hand is the "marking of the novelty of the information they carry". That is, the referent of the NP is not presented as a member of the contextually available set of alternatives, if it is post-verbal. For this reason, É. Kiss argues that both (5b) and (5c) are compatible with the question in (5a).

(5) a. Hol jártál a nyáron?

'Where did you go in the summer?'

b. Jártam Olaszországban.

go-PST.1SG Italy-in

'I went to Italy (among other places).'

c. Olaszországban jártam.

'It was Italy where I went.'

According to Surányi (2011) the factor that determines whether a preVf or a neutral sentence is used as an answer to a wh-question is a function of the "Question Under Discussion" in the sense of Roberts (1996). In Surányi’s account both preVf and the neutral sentence can represent a choice between contextually available set members; the neutral sentence is merely a subcase of preVf. According to the author, the choice between the preVf and neutral sentence types in answers

10. For a similar reasoning see also Brody \& Szendrői (2010). 
is determined by two mutually exclusive imperatives assumed by the hearer: (i) "Mention all", or (ii) "Mention some!" If the former is applicable, preVf is used, if the latter, then the neutral sentence type wins. Surányi's (2011) account thus allows both sentence types as felicitous answers to wh-questions suggesting that the choice is a pragmatic one. In sum, according to findings in the theoretical literature, the question types in (3a), (4a) and (5a) primarily trigger answers of the preVf word order, where the focused element corresponds to the wh-expression in the question.

The question now arises: what type of questions trigger the use of neutral sentences? According to Kenesei (2006) and Skopeteas and Fanselow (2011), answers given to questions of the type in (6a) will be neutral sentences.

(6) a. Miért örülnek az emberek a hídon?

'Why are the pople on the bridge happy?'

b. (Mert) Matyi fogott egy halat. (because) Mathias.nOM catch-PST.3sg a fish.ACC proposition: [p] '(Because) Mathias has caught a fish.'

c. (Mert) megérkezett a postás. proposition: [q] (because) arrive-PST.3sg the postman.NOM '(Because) the postman has arrived.'

d. (Mert) kisütött a nap. proposition: [r] (because) start-to-shine-PST.3sg the sun.NOM 'Because the sun started to shine.'

The sentence type exemplified in (6b), (6c) and (6d) is also called broad focus or sentential focus, since now it is the whole sentence (or rather the proposition denoted by it) that gets focused. For ease of reference, this question type (sometimes also called broad-wh-question) will be referred to as a sentential focus triggering question (SFT-question, henceforth). The SFT-question in (6a) evokes a set of alternatives at the propositional level: the potential answers to (6a) might be the propositions p, q, r, as indicated. Since now the focus is placed on the clauses corresponding to the proposition, the word order will be such that it expresses information focus as in É. Kiss (1998); or in our terminology, it will be a neutral sentence.

Regarding word order variants as potential responses to the question type at hand, Kenesei (2006) makes an interesting point. Consider example (7) (Kenesei 2006: 18).

(7) a. What's new?

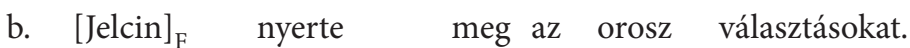
Jeltsin-NOM win-PST.3.sG VM the Russian election-PL.ACC 'Yeltsin has won the Russian elections.' 


\section{c. Jelcin meg-nyerte az orosz választásokat. 'Jeltsin has won the Russian elections.'}

According to Kenesei (2006), the answers in (7b) and (7c) are both congruent with the question in (7a). The choice is extra-linguistic, and depends on speaker expectations about the beliefs of the hearer: if the speaker assumes that the hearer is aware of the candidates for presidency (i.e. assumes a set of alternatives present in the universe of discourse), then (s)he will use a preVf sentence as an answer to identify the element of the implicitly assumed set. If, however, the speaker assumes that the hearer knows nothing about the options, broad focus (i.e. a neutral sentence) will be used to designate a proposition among the potential alternatives (e.g. [there was an earthquake], [it is snowing in the mountains], [there will be a pay raise for linguists] etc.). In sum, if the speaker assumes that the hearer is not aware of a set whose elements are smaller than a clause, a neutral sentence will be used as an answer to questions like those exemplified in (6a) and (7a). Otherwise, it is highly likely that the speaker will use a preVf sentence.

The second way preVf exploits the marking of the presence of alternatives is the expression of contrast, to which we now turn.

\subsubsection{Contrast}

Contrast is commonly associated with focus (see e.g. Rooth 1992; Krifka 1992; É. Kiss 1998; Kenesei 2006; Zimmerman 2008; Destruel \& Velleman 2014). É. Kiss (1998), for example claims that "the identificational foci of different languages are specified for the positive value of either or both of the features $[ \pm$ exhaustive] and [ \pm contrastive]" (p. 267). However, what is categorized as the contrastive use or function of focus is highly variable depending on the frame of analysis. Krifka (2008), ${ }^{11}$ for example, takes a strict stance on contrastivity in the case of focus: the author claims that contrast is only present if the alternatives are directly mentioned and contrasted in a corrective or additive way. Consider Example (8), (Krifka 2008: 259) in which the alternatives are names for people, and the contrast is made explicit: the proposition [x wants coffee] is not only true for John, but for Sue, as well.

(8) a. A: [John] wants coffee.

b. B: [Sue] wants coffee, too.

Krifka (2008) adds that the contrastive use of focus is instantiated through certain grammatical and prosodic features (see e.g. Selkirk 2002; Molnár 2002,

11. For a similar account of contrastive focusing see Selkrik (1984). 
Gussenhoven 2004). Hence, contrastive focus should be considered as a separate case of focusing.

In the present paper, Rooth's alternative semantics approach is adopted as intuitively formulated in Section 1.4. Since, according to this formulation, focus marks the presence of alternatives, its contrastive function is directly derivable: if focus serves to identify elements in a contextually available set, it follows, that the elements that are not identified by the focus (i.e. the complementary set) can be or will be contrasted. Indeed, according to É. Kiss (1998), "an identificational focus (i.e. preVf, in our terminology) is [+ contrastive] if it operates on a closed set of entities whose members are known to the participants of the discourse" (p. 267). Kenesei (2006) goes further. According to the author, both preVf and neutral sentences perform identification on a given set; the difference is the type of set identified with relation to the contextually available set of all alternatives. While a neutral sentence identifies a subset, preVf identifies a proper subset. If a proper subset is identified, it naturally follows that there will be at least one entity to which the proposition of the focus-containing sentence does not hold. Consequently, Kenesei (2006) terms preVf "contrastive focus". In sum, if a set is contextually available (implicitly or explicitly), and an utterance is made regarding this set, it is highly likely that a speaker would use a preVf sentence. In this case, the use of preVf may be contrastive. Otherwise a neutral sentence is used.

\subsection{The goal of the present study, hypotheses}

The goal of the present study is to examine contextual factors that facilitate the use of preVf sentences. More specifically, we are interested in two of the main factors identified in the theoretical literature: the presence of (i) identification and (ii) contrast.

Regarding identification, we hypothesize that in a context where identification is carried out the preVf sentence type is preferred. If the context does not support identification, either a preVf or a neutral sentence is used.

Regarding contrast, it is hypothesized that the presence of contrast facilitates the use of preVf sentences. If no contrast is present, a neutral sentence is preferred.

\section{Experiments}

In order to test the hypotheses formulated above, we carried out two guided production studies in the form of an online survey. The details of these experiments are outlined in the following sections. 


\subsection{Experiment 1}

\subsubsection{Participants}

68 native adult Hungarians (58 female, 10 male, mean age: 50.32, SD = 10.48) participated in the first experiment. Participants were recruited through a Facebook page available for this purpose. Since the experiment was carried out online, data was gathered from speakers from different regions of Hungary.

\subsubsection{Procedure}

The experiment was an online survey containing a series of trials. Each trial consisted of a panel containing a context text in the upper part of the screen (either one or two sentences depending on the experiment or condition (e.g. Mit tört el Márti? 'What did Márti break?' in Figure 1.), a cloud of words in the middle of the screen (e.g. törte 'break', Márti 'Martha', egy ujját 'a finger', el 'VM' in Figure 1), and a blank field between the two.

kitöltöttség

Mit tört el Márti?

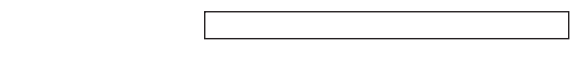

TÖRTE

MÁRTI

EGY UJJÁT

EL

Beküldés \& ugrás a következöre

Figure 1. Example panel of the survey

The words in the cloud were randomly arranged in an area under the blank field. The task of the participant was to produce sentences using the words in the cloud so that the resulting sentence is a natural continuation of the context text. Participants could produce a sentence by clicking on the words: once a word was selected by clicking, it appeared in the field above the cloud. Participants were asked to use all the words in the cloud. Once the sentence was built, the next trial was initiated by a click on a button at the bottom of the screen. Before proceeding to the next 
trial, participants were encouraged to reread the context text and the sentence together to make sure that their solution was natural and coherent. Responses could be modified as needed.

The experiment contained two blocks: a practice block following the instructions, and the test block. The practice block contained 5 trials similar to those in the test block. The test block contained three types of trials: (i) test, (ii) filler and (iii) hidden control trials (see details for (i) and (ii) in sections 2.1.3 and 2.2.3). In the hidden control trials, participants were given an instruction to put the words in the cloud in a given order; one that would have been very unlikely to be produced by chance. The inclusion of these trials was a practical one. In order to encourage participation, respondents were entered a draw in which a winner would be picked randomly at the end of data collection. The prize was a small fee; a voucher worth of 5000 HUF sent via post to the winner. The hidden control trials were included so that we could filter out respondents who participated only in the hope of winning the voucher: erroneous responses in the hidden control trial indicate that the participant did not read the instruction in these trials based on which it can be assumed that they did not read the context sentences in the rest of the trials either.

The experimental interface was developed by relying on the d3-cloud JavaScript package (Davies 2013) and was implemented in the in the IBEX online experimental environment (Drummond 2010).

\subsubsection{Materials}

Experiment 1 investigated whether identificatory and contrastive contexts have the effect of facilitating the use of preVf word order sentences. For the two different context types, two different test trial types were created.

To test the effect of identification, questions were introduced, as shown in (9). For contexts of identification (identification-condition), we used directive wh-questions (or narrow-wh-questions) (9a); and for contexts where identification was not present (no-identification-condition), SFT-questions (or broad-whquestions) (9b) were used.

(9) a. Mit veszített el Péter?

'What did Peter lose?'

b. Miért szomorú Péter?

'Why is Peter sad?'

The set of words comprising the cloud for the example in (9) is given in (10a) separated by commas. The elements of the word cloud were the same types of linguistic units in each critical trial: (i) a name in the nominative case, (ii) an NP comprising of an indefinite article and a noun in the accusative case, (iii) a verb in past tense and (iv) a corresponding VM. (10b) and (10c) are two example sentences that can be produced by ordering the words in the word cloud for the contexts in (9). The 
order and location of the elements in the cloud was randomly allocated in each trial.
(10)
a. Péter, egy órát, vesztett, el Peter-NOM, a watch-SG.ACC, lose-PST.3SG, VM 'Peter,' 'a watch', 'lost'
b. Péter egy órát vesztett el. 'Peter lost $[\text { a watch }]_{\mathrm{F}}$ '
c. Péter el-vesztett egy órát.
'Peter lost a watch.'

To test the effects of contrast, two-sentence contexts were created, as in (11). The first sentence designated an explicit set (11a) in both conditions. The experimental manipulation was introduced in the second sentence. In the contrast-condition, the second sentence identified one element of the designated set (11b). To avoid a syntactic priming effect, these sentences had a structure that could not be built with the words in the cloud: the NP referring to the identified element was in the nominative case, and the VP did not contain a transitive verb. In the no-contrastcondition, the second sentence did not identify any member of the contextually given set, but it always referred to some state of affairs that was irrelevant with respect to that set $(11 \mathrm{c})$. The structure of these sentences also differed from focus constructions for the aforementioned reasons.

(11) a. Ebéd után maradt desszertnek egy körte, egy alma és egy barack. 'After lunch there was a pear, an apple and an apricot for dessert.'
b. János desszertje az alma volt. John-NOM dessert-his-NOM.SG the apple-NOM.SG be-PST.3SG 'John had the apple for dessert.'
c. János desszert helyett szundított
John-NOM dessert-NOM.SG instead take-a-nap-PST.3SG
inkább kicsit.
rather little.ACC

'John didn't have dessert, he took a nap instead.'

The set of words comprising the cloud for the example in (11) is given in (12a) separated by commas. Just as in the previous case, the elements in the word cloud were of the same type in each trial: (i) a name in the nominative case, (ii) an NP consisting of a definite article and a noun in the accusative case, (iii) a verb in past tense and (iv) a VM. The two canonical word order variants that can be produced using elements listed in (12a) are provided in (12b) and (12c).
a. Péter,
a körtét,
ette, meg
Peter-NOM, the pear-SG.ACC, eat-PST.3SG, VM
'Peter,' 'the pear,' 'ate' 


\section{b. Péter a körtét ette meg. 'Peter ate $[\text { the pear }]_{\mathrm{F}}$ ' \\ c. Péter megette a körtét. \\ 'Peter ate the pear.'}

For the investigation of the possible effects of both identification and contrast, 16 critical trials were presented. The conditions were distributed equally: 8 trials in the identification condition, 8 trials in the no-identification condition, 8 trials in the contrast condition, and 8 trials in the no-contrast condition. This amounted to a total of 32 critical trials.

The experiment also contained 64 filler trials. In order to "conceal" the actual purpose of the experiment, we identified four key features for fillers. These features were the following: (i) whether the trial contains a one- or two-sentence context, (ii) the presence or absence of a question in the context, (iii) whether the sentence that fits the context (i.e., the one that the participant produces) should contain a separated or a non-separated VM-V complex, and (iv) the presence or absence of a VM in the sentence to be produced. The features listed were selected to correspond to all the manipulated variables (feature (i), (ii)), and the outcome variable (feature (iii)) in the experiment. Feature (iii) was especially important, since we wanted to encourage participants to regard VMs as elements that could appear in any potential position within the sentence. Additionally, feature (iv) was crucial to eliminate the potential impression that the experiment had anything to do with VMs. The distribution of features in filler trials is presented in Table 1.

Table 1. The distribution of key features in filler trials.

\begin{tabular}{llll}
\hline Feature & & Number \\
\hline 2-sent. context & Question & VM - V separ. & 4 \\
& No question & VM - V non-separ. & 4 \\
3-sent. context & Question & VM - V separ. & 4 \\
& & VM - V non-separ. & 4 \\
& No question & VM - V non-separ. & 4 \\
2-sent. context & Question & VM - V separ. & 4 \\
3-sent. context & No question & No VM & 4 \\
& Question & & 4 \\
& No question & & 8 \\
\hline
\end{tabular}




\subsubsection{Predictions}

In line with our hypotheses in Section 1.6, we predicted that in the case of whquestion types (9a), participants would produce preVf word order sentences (10b), whereas in the case of SFT-questions (9b), preVf (10b) and neutral sentences (10c) would be produced.

Regarding the effect of contrast, it was predicted that in the contrast-condition dominantly preVf sentences would be produced, whereas in the no-contrastcondition we expected the dominance of neutral sentences.

\subsubsection{Results}

PreVf response rates were analyzed in a Friedman's ANOVA model with four within-subjects conditions (narrow-wh-question, SFT-question, contrast context and no-contrast context). The results indicate that context has a significant effect on the choice of word order $\left(X^{2}=91.24, p<.001\right)$. Specifically, there is a sharp contrast in preVf response rates between the narrow-wh $(\mathrm{M}=.83, \mathrm{SD}=.17)$ and SFT $(\mathrm{M}=.17, \mathrm{SD}=.15)$ question conditions $(\mathrm{z}=7.20, p<.001)$ and between the contrast $(\mathrm{M}=.92, \mathrm{SD}=.10)$ and no-contrast $(\mathrm{M}=.63, \mathrm{SD}=.21)$ context conditions $(\mathrm{z}=4.35, p<.001)$. Further analyses using a series of one-sample Wilcoxon Signed Ranks tests reveal that the median rate of preVf responses significantly differs from chance in all four conditions: in the narrow-wh-question, contrast context and no-contrast context conditions it is above chance level $(\mathrm{z}=5.08,5.49$ and 3.32 respectively; $p \leq .001)$ while in the SFT-question condition it is below chance level $(\mathrm{z}=-5.25, p<.001)$.

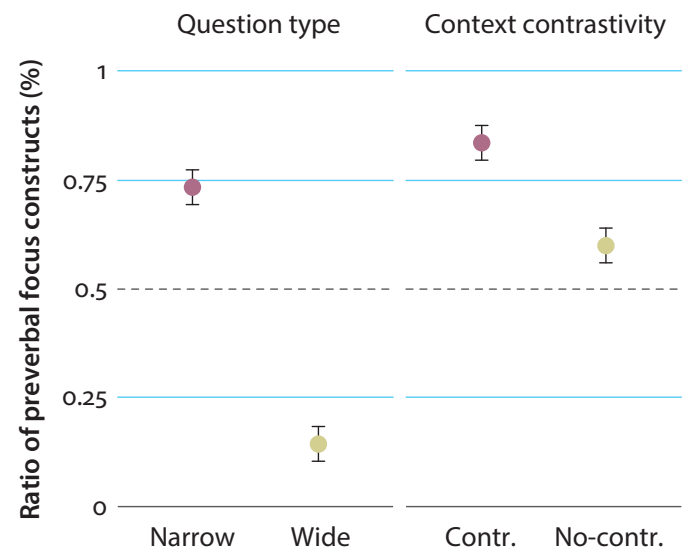

Figure 2. Proportion of sentence types in the two contexts (error bars: 95\% CI). The horizontal dashed line represents the level of chance. 


\subsubsection{Discussion}

The data obtained in Experiment 1 partly corroborated our hypotheses. The high proportion of preVf sentences produced in both contexts of identification and contrast are in line with our expectations, and clearly demonstrate that these two contextual factors facilitate the use of the sentence type at hand. The below-chance level rate of preVf sentences in the SFT-condition, and the above-chance level rate of preVf sentences in the no-contrast-condition, however, present an interesting puzzle. Note that in the former case, we predicted that this rate would be around chance, whereas in the latter, we predicted that it would be below chance. Based on the observed patterns, we conjectured that the answer may lie in the availability of sets. In the forthcoming discussion, the issue of sets will be taken up.

Let us return to our starting point regarding the function of focus: focus evokes alternatives (Rooth 1992, Krifka 2008). Using sets to represent what focus does, this formulation suggests that there must be a contextually available set from which a subset is identified by focus, which entails that there is also a complementary set of alternatives. Recall that this is exactly what Kenesei (2006) claims: focus identifies a proper subset of the contextually available set. More importantly, Kenesei adds that "whether or not the contrasting complementary set is explicit, in case of contrastive focus a complementary set is always created" (p. 137). If this is indeed true, preVf is triggered in contexts that either explicitly or implicitly contain a set whose members are potential referents of the focus of the proposition to be made. This explanation can straightforwardly account for the observation that in all of the conditions which contained a set or in which a set was evoked, the proportion of preVf structures was above chance level. Let us consider the conditions used in Experiment 1 from the point of view of sets. In contexts with a narrow-wh-question a set is evoked. Consider (3a) and (4b) again: the former evoked a set of potential owners ([x owns a gorilla]), whereas the latter evoked a set of entities that can be owned ([John owns $\mathrm{x}]$ ). In the case of SFT-questions no such set is evoked. Correspondingly, the observed rate of preVf sentences was well below chance level, and participants reliably produced neutral sentences. In the contrast- and no-contrast-conditions the set was not evoked; it was explicit, since the first sentence always designated a three-element set in the context. Note that apart from the SFT-question-condition, in which no set was available, the proportion of preVf sentences was above chance level in all conditions.

Considering the above reasoning, an important factor contributing to the production of preVf is the availability of sets. Thus, we hypothesized that if a set is either explicitly or implicitly present, a preVf sentence is used. Otherwise either a preVf or a neutral sentence is produced (cf. Examples (7b) and (7c) in Section 1.5.1). In order to test this hypothesis, we designed and ran Experiment 2. 


\subsection{Experiment 2}

\subsubsection{Participants}

118 native adult Hungarians participated in the experiment (99 female, 19 male, mean age: $48.37, \mathrm{SD}=12.43$ ). Participants were recruited through a Facebook page dedicated to obtaining participants. Since the experiment was carried out online, data was gathered from speakers from different regions of Hungary.

\subsubsection{Procedure}

The procedure of Experiment 2 was identical that of Experiment 1. For details see Section 2.1.2.

\subsubsection{Materials}

In order to test the potential effect of the contextual availability of sets, two-sentence contexts were created. The first sentence in the context either (i) designated a set explicitly (Table 2, sentence a), or (ii) implicitly (Table 2, sentence b), or (iii) designated no set at all (Table 2 expression c). In the case of (i), the set was made explicit through an enumeration, while in the case of (ii), the implicit set was implied. In case (iii), we used a label for a particular situation or place irrelevant with respect to the potential sets for the third (i.e. test) sentences. The second sentences were such that they either introduced a contrast with respect to the third sentence (Table 2, sentence d), or not (Table 2, sentence e).

The combination of sentence types in Table 2 resulted in altogether six conditions. These are presented in Table 3.

Example (13) presents the elements of the cloud for the example trial in Table 2 separated by commas (13a), and two potential word order variants that could be produced using these words: a preVf sentence (13b) and a neutral one (13c). The elements of the word cloud were the same type of linguistic units in each critical trial: (i) a name in the nominative case, (ii) an NP comprising of an indefinite article and a noun in the accusative case, (iii) a verb in past tense, and (iv) a corresponding VM.
a. Misi, egy várat, rakott, össze Mike-NOM, a castle-sG.ACC, put-PST.3SG, VM ( together) 'Mike,' 'a castle', 'built', 'up'
b. Misi egy várat rakott össze. 'Mike built [a castle] ${ }_{\mathrm{F}}$ '
c. Misi össze-rakott egy várat. 'Mike built a castle.'


Table 2. Sentences of the contexts used in Experiment 2

\begin{tabular}{|c|c|c|c|}
\hline Label & Number in context & Condition & Example \\
\hline a. & 1 & Expl. set & $\begin{array}{l}\text { A gyerekeknek kiosztottak egy csomó játékkockát. } \\
\text { Ezekből mindenfélét össze lehetett rakni: például } \\
\text { tornyot, várat, házat. } \\
\text { 'Kids were handed out lots of building blocks. } \\
\text { So many things could be built out of them: for } \\
\text { example a tower, a castle, a house.' }\end{array}$ \\
\hline b. & 1 & Impl. set & $\begin{array}{l}\text { A gyerekeknek kiosztottak egy csomó játékkockát, } \\
\text { amikből mindenfélét össze lehetett rakni } \\
\text { 'Kids were handed out lots of building blocks. So } \\
\text { many things could be built out of them.' }\end{array}$ \\
\hline c. & 1 & No set & $\begin{array}{l}\text { A játéksarokban: } \\
\text { 'In the playing corner:' }\end{array}$ \\
\hline d. & 2 & Contrast & $\begin{array}{l}\text { Bence már korábban is sok tornyot épített, így } \\
\text { most is ezt csinálta. } \\
\text { 'Ben had built a lot of towers before, so now he } \\
\text { did so again.' }\end{array}$ \\
\hline e. & 2 & No contrast & $\begin{array}{l}\text { Bence álmos volt, így csak nézte, ahogy a többiek } \\
\text { játszanak. } \\
\text { 'Ben was sleepy, so he just watched the others play'. }\end{array}$ \\
\hline
\end{tabular}

Table 3. Conditions in Experiment 2

\begin{tabular}{lll}
\multicolumn{2}{l}{ Experimental manipulation introduced in } \\
\hline First sentence & & Second sentence \\
\hline explicit set & - & contrast \\
explicit set & - & no-contrast \\
implicit set & - & contrast \\
implicit set & - & no-contrast \\
no set & - & contrast \\
no set & - & no-contrast \\
\hline
\end{tabular}

In Experiment 2, the availability of sets (explicit, implicit or no set) was a betweensubject factor, and the presence or absence of contrast was a within-subject factor. Each run of the experiment contained 12 test trials ( 6 in the contrast condition and 6 in the no-contrast condition) and 24 filler trials. Respondents were assigned to one of the three versions of the experiment randomly. As in Experiment 1, three types of fillers were used in equal proportion: the third sentence (i) had to be produced in a way that it contained a VM-V compound, (ii) the VM and V had to be 
separated, or (iii) the sentence did not contain a VM at all. Also as in Experiment 1 , this variation was introduced to encourage participants to regard VMs as elements that could appear in any potential position within the sentence.

\subsubsection{Predictions}

In line with our hypothesis formulated at the end of Section 2.1.6, we predicted the following. If contrast is present, dominantly preVf sentences will be produced. The availability of a set (either explicit or implicit) will facilitate the production of preVf sentences even if no contrast is present. If neither a set is available nor contrast is to be expressed, preVf sentences will not be produced reliably.

\subsubsection{Results}

The results were in line with our predictions. A Kruskal-Wallis test for the contrast-condition and one for the no-contrast-condition revealed that the presence or absence of an explicit or implicit set had no significant effect on word order choices in the contrast context condition $(\mathrm{H}(118)=2.63, p=.27)$, while in the no-contrast context condition it $\operatorname{did}((\mathrm{H}(118)=13.35, p=.001)$. Specifically, in the no-contrast condition, preVf was less likely to be used when no set was specified $(\mathrm{M}=.49$, SD $=.26)$ than when a set was either explicitly given $(\mathrm{M}=.69, \mathrm{SD}=.24 ; \mathrm{z}=3.67, p=$ $.001)$, or implicitly given $(\mathrm{M}=.62, \mathrm{SD}=.24 ; \mathrm{z}=2.54, p=.05)$. There was no significant difference between the explicit and implicit conditions. Wilcoxon Signed Rank tests comparing the medians to chance level revealed that in the presence of a contrast context, the probability of choice of preVf in all three set conditions (explicit, implicit, none) was significantly higher than chance $(z=5.39,5.27$ and 5.36; all $p$ s $<.001)$. In the absence of contrast, participants produced a preVf word order with

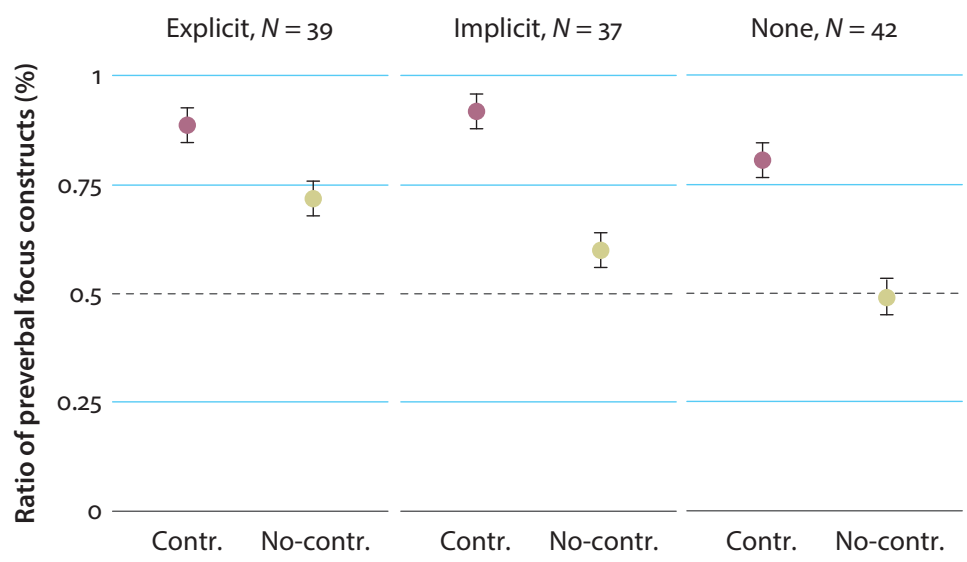

Figure 3. Proportion of sentence types in the three contexts (error bars: 95\% CI). The horizontal dashed line represents the level of chance 
higher than chance probability when an explicit or implicit set was given (explicit: $\mathrm{z}=3.64, p<.001$; implicit: $\mathrm{z}=2.72, p=.006$ ); but the choice between preVf and neutral word order did not differ from chance when no set was given.

\subsubsection{Discussion}

Data obtained in Experiment 2 corroborated our hypotheses: the availability of sets facilitates the production of preVf sentences. The facilitation effect is present irrespective of the expression of contrast for both explicit and implicit sets. However, in the case of implicit sets, this facilitation effect diminishes if no contrast is to be expressed. Altogether, contrast also facilitates the production of preVf sentences. Additionally, lack of contrast makes the production of preVf sentences less likely irrespective of the type (i.e. explicitness or implicitness) of the contextually available set. However, in the case of contrast, preVf is still reliably produced relative to chance level even if no set is available in the immediately preceding context. If both a contextually available set and contrast are missing, preVf is not produced reliably.

In sum, two important and intimately related factors have been identified which facilitate the production of preVf sentences: (i) the availability of a set and (ii) the expression of contrast.

\section{General discussion}

The present study investigated the factors that potentially facilitate the use of sentences in the preVf word order. Based on findings in the theoretical literature, it was hypothesized that two of these factors are the expression of (i) identification and (ii) contrast.

These factors were examined in a guided production study: in the experimental trials, participants were presented a context text and a cloud of words. The task was to produce sentences using the words in the cloud in a way that the newly constructed sentences fit the context and thus create a coherent text.

The results of the experiment showed that the aforementioned factors facilitate the use of preVf. However, it was also observed that even when no contrast was to be expressed, participants still reliably produced preVf sentences at a rate above chance level. In the case of SFT-questions, however, the rate of preVf sentences was reliably under chance level. The authors of the present study believe that the formulation of the function of focus as outlined in Section 1.4 is the most appropriate one to account for the observed results. This formulation states that focus is a means of indicating the presence of alternatives. Furthermore, alternatives can only be marked if there is a contextually available set (see e.g. Kenesei 
2006). In terms of sets, focus creates a distinction: it designates a proper subset of the contextually available set, and consequently, creates a complementary set. The former is an instance of identification; the latter is an instance of contrast. Note that a set was present in all but one conditions in Experiment 1. In the identification-condition, the narrow-wh-question created an implicit set of alternatives for the NP (cf. Examples (3) and (4)). In the contrast and no-contrast conditions, the first sentence of the contexts always contained an explicit set. In the SFT-questioncondition, however, in which a below chance level rate of preVf sentences was produced, neither an implicit nor an explicit set was present. For this reason, we conjectured that the availability of sets may be an underlying factor facilitating preVf use. In order to test this conjecture, a second experiment was run.

Experiment 2 tested conditions in which a set was either explicitly or implicitly present as well as conditions that referred to no set at all. In all cases, there were trials which contained contrast and trials which did not. It was predicted that in conditions that contained a set, preVf would be used. Likewise, if contrast is to be expressed, the rate of preVf sentences would be increased. The results of Experiment 2 were in line with the predictions. PreVf sentences were reliably produced in conditions where a set was present, irrespective of whether the set was explicit or implicit. Also, contrast in general facilitated the rate of preVf sentences with respect to the no-contrast conditions. The only conditions in which the rate of preVf sentences was around chance level was the no-set-no-contrast-condition. Interestingly, we also observed the dominance of preVf sentences in the no-setcontrast-conditions. This result deserves a mention. We believe that the high proportion of preVf sentences can be accounted for in terms of sets, as well. Consider the context for one such trial as shown in (14a).
a. IN THE PLAYING CORNER:
Ben had built a lot of towers, so he decided to build one now, as well.
b. [Mike built $\mathrm{x}$ ]
c. [a castle, a house, a bridge, etc]

Although the context does not designate a set either explicitly or implicitly as in the other two conditions, a set is still evoked with respect to the second sentence if contrast is to be expressed. The mechanism is analogous to the one where identification is triggered via a wh-question (cf. example (3) and (4)) as indicated in (14b) and (14c): by the contrastive use of focus a set of alternatives with respect to what can be built out of building blocks is introduced or evoked.

To conclude, the results of Experiment 1 and 2 jointly support the view that there is a general underlying factor determining the use of preVf sentences, namely, the contextual availability of a relevant set. The uses of preVf examined in the current paper are derivable from this factor. 
Another, independent observation may account for the dominating proportions of preVf sentences in the conditions containing sets in the present experiments. Káldi and Babarczy (2017) and Káldi and Babarczy (2018), in a series of visual world experiments, presented preVf, neutral and lexically marked focus sentences in contexts containing either explicit or implicit sets, and studied the rate of exhaustive interpretations of the presented sentence types. It was observed that in the case of preVf sentences, the rates of exhaustive interpretation were around $90 \%$ (where a chance level was 50\%) in all conditions. This is a high ratio compared to those found in the literature where the rate of exhaustive reading was measured in out-of-context preVf and neutral sentences. For example, an earlier study (Káldi, Babarczy \& Bende-Farkas 2016) found that the rate of exhaustive reading was $65 \%$ for out-of-context preVf sentences. In sum, the results of the experiments reported in the present paper and of those cited above show that the contextual availability of sets matters for two reasons. On the one hand the present experiments showed that the availability of a set facilitates preVf use. On the other hand, the results of Káldi and Babarczy (2017) and Káldi and Babarczy (2018) demonstrate that if this set is either explicitly or implicitly given, the likelihood that preVf is interpreted exhaustively increases. To approach the question from a different perspective, note that according to É. Kiss (1998), preVf sentences have an exhaustive interpretation: for example if an answer to a narrow-wh-question is to be understood exhaustively, a preVf is used. Now, if we postulate that in scenarios where identification and/or contrast is to be expressed, a felicitous utterance has to contain a structure that has exhaustive interpretation (i.e. the speaker obeys the implicit "Mention all!" imperative), it follows that this structure will be a preVf sentence. Apparently, the availability of sets and the typically exhaustive interpretation of preVf are in an intricate relationship. More experimental work is needed, however, to clarify the mechanisms through which these factors interact.

\section{Conclusion}

The results of the two experiments in the present paper showed that two important functions of the preVf word order sentences are identification and contrast. A crucial factor underlying both of these functions is the availability of sets. Sets can be present in a number of ways: they can either be explicitly mentioned (e.g. by an enumeration), implicitly referred to (e.g. by a category name) or evoked (e.g. by a question or contrast). If a set is present and one or more of its elements are to be identified or contrasted, a preVf sentence is most likely used. Furthermore, it is highly likely that the availability of sets is a critical factor contributing to the typically exhaustive interpretation of preVf sentences. 


\section{Acknowledgement}

The research was supported by NKFI 115544. Our thanks go to Balázs Surányi for his precious help.

\section{References}

Aronoff, Mark \& Janie Rees-Miller (eds.). 2017. The handbook of linguistics. Wiley, Blackwell. https://doi.org/10.1002/9781119072256

Brassai, Sámuel. 1852. Tapogatódzások a magyar nyelv körül [Exploring the Hungarian Language]. Pesti Napló 802.

Brassai, Sámuel. 1860. A magyar mondat [The Hungarian Sentence]. Magyar Akadémiai Értesítő. A széptudományi Osztály közlönye 1. 279-399.

Brassai, Sámuel. 1885. A mondat dualismusa [The dualism of the sentence]. Értekezések a Magyar Tudományos Akadémia Nyelv-és Széptudományi Osztály Köréből 12.

Brody, Mihály \& Kriszta Szendröi. 2010. Exhaustive focus is an answer. Unpublished Manuscript. http://ling.auf.net/lingbuzz/001113.

Davies, Jason. 2013. d3-cloud. https://github.com/jasondavies/d3-cloud

Destruel, Emilie J. \& Leah Velleman. 2014. Refining contrast: Empirical evidence from the English it-cleft. Empirical Issues in Syntax and Semantics 10. 197-214.

Drummond, Alex. 2010. Ibex (Internet Based Experiments). http://spellout.net/ibexfarm/

É. Kiss, Katalin. 1995. Discourse configurational languages. Oxford: Oxford University Press.

É. Kiss, Katalin. 1998. Identificational focus versus information focus. Language 72(2). 245273. https://doi.org/10.1353/lan.1998.0211

É. Kiss, Katalin. 2002. The syntax of Hungarian. Cambridge: Cambridge University Press. https://doi.org/10.1017/CBO9780511755088

É. Kiss, Katalin. 2008. A pioneering theory of information structure. Acta Linguistica Hungarica 55. 23-40. https://doi.org/10.1556/ALing.55.2008.1-2.2

Gussenhoven, Carlos. 2004. The phonology of tone and intonation. Cambridge: Cambridge University Press. https://doi.org/10.1017/CBO9780511616983

Halliday, Michael. 1967. Notes on transitivity and theme in English: Part 2. Journal of linguistics 3(2). 199-244. https://doi.org/10.1017/So022226700016613

Hamblin, Charles L. 1973. Questions in montague English. Foundations of language 10(1). 41-53.

Káldi, Tamás, Anna Babarczy \& Ágnes Bende-Farkas. 2016. Hungarian focus: Presuppositional content and exhaustivity revisited Language and Linguistic structure. In Joseph Edmonds, Michaela Martinková \& Marketa Janebova (eds.), Proceedings of the Olomouc Linguistics Colloquium 2016. Olomouc: Palacký University Olomouc.

Káldi, Tamás \& Anna Babarczy. 2017. A kontextus hatása a magyar preverbális fókusz értelmezésére: egy szemmozgás-követéses vizsgálat [The effect of context on the interpretation of the Hungarian pre-verbal focus: an eye-tracking study] In Zoltán Bánréti \& István Kenesei (eds.), Általános Nyelvészeti Tanulmányok. XXIX, 99-126. Budapest: Akadémiai Kiadó.

Káldi, Tamás \& Anna Babarczy. 2018. Linguistic exhaustivity inference is context dependent: A visual-world eye-tracking study on Hungarian focus. Acta Linguistica Academica 65(4). 547-595. https://doi.org/10.1556/2062.2018.65.4.2 
Kálmán, László. 1985. Word order in neutral sentences. In István Kenesei (ed.), Approaches to Hungarian 1, 13-23. Szeged: JATE.

Kenesei, István. 2006. Focus as identification. In Valéria Molnár \& Susanne Winkler (eds), The architecture offocus, 137-168. Mouton de Gruyter. https://doi.org/10.1515/9783110922011.137

Krifka, Manfred. 1992. A framework for focus-sensitive quantification. Semantics and Linguistic Theory 2. 215-236. https://doi.org/10.3765/salt.v2io.3024

Krifka, Manfred. 2001. For a structured meaning account of questions and answers. In Caroline Féry \& Wolfgang Strenfeld (eds.), Audiatur Vox Sapientiae: A Festschrift for Arnim von Stechow (Studia grammatica, Band 52), 287-319. De Gruyter Akademie Forschung.

Krifka, Manfred. 2008. Basic notions of information structure. Acta Linguistica Hungarica 55(34), 243-276. https://doi.org/10.1556/ALing.55.2008.3-4.2

Miller, Jim. 2006. Focus. In Keith Brown (ed.), Encyclopedia of language and linguistics (2nd ed.), 511-518. Elsevier. https://doi.org/10.1016/Bo-08-044854-2/00575-7

Molnár, Valéria. 2002. Contrast - from a contrastive perspective. Language and Computers 39(1), 174-161.

Roberts, Craige. 1996. Information structure in discourse: Towards an integrated formal theory of pragmatics. In Jae-Hak Yoon \& Andreas Katjol (eds.), Working Papers in Linguistics-Ohio State University Department of Linguistics 49, 91-136. Columbus: The Ohio State University Department of Linguistics.

Rooth, Mats. 1985. Association with focus. Ph.D. thesis. Massachussets Institute of Technology.

Rooth, Mats. 1992. A theory of focus interpretation. Natural Language Semantics 1(1). 75-116. https://doi.org/10.1007/BFo2342617

Selkirk, Elisabeth. 1984. Phonology and syntax. Cambridge: The MIT Press.

Selkirk, Elisabeth. 2002. Contrastive FOCUS vs. presentational focus: Prosodic evidence from right node raising in English. In Bernard Bel \& Isabelle Marlin (eds.), Speech Prosody 2002: Proceedings of the First International Speech Prosody Conference, 643-646. Laboratoire Parole et Langage, Université de Provence.

Skopeteas, Stavros \& Gisbert Fanselow. 2011. Focus and the exclusion of alternatives: On the interaction of syntactic structure with pragmatic inference. Lingua 121(11). 1693-1706. https://doi.org/10.1016/j.lingua.2011.05.005

Surányi, Balázs. 2011. A szintaktikailag jelöletlen fókusz pragmatikája [The pragmatics of syntactically unmarked focus]. In Huba Bartos (ed.), Általános Nyelvészeti Tanulmányok 23, 281-313. Budapest: Akadémiai Kiadó.

Zimmermann, Malte. 2008. Contrastive focus and emphasis. Acta Linguistica Hungarica 55. 347-360. https://doi.org/10.1556/ALing.55.2008.3-4.9 


\title{
Testing variability effects in Hungarian vowel harmony
}

\author{
Fanni Patay ${ }^{1}$, Ágnes Benkő ${ }^{1,2}$, Ágnes Lukács ${ }^{3}$, Péter Rebrus ${ }^{1} \&$ \\ Miklós Törkenczy ${ }^{1,2}$ \\ ${ }^{1}$ MTA Research Institute for Linguistics / ${ }^{2}$ Eötvös Loránd University / \\ ${ }^{3}$ Department of Cognitive Science, Budapest University of Technology and \\ Economics, MTA-BME Lendület Language Acquisition Research Group
}

Hungarian backness harmony shows various degrees of transparency and variation, but the empirical testing of these variability effects in corpora is problematic because of data sparseness. We have created an experiment using harmonically mixed stems and four different harmonic suffixes, and collected information about the variants from native speakers in the form of a sentence completion task. We show that there are significant differences between stem types, and that the harmonic suffix can also affect the behaviour of the stem. Our results confirm that native speakers can learn unnatural patterns and that they obey the Law of Frequency Matching (Hayes et al. 2009).

Keywords: vowel harmony, variation, vacillation, neutral vowels, experimental phonology

\section{Harmony}

The backness harmony system of Hungarian (henceforward HVH) is both determined and underdetermined by phonology. This manifests itself in variation where some stems that are identical in their phonological properties relevant in harmony behave in more than one way harmonically. This may be lexical variation, where different stems of the same phonological shape belong to different harmonic classes (e.g. haver-ok 'mate-PL' vs. kontsert- $\underline{\text { k }}$ 'concert-PL'), or vacillation, where the same stem may take front or back alternants of the same suf-

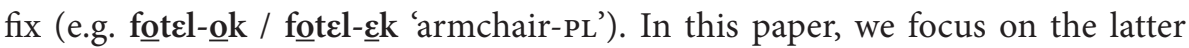
type of variation. Vacillation is confined to a phonologically identifiable 'zone of variation' (Hayes \& Cziráky Londe 2006): it can occur after harmonically mixed stems whose final portion consists of a back-vowelled syllable followed by one 
or more syllables whose vowel is a neutral one, schematically $\left[\mathrm{BN}^{+}\right] \cdot{ }^{1}$ Vacillation is motivated by two effects which modify the basic pattern of neutral-vowel transparency in HVH. While the neutral vowels /i/ and /ir/ are totally transparent ([Bi]B, e.g. forint-nak 'florin-DAT'), the other neutral(-like) vowels are variably transparent: $[\mathrm{Be}] \mathrm{B} / \mathrm{F}$ (e.g. arzein-nak/nck 'arsenic-DAT') and $[\mathrm{B} \varepsilon] \mathrm{F} / \mathrm{B}$ (e.g. hotel-nek/nak 'hotel-DAT'). This is called the Height Effect. An additional effect obtains when two neutral vowels follow the back vowel: [BNN]. In this case either variable transparency or non-transparency occurs: e.g. [Bii]B/F (aspirin-nak/ nek 'aspirin-DAT') or [Bie]F (saniter-nek 'sanitary ware-DAT'). This is called the Count Effect. The two effects are shown schematically in (1), where $x<y$ means: ' $y$ is more front than $x$ '.

$(1)^{2} \quad$ a. Height Effect: $[\mathrm{Bi}(\mathrm{:})]<[\mathrm{Ber}]<[\mathrm{B} \boldsymbol{\varepsilon}]$

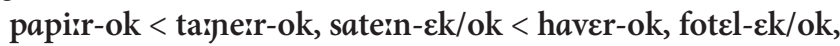
kontsert- $\varepsilon$ k

b. Count Effect: $[\mathrm{BN}]<\left[\mathrm{BNN}^{+}\right]$

parti-ra $<$ alibi-ra/re, horribilif-ra/re

ta:nerr-ra $<$ klarineit-re/ra, prote:zif-re/ra

These effects were known in the literature, and were typically impressionistically described based on intuition/introspection (e.g. in Vago 1980, Siptár \& Törkenczy 2000; see Törkenczy 2016 for an overview) before they were named by Hayes et al. $(2006,2009)$, but the latter are the first empirical studies ${ }^{3}$ based on extensive corpus-based research and psycholinguistic experiments. Hayes and Cziráky Londe (2006) has shown that the Height Effect and the Count Effect (i) manifest themselves in type frequency, measured in the ratio of back/front suffixed forms to all harmonically suffixed forms in a corpus; and that (ii) native speaker reaction, based on wug testing, matches the results of the corpus study. That is, they obey what Hayes et al. (2009) call the "Law of Frequency Matching" and define as the state of affairs when "[s]peakers of languages with variable lexical patterns respond

1. B, F and N are back, front and neutral vowels, respectively; [ and ] mark the edges of stems. Some vowels that are neutral in roots and invariable suffixes may also occur in the front alternants of harmonically alternating suffixes; in this last case we have encoded them as front (F), e.g. dative -nek (-nak), adessive -nell (-na:l). Unless otherwise indicated, in order to avoid unnecessary clutter we suppress the consonants, the non-final portions of stems and the length mark ' $?$ ' in formulas throughout the paper.

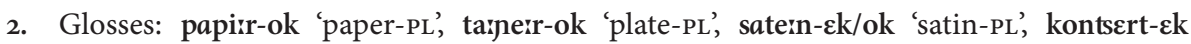
'concert-PL', parti-ra 'party-SUBL', alibi-ra/re 'alibi-sUBL', horribilif-ra/re 'horrible-suBL', klarinert-re/ra 'clarinet-SUBL', prote:zif-re/ra 'prosthetic-sUBL'.

3. Ringen \& Kontra (1989) is a notable exception in the earlier literature. 
stochastically when tested on such patterns. Their responses aggregately match the lexical frequencies" (p. 826). However, Hayes and Cziráky Londe (2006) presents a simplified picture in several respects (e.g. they examined word forms with one and the same harmonic suffix (the dative) only). There is every indication that the patterning of variation and its conditioning in the zone of variation in Hungarian is far richer and is conditioned by many and varied factors, which include syllable count ([BN] vs. [BBN] stems, cf. Ringen \& Kontra 1989), the place and manner of articulation of stem-final consonants (cf. Hayes et al. 2009), the phonological shape of the harmonic suffix (C-initial vs. V-initial, cf. Rebrus \& Törkenczy 2013), paradigm uniformity $([[\mathrm{BN}] \mathrm{N}]$ vs. [BNN] stems, cf. Rebrus \& Törkenczy 2015, Rebrus \& Szigetvári 2016), the fuzziness of harmonic domain boundaries due to the gradience of morphological complexity (cf. Rebrus \& Törkenczy 2017) and the multiple application of the Height Effect (stems in which the Height Effect and the Count Effect can combine: $\left[\mathrm{BN}_{\mathrm{x}} \mathrm{N}_{\mathrm{y}}\right]$ vs. $\left[\mathrm{BN}_{\mathrm{z}} \mathrm{N}_{\mathrm{w}}\right]$ stems, cf. Rebrus \& Törkenczy 2016). In this study, we take a closer look at the last one of these factors.

It has not been sufficiently explored what the combined effect of the Count and the Height Effects is for those stems that end in a back vowel followed by two neutral vowels (BNN-stems). Rebrus and Törkenczy $(2015,2016)$ quantify these two effects in terms of a measure of variability, the Frontness ratio (F-ratio). ${ }^{4}$ The F-ratio of a stem class is the ratio of the number of front suffixed forms to the number of all harmonically suffixed forms whose stems belong to the relevant stem-class. The F-ratio is measured in type frequency, i.e. the number of different word-forms (as opposed to tokens) is counted:

(2) The Frontness Ratio

$$
\mathrm{F}-\text { ratio }=\frac{\text { number of front suffixed forms }}{\text { number of front suffixed forms }+ \text { number of back suffixed forms }}
$$

The F-ratio increases (i.e. the transparency decreases) between the relevant forms as defined by the Height and the Count Effects. Because of the Height Effect, the transparency of the neutral vowel in [Bi] stems is greater than in $[\mathrm{Be}]$ stems, and the same holds between [Be] and $[\mathrm{B} \varepsilon]$ stems; expressed in F-ratios, this is [Bi] $<[\mathrm{Be}]<[\mathrm{B \varepsilon}]$. In accordance with the Count Effect, transparency decreases in $\left[\mathrm{BNN}^{+}\right]$stems compared to $[\mathrm{BN}]$ stems. Minimally, ${ }^{5}$ this means that if one of the

4. Compare Hayes \& Cziráky Londe (2006) for a similar measure.

5. Since we do not know the relative strengths of these effects, we cannot tell whether the Count Effect applies independently of the identity of the neutral vowels involved or not, i.e. what the relationship is between $\left[\mathrm{BNN}^{+}\right]$stems and $[\mathrm{BN}]$ stems when they do not share a neutral vowel, e.g. [Be] vs. [Bii]. 
neutral vowels is fixed while the other varies, transparency decreases in accordance with the Height Effect, e.g. $[\mathrm{Bi}]<[\mathrm{Bie}]\left(\right.$ fixed $\mathrm{N}_{1}$ ) and e.g. $[\mathrm{B} \varepsilon]<[\mathrm{Bec}]\left(\right.$ fixed $\mathrm{N}_{2}$ ).

BNN-stems are a context for the combined application of the Height Effect and the Count Effect. Given the three neutral vowels $/ \mathrm{i}(\mathrm{i}) /$, /e:/ and $/ \varepsilon /$, there are nine types of BNN-stems, shown in (3). ${ }^{6}$

(3) Types of BNN-stems ${ }^{7}$

\begin{tabular}{|c|c|c|c|}
\hline & $\mathrm{i}(:)$ & e: & $\varepsilon$ \\
\hline $\mathrm{i}(:)$ & [Bii] alibi & [Bie] klarine:t & [Bie] kabinet \\
\hline e: & [Bei] protezzi & [Bee] aterne: & [Bee] konterner \\
\hline$\varepsilon$ & [Bei] bakelit & [Bee] suvere:n & {$[\mathrm{B} \varepsilon \varepsilon]$ kompeten] } \\
\hline
\end{tabular}

Rebrus \& Törkenczy (2016) argue that in BNN-stems, which are subject to the Height Effect and the Count Effect, there are two additional effects, Cumulativity and Locality.

Cumulativity means that since we have two neutral vowels in BNN-stems, the Height Effect applies twice: (i) for the second neutral vowel with a fixed quality of the first one, and (ii) for the first neutral vowel with a fixed quality of the second one. Cumulative interaction between the two neutral vowels in a $\left[\mathrm{BN}_{1} \mathrm{~N}_{2}\right]$ environment is defined as in (4) (where $x, y, z$ are neutral vowels). In the definition, the ordering " $\leq$ " (which allows equality (or near-equality) of F-ratios) is used instead of the strict ordering " $<$ " because some BNN-classes have F-ratios that are very close and nearly equal to 1 (which is the maximal possible value of an F-ratio).

(4) Cumulativity

i. Height Effect for $\mathrm{N}_{2}$ : if $[\mathrm{B} x] \leq[\mathrm{B} y]$ then $[\mathrm{B} z x] \leq[\mathrm{B} z y]$

ii. Height Effect for $\mathrm{N}_{1}$ : if $[\mathrm{B} x] \leq[\mathrm{B} y]$ then $[\mathrm{B} x z] \leq[\mathrm{B} y z]$

iii. transitivity: if $\left[\mathrm{B} x_{1} x_{2}\right] \leq\left[\mathrm{B} y_{1} y_{2}\right]$ and $\left[\mathrm{B} y_{1} y_{2}\right] \leq\left[\mathrm{B} z_{1} z_{2}\right]$ then $\left.\left[\mathrm{B} x_{1} x_{2}\right] \leq \mathrm{B} z_{1} z_{2}\right]$

The ordering relation defined in (4) yields 27 different ordered pairs of the 9 possible BNN sequences (where only the Ns vary between the 3 different values). This is shown in (5), where ordered pairs are connected by arrows, the direction of an arrow corresponds to the ordering $\leq$, and ordering by transitivity (4iii) is left unindicated to avoid clutter.

6. No distinction is made between long is and short i. We only consider $\left[\mathrm{BNN}^{+}\right]$stems with exactly two neutral vowels since those with longer $\mathrm{N}$ sequences are extremely rare (e.g. kompatibilif 'compatible').

7. Glosses: alibi 'alibi', klarinert 'clarinet', kabinet 'cabinet', prote:zif,' prosthetic', aterne: 'Athena', konterner 'container', bakelit 'bakelite', suverein 'sovereign', kompetenf 'competent'. 
(5) Ordering by Cumulativity

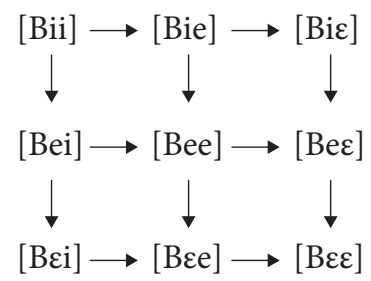

In (5), the stem classes that are greater in F-ratio are those which are to the right and/or down, and those that are smaller are to the left and/or up. The other pairs (i.e. those that are to the right and up or are to the left and down) are not defined to be in relation by Cumulativity.

Rebrus and Törkenczy (2016) has found on the basis of the frequencies (F-ratios of BNN-stems) in the Szószablya webcorpus (Halácsy et al. 2004) that Cumulativity holds true of the interaction of the three neutral vowel qualities. ${ }^{8}$

Rebrus and Törkenczy (2016) propose that another effect, Locality, applies to BNN-stems. Locality is the dominance of the Height Effect of $\mathrm{N}_{2}$, the neutral vowel closer to the suffix in a $\left[\mathrm{BN}_{1} \mathrm{~N}_{2}\right]$ environment. It is defined as in (6), (where $x, y$ are neutral vowels):

(6) Locality

$$
\text { If }[\mathrm{B} x] \leq[\mathrm{B} y] \text { then }[\mathrm{B} y x] \leq[\mathrm{B} x y]
$$

Locality introduces three further orderings: $[\mathrm{B} \varepsilon \mathrm{i}] \leq[\mathrm{Bi \varepsilon}],[\mathrm{B} \varepsilon \mathrm{e}] \leq[\mathrm{Be \varepsilon}],[\mathrm{Bei}] \leq$ [Bie]. As can be seen in (7), the F-ratios of BNN-stems in the webcorpus reflect the ordering by Locality in the first two cases, but not in the last one: [Bei] (0.726) $\leq$ [Bic] $(0.987)$, [Bee] $(0.864) \leq$ [Bec] $(1.000)$ but [Bei] $(0.674) \not$ [Bie] $(0.579)$ :

(7) F-ratios of BNN-stems

\begin{tabular}{llll}
\hline & $i(:)$ & e: & $\varepsilon$ \\
i(:) & 0.560 & 0.579 & 0.987 \\
e: & 0.674 & 0.931 & 1.000 \\
$\varepsilon$ & 0.726 & 0.864 & $0.996 \approx 1.000$ \\
\hline
\end{tabular}

However, a closer look at the F-ratios of BNN-stems shows that this 'anomaly' is related to the fact that (in contrast to the other ones) the [Bie] stem type is

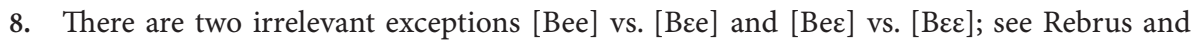
Törkenczy (2016) for details and explanation. 
not internally harmonically consistent. Internal harmonic consistency means that given a division of a stem type into subtypes, the F-ratios of the subtypes are not significantly different. Given a division of BNN-stems into consonant-final $[\mathrm{BNNC}]$ and vowel final [BNN\# $]^{9}$ subtypes, the internal harmonic consistency of a BNN-stem type can be defined as in (8):

(8) Internal harmonic consistency: $[\mathrm{Bxy} \#] \approx[\mathrm{BxyC}]$

(where $\mathrm{X} \approx \mathrm{Y}$ means that the F-ratio of $\mathrm{X}$ is not significantly lower/higher than that of $Y$ )

The F-ratios in (9) show that the stem type [Bie] is indeed inconsistent (nonhomogeneous) as opposed to the other BNN types, three of which are shown for contrast. Note also that the non-homogeneity of [Bie] results in the fact that the F-ratio of its vowel-final subtype [Bie\#] is rather low; i.e. stems that belong to this subtype have a preference for the back alternants of harmonic suffixes.

(9) The internal harmonic consistency of the [Bie] type

i. homogeneous

$$
\begin{array}{ll}
{[\mathrm{Bii} \#] \approx[\mathrm{BiiC}]} & 0.63 \text { vs. } 0.51 \\
{[\mathrm{Bei} \#] \approx[\mathrm{BeiC}]} & 0.61 \text { vs. } 0.70 \\
{[\mathrm{B \varepsilon i} \#] \approx[\mathrm{B \varepsilon iC}]} & 0.77 \text { vs. } 0.70
\end{array}
$$

ii. non-homogeneous

$$
[\mathrm{Bie} \#] \approx[\mathrm{BieC}] \quad 0.33 \text { vs. } 0.75
$$

Although the corpus study in Rebrus and Törkenczy (2016) has found these effects, the question arises whether native speakers indeed observe the Law of Frequency Matching in this case (shown for the Height Effect and the Count Effect separately by Hayes et al. 2006, 2009). ${ }^{10}$ Furthermore, the empirical testing of these variability effects in corpora is problematic because of data sparseness: these classes represent stems whose harmonically suffixed forms can be extremely rare. These are the main motivations for psycholinguistic testing, i.e. for collecting information about the variants from native speakers directly. In this paper, we report on our findings based on the psycholinguistic experiment we conducted. We wanted to find

9. We use the string of symbols "N\#]" to indicate that the stem ends in a neutral vowel.

10. There are some important differences: Hayes et al. $(2006,2009)$ counted forms with the dative suffix -nak/-nek only whereas Rebrus \& Törkenczy (2016) considered singly suffixed forms containing any harmonically alternating monosyllabic suffix. Hayes and Cziráky Londe (2006) did examine the application of the Height Effect in BNN-stems but (over)simplified the effect. They assumed that the ordering of the $\mathrm{N}_{1} \mathrm{~N}_{2}$ sequences solely depends on the last neutral vowel $\left(\mathrm{N}_{2}\right)$ in the stem: the more transparent $\mathrm{N}_{2}$ is according to the Height Effect, the more transparent the sequence is. 
answers to the following questions: In which cases are (i) the Height Effect, (ii) the Count Effect, (iii) the Cumulativity Effect and (iv) the Locality Effect satisfied or violated? Furthermore: (v) Are the stem classes homogeneous in their harmonic behaviour: do consonant-final and vowel-final stems behave in the same way?

\section{Experiment}

\subsection{Participants}

21 adults participated in the experiment (14 women (mean age: 33 years, range 19-66 years; 7 men (mean age: 44 years, range 26-67 years). All participants were native speakers of Hungarian, 19 currently living in Budapest (10 born \& raised there).

\subsection{Stimuli}

We set up 9 classes of real monomorphemic stems representing the relevant groups. For BN-stems there are 2 bisyllabic stem classes $[\mathrm{Be}]$ and $[\mathrm{B} \varepsilon]$. We did not test class [Bi] because it shows no variability: all such stems take back suffixes. We included two trisyllabic stem classes in the experiment: [BBe] and [NBe]. For $\mathrm{BNN}$-stems, each neutral vowel quality in each position is represented, except for [Bee], which is practically empty; and [BNe] stems, which do not show variation in the corpus, all such stems always take front suffixes: [Bii], [Bei], [Bie], [Bei], [Bre]. The number of stems in each class roughly corresponds to the real size of the class (all the stems in the class) ${ }^{11}$ and in each one, we have a balanced sample, with both consonant-final and (different) vowel-final stems in each class where relevant. Consider the table of comparisons in (10) below, where the columns and the rows are stem subtypes and a cell at the intersection of a row and a column is a comparison of two subtypes, i.e. a potential ordering between them. The cells show the orderings imposed by the effects discussed in Section 1 (cf. (1), (4), (6), and (8)). The notation, where each symbol represents an ordering between the subtypes compared by these effects, is as follows:

- Height Effect: $<_{\mathrm{HE}}$

- Count Effect: $<_{\mathrm{CE}}$

11. We wanted to include as many stems as possible, hence the difference in stem tokens across types. Testing fewer stems of the bisyllabic types would not have provided us a detailed picture of the variation observed in and across different types. 
- the transitive corollary of the Height Effect and the Count Effect: $(<)$

- Cumulativity: $\leq$

- the transitive corollary of Cumulativity: $(\leq)$

- Locality: $\leq_{\text {LOC }}$

- internal harmonic consistency: $\approx$

The shaded cells represent comparisons where these effects do not impose an ordering on the subtypes of stems.

(10) A table of comparisons between stem subtypes

\begin{tabular}{|c|c|c|c|c|c|c|c|}
\hline & $\mathrm{Be}$ & $\mathrm{B} \varepsilon$ & Bii & Bei & Bie & Bei & Bee \\
\hline$(\mathrm{Bi}=0)$ & $<_{\mathrm{HE}}$ & $<_{\mathrm{HE}}$ & $<_{\mathrm{CE}}$ & $<_{\mathrm{CE}}$ & $<_{\mathrm{CE}}$ & $<_{\mathrm{CE}}$ & $(<)$ \\
\hline $\mathrm{Be}$ & $\approx$ & $<_{\mathrm{HE}}$ & & $<_{\mathrm{CE}}$ & $<_{\mathrm{CE}}$ & $(<)$ & $<_{\mathrm{CE}}$ \\
\hline $\mathrm{B} \varepsilon$ & & $\approx$ & & & & $<_{\mathrm{CE}}$ & $<_{\mathrm{CE}}$ \\
\hline $\mathrm{Bii}$ & & & $\approx$ & $\leq$ & $\leq$ & $\leq$ & $(\leq)$ \\
\hline Bei & & & & $\approx$ & $\leq_{\mathrm{LOC}}$ & $\leq$ & $(\leq)$ \\
\hline Bie & & & & & $\approx$ & & $\leq$ \\
\hline Bei & & & & & & $\approx$ & $\leq$ \\
\hline Bce & & & & & & & $\approx$ \\
\hline
\end{tabular}

Altogether, 104 stems were tested in the 9 classes. Each stem appeared with 4 different consonant-initial suffixes (dative -nak/-nek, instrumental -val/-vel, elative -bo:l/-bøl and allative -hoz/-hez), yielding 416 experimental sentences altogether. See (11) for the distribution of stems across stem classes in the experiment.

(11) The distribution of the number of stems across stem classes in the experiment $^{12}$

\begin{tabular}{lll}
\hline Stem type & Number of stems & Example \\
\hline Be & 37 & ta:ne:r, sate:n \\
Be & 37 & haver, fotel \\
Bii & 6 & aspirin, kolibri \\
Bie & 6 & matine:, klarine:t \\
Bei & 3 & prote:zif, poe:zif \\
\hline
\end{tabular}

12. Glosses: kolibri 'hummingbird', matine: 'matinee', poezzif 'poetry', Jpagetti 'spaghetti', sutcre:n 'basement', indone:z 'Indonesian', fina:ler 'finale', majone:z 'mayonnaise', karantern 'quarantine'. 


\begin{tabular}{lll}
\hline Bei & 6 & bakelit, Spagetti \\
Bee & 3 & suvere:n, sutere:n \\
NBe & 3 & indone:z, fina:le: \\
BBe & 3 & majone:z, karante:n \\
\hline
\end{tabular}

The experimental sentences were complemented by 208 filler sentences. Filler sentences were 4-6 words long, they did not contain mixed stems or any of the target suffixes. Experimental sentences were sorted into two batches, yielding two versions of the experiment (A and B). Each participant heard every target stem with two different suffixes, an $a / \varepsilon$ (dative or instrumental) suffix and a non- $a / \varepsilon$ suffix (allative or elative) out of the four (208 target sentences) and 208 filler sentences. Filler sentences were the same in the two batches.

\subsection{Method and procedure}

We collected data from adult participants in an elicited production task disguised in the form of a sentence repetition task. Each target word+suffix combination was presented acoustically, as part of a digitally prerecorded sentence. The target inflections in each sentence (and sometimes another syllable in the sentence) were masked by a carefully inserted cough that prevented the participant from hearing the inflection, but not the stem or the remaining portions of the sentence, as illustrated below (where strikethrough represents the cough):

Valamiért sosem voltam híve az aszpirinnak/nek.

'For some reason I have never been devoted to aspirin-DAT.'

A trópusi kolibrinak/nek kék a tollazata.

'The tropical hummingbird-DAT (has) blue plumage.'

The audible parts of the sentence make it clear which inflection is missing, but provide no cues to the frontness of the actual suffix alternant. After hearing the sentence, participants were asked to repeat the sentence. This design was modeled after Warren's (1970) phoneme restoration procedure. Restoration with the same procedure works at the morpheme level e.g. for affixes in Hungarian (Dankovics \& Pléh 2001), and has been successfully used as an elicited production method for suffixes with children (Lukács et al. 2009). In this design, participants are usually unaware that the inflections are missing, which allows us to examine the differences in variability in production without relying on metalinguistic awareness and conscious decision about the front/back variants. Crucially, it also allows us to collect data for stem+suffix combinations that are rarely or never attested in corpora, thus providing new sets of data for systematically testing the above hypotheses. 


\subsection{Results}

The dependent variable in all cases was the frontness of the inflection the participants produced. To test the Count Effect, the Height Effect and the Cumulativity Effect, the effect of stem type and stem subtype was tested on mean percentages of front answers. Since Type and Subtype were within-subject factors, the results were analyzed by a Repeated measures ANOVA (analysis of variance), and were further tested by post-hoc pairwise comparisons.

\subsubsection{Results by generalized type - Count Effect}

First, we tested the Count Effect by comparing mean percentages of front answers in a repeated measures GLM with Type as a 4-level factor (BN, BBN, NBN, BNN). A significant main effect of Type was observed $(\mathrm{F}(3,60)=44,66 ; p<0.001)$. Post hoc pairwise comparisons showed that $\mathrm{BN}$-stems were significantly different from all others $(p<0.001)$, and, as expected by the Count Effect, BNN-stems were associated with a significantly higher ratio of front answers than stem types with a single neutral vowel between the back vowel of the stem and the suffix (i.e. BN, BBN, NBN stems). ${ }^{13} \mathrm{BBN}$ and BN stems differed significantly $(p<0.05)$. No other pairwise differences were significant. The results are shown in Figure 1.

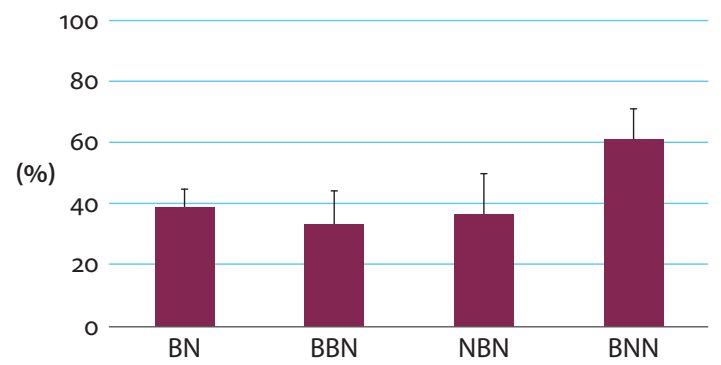

Figure 1. Mean percentage of front answers across participants by stem type. Error bars indicate standard deviations (SDs)

\subsubsection{Height Effect}

To test the Height Effect, we compared mean percentages of front answers in a repeated measures GLM with Subtype as a 4-level factor ([Be], [BBe], [NBe], [Be]),

13. Note that the difference would have been even greater if we had included [Bi] and [BNE] stems. 
which revealed a significant main effect of Subtype $(\mathrm{F}(3,60)=184.46 ; p<0.001)$. Post hoc pairwise comparisons showed significant differences between all pairs of subtypes $(p<0.001)$ except for $[\mathrm{NBe}]$ vs. [BBe], which did not differ statistically. The standard deviation is also higher in these subtypes, ${ }^{14}$ and, compared to $\mathrm{BN}$ types, the number of roots tested is lower (3 vs. 37).

The results illustrating the Height Effect by subtype are shown in Figure 2.

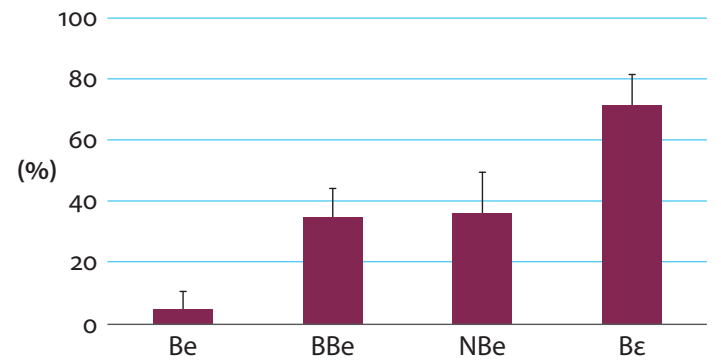

Figure 2. Mean percentage of front answers across participants by stem subtype. Error bars indicate SDs

\subsubsection{Cumulativity 1}

The Cumulativity hypothesis was first tested by comparing the results for [Bii], [Bei], [Bie] and [Bei] in a repeated measures GLM with Subtype as a 4-level factor, which revealed a significant main effect of Subtype $(\mathrm{F}(3,60)=26.485 ; p<0.001)$. Post hoc pairwise comparisons showed significant differences between all pairs of subtypes ([Bie] $<$ [Bei], [Bei], [Bii] at $\mathrm{p}<0.001$; [Bii $]<[\mathrm{B} \varepsilon \mathrm{i}]$ and $[\mathrm{Bei}]<[\mathrm{B} \varepsilon \mathrm{i}]$ at $p<0.01$ ) except for [Bei] vs. [Bii], which did not differ statistically. The results by subtype are shown in Figure 3.

14. The F-ratios of the stems belonging to the $[\mathrm{BBN}]$ type were the following: pararde 'parade' $0.7 \%$, karantern 'quarantine' 8\%, majone:z 'mayonnaise' 93\%; and that of the stems in the [NBN] type were: finalle: 'finale' $0 \%$, diade:m 'diadem' $31 \%$, indone:z 'Indonesian' $73 \%$. Presenting the averaged F-ratios of these types hides the extent of variation within the types, although this might provide an explanation for the lack of significant difference between the two types. It seems that the two types are also not harmonically consistent (similarly to the type [Bie], see (9) above). That is, consonant-final and vowel-final stems do not behave in a uniform way. 


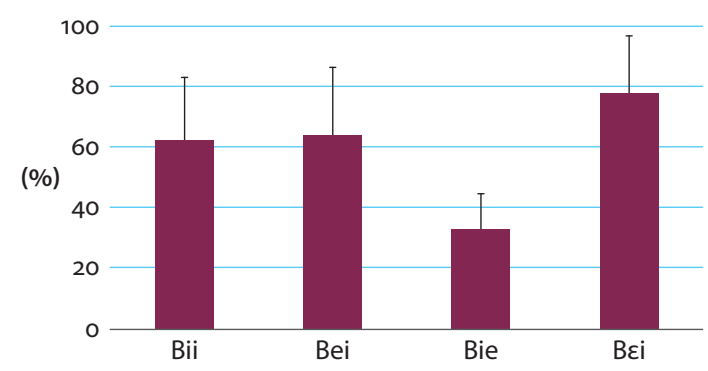

Figure 3. Mean percentage of front answers across participants by stem subtype. Error bars indicate SDs

Our hypotheses expected [Bei] $\leq$ [Bie] to hold, but since [Bie] stems have significantly lower F-ratios than all other BNN-stems, they violate both the Cumulativity and the Locality Effects. This is consistent with the corpus results shown in (7) above, but the difference is more pronounced in our results.

\subsubsection{Cumulativity 2}

The Cumulativity hypothesis was also tested by comparing the results for [Be], [Bei], [Bie] and [Bre] stems in a similar repeated measures GLM with Subtype as a 4-level factor, which revealed a significant main effect of Subtype $(\mathrm{F}(3,60)=$ $128.471 ; p<0.001)$. Post hoc pairwise comparisons showed significant differences between all pairs of subtypes ([Bre] $<[$ Bei] at $\mathrm{p}<0.05$; all others at $p<0.001$ ). The results by subtype are shown in Figure 4.

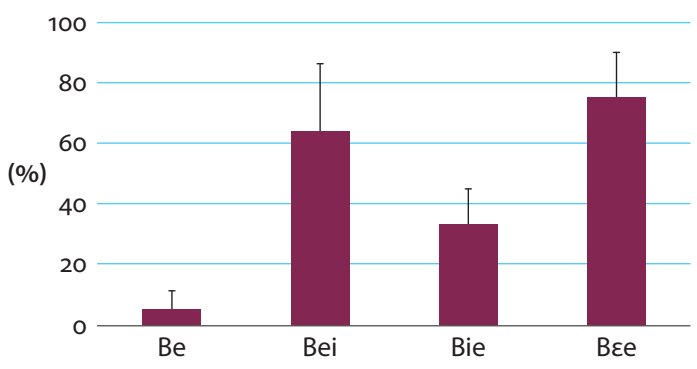

Figure 4. Mean percentage of front answers across participants by stem subtype. Error bars indicate SDs

Figures 3 and 4 show that the order and the quality of the neutral vowels in a BNN-stem can cause significant differences in their F-ratios, and that the harmonic behaviour of a stem is affected by both $\mathrm{N}_{1}$ and $\mathrm{N}_{2}$ (i.e. the last vowel is not the only one responsible for harmonic behaviour, contra Hayes \& Cziráky Londe 
2006, Bowman 2013). According to the experiment, native speakers follow the general trends found in Rebrus and Törkenczy's (2016) corpus results, but the differences can be more marked.

\subsubsection{Comparisons of C-final vs V-final roots}

A corpus study (Rebrus and Törkenczy 2016) has shown that consonant-final BNN-stems ([BNNC]) and vowel-final BNN-stems ([BNN\#]) are not necessarily homogeneous in their harmonic behaviour in all subtypes. In (12), we show the F-ratios of [BNNC] and [BNN\#] stems, comparing experimental data with word forms in the webcorpus that contain the same stem+suffix combinations that we tested in the experiment. According to the Cumulativity Effect, the F-ratios should be the following: $[\mathrm{Bii}] \leq[\mathrm{Bie}] \leq[\mathrm{Bri}]$. As can be seen in (12), this only holds for $[\mathrm{BieC}] \leq[\mathrm{BriC}],[\mathrm{Bii} \#] \leq[\mathrm{Bri} \#]$ and $[\mathrm{Bie} \#] \leq[\mathrm{Bri} \#]$ in the webcorpus and not for the other three ([BiiC] $\$[\mathrm{BieC}],[\mathrm{BiiC}] \$[\mathrm{BriC}]$, [Bii\#] $\$$ [Bie\#]) of the theoretically possible six pairs. ${ }^{15}$ The results of the experiment are a close match for the corpus frequencies. The two pairs violating Cumulativity are $[\mathrm{BiiC}] \$[\mathrm{BieC}]$ and [Bii\#] $\$$ [Bie\#]; the others all conform to the ordering by Cumulativity. Note that with one exception ([BiiC] $\$$ [BziC] in the webcorpus), the pairs violating ordering by Cumulativity all involve [Bii] vs. [Bie] comparisons.

The difference between the F-ratios of [BiiC] stems (webcorpus: 0.94, experiment: 0.50 ) is due to the fact that the webcorpus contains only one stem out of the three which were tested (aspirin 'id.). However, this stem in the experiment has an F-ratio of 0.81 , which fits in with the general patterns observed in the webcorpus.

(12) Internal consistency: front-ratios of the $\mathrm{C} \#$ and $\mathrm{V} \#$ roots used in the experiment in the webcorpus and the experiment

\begin{tabular}{llllllrl}
\hline \multicolumn{7}{l}{ Webcorpus } & \multicolumn{7}{l}{ Experiment } \\
\hline & C\# & V\# & diff. & \multicolumn{1}{l}{ C\# } & V\# & diff. & \multicolumn{1}{c}{$p$} \\
\hline$[$ Bii $]$ & 0.94 & 0.81 & $\mathbf{0 . 1 3}$ & 0.50 & 0.75 & $-\mathbf{0 . 2 5}$ & 0.002 \\
{$[$ Bie $]$} & 0.43 & 0.20 & $\mathbf{0 . 2 3}$ & 0.46 & 0.21 & $\mathbf{0 . 2 5}$ & 0.000 \\
{$[$ Bei $]$} & 0.88 & 0.91 & $-\mathbf{0 . 0 3}$ & 0.73 & 0.86 & $-\mathbf{0 . 1 3}$ & 0.058 \\
\hline
\end{tabular}

As can be seen in (12), Cumulativity holds for consonant-final (C\#) stems in the experiment; the difference between $[\mathrm{BiiC}]$ and $[\mathrm{BieC}](0.50$ vs. 0.46$)$ is not

15. Compare (7) where (i) all available BNN-stems were counted with all available harmonic suffixes, and (ii) consonant-final and vowel-final stems were not distinguished. 
significant. However, with vowel-final (V\#) stems, Cumulativity is violated by the [Bie] subtype. Regarding internal harmonic consistency, it has already been noted that [Bie] stems are not consistent (cf. (9ii)). The experimental results also show that [Bii\#] and [BiiC] stems differ significantly, but in the other direction: [Bii\#] stems are more likely to take a front suffix than $[\mathrm{BiiC}]$ ones, while [Bie\#] stems are more likely to take back suffixes than $[\mathrm{BieC}]$ stems.

If we look at all of the subtypes and their harmonic behaviour according to the webcorpus results (taking the same stem+suffix combinations that we tested), and compare them to the experimental data in (13) below, we can see that there are three marked differences ([Bii], [Bei], [Bee]). In the case of [Bii] stems, the difference may be due to the fact that out of the six stems we tested, only three were found in the webcorpus, yielding an F-ratio of 0.86 , while the experimental result is 0.63 . [Bei] stems show a $31 \%$ difference (webcorpus: 0.95 , experiment: 0.64 ), and [Bee] stems show a $24 \%$ difference in their F-ratios (webcorpus: 0.99, experiment: 0.75 ). The differences here are probably due to the fact that the words tested in these subtypes are very infrequent. Nevertheless, it is clear that the general trends in harmonic behaviour in the corpus are a close match for our results, i.e. native speakers do observe the Law of Frequency Matching.

(13) Harmonic behaviour of BNN-stems in the webcorpus and in the experiment

\begin{tabular}{|c|c|c|c|c|c|c|c|c|}
\hline \multicolumn{3}{|c|}{ Types } & \multicolumn{3}{|c|}{ Webcorpus } & \multicolumn{3}{|c|}{ Experiment } \\
\hline $\mathrm{Bii}$ & Bie & $\mathrm{Bi \varepsilon}$ & 0.86 & 0.30 & $((0.99))$ & 0.63 & 0.33 & - \\
\hline Bei & Bee & Bec & 0.95 & - & $((1.00))$ & 0.64 & - & - \\
\hline Bei & Bre & 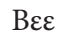 & 0.89 & 0.99 & $((1.00))$ & 0.79 & 0.75 & - \\
\hline
\end{tabular}

\section{Conclusion}

Previous studies of variability in Hungarian vowel harmony were based on corpus data, which has its known limitations (e.g. data sparseness on rare combinations), and/or wug testing using a single alternating suffix, which may oversimplify the dimensions and the range of variation. Our experiment provided direct data from native speakers, which made it possible to examine a larger set of stem+suffix combinations, and thus shed light on several lesser examined areas of HVH. The data provided new insights about the combined workings of the Height and the Count Effect, the behaviour of different harmonically alternating suffixes, and the harmonic behaviour of consonant-final and vowel-final stems. The experiment has also allowed us to confirm previous 
hypotheses that were formed based on the basis of corpus data and to identify areas/directions where more research is needed.

We have examined the harmonic behaviour of existing words combined with four different suffixes, based on an experiment with native speakers, and we provided a statistical analysis. Our results confirm the Height Effect and the Count Effect previously observed in corpus studies (Hayes \& Cziráky Londe 2006 (based on Google searches), Rebrus \& Törkenczy 2016 (based on the Szószablya webcorpus)) and wug tests (Hayes \& Cziráky Londe 2006): [Be] stems are more transparent (i.e. less front) than $[\mathrm{B \varepsilon}]$ stems, and the frontness of $\mathrm{BNN}$-stems is significantly higher than that of BN-stems. Furthermore, our results also confirm the Cumulativity and Locality Effects in native speaker behaviour: the quality of $\mathrm{N}_{1}$, the quality of $\mathrm{N}_{2}$, and the order of the two neutral vowels, are all important in determining a $\left[\mathrm{BN}_{1} \mathrm{~N}_{2}\right]$ stem's harmonic behaviour, contrary to the simplified view in Bowman 2013 and Hayes \& Cziráky Londe 2006, who assume that only the last neutral vowel $\mathrm{N}_{2}$ is relevant. Internal consistency effects were also observed in the experiment: the stem types [Bie] and [Bii] are not internally homogeneous. The stems in these types show different harmonic behaviour depending on whether their final segment is a consonant or a vowel, albeit with an opposite harmonic bias (i.e. [Bie\#]: back bias; [Bii\#]: front bias). The experiment has also confirmed the violation of Cumulativity found in the corpus involving the stem type [Bie\#].

Interestingly, harmonic suffixes do not show a uniform behaviour either contrary to virtually all analyses of $\mathrm{HVH}$, which typically assume that harmonically alternating suffixes are uniform in their harmonic behaviour (but see Rebrus \& Törkenczy 2013). Further research is needed to map out the exact way in which different suffixes behave when attached to $\mathrm{BN}$ and $\mathrm{BNN}$-stems, but we can see the general patterns in Figure 5. We can observe differences in F-ratio between the harmonic suffixes examined in every stem type.

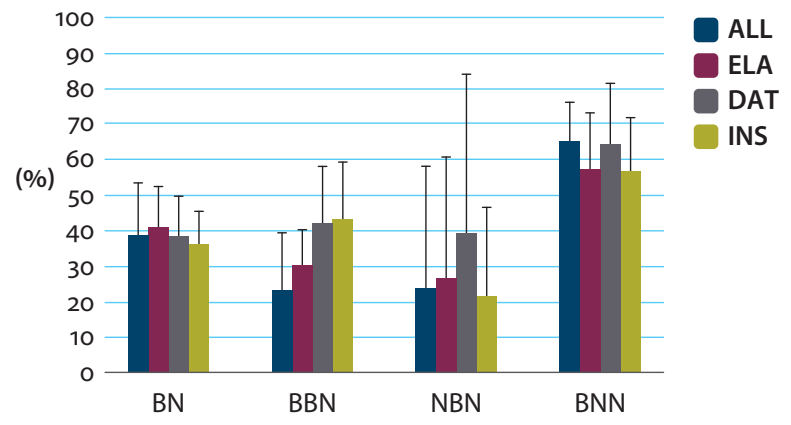

Figure 5. Mean percentage of front answers across participants by stem type+suffix. Error bars indicate SDs 
Even with a relatively small sample of roots and a completely different methodology of data collection, our results correspond to the tendencies observed in the webcorpus. However, we have to emphasize that the conditioning of harmonic variation may be even more fine-grained. For instance, it is itself a generalization that we treat different stems of the same harmonic pattern (i.e. stems that have the same neutral vowels following a back vowel) as belonging to the same subtype (e.g. bakelit 'bakelite' and Jpagetti 'spaghetti' belonging to the subtype [Bei]). However, the frequency of the stems themselves and their harmonic behaviour may differ from the generalized subtype. This means that even though the six stems in the [Bii] subtype are labelled by a certain number that represents their F-ratio (in this case, 0.63 ), the individual stems themselves may have different harmonic behaviour (F-ratios); e.g. aspirin 'id.' and kolibri 'hummingbird' do not behave exactly the same way.

It is a further generalization that we treat the experimental and webcorpus data as the same. We have pointed out above that our results conform to the Law of Frequency Matching. Nevertheless, we have found some interesting differences between the frequencies gained from the corpus and the native speaker reactions in our experiment. The difference in F-ratios between the webcorpus and the experiment may indicate that the comparison of written and experimental data is not straightforward, as token and type frequencies taken from the corpus are merely a simulation of gaining data from participants.

\section{Acknowledgements}

We would like to thank Katalin Mády and Bertalan Polner for their help with the experiment. This work has been supported by the National Scientific Grant NKFI-119863 'Experimental and theoretical investigations of vowel harmony patterns'

\section{References}

Bowman, Samuel R. 2013. Two arguments for a positive vowel harmony imperative. Ms. Stanford [ROA 1181].

Dankovics, Natália \& Csaba Pléh. 2001. Hangrestaurációs jelenségek és alaktani feldolgozás a magyarban: Azt halljuk-e, amit várunk? [Sound restauration and morphological processing in Hungarian: Do we hear what we expect to hear?] In Csaba Pléh \& Ágnes Lukács (eds.), A magyar morfológia pszicholingvisztikája [The psycholinguistics of Hungarian morphology], 55-83. Budapest: Osiris.

Halácsy, Péter, András Kornai, László Németh, András Rung, István Szakadát \& Viktor Trón. 2004. Creating open language resources for Hungarian. In Proceedings of Language Resources 
and Evaluation Conference (LREC04). LREC, 203-210. http://szotar.mokk.bme.hu/szoszablya/searchq.php

Hayes, Bruce \& Zsuzsa Cziráky Londe. 2006. Stochastic phonological knowledge: The case of Hungarian vowel harmony. Phonology 23. 59-104. https://doi.org/10.1017/So952675706000765

Hayes, Bruce, Kie Zuraw, Péter Siptár \& Zsuzsa Londe. 2009. Natural and unnatural constraints in Hungarian vowel harmony. Language 85. 822-863. https://doi.org/10.1353/lan.0.0169

Lukács, Ágnes, Laurence B. Leonard, Bence Kas \& Csaba Pléh. 2009. The use of tense and agreement by Hungarian-speaking children with language impairment. Journal of Speech, Language and Hearing Research 52/1. 1-22.

Rebrus, Péter \& Péter Szigetvári. 2016. Diminutives: Exceptions to harmonic uniformity. Catalan Journal of Linguistics 15. 101-119. https://doi.org/10.5565/rev/catjl.186

Rebrus, Péter \& Miklós Törkenczy. 2013. Magánhangzó-diszharmónia [Vowel disharmony]. Talk delivered at the Research Institute for Linguistics, Hungarian Academy of Sciences, Budapest, 22 October.

Rebrus, Péter \& Miklós Törkenczy. 2015. Monotonicity and the typology of front/back harmony. Theoretical Linguistics 41(1-2). 1-61. https://doi.org/10.3765/amp.v2io.3769

Rebrus, Péter \& Miklós Törkenczy. 2016. A non-cumulative pattern in vowel harmony: A frequency-based account. In Gunnar Ólafur Hansson, Ashley Farris-Trimble, Kevin McMullin \& Douglas Pulleyblank (eds.), Proceedings of the 2015 Annual Meeting on Phonology. Washington, DC: Linguistic Society of America. https://doi.org/10.3765/amp.v3io.3692

Rebrus, Péter \& Miklós Törkenczy. 2017. Gradient harmonicity in compounds. In Karen Jesney, Charlie O'Hara, Caitlin Smith \& Rachel Walker (eds.), Proceedings of the 2016 Annual Meeting on Phonology. Washington, DC.: Linguistic Society of America.

https://doi.org/10.3765/amp.v4io.4007

Ringen, Catherine \& Miklós Kontra. 1989. Hungarian neutral vowels. Lingua 78. 181-191. https://doi.org/10.1016/0024-3841(89)90052-1

Siptár, Péter \& Miklós Törkenczy. 2000. The phonology of Hungarian. Oxford: Oxford.

Törkenczy, Miklós. 2016. Hungarian vowel harmony. In Mark Aronoff (ed.), Oxford bibliographies in linguistics. New York: Oxford University Press.

https://doi.org/10.1093/obo/9780199772810-0134

Vago, Robert. 1980. The sound pattern of Hungarian. Washington: Georgetown University Press.

Warren, Richard M. 1970. Perceptual restorations of missing speech sounds. Science, 167.392-393. https://doi.org/10.1126/science.167.3917.392 



\title{
With or without the definite article
}

\section{On the syntax of anaphoric possessor strategies in Hungarian}

\author{
György Rákosi \\ Department of Linguistics, University of Debrecen
}

\begin{abstract}
That noun phrases may constitute a binding domain is a key component among the parallelisms between the syntax of noun phrases and clauses. Reuland (2007, $2011)$ and Despić $(2011,2015)$ have shown recently that the definite article plays a crucial role in delimiting this domain, since dedicated possessive reflexive anaphors are only possible in languages that lack a prenominal definite article. Hungarian has several anaphoric possessor strategies, which vary in whether they require, allow, or prohibit the use of the definite article in the possessive noun phrase. This paper gives an overview of the grammar of these strategies, and presents a discussion of the results of a questionnaire survey that was conducted to better understand the delicate distribution of the definite article in these constructions. The importance of these Hungarian data lies in showing that Reuland's conjecture describes an important factor not only in cross-linguistic, but also in language internal variation in definite article use in possessive DP's.
\end{abstract}

Keywords: anaphor, definite article, Hungarian, logophor, noun phrase, phase, possessive, pronoun, reflexive, reciprocal

\section{Introduction}

The Hungarian possessive construction has figured prominently in research on the syntax of the noun phrase, and, in particular, in the development of the parallel analysis of the structure of the noun phrase and the clause (see Szabolcsi 1983, $1987,1989,1994)$. It is expected under the analogous treatment of the DP and the $\mathrm{CP}$ that the possessive noun phrase acts as a binding domain, a prediction that $\mathrm{E}$. Kiss (1987) shows to be accurate for Hungarian. What escaped attention in the GB-theoretic analyses as well as in the subsequent literature, is the crucial role that 
the definite article plays in the determination of this binding domain. ${ }^{1}$ This paper offers an overview of the grammar of the major anaphoric possessor strategies of Hungarian, and it makes the principal claim that the dependency between anaphoric possessor and matrix antecedent is local in the absence of a definite article in the D-head, but it is non-local in its presence.

In Hungarian, each argument anaphor can function as an anaphoric possessor, including the primary reflexive maga 'oneself' ( $1 \mathrm{~b}$ ) and the complex reflexive önmaga 'oneself'(2b), as well as the reciprocal egymás 'each other' (2a). The definite article shows an interesting distribution across these strategies: it is obligatory if the possessor is a pronoun (irrespective of whether it is coreferential with a matrix antecedent or not) or the primary reflexive (1), but it is ungrammatical or barely acceptable if the possessor is the reciprocal anaphor or the complex reflexive (2). ${ }^{2}$

(1) a. János ${ }_{\mathrm{i}}$ ismeri $\quad\left[_{\mathrm{DP}}{ }^{*}(a z) o_{\mathrm{i} / \mathrm{k}}\right.$ korlát-a-i-t] .

John know.3sg the he limit-Poss-PL-ACC

'John knows his limits.'

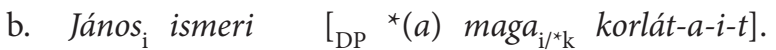

John know.3sg the oneself limit-Poss-PL-ACC

'John knows his limits.'

(2) a. A fiúk ismerik $\left[_{\mathrm{DP}}\left({ }^{* / ? ? a z)}\right.\right.$ egymás $s_{\mathrm{i} / \mathrm{k}_{\mathrm{k}}}$ korlát-a-i-t].

the boys know.3PL the each_other limit-POss-PL-ACC

'The boys know each other's limits.'

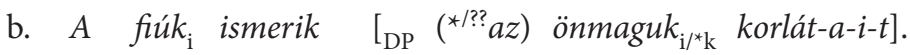
the boys know.3PL the themselves limit-POss-PL-ACC 'The boys know their own limits.'

This partition may seem surprising at first sight, since the primary reflexive patterns up with the personal pronoun (1), rather than with the rest of the anaphors (2).

1. The list of further standard references on the Hungarian possessive noun phrase include Bartos (1999), Dékány (2011), den Dikken $(1999,2006)$, É. Kiss $(2000,2002)$ and Laczkó (1995). I refer the reader to these works for comprehensive descriptions of the syntax of the Hungarian noun phrase. In this paper, I only focus on details that are directly relevant for our purposes.

2. Abbreviations in the glosses: $1=$ first person, $2=$ second person, $3=$ third person, $\mathrm{ACC}=$ accusative case, $\mathrm{COND}=$ conditional mood marker, $\mathrm{DAT}=$ dative case, $\mathrm{DEV}=$ deverbal nominal izing suffix, $\mathrm{FREQ}=$ frequentative suffix, $\mathrm{IMP}=$ imperative mood marker, $\mathrm{MASC}=$ masculine, $\mathrm{PL}$ $=$ plural, poss $=$ possessedness suffix $($ on the possessum), $\mathrm{PRT}=$ verbal particle, $\mathrm{SG}=$ singular . 
In recent work (Rákosi 2017), I have shown that this distribution can be better understood from the vantage point of Reuland's $(2007,2011)$ conjecture on dedicated possessive reflexives. Reuland argues that dedicated possessive reflexives (like the Latin suus 'self's' or the Russian svoj 'self's) are available only in languages without a prenominal definite article, which creates an impenetrable domain for binding. As is, this conjecture is a typological universal, but this line of inquiry provides an explanatory framework for the Hungarian data in (1) and (2). The dependency between the anaphor and antecedent is local in the case of the examples in (2), and it is non-local in (1). This prevents a Principle B violation in (1a), and this renders the reflexive in (1b) an exempt anaphor.

My fundamental aim in this paper is to provide further support for this analysis. I have investigated transitive constructions in my earlier work (as in (1) and (2)), but judgements on the distribution of the definite article may be more subtle in other syntactic contexts. To gain a better understanding of the data patterns, I have conducted a questionnaire study. The results of this study strengthen the principal hypothesis on the role of the definite article in the determination of the binding domain for anaphoric possessors in Hungarian. In particular, I argue that possessive anaphors are either exempt in the presence of the definite article in the D-head of the possessive phrase, or they have an antecedent inside of the possessive construction. These results also give further support to the claim that binding domains are phase-based and the DP is a phase (see Despić 2011,2013, 2015 for more on these claims in the context of possessive reflexives).

The structure of the paper is as follows. In Section 2, I give a brief overview of Reuland's observation and related work, as well as a survey of pertinent remarks in the literature on Hungarian. In Section 3, I describe the results of the questionnaire survey, and provide an analysis for each of the anaphoric possessor constructions discussed. Section 4 rounds up the paper with the conclusions and an outlook on remaining research questions.

\section{The background of the study}

2.1 Reuland's $(2007,2011)$ conjecture on dedicated possessive reflexives

Languages differ in whether they employ a dedicated possessive reflexive or not. English, for example, does not avail itself of this option. This creates a potential ambiguity between bound variable and referential readings of possessive pronouns as in (3). 
(3) Everyone loves his $_{\mathrm{i} / \mathrm{k}}$ mother.

The two readings are disambiguated through the use of two distinct possessive pronoun strategies in many languages. The minimal pair in (4) is from Serbo-Croatian.

(4) Serbo-Croatian

(Marelj 2011: 205)
a. Svako ${ }_{\mathrm{i}}$ voli njegovu * $_{\mathrm{i}_{\mathrm{k}} \mathrm{k}} \quad$ majku. everyone loves his.3sG.MASC mother
'Everyone loves his mother.'
b. Svako voli $_{\mathrm{i}}$ svoju $_{\mathrm{i} / \mathrm{k}_{\mathrm{k}}}$ majku. everyone loves self's mother 'Everyone loves his mother.'

Serbo-Croatian has a $\varphi$-complete pronominal possessor fully specified for person, number, and gender. This pronoun is referential, and it does not license the bound variable reading in (4a). Serbo-Croatian also has a dedicated possessive reflexive, svoj, which is $\varphi$-deficient (4b), and which needs to be bound to a matrix antecedent. $^{3}$

Reuland (2011: 167) observes that the availability of dedicated possessive reflexives of the svoj-type strongly correlates with the absence of prenominal definitess marking. In other words, dedicated possessive reflexives are only available in languages with postnominal definiteness marking (Bulgarian, Icelandic, Romanian, Swedish, etc.), or in languages with no definiteness marking at all (Chinese, Hindi-Urdu, Latin, Russian, Serbo-Croatian, etc.). ${ }^{4}$ Both Reuland and Marelj (2011) note that Italian, French and Spanish contrast with their Latin ancestor in a particularly interesting manner. Latin has no definiteness marking, and it has a dedicated possessive reflexive suus, together with a fully specified pronominal paradigm (eius 'his'), with a share of labour between the two that is similar to what is attested in Serbo-Croatian. Italian has a prenominal definite article, and the cognate of the Latin suus patterns up with the English possessive pronouns in licensing both referential and bound variable readings:

(5) Italian

(Reuland 2011: 168)

Gianni $_{\mathrm{i}}$ ama [DP $_{\mathrm{DP}}$ le sue $\mathrm{i}_{\mathrm{i} / \mathrm{k}}$ due macchine $]$.

Gianni loves the his two cars

'Gianni loves his two cars.'

3. Marelj (2011) and Despić (2013) both provide an in-depth discussion of the Serbo-Croatian data, though their analyses differ. We discuss the relevant aspects of Despićs proposal below.

4. Despić (2015: 203) provides a detailed inventory of these language types. 
So a change towards overt coding of definitiness brought about important changes in the use of the descendants of suus. Reuland assumes furthermore that the $\mathrm{D}$-position is also present in possessives in languages that have an overt definite article but do not employ it in possessive structures. English and Dutch are such languages. In sum, the gist of Reuland's conjecture is that the D-position marks an impenetrable domain for binding, rendering the dedicated possessive reflexive strategy an unavailable option in languages that have prenominal definite articles.

Reuland leaves it open whether the definite article in these languages causes a minimality intervention or it defines a phase domain. The latter position is argued at length in Despić (2015). To account for the English facts specifically, he assumes that reciprocal and pronominal possessors do not occupy the same position. ${ }^{5}$ Pronominal possessors are situated in the complement of the $\mathrm{D}$ head, in Spec,PossP (6b). Given that the DP is a phase, and binding domains are phasebased, pronominal possessors are free to take antecedents outside of their local domain. So they can be bound by the subject, as happens in (3). Reciprocals, on the other hand, are in Spec,DP, with the possessive morpheme 's occupying the D-position (6a).

(6) a. $\quad\left[_{\mathrm{DP}}\right.$ each other $\left[{ }_{\mathrm{D}}, s\left[_{\mathrm{Poss}}\left[{ }_{\mathrm{NP}}\right.\right.\right.$ friends $\left.\left.\left.]\right]\right]\right]$

b. $\left[_{\mathrm{DP}}\left[{ }_{\mathrm{D}}, \mathrm{D}\left[\left[_{\text {PossP }}\right.\right.\right.\right.$ their $\left[{ }_{\text {PossP }}\right.$ POSs $\left[_{\mathrm{NP}}\right.$ friends $\left.\left.\left.\left.]\right]\right]\right]\right]$

Since Spec,DP is the edge of the DP phase, reciprocal possessors can be bound directly from the next higher phase (the $v \mathrm{P}$ ). Consequently, a reciprocal possessor bound by an antecedent in the embedding clause is a true anaphor in English. ${ }^{6}$

5. One argument that Despić builds on to substantiate this claim is the fact that reciprocal possessors, like lexical possessors and unlike pronominal possessors, allow the ellipsis of the material that follows them (Despić 2015: 212-213). For arguments that pronominal possessors are lower in the possessive structure than lexical possessors, see Bernstein and Tortora (2005).

i. $\quad$ They could read their own files, but they could not read each other's.

ii. They could read their own files, but they could not read John's.

iii. *They could read their own files, but they could not read my.

6. The Serbo-Croatian facts observed in (4) above are explained in this approach under the assumption that no DP is projected in the Serbo-Croatian possessive noun phrase. Since Hungarian is a DP-language, articleless languages are not directly relevant for the current discussion. See, among others, Bošković (2005, 2014), Despić (2011, 2013, 2015) and Marelj (2011) for three alternative accounts of the Serbo-Croatian facts. 
Hungarian is a DP-language. As such, it does not have a dedicated possessive reflexive, but all the anaphors that can serve as internal arguments of the verb are also licit in the possessor position. They together instantiate each of the three scenarios that Reuland and Despić describe for languages with a prenominal definite article. Some anaphoric possessors co-occur with a definite article in the $\mathrm{D}$-cap of the possessive phrase. This definite article is normally overt, but it can also have a covert form in the right (discourse) context. Other anaphoric possessors are licensed in Spec, DP, without an article in D. Whether the dependency between the possessor and its antecedent is local, is determined by the respective position of the possessor in the possessive DP, and by the concomitant presence or absence of the article in D. Thus Hungarian is a language that itself entertains all the syntactic variation that is attested across DP-languages.

\subsection{The Hungarian background}

É. Kiss (1987) is essentially the sole locus in the literature on Hungarian that extensively discusses issues concerning the claim that the Hungarian noun phrase is a binding domain. In particular, she argues that the pronominal coding of anaphoric possessors is the unmarked case, and using the primary reflexive for the same function is a marked strategy (É. Kiss 1987: 197-198). Consider the following examples for illustration.

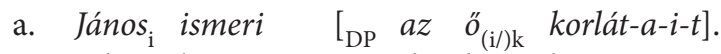 John know.3sg the he limit-Poss-PL-ACC 'John knows his limits.'

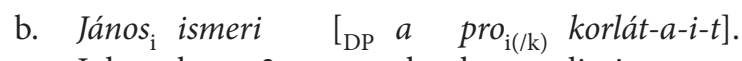 John know.3sg the he limit-Poss-PL-ACC 'John knows his limits.'
c. János $s_{\mathrm{i}}$ ismeri ${ }_{\mathrm{DP}}$ a maga $_{\mathrm{i} /{ }_{\mathrm{k}}}$ korlát-a-i-t] . John know.3sg the oneself limit-POss-PL-ACC 'John knows his limits.'

My own judgements of these data are consistent with those of É. Kiss, and I show in 3.3 below that the marked nature of $(7 \mathrm{c})$ derives from the dependence of the anaphoric possessor on an antecedent that is construed as a perspective holder. Pronominal possessors are normally pro-dropped, unless they bear a discourse function. The overt pronominal possessor is typically interpreted as non-coreferential with the subject (7a), whereas the most prominent reading of $(7 b)$ is the 
bound variable interpretation. ${ }^{7}$ But this is certainly not a strict syntactic constraint, both sentences can have both interpretations in facilitating contexts. ${ }^{8}$

This interpretation of the data entails that the possessive noun phrase is a binding domain. Another argument to support this claim comes from possessors external to the possessive DP. ${ }^{9}$ Possessors can occur outside of the possessive phrase if they receive dative case. If that happens, a pronominal possessor cannot be coreferential with the clausemate subject (8a), and a reflexive needs to be used to obtain the anaphoric interpretation $(8 \mathrm{~b}) .{ }^{10}$

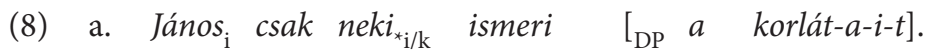

John only DAT.3sg know.3sg the limit-Poss-PL-ACC

'It is only his limits that John knows.'

7. A reviewer raises the issue of whether the rules that guide the preferential readings of (7a) and (7b) are also relevant in the interpretation of embedded subjects. Though many other factors may intervene in the case of clausal embedding, the covert pronoun strategy is often a sign of topic continuity with the matrix clause (ii), and the overt pronoun is more likely to be used when topic switch happens (i).

(i) János $s_{\mathrm{i}}$ megígérte Peti-nek $k_{\mathrm{k}}$, hogy ö ${ }_{(\mathrm{i} /) \mathrm{k}}$ ittmarad. John promised.3sg Peti-DAT that he here.stay.3sG 'John promised Pete that he stays here.'

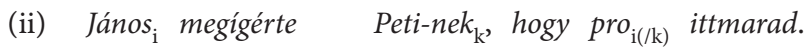
John promised.3sg Pete-DAT that he here.stay.3sG 'John promised Pete that he stays here.'

Thus pronoun possessors and subject pronouns in finite embedded clauses show a converging pattern in what preferential readings they manifest. For pertinent discussion, see Pléh (1983) on cross-sentential anaphora.

8. The coreferential use of overt pronouns often becomes more available if some material is added between the possessor and the possessum. This is the preferred option, for example, if the possessum is modified by the speaker-oriented, non-referentially used adjective kis 'little':
(i) János ismeri $\quad\left[_{\mathrm{DP}}\right.$ az $o_{\mathrm{i} /(\mathrm{k})}$ kis korlát-a-i-t].
John know.3sg the (s)he little limit-Poss-PL-ACC
'John knows his little limits.'

9. In principle, the dative possessor can be truly extracted from its position internal to the possessive DP, or it can be base-generated in the matrix clause (see É. Kiss 2014 for a comprehensive discussion of this variation). The differences between the two constructions do not matter for the argument presented here.

10. (8b) arguably has a marked character, just like (7c). But this has nothing to do with the binding facts, and (8b) sharply contrasts with (8a) in grammaticality. 
b. János csak magá-nak $\mathrm{i}_{\mathrm{i} /{ }_{\mathrm{k}}}$ ismeri $\quad \mathrm{C}_{\mathrm{DP}}$ a korlát-a-i-t $]$. John only himself-DAT know.3sG the limit-Poss-PL-ACC 'It is only his limits that John knows.'

The contrast between (7a) and (8a) is strong, and it instructs us once again that the possessive DP is a distinct binding domain.

The facts concerning the use of the definite article in these constructions, as I argue in this paper, point towards the same conclusion. It is all the more interesting that these facts have not been investigated in the literature on Hungarian. The single exception that I am aware of is Marácz (1989: 396-397). Marácz notes that the definite article is unacceptable if the possessor is the reciprocal anaphor. I repeat (2a) as (9) for illustration.

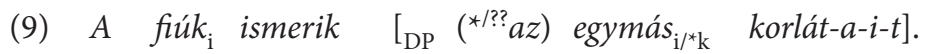
the boys know.3PL the each_other limit-Poss-PL-ACC 'The boys know each other's limits.'

He takes the article facts at face value and draws the conclusion that possessive phrases with reciprocal possessors are smaller than DP. ${ }^{11}$ But in fact all the possessive phrases investigated here behave as DP's in the structure of the Hungarian clause, and there is no positive evidence that the possessive in (9) is smaller than a DP. We will also see in 3.4 that reciprocal possessors are not made incompatible with the definite article: they can co-occur with one if their antecedent is inside of the possessive phrase. Thus Marácz's conclusion seems unwarranted, and a more explanatory account of the behaviour of reciprocal possessors can be elaborated under the assumption that the possessive phrase that contains them is a D.

\section{Anaphoric possessors with or without the definite article}

\subsection{Pronominal possessors}

The definite article is obligatory in Hungarian if the possessor is an overt personal pronoun. I repeat (1a) as (10) for illustration.

(10) János $s_{\mathrm{i}}$ ismeri $\quad\left[_{\mathrm{DP}}{ }^{*}(a z) \dddot{o}_{\mathrm{i} / \mathrm{k}}\right.$ korlát-a-i-t].

John know.3sg the he limit-Poss-PL-ACC

'John knows his limits.'

The only exception to this is the case of vocatives. Szabolcsi (1989) points out that the definite article is ungrammatical in vocatives in Hungarian:

11. They are NP's in the GB-theoretic framework he adopts. 
(11)
a. Én barát-om, gyere!
I friend-Poss.1sg come.IMP.2sG
b. ${ }^{*} A z$ én barát-om, gyere! the I friend-Poss.1sg come.IMP.2sG 'My friend, come!'

In her system, the article is needed to create an argumental noun phrase, and its subordinating function is analogous to the role that the complementizer plays in clauses. In the current proposal, the article creates a phasal domain that helps avoid a potential Principle B violation in case there is a clause-mate antecedent for the pronominal possessor. There is no need for such protection in vocatives, where no potential linguistic antecedent is available. Thus nothing forces the presence of the article in (11), and the ungrammaticality of (11b) may in part be due to reasons of economy in this respect. ${ }^{12}$

The article facts are somewhat more complex if the pronominal possessor is pro-dropped, which is in fact the most frequently used strategy to code a dependency with a clause-mate antecedent. The definite article can be omitted mostly if the possessum is uniquely identifiable through the possessor in the context of use. So article drop is natural in (12a) because one normally has a salient and uniquely identifiable homeland. Bus stops are different in this respect, so the drop of the article in (12b) is unnatural.
a. Elindultam $\left[_{\mathrm{DP}}\right.$ (a) pro szép hazá-m-ból]. departed.1sG the pro beautiful homeland-Poss.1sG-from 'I departed from my beautiful homeland.'
b. Elindultam $\left[_{\mathrm{DP}} \#(a)\right.$ pro buszmegálló-nk-tól]. departed.1sG the pro bus_stop-Poss.1PL-from 'I departed from our bus stop.'

12. (11a) has a somewhat archaic character, but the contrast between (11a) and (11b) is real nevertheless. Szabolcsi (1989: 24) argues that vocatives are DP's, because the possessor can be dative-marked and then it occupies Spec,DP in her system. Her example contains a lexical possessor, but in fact dative pronominal possessors are ungrammatical in vocatives:
(i) ${ }^{*}$ Nek-em (a) barát-om! DAT-1sG the friend-Poss.1sG 'My friend!'

It has been argued that Romance vocatives are DPs (d'Hulst et al. 2007), and see Hill (2007) for the same claim concerning Romanian, Bulgarian and Umbundu. The ungrammaticality of (i) leaves us without obvious positive evidence for the presence of a DP-cap in (11a). I leave this issue open here. 
It is important to emphasize that this article drop is not compulsory in any variety of Hungarian, and the use of the article is always an option with argument possessives. The awkward nature of article drop in (12b) is the result of the lack of a supportive discourse context, and thus the problem is essentially pragmatic, and not syntactic in nature. ${ }^{13}$ I conclude that the definite article can have a phonologically zero variety in Hungarian, licensed in the contexts represented by (12a). Note that the possessum is non-restrictively modified in (12a), and the overt definite article is still not compulsory. ${ }^{14}$ This renders an N-to-D movement account of (12a) implausible. The postulation of a covert definite article captures the modifier-possessum linearization facts successfully, and it is also a plausible account of the fact that article drop by pro-possessors is never compulsory.

In sum, when the possessor is an overt or a pro-dropped personal pronoun, the D-position of the possessive phrase is always filled by the definite article. The article has a phonetically empty variant that is licensed only by pro-dropped possessors in the right discourse setting. ${ }^{15}$

$$
\begin{aligned}
& \text { a. }\left[_ { \mathrm { DP } } \left[{ } _ { \mathrm { D } } \text { az } \text { az } { } _ { \mathrm { FP } } \text { én } \left[{ }_{\mathrm{NP}}\right.\right.\right. \text { hazá-m]]]] } \\
& \text { the I homeland-Poss.1sG } \\
& \text { 'my homeland' } \\
& \text { b. }\left[_{\mathrm{DP}}\left[\left[_{\mathrm{D}}, a / \emptyset_{\mathrm{DEF}}\left[{ }_{\mathrm{FP}} \text { pro }\left[{ }_{\mathrm{NP}} h a z a ́-m\right]\right]\right]\right]\right. \\
& \text { the pro homeland-Poss.1sG } \\
& \text { 'my homeland' }
\end{aligned}
$$

This means that pronominal possessors are always inside the phasal domain constituted by the possessive DP. Any potential clause-mate antecedent is outside of this domain, and therefore Principle B violations cannot arise in dependencies involving the pronominal possessor and an antecedent external to the possessive structure.

13. Dóla et al. (2017) and Virovec (to appear 2019) are two recent discussions of the complex web of factors that influence the acceptability of article drop in Hungarian possessive constructions with covert pronominal possessors.

14. This is not the case with personal names, which do require the presence of the definite article if they are modified by an adjective. Dékány (2011: 94) gives an overview of the facts and the pertinent literature.

15. I simply assume for the purposes of this article that possessors are merged in a functional projection FP. See the literature listed in footnote 1 for different syntactic models of the possessive structure in Hungarian. 


\subsection{The survey}

While the definite article is obligatorily spelt out in the D-head of the possessive phrase if the possessor is a personal pronoun, there is some variation in judgements concerning the use of the article if the possessor is an anaphor. I have conducted a web-based questionnaire survey for a firmer grip on the data, the results of which are incorporated in the discussion in sections 3.3-3.5.

The questionnaire contained 26 target sentences with anaphoric possessors and 6 filler sentences. The target sentences formed 13 minimal pairs which only differed in the presence or the absence of the definite article in the possessive DP. The possessor was the reciprocal egymás 'each other' in 5 sentence pairs, the primary reflexive maga 'oneself' in 4 sentence pairs, and the complex reflexive önmagam 'oneself' in 3 pairs. ${ }^{16} \mathrm{I}$ adopted some of the test sentences from the linguistic literature, whereas the rest were mostly (based on) corpus examples. The major conditions tested were the presence or the absence of a clause-mate antecedent and the respective order of the antecedent and the anaphor. The test sentences only included nominative possessors. ${ }^{17}$

The sentences were presented in a fixed, pre-randomized order with nonadjacent minimal pair test items. The test was self-paced, and participants could see one test item at a time. Participants were asked to evaluate the sentence using a 5 -point Likert-scale ( 5 = fully acceptable, $1=$ totally unacceptable). 149 native speakers participated in the survey, each raised and educated in Hungary. The responses from 8 are not included in the results because these participants' evaluation diverged from the expected value (5 or 1 ) by at least 2 points on at least two

16. One another pair included the special logophoric reflexive jómagam 'myself', but I decided not to include it in the current discussion. This reflexive is mostly used in colloquial varieties of Hungarian, but speakers are divided in their overall evaluation of this form. Those who judged it more favourably tended to prefer the absence of the article in the possessive D-head to its absence. This pattern is similar to what we find attested in the case of önmaga 'oneself', to be discussed in 3.5 below.

17. Alternatively, the unmarked possessor receives no case. The decision between the two analyses has no direct relevance for the current discussion. See É. Kiss (2002) and Dékány (2011) for some discussion. Dative possessors require the spellout of the definite article in D if the possessive phrase is definite (see 8 in the text), therefore they are less interesting in the context of the current inquiry. 
filler sentences. Therefore the data reported in this paper include judgements from 141 native speakers. ${ }^{18}$

\subsection{The primary reflexive as a possessor}

As we have seen in the previous section, the default strategy to code bound variable readings for pronominal possessors in Hungarian is to pro-drop them. Using the primary reflexive for the same purpose is a marked strategy in this respect. What renders reflexive possessors marked, in comparison to argument reflexives, is that they do not create a reflexive relation themselves, and they frequently have a logophoric character. Let us investigate now how the results of the questionnaire survey can be interpreted in the framework of these assumptions.

Figure 1. provides an overview of the results pertaining to the 4 sentence pairs that contained the primary reflexive. The sentence pairs are referenced as below from (14) to (17).

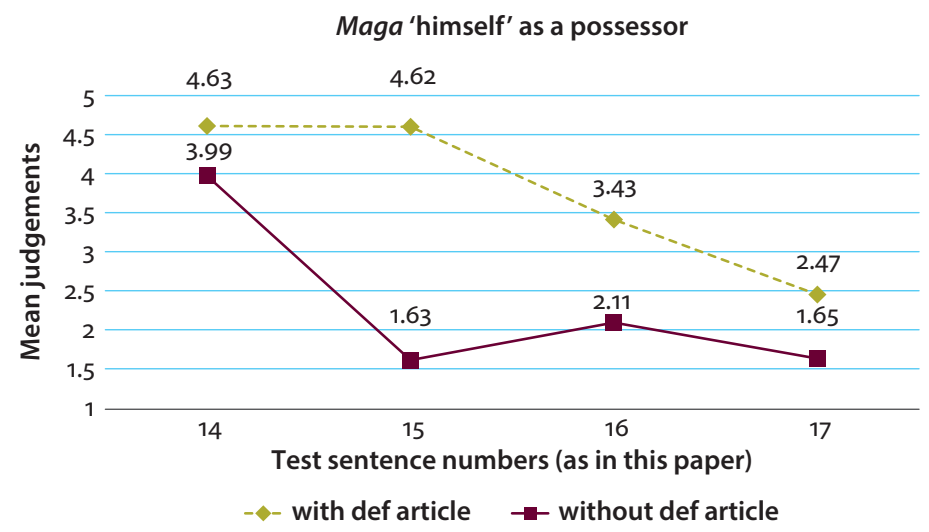

Figure 1. Mean judgements for the reflexive possessor sentences (14-17)

(14) with article: 4.63 , without article: 3.99

[DP $(A)$ magam rész-é-röl] egyetértek.

the myself part-Poss-from agree.1sG

'For my part, I agree.'

18. The mean age of these respondents was 31 , and 111 of them were female. Most participants were from the eastern part of Hungary, but each major regional dialect was represented in the survey. The response patterns do not correlate obviously with these social factors (age, gender, place of birth and living, education), and I assume that any inter-speaker variation is idiosyncratic in this respect. 
(15) with article: 4.62 , without article: 1.63

Mi csináltuk $\left[_{\mathrm{DP}}(a)\right.$ magunk dolg-á-t $]$.

we did.1PL the ourselves thing-Poss-ACC

'We went about our own business.'

(16) with article: 3.43 , without article: 2.11

Túlságosan sokra becsültem ${ }_{\mathrm{DP}}$ (a) magam ere-jé-t $]$.

too much.to estimated.1sG the myself strength-Poss-ACC

'I much overestimated my own strength.'

(17) with article: 2.47 , without article: 1.65

$\mathrm{Ez}$ a változás mintha ${ }_{\mathrm{DP}}$ (a) magam

this the change as.though the myself

gondolkod-ás-á-t] is megváltoztatta volna.

thinking-NOMSUF-POss-ACC too altered.3sg COND

'As though this change had altered my own way of thinking, too.'

As is evident, the participants of the survey preferred the use of the definite article to its absence in each condition. Thus the primary factor that determines the distribution of the definite article is the choice of the reflexive itself. Nevertheless, there is obvious variation in the mean judgements across the sentences.

The two sentences (14-15) that received the highest score each include an underlying relation that is normally reflexive. One can go about one's own business, and one can normally express one's consent on one's own behalf. Most of the corpus examples for reflexive possessors represent this sort of use, in which the semantic contribution of the primary reflexive is minimal. There is a pronounced difference in judgements concerning the drop of the definite article. It is barely an option in (15), in which the possessive phrase is an argument inside of the VP; but the article-less variant received much higher scores in (14), in which the possessive phrase is an adjunct in topic position. The participants consistently rated this sentence without the article either as good as the variant with the article, or only a little worse. I assume that this is an instance of article drop in topic position, manifesting the phonologically zero form of the definite article that we discussed in 3.1.

Examples (16) and (17) do not include an underlying reflexive relation. One can, for example, quite naturally overestimate somebody else's strength. (17), which is based on a sentence from the Hungarian National Corpus (Oravecz et al. 2014), does not even include a clause-mate antecedent. I have argued in Rákosi (2014) that the reflexive is a perspective-dependent, logophoric pronoun in this example. (17) becomes totally unacceptable if it is embedded in a context that represents somebody else's perspective. This sentence, just like all the others, was presented out of context, which might be the reason why the participants did not evaluate it favourably. Perspective dependence also plays a role in the interpretation of (14) 
and (15), though this factor is much less prominent there than in the case of (16) and (17). The native speakers that I consulted on this in a follow-up inquiry were in agreement that (15) is awkward or less felicitous in a context where the pointof-view holder is not the antecedent of the reflexive. Compare (18a) to (18b). was.happy.1sG that 'I was happy that...'
a. VÖrültem, hogy...
b. (?)János örült, hogy... John was.happy.3sg that 'John was happy that...'
...mi csinálhattuk $\left[_{\mathrm{DP}}(a)\right.$ magunk dolg-á-t $]$. we could.do.1PL the ourselves thing-POss-ACC 'we could go about our own business.'

Thus even if these uses are not logophoric in the strict sense of the term, sensitivity to the presence of an antecedent whose perspective structures the piece of discourse around the reflexive is an evident factor in its licensing.

The emerging picture is that these reflexive possessors are exempt anaphors, and as such, they do not need a local syntactic antecedent. They may show different degrees of logophoricity, and they tend to sound best when the semantics of the embedding clause inherently requires the identity of the possessor and a clausemate antecedent (usually the subject). They co-occur with the definite article in the D-head of the possessive phrase exactly for the reason that they do not act as locally bound variables. Within the current set of assumptions, this means that they are inside of the phasal domain of the possessive phrase, just like pronominal possessors, and their antecedent - if there is one - is outside of this domain.

\subsection{The reciprocal anaphor as a possessor}

What sets a reciprocal possessor apart from the primary reflexive possessor, is that the former does not have a marked character in canonical transitive constructions containing a subject antecedent and a possessive DP object, and that reciprocal possessors do not take the definite article in this configuration. But the overall picture on article use is slightly more complex.

The results of the survey are summarized in Figure 2, and the test sentences are listed below.

(19) without article: 4.61 , with article: 1.87
A fiúk feljelentették ${ }_{\mathrm{DP}}$ (az) egymás szüle-i-t]
the boys reported.3PL the each_other parent.Poss-PL-ACC
a rendörség-en.
the police-on
'The boys reported each other's parents to the police.' 


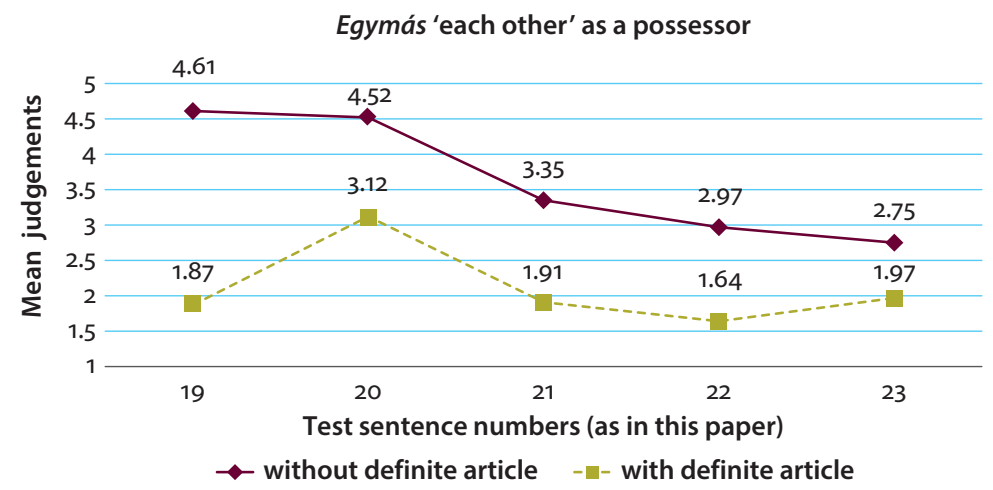

Figure 2. Mean judgements for the reciprocal possessor sentences (19-23)

(20) without article: 4.52 , with article: 3.12

Már kicsit unalmas ${ }_{\mathrm{DP}}(a z)$ egymás feljelentget-és-e]. already little boring the each_other report.FREQ-DEV-POss 'The constant reporting of each other (to the police) is a little boring already'.

(21) without article: 3.35 (Rákosi 2015, 261: $\sqrt{ }$ ), with article: 1.91 ${ }_{\mathrm{DP}}(\mathrm{Az})$ egymás szüle-i] tetszenek a gyerekek-nek. the each_other parent.POss-PL appeal.3PL the children-DAT 'The children like each other's parents.'

(22) without article: 2.97 (É. Kiss 2008, 464: $\sqrt{ }$ ), with article: 1.64 A fiúk-at feljelentették ${ }_{\mathrm{DP}}(a z)$ egymás szüle-i] the boys-ACC reported.3PL the each_other parent.POss-PL

a rendörség-en.

the police-on

'The boys, each other's parents reported to the police.'

(23) without article: 2.75 (É. Kiss 1987, 200: ?), with article: 1.97

A lányok féltek, hogy $\left[_{\mathrm{DP}}(a z)\right.$ egymás

the girls feared.3PL that the each_other jelölt-je-i] nyer-nek.

candidate-POss-PL win-3PL

'The girls were afraid that each other's candidates would win.'

As is clear, the variant without the definite article is rated highest in each case. The greatest distance between the two variants is in what we regard as the canonical binding configuration (19). (22) is from É. Kiss (2008), who uses it to illustrate the claim that the object can bind into the subject in Hungarian if the former precedes the latter, and who considers the articless variant grammatical. But this sentence was in fact rated much lower in this survey than (19), and even (21) received 
higher scores. In (21), the internal experiencer argument binds into the internal subject argument, the latter preceding the former. ${ }^{19}$ What is noteworthy about this example is that the lack of a linear precedence relation between antecedent and anaphor does not improve the acceptability of the article in a significant manner.

The same pattern emerges in the case of example (23), which was the lowest rated sentence in this group in the no-article condition. The reciprocal possessor is embedded within the subordinate subject DP, and its antecedent is in the matrix clause. The example is from É. Kiss (1987), who gives it a question mark, and who considers it an exempt anaphor (being "excluded from the domain of anaphora", op. cited p. 201). The anaphor and the antecedent are in two distinct binding domains in the phase-based approach, too, given that the finite subordinate clause constitutes a phase. I therefore also treat this reciprocal as an exempt anaphor. ${ }^{20}$ We would then expect the definite article to be more acceptable in this configuration than in the previous three, but it fared only slightly better. Only 20 participants out of 141 rated this sentence higher with the article than without it, with an average 1,35 points difference between the respective judgements.

19. Rákosi (2015) extensively argues for the two-place unaccusative analysis of dative experiencer verbs in Hungarian.

20. This conclusion is also supported by the general uncertainty in the judgements. The reciprocal possessor can be bound by a local dative antecedent (i), and if it is part of the subordinate subject, it can marginally take either a dative or a nominative argument as its antecedent (ii-iii). If both the nominative and the dative arguments of the matrix verb are plural, then the reciprocal can co-refer with either with a moderate level of success (not shown). More research is needed on the factors that govern grammaticality judgements here, but this construction is apparently not an instance of a well-behaving, local referential dependency.

(i) Megmutattam a lányok-nak egymás jelölt-je-i-t. showed.1sG the girl.PL-DAT each_other candidate-POSs-PL-ACC 'I showed the girls each other's candidates.'

(ii) ?(?) Megmutattam a lányok-nak, hogy egymás jelölt-je-i showed.1sG the girl.PL-DAT that each_other candidate-POss-PL hova állnak. where.to stand.3PL

'I showed it to the girls where each other's candidate will stand.'

(iii) ?(?)A lányok megmutatták nek-em, hogy egymás the girls showed.3PL DAT-1SG that each_other jelölt-je-i hova állnak. candidate-Poss-PL where.to stand.3PL 'The girls showed me where each other's candidates will stand.' 
In comparison, the definite article was much better received in (20). This example contains a possessum which is an action nominalization that comes with a local antecedent (the agent of the verbal base of the possessum) that can bind the reciprocal. ${ }^{21}$ Since the search for the antecedent is within the possessive DP, the presence of the article is expected. And it was fully acceptable (5) for 35 participants out of 141, with 29 of them rejecting it altogether (1). This indicates that there is a split across the speakers, but a much bigger portion of them accepts the article here than in the other conditions. It is also noteworthy that the majority of the relevant examples (a reciprocal possessor with a preceding definite article) that one may find in corpora are possessive phrases containing a nominalized verbal head. (24) is one such example from the Hungarian National Corpus.

A csapatjátéknál $\left[_{\mathrm{DP}}\right.$ az egymás segit-és-é-n]
the team_game.at the each_other help-DEV-POss-on is
a hangsúly.
the emphasis
'In a team game, the emphasis is on helping each other.'

The importance of this configuration is in demonstrating that reciprocal possessors are not incompatible with the definite article, or at least not totally for most speakers. If the antecedent is available within, the article can be spelled out in the possessive DP.

So in this case the reciprocal possessor stays low in the possessive structure (25a). When the reciprocal possessor has an antecedent in the embedding clause, the D-position of the possessive DP contains no article. Instead, the reciprocal, which is based generated in the specifier of a possessive functional projection (called FP in this paper), moves to the specifier of the DP. ${ }^{22}$ This movement is driven by the $\varphi$-deficient nature of the reciprocal anaphor, and also by the lack of an alternative strategy to express reciprocal meanings.
a. [DP $\left[{ }_{D}\right.$, DEFINITE ARTICLE [FP RECIPROCAL POSSESSOR [ ${ }_{\text {NP }}$ POSSESSUM $\left.\left.\left.]\right]\right]\right]$
b. [DP RECIPROCAL POSSESSOR [FP RECTPROCAL POSSESSOR [NP POSSESSUM]]]

In (25b), the reciprocal possessor occupies a position at the edge of the DP phase and it can be directly bound by an antecedent from the embedding clause.

21. How exactly this agent argument is represented in syntax is less crucial in the context of the current discussion. See Kenesei (2005) and Laczkó (2009) for two opposing views.

22. This is analogous to how É. Kiss (2002: 166) treats lexical possessors. I also assume with her that dative possessors are hosted in the specifier position of an extra DP adjoined to the core DP-layer represented in (25b). 


\subsection{The complex reflexive önmaga 'oneself' as a possessor}

The primary reflexive maga 'oneself' has several more complex variants. The most frequent one of these is önmaga 'oneself'. This anaphor is primarily used in predicates where a reflexive relation is not expected, and its syntax is similar in certain ways to the syntax of personal names. It can, for example, be modified by a nonrestrictive adjective:
a. *(a) korábbi János the former John 'the former John'
b. (a) korábbi önmaga the former oneself 'his former self'

The difference between the name and the reflexive is that the former necessarily combines with the definite article in this construction (26a), while the article is optional for the reflexive (26b).

The survey contained 3 sentence pairs with this anaphor, as is summarized below.

\section{Önmaga 'himself' as possessor}

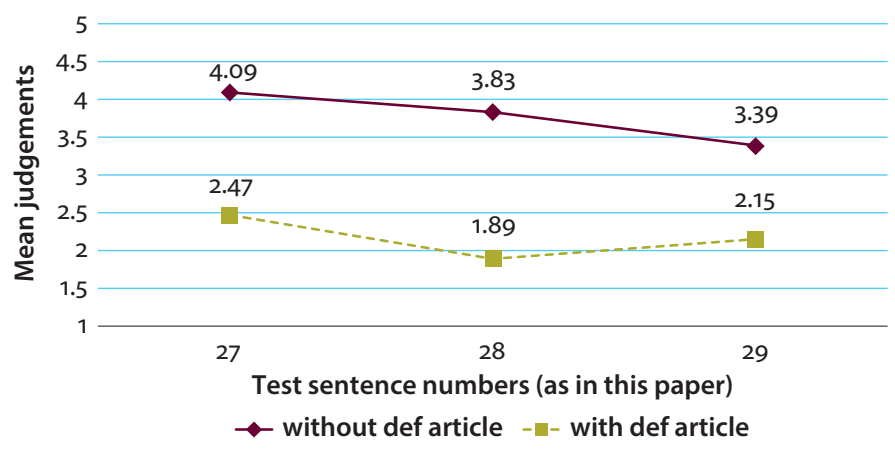

Figure 3. Mean judgements for the complex reflexive possessor sentences (27-29)

(27) without article: 4.09 , with article: 2.47
Minden nap $\left[_{\mathrm{DP}}(a z)\right.$ önmagam leleplez-és-e is $]$ volt. every day the myself expose-DEv-poss too was 'Every day was the exposing of my own self, too.'

(28) without article: 3.83 , with article: 1.89
A fiúk felfedezték [ ${ }_{\mathrm{DP}}$ (az) önmaguk határ-a-i-t].
the boys discovered the themselves limit-POss-PL-ACC 'The boys discovered their own limits.' 
(29) without article: 3.39 , with article: 2.15

${ }_{\mathrm{DP}}(A z)$ önmaga szerep-é-t] Péter is hasonlóan élte meg. the himself role-Poss-ACC Peter too similarly lived.3sG PRT 'His own role, Peter experienced in a similar manner.'

(27) received the highest scores in both conditions. The possessum is a nominalized form of a verbal predicate, and thus the reflexive anaphor has an antecedent within the possessive DP. It is for this reason that a subset of the participants of the survey gave higher scores to the variant with the definite article than in the other conditions. The overall distribution of the judgements is similar to what we have seen with reciprocals, though there the definite article is somewhat more acceptable in the presence of a DP-internal antecedent (compare (20) and (27)).

I therefore assume a similar analysis for the two anaphors. The definite article is acceptable here too at least for some speakers if the antecedent is within the possessive DP (30a). But this reflexive has an antecedent in the embedding clause in the usual case, and then the definite article is absent. It is the complex reflexive itself which moves from the DP-internal functional projection to the specifier of the DP-cap to occupy a position at the edge of the DP-phase (30b).

$$
\begin{aligned}
& \text { a. [DP } \left.\left.\left[{ }_{D} \text {, DEFINITE ARTICLE }{ }_{\mathrm{FP}} \text { COMPLEX REFLEXIVE }\left[_{\mathrm{NP}} \text { POSSESSUM }\right]\right]\right]\right] \\
& \text { b. [DP }
\end{aligned}
$$

What triggers this movement in this case is the analogy with lexical possessors (names), since this reflexive is characterised by a degree of referentiality that sets it apart from run-of-the-mill reflexive anaphors. But önmaga 'oneself' is an anaphor nevertheless, and it can be bound within the next phasal domain higher up in the tree as a result of this movement.

\section{Summary and outlook}

I have argued in this paper that the apparently complex distribution of the definite article in Hungarian possessive DP's containing an anaphoric possessor can be better understood once the role of the definite article in determining the binding domain for the possessor is recognized. In particular, I have shown that the definite article in the D-head of the possessive phrase allows the anaphoric possessor to find an antecedent within the possessive DP, but it blocks the establishment of a local binding dependency between the possessor and an antecedent external to the possessive phrase. Overt or pro-dropped personal pronouns require the presence of the article in $\mathrm{D}$, and thus they do not induce a Principle B violation even in the presence of a clause-mate antecedent. The primary reflexive possessor maga 'oneself' also requires an article in $\mathrm{D}$, and it acts as an exempt anaphor. The 
reciprocal egymás 'each other' and the complex reflexive önmaga 'oneself' move up to Spec,DP to be on the edge of the DP phase, which allows them to be bound from the next phase higher up in the tree. The $\mathrm{D}$-position is not filled in this scenario, but some speakers do find the definite article acceptable with these two anaphors if an antecedent is available within the DP.

This discussion introduces a novel, binding theoretic perspective to the syntax of the Hungarian possessive construction, and the paper also provides a survey of an empirical field that has been relatively neglected in pertinent research. The source of inspiration for this analysis is Reuland's $(2007,2011)$ observation on the role of the definite article in binding dependencies involving anaphoric possessors. Reuland shows that dedicated possessive reflexives are only available in languages without prenominal articles. This paper has provided data from Hungarian in support of the claim that the definite article creates an impenetrable domain for binding into possessives, thereby illustrating that Reuland's conjecture describes an important factor not only in cross-linguistic, but also in language internal variation in definite article use in possessive DP's. Following Despić (2011, 2013, 2015), I assumed a phase-based approach to the description of the data discussed. The paper demonstrates the role of the definite article in spelling out the boundaries of the phase constituted by the possessive DP. These are also the boundaries of the binding domain for the possessor, which only becomes accessible to the next higher phase if it moves to the edge of the DP phase, to Spec,DP.

The survey that I have reported in this paper is an initial attempt at understanding the empirical data in a more comprehensive manner. The primary data show variation in some of the conditions, especially in the case of exempt anaphoric uses, or in the cases when article use deviates from what we see attested in canonical transitive constructions with subject antecedents and anaphoric possessors in the DP object. It is an important objective for further research to develop a better understanding of variation in definite article use in possessive constructions in general, and variation in native speakers' assessment of exempt anaphoric possessor strategies. I believe nevertheless that more fine-grained surveys of the empirical field will only give further support to the analysis that I have proposed in this paper.

\section{Acknowledgements}

I am grateful to the two anonymous reviewers for their comments on the paper, as well as the editors for their help. Any remaining errors are solely mine.

The project no. 111918 (New approaches in the description of the grammar of Hungarian pronominals) has been implemented with the support provided from the National Research, Development and Innovation Fund of Hungary, financed under the K funding scheme. 


\section{References}

Bartos, Huba. 1999. Morfoszintaxis és interpretáció: A magyar inflexiós jelenségek szintaktikai háttere. [Morphosyntax and interpretation: The syntactic background of inflectional phenomena in Hungarian.] Doctoral thesis. Budapest: ELTE Elméleti Nyelvészet Doktori Program.

Bernstein, Judy B. \& Christina Tortora. 2005. Two types of possessive forms in English. Lingua 115. 1221-1242. https://doi.org/10.1016/j.lingua.2004.03.002

Bošković, Željko. 2005. On the locality of left branch extraction and the structure of NP. Studia Linguistica 59. 1-45. https://doi.org/10.1111/j.1467-9582.2005.00118.x

Bošković, Željko. 2014. Now I'm a phase, now I'm not a phase: On the variability of phases with extraction and ellipsis. Linguistic Inquiry 45(1). 27-89.

https://doi.org/10.1162/LING_a_00148

Dékány, Éva. 2011. A profile of the Hungarian DP. The interaction of lexicalization, agreement and linearization with the functional sequence. Doctoral thesis. Tromsø: University of Tromsø.

Despić, Miloje. 2011. Syntax in the absence of determiner phrase. Doctoral thesis. University of Connecticut.

Despić, Miloje. 2013. Binding and the structure of NP in Serbo-Croatian. Linguistic Inquiry 44(2). 239-270. https://doi.org/10.1162/LING_a_00126

Despić, Miloje. 2015. Phases, reflexives, and definiteness. Syntax 18(3). 201-234. https://doi.org/10.1111/synt.12031

d'Hulst, Yves, Martine Coene \& Liliane Tasmowski. 2007. The romance vocative and the DP hypothesis. In Alexandra Cunita, Coman Lupu \& Liliane Tasmowski (eds.), Studii de lingvistica si filologie romanica: Hommages offerts à Sanda Reinheimer Rîpeanu, 200-211. Bucharest: Editura Universitatii din Bucuresti.

Dikken, Marcel den. 1999. On the structural representation of possession and agreement. The case of (anti-)agreement in Hungarian possessed Nominal Phrases. In István Kenesei (ed.), Crossing boundaries: Theoretical Advances in Central and Eastern European Languages, 137-178. Amsterdam: John Benjamins. https://doi.org/10.1075/cilt.182.10dik

Dikken, Marcel den. 2006. When Hungarians Agree (to Disagree) - The Fine Art of 'Phi' and 'Art'. Ms. New York: CUNY Graduate Center.

Dóla, Mónika, Anita Viszket \& Judit Kleiber. 2017. A határozott névelő a birtokos szerkezetben. [The definite article in the possessive construction.] Hungarológiai Évkönyv 18. 38-69.

É. Kiss, Katalin. 1987. Configurationality in Hungarian. Budapest: Akadémiai Kiadó. https://doi.org/10.1007/978-94-009-3703-1

É. Kiss, Katalin. 2000. The Hungarian noun phrase is like the English noun phrase. In Gábor Alberti \& István Kenesei (eds.), Approaches to Hungarian VII. Papers from the Pécs Conference, 119-150. Szeged: JATEPress.

É. Kiss, Katalin. 2002. The syntax of Hungarian. Cambridge: Cambridge University Press. https://doi.org/10.1017/CBO9780511755088

É. Kiss, Katalin. 2008. Free word order, (non)configurationality, and phases. Linguistic Inquiry 39(3). 441-475. https://doi.org/10.1162/ling.2008.39.3.441

É. Kiss, Katalin. 2014. Ways of licensing external possessors in Hungarian. Acta Linguistica Hungarica 61(1). 45-68. https://doi.org/10.1556/ALing.61.2014.1.2

Hill, Virginia. 2007. Vocatives and the pragmatics-syntax interface. Lingua 117. 2077-2105. https://doi.org/10.1016/j.lingua.2007.01.002 
Kenesei, István. 2005. Nonfinite clauses in derived nominals. In Christopher Piñón \& Péter Siptár (eds.), Approaches to Hungarian 9: Papers from the Düsseldorf Conference, 159-186. Budapest: Akadémiai Kiadó.

Laczkó, Tibor. 1995. The syntax of Hungarian noun phrases. A Lexical-Functional approach. Metalinguistica 2. Frankfurt am Main: Peter Lang.

Laczkó, Tibor. 2009. On the -ás suffix: Word formation in the syntax? Acta Linguistica Hungarica 56 (1). 23-114. https://doi.org/10.1556/ALing.56.2009.1.2

Marácz, László. 1989. Asymmetries in Hungarian. Doctoral thesis. Rijksuniversiteit Groningen.

Marelj, Marijana. 2011. Bound-variable anaphora and Left Branch Condition. Syntax 14(3). 205-229. https://doi.org/10.1111/j.1467-9612.2011.00156.x

Oravecz Csaba, Váradi Tamás \& Sass Bálint. 2014. The Hungarian Gigaword Corpus. Proceedings of LREC 2014.

Pléh, Csaba. 1983. Some semantic and pragmatic factors of anaphoric interpretation in Hungarian. Acta Linguistica Academiae Scientiarum Hungaricae 33(1/4). 201-211.

Rákosi, György. 2014. Possessed by something out there: On anaphoric possessors in Hungarian. Argumentum 10. 548-559.

Rákosi, György. 2015. Psych verbs, anaphors, and the configurationality issue in Hungarian. In Katalin É. Kiss, Balázs Surányi \& Éva Dékány (eds.), Approaches to Hungarian 14. Papers from the 2013 Piliscsaba Conference, 245-265. Amsterdam: John Benjamins. https://doi.org/10.1075/atoh.14.10rak

Rákosi, György. 2017. The definite article and anaphoric possessors in Hungarian. Linguistica Brunensia 65 (2). 21-33.

Reuland, Eric. 2007. Binding conditions: How can they be derived? Lectures on Binding. Department of Linguistics, St Petersburg University. Joint PhD program St Petersburg- Utrecht University. April 24-May 3, 2007. [Retrieved 31.01.2017] Available at: http://slioussar. narod.ru/reuland2007.htm

Reuland, Eric. 2011. Anaphora and language design [Linguistic Inquiry Monograph 62]. Cambridge, MA: The MIT Press.

Szabolcsi, Anna. 1983. The possessor that ran away from home. The Linguistic Review 3. 89-102. https://doi.org/10.1515/tlir.1983.3.1.89

Szabolcsi, Anna. 1987. Functional categories in the noun phrase. In István Kenesei (ed.), Approaches to Hungarian 2, 167-190. JATE: Szeged.

Szabolcsi, Anna. 1989. Noun phrases and clauses: Is DP analogous to IP or CP? Ms. Retrieved from http://www.nyu.edu/projects/szabolcsi/szabolcsi_DP_IP_CP.pdf

Szabolcsi, Anna. 1994. The noun phrase. In Ferenc Kiefer \& Katalin É. Kiss (eds.), The syntactic structure of Hungarian. Syntax and Semantics 27, 179-275. New York: Academic Press.

Virovec, Viktória. 2019. A határozott névelő használatáról üres névmási birtokosok mellett. [On the use of the definite article with covert pronominal possessors.] In György Scheibl (ed.), LingDok 17. Nyelvészdoktoranduszok dolgozatai. Szeged: SZTE Nyelvtudományi Doktori Iskola. 


\title{
Word order effects of givenness in Hungarian:
}

\section{Syntax or prosody?}

\author{
Ádám Szalontai ${ }^{1} \&$ Balázs Surányi ${ }^{1,2}$ \\ ${ }^{1}$ Research Institute for Linguistics, Hungarian Academy of Sciences \\ ${ }^{2}$ Pázmány Péter Catholic University
}

\begin{abstract}
This pioneering study presents results from a forced choice experiment designed to investigate the favoured linear placement of given constituents within the postverbal domain of Hungarian. Specifically, the experiment tested the preferred relative position of textually given topical adjunct phrases. The results indicate that speakers prefer to place topical given constituents in the immediately postverbal position, preceding contextually new items in the clause final position. The paper makes the argument that the results are best explained by an interface approach that sees word order variation as driven by the prosodic marking associated with givenness.
\end{abstract}

Keywords: word order, post-verbal field, information structure, givenness, prosodic marking

\section{Introduction}

Information structural (IS) categories like focus and givenness are associated with word order alternations in many of the world's languages. Over the past decades the word order effects of focus have been investigated in great detail from a variety of formal perspectives. Popular accounts range from the purely syntactic and those formulated in terms of the syntax-IS interface to those lying at the prosody-IS interface. Indeed, in transformational generative grammar, much of this research has centered around charting the precise division of labor of the relevant grammatical components in focus-related word order phenomena. While no less prominent in functionalist schools of thought than focus, the ordering effects of givenness have received comparatively less attention in transformational grammar. A key observation, first explored in detail by the Prague School, is the tendency of given elements to linearly precede new elements. This given-before-new generalisation, however has not been widely adopted in transformational theories as a general principle. In addition to the difficulty in pinning down the linguistically relevant 
notion of givenness, reasons for this lapse include the extensive, yet ill-understood variation in givenness-related word order effects, which include across-the-board obligatory reordering, obligatory reordering applying only to a restricted range of elements, and cases in which the generalization appears to be blatantly violated; phenomena which have all been observed in a variety of Slavic and Germanic languages.

Especially challenging from a generative syntactic perspective are variations in word order due to givenness that are best described as tendencies or preferences, rather than discrete and unambiguous effects. These types of phenomena are worth exploring since they make available potentially fruitful comparisons with better studied mandatory syntactic effects associated with IS, and are thus bound to inform general theories of the relation between IS and syntax.

This paper presents a two-alternative forced choice experiment that was designed to examine whether givenness plays any role in the word order of the post-verbal domain of the Hungarian sentence. In this domain major constituents of the sentence appear in a free word order, and currently it is not clear whether any information structural categories are relevant to the choice between different post-verbal word order alternants. After providing the necessary background regarding basic notions of givenness and characteristic ways of its grammatical marking in Section 2, in Section 3 we briefly review previous analyses of the syntax of the post-verbal region of the Hungarian sentence and prior claims concerning the effect of givenness in this syntactic domain. Section 4 presents our forcedchoice experiment. The results reveal that while givenness does not determine word order in a categorical way, speakers tend to prefer for the given phrases to precede the new phrases in the critical sentences. In Section 5 we discuss possible syntactic and prosodic accounts of these results, and argue for the viability of a prosodic approach that views the relevant word order variation as driven by the prosodic requirements associated with givenness. Section 6 concludes with a summary and identifies open questions for future research.

\section{Givenness}

\subsection{Notions of givenness}

Givenness can be defined in a number of ways, which vary in how one assumes that an expression or its denotation are already present in discourse (Rochemont 2016). Chafe (1974) frames givenness in terms of cognitive activation (or salience), Clark and Haviland (1977) and Prince (1981) in terms of familiarity, and Ariel (1990) in terms of accessibility, to name three key points of reference. From a linguistic perspective, givenness is commonly understood in current approaches not 
as a singular notion, but as a complex category encompassing various potentially related but distinct contextual properties. Ladd (1980), for one, discriminates between referential and textual senses of givenness. While extensionally these two senses may overlap, they do not necessarily coincide: something that is textually given may or may not be referentially given, and a referentially given entity may or may not be textually present (see Baumann and Riester 2013).

It is often posited that different combinations of these and other basic properties comprising different particular notions of givenness will lead to different degrees of givenness in a more encompassing sense. This assumption is common to a number of models that have been set up to capture the gradual or scalar nature of givenness (Chafe 1974; Prince 1981; 1992; Ariel 1990; Gundel et al. 1993; Arnold 1998; Kaiser 2011 among others). These models propose that the level of givenness of a particular item can be placed on a scale or hierarchy. The differential, and potentially graded, nature of givenness is revealed in its differential linguistic marking, potentially reflected, for instance, in the choice among alternative nominal forms that can be used to refer to the given entity (Ariel 1990; Gundel et al. 1993), or in differences in accent type and deaccentuation (Baumann 2006; Baumann \& Grice 2006). Givenness markers can thus be defined in a way in which they reflect the varying degrees of givenness they are associated with (Krifka, 2008).

Thus, givenness may be of varying types and/or degrees, as revealed by potential differences in their linguistic marking. The aim of the present empirical study is modest: it concentrates on one type of given elements in Hungarian, namely, topical textually given phrases. This type would be positioned comparatively high on any givenness scale. Textual givenness is a relatively simple affair: textually given items are part of the common ground because they have a salient matching linguistic antecedent in prior discourse. As for topicality, this notion overlaps with givenness a number of ways. It requires the presence (or accommodation) of a corresponding element in the common ground (Chafe 1976; Gundel et al 1993; Lambrecht 1994; Prince 1981) Further more, it sometimes may also be understood as being scalar (Givón 1983; Ariel 1991). Two basic types of topics are commonly distinguished: aboutness topics (or sentence topics), of which the comment part of the sentence is predicated (Reinhart 1981; Lambrecht 1994), and discourse topics, namely themes of particular discourse segments (van Dijk 1976; Prince 1981). The two notions are not mutually exclusive in the sense that an element that is marked linguistically as the aboutness topic of a sentence may be, or may become, the discourse topic at that point of the discourse. For instance, in a dialogue context, if an item is marked as the aboutness topic in the question, then that item may function as the discourse topic (though not necessarily the aboutness topic) for the answer directly addressing that question. ${ }^{1}$ In the experiment to be presented below we

1. For the relation between aboutness topic and discourse topic, see also Asher (2004: 191). 
examine the syntactic positioning of phrases that are both textually given and topical in a a sense of topicality to be defined below (we will refer to them as topically given, for short).

\subsection{The grammatical marking of givenness}

Givenness has been shown to be associated in a wide range of languages with specific realisations both in terms of syntax and prosody. The syntactic reflexes of givenness often involve the use of non-canonical word order as reflected by the given-before-new generalization introduced above. In terms of prosody, on the other hand, givenness marking typically takes the form of reduced prosodic prominence, such as deaccentuation (Halliday 1967; Chafe 1976; Ladd 1980; Cruttenden 1997). One possibility with regard to any particular manifestations of these two types of reflexes is to assume that they arise independently of each other; that is, givenness exerts its influence on word order and on prosody separately. The other main possibility, capitalizing on the fact that syntactic form and prosodic form are highly interrelated, is to approach syntactic effects of givenness from the perspective of its prosodic effects, uncovering how the former may in fact be motivated by the latter. In the remaining part of this section, we survey some prominent accounts of the syntactic effects of givenness exemplifying each of these two possible approaches. We will return to them in Section 3.2 below, where we consider both of these possibilities in relation to the word order effects of givenness we have found in Hungarian.

A long established generalisation going back to the work of Henri Weil, Hermann Paul and the Functional Sentence Perspective of the Prague School, and also adopted in some form in a great deal of linguistic research since (e.g. Clark \& Clark 1977; Clark \& Haviland 1977; Gundel 1988; Kučerová 2007, 2012; Skopeteas \& Fanselow 2009), is that given material generally precedes new material. A careful formulation of this generalisation is presented in Neeleman and van de Koot (2016):

(1) Given-before-New Generalisation

If a language uses word order alternations to mark givenness, then in the marked order the given material precedes the new material.

The following Czech examples illustrating this generalization are taken from Kučerová (2007). When the subject is interpreted as a (new, nonspecific) indefinite and the object is interpreted as a definite, the basic SVO order changes to OVS (2b). If the subject is definite, or both the subject and the object are novel indefinites, then the basic SVO order surfaces (2a). 
(2)

a. Chlapec našel lízátko

boy.NOM found lillipop.ACC

'The boy found a lollipop' 'A boy found a lollipop' 'The boy found the lollipop'

b. Lízátko našel chlapec

lollipop.ACC found boy.NOM

'A boy found the lollipop'

Kučerová $(2007,2012)$ puts forward a syntactically based analysis, proposing a givenness operator (G-operator) to account for this effect. Her account can be said to be syntactically flexible in that the G-operator has no fixed position in the functional hierarchy of the clause: it may be inserted in one of several positions. Wherever the G-operator is inserted within the structure of the clause, for each c-commanding phrase within the containing propositional clausal constituent it introduces the presupposition that that phrase must be given. It then follows from the Maximize Presupposition principle (Heim 1991) that all given phrases must c-command, and thus (due to the right-branching nature of Czech clause structure) must precede, all new phrases. ${ }^{2}$

The overlap between givenness and topicality means that given elements may also be syntactically marked on account of being topical. Of special relevance to our current concerns is the notion of familiarity topic. A familiarity topic, also called givenness topic or continuity topic (Bianchi \& Frascarelli 2010), is a given expression linked to a previously established aboutness topic and/or used for topic continuity (Givón, 1983, 1990; Lambrecht 1994), which gets "an already introduced aboutness topic" "merely refreshed" (Bianchi \& Frascarelli 2010). This particular notion of familiarity topic is similar to what van Dijk (1981) dubs 'sequential topic', and what Erteschik-Shir (2007) refers to as 'continued topic.'

Basing themselves on the cartographic approach (Rizzi 1997), Frascarelli and Hinterhölzl (2007) show that in Italian familiarity topics are associated specifically with a low IP-external position that is located below the position of aboutness/ shifted topics (Reinhart 1981), contrastive topics (Büring, 1997), and left-peripheral

2. As noted in the preceding subsection, different types and/or degrees of givenness may elicit varying forms of associated linguistic marking. Kučerová $(2007,2012)$ claims that an object in Czech is marked by reordering as in (2b) only if it is "presupposed" in addition to being given in the common ground, where presuppositionality is roughly equivalent to Enc's (1991) notion of specificity. Šimík and Wierzba (2015) argue that this extra requirement is both too strong and too weak for an adequate description of Czech.

3. Familiarity topic status has been shown to influence word order phenomena (Cowles \& Ferreira 2011). 
focus, as shown in the clausal sub-hierarchy of dedicated left-peripheral functional projections below. ${ }^{4}$

(3) $\left[_{\text {ShiftP }}\left[_{\text {ContrP }}\left[_{\text {FocP }}\left[_{\text {FamP }}\left[_{I P}\right.\right.\right.\right.\right.$

Thus, in some cases the syntactic marking of given constituents may be due specifically to their familiarity topic status.

Both the flexible account and the cartographic account presented thus far regard givenness related word order phenomena as primarily syntactic, without assuming that the prosodic properties of given constituents play a significant role in these word order variations. With regard to the word order effects of focus, this has been a prominent line of research, culminating in what have come to be called cartographic syntactic accounts of focus (Bródy 1995; Rizzi 1997). ${ }^{5}$ At the same time, some focus-related word order alternations have been treated as being governed by the prosodic need of focus to bear the nuclear accent. Namely, it has been suggested that marked word orders may result from the syntactic alignment of the focused constituent with the default position of sentence-level nuclear prominence (Neeleman \& Reinhart 1998; Zubizarreta 1998; Ishihara 2003; Szendrői 2003). It is also eminently possible to approach the apparent syntactic effects of givenness from the perspective of the prosodic properties associated with it, uncovering how the former may in fact be motivated by the latter. The key idea on which this type of approach is based is that, in inverse analogy to focus, given elements prefer to avoid surfacing in a syntactic position which is assigned prosodic prominence by default. Šimík and Wierzba (2015) argue in favour of such an account of the word order effects of givenness in Czech, one example of which was cited above. They show that, in the absence of stress shift, Czech disfavours a new " given ordering of arguments if and only if the given element is in a sentence-final position, where it receives the default nuclear stress (see also Šimík et al. 2014; Šimík \& Wierzba 2017). Under this approach word order interacts with givenness via the prosodic needs of given constituents.

It is worth noting that this general type of account is only applicable to languages in which givenness (or rather, the particular type of givenness at issue) imposes special prosodic requirements. While in many languages givenness is associated with deaccentuation, this is not a universal property. For instance,

4. In Italian familiarity topics are less restricted than the other topic types in that, due to some other constituents' options for movement in the clause, they may linearly en up either at the right or the left periphery; see Frascarelli and Hinterhölzl (2007).

5. For a flexible syntactic approach to focus, see Neeleman and van de Koot (2008); for a hybrid syntactic/prosodic flexible approach to focus in Hungarian, see Surányi (2012). 
in languages like Italian and Romanian the givenness of a constituent does not license its deaccenting (Ladd 2008: 323; see Ladd 1990).

In this section we have reviewed some of the key notions of givenness, along with several prominent approaches to its grammatical marking. Before proceeding to present our experiments, in what follows we provide the relevant background on Hungarian.

\section{Background on Hungarian}

\subsection{Free word order in the post-verbal field}

Hungarian is a discourse-configurational language that has both a Topic and a Focus position in its sentence structure (É. Kiss 1995). The focus position is unique: focus is canonically situated immediately before the finite verb. Topics, which are recursive, precede the comment, thus they are located to the left of the verb, and also to the left of the pre-verbal focus, if there is one. The standard structural analysis of the Hungarian sentence is given schematically in (4a). (4b) spells out a possible implementation of this constituent structure in terms of functional projections. ${ }^{6}$ The Topic position houses aboutness topics or contrastive topics (É. Kiss 2002; Gécseg \& Kiefer 2009). Aboutness topics are generally shifted topics.

(4) a. [Topic ${ }^{\star}[$ Focus $\left.[\mathrm{V}[\mathrm{XP} \ldots \mathrm{YP}]]]\right]$

b. $\quad\left[_{\text {TopP }}\right.$ Topic $\left[_{\text {TopP }}\right.$ Topic $\left[{ }_{F o c P}\right.$ Focus $\left[{ }_{F o c} \mathrm{~V}\right][V$ P XP ... YP $\left.\left.\left.]\right]\right]\right]$

Example (5) below exemplifies a sentence in which the object is topicalized to a pre-verbal position. If the verb has a verbal particle, then in broad focus sentences like (5), it is immediately pre-verbal.
a. Pistá-t el-vitték
a Bahamák-ra
Steve-ACC PRT-take.PAST.3sg the Bahamas-onto
'Steve was taken to the Bahamas.'

While the pre-verbal domain of the Hungarian sentence has been described in terms of a hierarchical structure within which different word orders give rise to different assignments of topic and focus information structural roles, the structure of the post-verbal domain has been a matter of controversy. Post-verbal constituent order has been described as "free" (including both arguments and adjuncts) in

6. A number of proposals have been offered in the literature that implement (4a)) in different ways (e.g. Bródy 1995; Puskás 2000; É. Kiss 2002). The choice among the different alternatives will be immaterial for our present purposes. 
the sense that different orders are not mapped to differences in the distribution of topic and focus functions:
a. El-magyaráztam a feladat-ot
a diákok-nak. PRT-explained.1SG the assignment-ACC the students-DAT 'I explained the assignment to the students.'
b. El-magyaráztam a diákok-nak a feladat-ot. PRT-explained.1SG the students-DAT the assignment-ACC 'same'

One point of debate has been whether or not the post-verbal domain has hierarchical surface structure, showing structural asymmetries between subject and object arguments, or whether this domain of the sentence is best analyzed as structurally "flat", with major constituents in sister positions. The best elaborated account is É. Kiss's analysis, who argues forcefully in a number of studies (1987, 1994, 2002, 2008 ) in favor of the "flat" view of the surface structure of the post-verbal domain. Surányi $(2006 \mathrm{a}, \mathrm{b})$ advocates a right-branching hierarchical analysis of the postverbal domain, proposing a scrambling movement based account of the free postverbal order of major constituents. Importantly from the present perspective, the scrambling operation does not affect the assignment of topic or focus roles according to this movement based approach either.

While the order of non-focal post-verbal constituents is syntactically free, it may be modulated by non-syntactic factors. These may include specificity and human reference (É. Kiss, 2002), as well as "phonological weight", which is subject to Behagel's (1932) law of growing constituents (according to which shorter constituents precede longer ones; É. Kiss 2008).

\subsection{Givenness in Hungarian}

There have been few attempts to characterise the role of givenness in Hungarian. In the remainder of this section we briefly summarise existing proposals regarding the effect of givenness in prosody, and in syntax.

It is not clear whether or not information structurally given material is, as a rule, deaccented in Hungarian, and as far as we are aware, there is no experimental evidence to back up either position. According to Varga $(1981,2002)$ and Gyuris (2012), given elements are deaccented as a rule. Although they do not explicitly make this point, Kálmán and Nádasdy (1994) do not posit that givenness based deaccenting is a general process in Hungarian as an obligatory process. They suggest, however, that obligatory deaccenting applies, in the presence of a pre-verbal narrow focus, to (non-focal) background elements in the post-verbal domain (a view also shared by Vogel \& Kenesei 1987, and Kenesei \& Vogel 1989). They also 
claim that pre-verbal given topics preceding a pre-verbal focus are deaccented as an option (Kálmán \& Nádasdy 1994: 459).

There are few studies that make any mention of the role of givenness or newness in post-verbal constituent order. Varga (1981:200) is a notable exception. He provides the pair of examples in (7b) and (7c), noting that the order of the postverbal elements is free as long as both of them are informationally new or both of them are given.
a. Mit csinált a konyhá-ban?
what do.PAST.3sg the kitchen-in
'What did he do in the kitchen?'
b. Be-gyújtott a konyhá-ban a fi-á-nak. 'He lit a fire in the kitchen for his son.' PRT-lite.PAST.3SG the kitchen-in the son-POSS-DAT
c. Be-gyújtott1 a fi-á-nak a konyhá-ban. PRT-lite.PAST.3sG the son-POSS-DAT the kitchen-in 'He lit a fire for his son in the kitchen.'

Varga goes on to suggests that in a context like (7a) while (7b) is natural, (7c) is unacceptable (which he marks with an asterisk, indicating ungrammaticality). $\mathrm{He}$ does not provide a description of the grammatical mechanisms that are responsible for this asymmetry, but formulates the generalization that in case the postverbal part of the comment contains a given element and a new element, then the new, and consequently accent-bearing, element may only occur in the commentfinal position.

É. Kiss $(1996,1998)$ points out that Varga's (1981) prosody-based generalization regarding given and new post-verbal elements fails to apply in sentences containing two narrow foci, one of them in the pre-verbal slot and the other in a post-verbal position. In her judgment, in such sentences an informationally new post-verbal focus is preferably not comment-final in the presence of an additional informationally given element; instead, the post-verbal focus prefers to precede any given phrases. She proposes that this is because in a double focus sentence the post-verbal focus does not occupy an in situ position, but instead, extending the functional structure in (4b), it is located in a higher, functional specifier position: it is raised to a post-verbal FocP. Since given argument phrases normally remain low in their argument positions, they linearly follow this post-verbal focus. É. Kiss acknowledges that post-verbal given material may also occur to the left of the post-verbal focus, but she suggests that this material is topical (or else it is quantificational, a special case that is irrelevant to our present concerns). She argues that while such post-verbal topics are not interpreted as aboutness topics, they nevertheless do possess topic properties: they must be interpreted as specific 
or definite (referential). Thus, the relevant part of the functional structure É. Kiss (1998) proposes for the post-verbal region of Hungarian is an iteration of the relevant portion of the functional structure in the pre-verbal field: ${ }^{7}$

$$
\left[{ }_{\text {TopP }} \ldots\left[_{\text {FocP }} \ldots \mathrm{V} \ldots\left[_{\text {TopP }}\left[\ldots\left[\left[_{\text {FocP }} \ldots\right]\right]\right]\right]\right]\right.
$$

In summary, É. Kiss's $(1996,1998)$ proposal differentiates between topical and non-topical post-verbal given elements, without making direct reference to pure givenness. On the assumption that the domain to the right of the lowest discourserelated functional projection, which is comprised by elements that are neither focal nor topical, exhibits free word order, a non-topical given element is expected to be able to both precede and follow a non-focal new element, while a topical given element is predicted to precede it.

\section{Experimental treatment}

While there have been proposals for the existence of givenness related word order effects in Hungarian, no formally gathered empirical evidence is available to support them. In order to explore these effects, we present the results of a forced choice experiment that addresses this issue. The experiment was part of a series of experiments that have been designed to look at the effects of Focus and Givenness on the word order of post-verbal constituents in Hungarian. The scope of this paper is limited to the analysis of the effects of topical givenness alone.

\subsection{Methods and materials}

Participants were asked to complete a two-alternative forced choice experiment. In each step of the experiment they were presented with a context question, and two possible answers, which only differed in the linear order of their two postverbal phrases. The task of the participants was to read the context question first, and then to pick the answer which they felt was the more felicitous. The dependent variable to be analyzed was the proportion of word orders chosen in relation to the total number of responses recorded for each condition.

7. A similar set of iterated A-bar projections is proposed by Szabolcsi (1997). A partial representation is given below. RefP can only be occupied by (non-focal) referential phrases, including definite NPs. Movement to the post-verbal RefP, however, is not assumed to be overt.

(i) $\quad[\operatorname{HRefP}[\ldots[\operatorname{FocP}[\operatorname{AgrSP} V[\operatorname{RefP}[\ldots[\operatorname{FocP} \ldots]]]]]]]$ 
The context for each condition was presented in the question, while the two answers represented two possible word order realisations of the same target sentence. A template is given in (9), in which the two word orders are labeled as 'Answer 1' and 'Answer 2'. We will use the term target sentence to refer to the pair of sentences presented as possible answers, abstracting away from their post-verbal word order.

\section{(9) Context question}
a. Answer 1: TOPIC V XP YP
b. Answer 2: TOPIC V YP XP

A total of 16 lexicalizations matching this template were created.

The target sentences always contained a topic, which was followed by a verb, and two post-verbal constituents. The topic functioned as a grammatical subject, and it was invariably a singular definite expression referring to a person. Formally, it was either a proper name or a noun phrase consisting of a definite determiner and a noun. The verb may or may not have contained a verbal prefix. As noted in above in Section 2, a number of factors may influence the word order preferences regarding post-verbal constituents. In order to isolate the effects of givenness, the two constituents were matched for other possible factors that might possibly have an effect or ordering preferences. They were both adjuncts, to rule out asymmetrical argument structural relations. They were both of the same syllable count to rule out any effect of prosodic weight (i.e. Behagel's law of growing constituents). They were both specific and definite. Finally, the two post-verbal phrases were also matched for animacy.

In order to further counterbalance the experiment and to rule out any possible lexical effects that might influence word order preferences, the set of participants was divided into two groups. If in Group 1 one of the two post-verbal phrases, say $\mathrm{XP}$ in (9), was Given, then in Group 2 it was the other post-verbal constituent, namely YP in (9), that had a Given status; and vice versa.

Each trial was displayed on a separate screen. The context setting question appeared at the top of the screen, and the two answers representing two possible post-verbal word orders of the target sentence appeared in the centre of the screen, one below the other. Within each trial, the presentational order of the two answers was randomized in order to remove any presentational bias.

The experiment consisted of four conditions, and followed a Latin square design, based on four counterbalanced lists of critical items. Within each list, each condition was represented by four items. Each participant saw each of the sixteen lexicalizations in one of the four conditions. Of the four conditions the present paper considers only those that are relevant to the analysis of the effects of Givenness on post-verbal word order preferences. 
In particular, we analyze two conditions: (i) a critical condition, and (ii) a baseline condition. In the baseline condition both post-verbal phrases were new. In the critical condition one of the two post-verbal phrases was new, while the other one was given. In particular, the given phrase had a linguistically matching antecedent in the context setting question that was syntactically marked there as an aboutness topic. This lent the given phrase in the target sentence both textual and topical givenness. Neither the critical nor the baseline items contained a narrow focus, i.e., they were all broad focus sentences.

Table 1 presents an overview of the experimental conditions analyzed in this study.

Table 1. Experimental conditions

\begin{tabular}{lll}
\hline Conditions & One of the post-verbal phrases & The other post-verbal phrase \\
\hline Baseline condition & new & new \\
Critical condition & textually given + topical & new \\
\hline
\end{tabular}

A sample target sentence is given in (10), showing the two possible word order realisations that formed the alternatives in the forced choice task.
a. Az unoká-m
be-vásárolt
[a hétvégé-n]
the grandson-POss PRT-buy.PAST.3sG the weekend-on
[a csarnok-ban].
the hall-in
'My grandson did the shopping on the weekend in the market hall.'
b. Az unoká-m bevásárolt [a csarnok-ban] the grandson-POss PRT-buy.PAST.3sg the hall-in
[a hétvégé-n].
the weekend-on
'My grandson did the shopping in the market hall on the weekend.'

In the baseline condition the target sentence was presented with a context question that determined both post-verbal constituents to be contextually new. The relevant question for (10) is presented in (11).
(11) Hogy segít neked Andris? How help.3sg you.DAT Andrew 'How does Andrew help you?'

This context question did not contain any of the post-verbal constituents, therefore givenness was not expected to play a role in the word order choices of the participants. It was hypothesised that this condition would induce the choices between the two candidates in (10) to be at chance levels, thus the baseline 
condition would serve as the basis of comparison against which the effects of givenness could be measured. If the results indeed reflect chance levels, then that also confirms that biases for possible word orders have been successfully controlled for. Note, however, that this condition properly fulfills its role as a baseline even if it does not yield chance level results, i.e., if it turns out that due to some hidden factor(s) we find that participants exhibit a certain degree of preference towards one of the two orders. This is because the same factor(s) are expected to also be present in the matched target sentences of the critical condition. What is crucial is whether the critical condition reveals a significant difference as compared to this baseline. ${ }^{8}$

In the critical (new-given) condition, givenness was elicited in two ways. First, the context question contained an antecedent phrase that was textually identical to one of the two post-verbal phrases in the answer (this will be referred to as the target phrase). Second, the given phrase was also syntactically marked as a syntactic topic in the context question, which is a reliable trigger of an aboutness topic interpretation in Hungarian. We assumed that marking the target constituent as an aboutness topic (A hétvégén in (12a)) in the context question would make this phrase topical in the target sentence: it would have the effect of interpreting this constituent as a familiarity topic.

An example of a pair of context questions used in the critical condition is given in (12).
a. A hétvégé-n
mit csinált
Andris?
the weekend-on what do.PASt.3sg Andrew
'What did Andrew do on the weekend?'
b. A csarnok-ban mit csinált Andris? the hall-in what do.PAST.3sg Andrew 'What did Andrew do in the market hall?'

The context questions shown in (12) contain one of the post-verbal constituents of the target sentence, which is a hétvégén 'on the weekend' in (12a), the context question presented to Group 1, and a csarnokban 'in the (market) hall' in (12b), the context question presented to Group 2. The hypothesis was that if the type of givenness employed in the experiment has an effect on the word order of the postverbal constituents, then this preference will be reflected in a significant difference between the results of the baseline and the new-given conditions.

8. We are making the simplifying assumption here that the potential hidden factor(s) at issue have the same effect in the critical condition as in the baseline condition. 
The experiment was conducted with 192 participants $(171 \mathrm{f} / 21 \mathrm{~m}$, age range: $18-85$, mean $=54)$. Participants were volunteers recruited online through advertisements posted on the social networking site Facebook.

The dependent variable was the ratio in which participants chose one possible word order over another in the contexts provided. The ratios were analyzed with the progam R (version 3.3.0, R Core Team, 2013), using logistic mixed effects models implemented with the lme4 package (Bates et al. 2015), where the fixed effects were the conditions (critical and baseline), and the random effects were the participants and the target sentences. A series of models were fitted, and the most parsimonious model was selected by backward elimination, using ANOVAs.

The models calculated the slope and intercepts for both random effects. Additionally, pairwise comparisons were conducted using the lsmeans package, with Tukey correction. These compared all conditions that formed part of the larger experiment. Below we will only include the two conditions in Table 1. Finally, we also checked, using a one-sample $t$-test, whether or not the proportion of the two selected orders in the baseline condition was significantly different from chance level. The following section will describe the results of the experiment.

\subsection{Results}

As reflected in the plots in Figure 1, a substantial difference seems to surface between the ratios of the selected word orders in the two conditions.

After fitting logistic mixed effect models, pairwise comparisons were run. The results indicate that givenness had a significant effect on the word order preferences: participants favoured the placement of the given item in the immediately post-verbal position over having it in the clause-final position (z-ratio $=2.26, p=$ 0.044 , standard error: 0.105$)$. The results of the one-sample $t$-test that compared the baseline condition to chance level revealed that participants' choices in this condition did not differ from chance level.

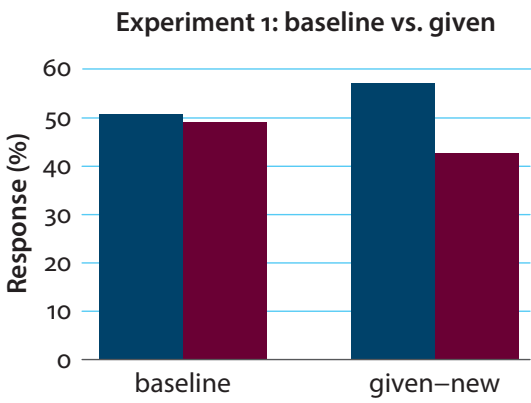

Figure 1. Placement of target item in the baseline and new-given conditions. red $=$ target item in clause final position, blue $=$ target item in immediately post-verbal position 


\subsection{Discussion}

The foregoing outcomes reveal that, at least when textual givenness is coupled with familiarity topic status, the immediately post-verbal positioning of the given phrase is favoured over its clause-final placement. Thus, free word order in the Hungarian post-verbal field is sensitive to topical givenness in that, when other factors are appropriately controlled for, a given » new ordering preference emerges.

This result is convergent with Varga's (1981) intuitions regarding the superiority of the given " new order as compared to the new " given linearization after the verb. The convergence is only partial for two reasons. First, rather than applying to givenness across the board, the effect is only shown here to cases of topical givenness (cf. Section 2.1). Second, our results suggest that the effect does not involve a categorical difference between word order choices, which would be indicative of a grammatical distinction between the possible word orders (as implied by the asterisk assigned to the new " given order in Varga 1981: 200). Instead, the responses appear to reflect tendencies or preferences. Having said that, the convergence with the pattern laid out by Varga (1981) seems sufficiently clear. ${ }^{9}$

As noted in the introduction, there are two main routes that can be taken in modelling word order effects of givenness. Givenness-related syntactic alternations may be assumed to reflect givenness directly, implicating the mapping between syntax and information structure. Alternatively, they may be motivated by the prosodic needs associated with givenness, rendering the syntax-givenness relation indirect. In the next section we first consider how our results may be interpreted in terms of the syntactic proposals reviewed in Section 2.2, and then we explore the prospects of an indirect prosodic approach.

\section{General discussion}

\subsection{Syntactic approaches}

As will be recalled from Section 2.2, Kučerovás $(2007,2012)$ flexible syntactic approach posits a givenness-operator (G-operator) that imposes the presupposition that elements that c-command it within a propositional unit are given. It follows from the Maximize Presupposition principle (Heim 1991) that in a language whose syntax is sufficiently flexible to permit it, all given phrases will c-command all new phrases. In turn, assuming that the domain at issue in which

9. As we came across the relevant passage of Varga's (1981) squib only after we have designed the experiments and analysed their results, we find this convergence strongly suggestive that the effects we have found are real. 
the relevant structural reordering takes place is right-branching, this will linearly order all given phrases before all new phrases. Recall also that the property of givenness that is imposed by the G-operator in Czech includes a combination of givenness and specificity (see footnote 2). As the post-verbal given phrases in our experiment were definite NPs, they satisfy the requirement of specificity.

One serious complication for a G-operator approach is related to the syntactic domain to which its ordering effect needs to be limited. On Kučerovás proposal the givenness operator divides the clause (for her, a propositional domain) into a given and a non-given portion (Kučerová 2012: 14): all material above the G-operator is given, and all material below it is new. This does not seem to hold for Hungarian. It is in fact the norm in Hungarian to place new information into a position before the verb, which is normally higher than elements of the postverbal field, given the right-branching character of Hungarian clause structure. As reviewed in Section 3.1, Hungarian clause-structure is generally assumed to be hierarchical and right-branching all the way from its left edge at least to that head-initial projection whose head is overtly filled by the verb. In order for it to be viable in the first place, the G-operator-based account of the post-verbal ordering preference furthermore presupposes that the surface structure of the post-verbal domain too is hierarchical and right-branching. This is compatible with Surányi (2006a, b), though not with É. Kiss (1987, 1994, 2002, 2008); see Section 3.1 above. In all sentences that contain an informationally new exhaustive focus, the focus routinely occupies the pre-verbal position, independently of the givenness status of any post-verbal constituents. This is represented schematically in (13a). It might be argued, however, that this type of systematic counterexample is irrelevant, if one assumes that the pre-verbal focus is located outside of what Kučerová describes as a 'propositional' unit. If so, a range of other systematically available word orders make the same point. For instance, as schematized in (13b), in broad focus sentences an informationally new bare noun phrase argument normally also appears in an immediately pre-verbal position, again independently of whether or not any of the post-verbal phrases, which it c-commands, is given (for illustrative examples, see É. Kiss 2002: Chapter 3.6). The same holds of manner and other predicate phrase internal adverbials, which routinely occupy a (not necessarily immediately) pre-verbal position when they are informationally new, again irrespective of the givenness of post-verbal phrases; see (13c) (for an example, see É. Kiss 2002: 21, (24a)).
(13)
a. Focus $_{\text {new }} \mathrm{Verb}_{\text {given }} \mathrm{XP}_{\text {given/new }} \mathrm{YP}_{\text {given/new }}$
b. Bare- $\mathrm{NP}_{\text {new }} \mathrm{Verb}_{\text {new }} \mathrm{XP}_{\text {given/new }} \mathrm{YP}_{\text {given/new }}$
c. $\mathrm{ADV}_{\text {new }} \mathrm{Verb}_{\text {new }} \mathrm{XP}_{\text {given/new }} \mathrm{YP}_{\text {given/new }}$ 
In view of such facts, the domain of application of the G-operator would have to be restricted to the post-verbal domain in Hungarian. Effectively, the operator must be stopped from imposing the presuppositon of givenness on any c-commanding phrase above the surface position of the verb. While this could be doable, it would be stipulative, since it would limit the effect of the G-operator to what is considered a smaller-than-propositional clausal unit on most extant analyses of Hungarian clause structure. This in itself makes the approach less attractive to account for our experimental results. In fact, limiting the G-operator's application to the empirically required linearly post-verbal domain may well be a non-trivial task if the structural 'height' at which the verb surfaces is not constant across the various constructions, i.e. if the verb raises to a higher or lower position within the clausal functional hierarchy depending on what occurs in the pre-verbal domain (see Bródy 1995; Puskás 2000; É. Kiss 2002).

A second major challenge to the G-operator approach is the fact that that approach predicts a much greater effect of givenness on word order than we have found (see Šimík \& Wierzba 2017 for the same issue posed by their Czech experimental data). The degradation that results from leaving a given element below the G-operator is due on Kučerovás theory to the violation of Heim’s (1991) Maximize Presupposition. Indeed, violations of this principle generally give rise to a relatively perceptible infelicity, as illustrated by the sentence in (14b), uttered in a context in which it is part of the common ground that the speaker has exactly one neighbour (14a).

(14) a. Common ground: the predicate 'neighbour of mine' has a unique individual in its extension.

b. \#A neighbour of mine broke into my attic.

By contrast to this type of infelicity, what our results from Hungarian reflect is a preference of one post-verbal order over the other, rather than a sharp difference between the two. This remains unexplained under a G-operator based analysis.

It seems fair to conclude, then, that a G-operator based account of our empirical findings has little to offer itself.

Let us turn now to how a cartographic approach could handle the current empirical results. As will be recalled from Section 3.2, É. Kiss $(1996,1998)$ offered a syntactic analysis of the post-verbal domain of Hungarian in terms of discourserelated functional projections. The relevant parts of this analysis are reproduced in (15) below for convenience. É. Kiss suggested that when two identificational foci are present in the Hungarian clause, the post-verbal focus occupies a post-verbal FocP position, which may be preceded within the post-verbal field by topics.

$$
\left[\left[_{\text {Focus } P} \text { Focus Verb }\left[{ }_{\text {TopicP }} \ldots\left[_{\text {Focus } P}[\ldots \text { (in situ) ...] }]\right]\right]\right]\right.
$$


In order to be able to adopt this analysis as a model of our experimental findings, assume now that a post-verbal TopP may be present even in the absence of a postverbal FocP, i.e., when no focus appears in the post-verbal domain. This is a natural assumption, as both TopP and FocP, including their pre-verbal instantiations in Hungarian, are generally taken to be projected only when a corresponding topic and focus element is present.

For the sake of the argument, we may support the postulation of a postverbal topic position in Hungarian by making a combination of two points. First, É. Kiss herself does not specify what type of topic interpretation is assigned in this position, but notes that it is not an aboutness topic interpretation. We suggest that elements in this position could be viewed as familiarity topics in the sense of Givón (1990), Lambrecht (1994) and Frascarelli and Hinterhölzl (2007). Second, as noted in Section 2.2, Frascarelli and Hinterhölzl (2007) demonstrate that FamP, the position of familiarity topics, is relatively low in Italian (see (3). It is lower than the position of aboutness and contrastive topics. Indeed, in Hungarian too both of these are located higher than the purported topic position in the post-verbal domain (namely, aboutness and contrastive topics are in the pre-verbal field, see Section 3.1). In Italian, FamP is also lower than the position of a fronted focus. Indeed, the position in question is lower than the canonical (pre-verbal) position of focus in Hungarian clause structure too.

The cartographic analysis under consideration then posits a dedicated immediately post-verbal position in Hungarian for topical items. This makes such an analysis seem highly suitable to treat the present result that topical given elements favour an immediately post-verbal placement over the clause-final position. Let us consider then (16) below as the structural analysis of those target sentences in which the given element preceded the new element.

$$
\text { [ Prt-Verb }\left[_{\text {FamP }}\right. \text { given ... [ ...new ...]]] }
$$

One challenge to this type of approach is posed by the preferential nature of the word order phenomena at issue. While movement to the pre-verbal topic position is practically obligatory in Hungarian, and indeed, movement of all topic types is obligatory in Italian according to Frascarelli and Hinterhölzl, this is apparently not the case for the post-verbal topic position that is hypothesized to play a role in our experimental data.

More detrimentally to the account under consideration, the very existence of a post-verbal FamP projection is dubious. First, there are no strong positional arguments in its favour. For instance, as shown in (17) below, a post-verbal familiarity topic can not only precede but it can also follow a post-verbal focus. Second, it is expected that non-specific bare NPs cannot occur in the FamP position, since topics must be specific (including definites and specific indefinites). This, however, 
is disconfirmed by data such as (18), in which the object gyógymódot 'cure' is a non-specific bare nominal. ${ }^{10}$

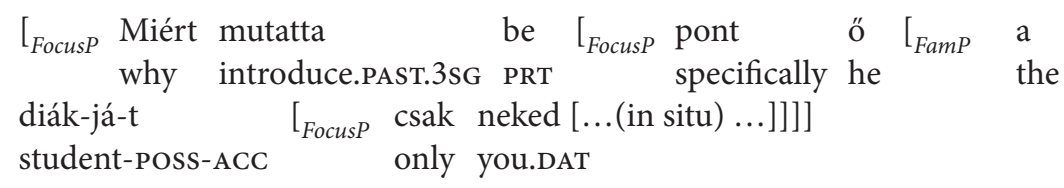

'Why was it specifically him who introduced his student only to you'

(18) Ki fejleszt-ene ki gyógymód-ot pont erre who develop-COND.3SG PRT cure-ACC specifically this a betegség-re?

the illness-for

'Who would develop (some sort of) a cure specifically for this illeness?'

In the foregoing we have examined a flexible and a cartographic syntactic approach to the outcomes of our experiment, and have found that they face a number of difficulties. Two types of issues appear to stand out. First, both approaches are difficult to make consistent with other facts of Hungarian that fall outside the explanandum at issue.

Second, they have no story to tell as to why the detected effects are 'merely' preferential. In the remaining part of this section, we explore an alternative, prosodic approach, which is potentially able to give a more principled explanation of the facts at hand.

\subsection{A prosodic approach}

The prosodic approach to the uncovered word order effects of givenness that we would like to put forward is, in a sense, the inverse of the suggestion made by Varga (1981). As we pointed out in Section 3.2, Varga (1981: 200) claimed that if the post-verbal field is comprised by a new and a given element, then it is the new, and

10. An example similar to (18) is discussed by É. Kiss (1998: 26), reporting that some speakers disprefer the 'bare NP » focus' order to the 'focus » bare NP' order in the post-verbal field, the latter of which is reproduced in (i). As in this example the bare NP contains an adjectival modifier, it may be that some speakers interpreted the bare NP as another focus. When interpreted as a focus, it falls within the scope of the other post-verbal focus ('only John') on the most plausible interpretation of the sentence (given in (i)). As this relative scope is reflected in the linearization in (a), this might be the reason why some speakers preferred this order.

(i) Melyik teszt-ben követett el CSAK JÁNOs súlyos hibá-t. which test-in made.PAST.3sG PRT only John fatal mistake-ACC 'Which test is such that it was only John who made a grave error in it?' 
therefore accented, element that must be sentence-final. Although Varga does not comment further on the grammatical mechanisms underlying this generalization, the formulation of his generalization seems to imply that the comment-final (or sentence-final) position better serves the prosodic needs of the new element than a comment-medial position would. This reasoning would be analogous to that of Šimík and Wierzba (2017) proposed for Czech, in that it takes the the syntactic order of given and new elements to be ultimately regulated by prosodic needs. At the same time, it differs from Šimík and Wierzba's account in that it views the prosodic requirements associated with newness, rather than givenness, as the key driving force in Hungarian. This latter hypothesis is difficult to maintain, however, because newness generally seems to be a prosodically and information structurally unmarked status, with no special prosodic requirements (Selkirk 2008; Katz \& Selkirk 2011; Féry \& Ishihara 2010); only focus needs to receive special (nuclear) prominence. Further, it incurs no deviation from default prosody for a new element to receive an accent in a sentence-medial position.

Instead, we propose to adopt the inverse perspective, namely the one put forward by Šimík and Wierzba’s (2017) for Czech (and more generally, West Slavic). A key ingredient of their approach is that in these languages the sentence-final position is the default position of nuclear stress. The nuclear stress is commonly taken to be more prominent than any other stresses located in the same prosodic domain.

By analogy, here we submit the following claim for Hungarian:

(19) The right edge of the Hungarian sentence is prosodically special in that by default it is aligned with special prosodic prominence.

According to (19), in a default syntax-prosody mapping the right edge of the sentence is a position that is prosodically more prominent than clause-internal positions, including the position of any other post-verbal element. Admittedly, as it stands, the claim formulated in (19) is informal, leaving open various issues of implementation. It can be formally implemented in a number of different conceivable ways, but since our paper has an empirical focus we prefer to remain agnostic with regard to these choices here, leaving a formal treatment for another occasion.

Šimík and Wierzba's (2017) hold that in the absence of stress shift, Czech disfavours a new » given ordering of arguments if the given element is in a sentencefinal position, because in that position the given item is aligned with the default position of the nuclear stress. This, in turn, represents a mismatch between the default prosodic pattern and the prosodic requirement associated with givenness, which in Czech they take to be deaccenting. Scrambling a given element away from a clause-final position, yielding a given » new order, has the beneficial consequence that the (scrambled) given element can be deaccented, as required, without 
diverging from the default alignment of the special clause-level prominence with the end of the clause (now occupied by a new element). Thus, leaving the given phrase in its clause-final position would either result in a deviation from default sentence prosody (if the given element is deaccented), or else the deaccenting requirement of givenness would have to be violated.

On the syntactic side, the approach only needs to assume that the derivation of a scrambled word order is either syntactically costless, or its cost is lower than the cost that would be incurred by deviating from the default prosodic pattern. Considering Hungarian, we can make the same assumption in a scrambling-based analysis of the post-verbal field (Surányi 2006a, b), while on the flat structural analysis of this field advocated by É. Kiss (1987 et seq.) the equal cost of different linear orders is the null hypothesis. But independently of the syntactic analysis of the Hungarian post-verbal field, if we assume that the attachment of adjuncts is syntactically free, then due to the adjunct status of both post-verbal phrases in our target sentences, neither of the two linearizations is expected to incur higher syntactic cost than the other. Thus, as far as the syntax is concerned, a Šimík and Wierzba-style approach can be straightforwardly adapted to Hungarian.

The crucial assumption that this account of our results needs to make is that topical givenness can lead to deaccenting in Hungarian. The hypothesis that it is possible (though not obligatory) to deaccent given topical elements in Hungarian is not without antecedent. Although they restrict it to sentences containing a narrow focus, Kálmán and Nádasdy (1994) make the claim that preverbal aboutness topics are optionally deaccented in Hungarian when they are given (see Section 3.2). Our suggestion is that this phenomenon is more general, and it carries over to post-verbal familiarity topics too: it is topical givenness, independently of aboutness, that licenses optional deaccenting.

To sum up, a possible prosodic account of the outcome of our forced-choice experiment is based on the following assumptions regarding Hungarian:

(20) a. Topical textually given elements may be deaccented.

b. The end of the clause is a distinguished position in that it is aligned in a default syntax-prosody mapping to special prosodic prominence; a deviation from this alignment is prosodically marked

c. Other things being equal, neither one of the possible linearizations of two post-verbal adjunct phrases is syntactically more costly than the other

On this account, it is the prosodic markedness in (20-b) that ultimately triggers the word order preference detected in our experiment. The markedness is simply the result of the fact that a non-default prosodic form is used even though a default prosodic form would also be available, with a different, but syntactically no less 
economical (i.e. no less marked) word order targeting the same semantic interpetation and information structure (cf. Reinhart 2006).

The fact that the preference we have found is relatively mild can also receive an explanation on this approach. First, in general, prosodic markedness does not necessarily have the status of grammatical ill-formedness. Second, independently of the status of the marked prosodic form, the mildness of the preference also follows if deaccenting of topical given elements is optional rather than obligatory (in line with the suggestion made by Kálmán and Nádasdy 1994).

\section{Conclusion}

This pioneering study explored the effect of givenness on post-verbal constituent order in Hungarian, addressing the issue experimentally for the first time.

Based on a two-alternative forced choice experiment, it was found that in the case of topical textually given elements, speakers prefer a given » new order to a new " given order: they opt for placing the given constituent in the immediately post-verbal position rather than in the clause-final position in sentences containing two post-verbal phrases.

Examining a flexible and a cartographic syntactic approach to these outcomes, it was concluded that while these accounts are feasible when it comes to the attested linear asymmetry itself, they face difficulties when faced with additional empirical facts of Hungarian. Furthermore, these approaches have no straightforward explanation for the preferential nature of the uncovered effect.

The prosodic approach that we have proposed, which successfully avoids these problems, holds instead that in Hungarian (i) the right edge of the clause is aligned in default syntax-prosody mapping to special prosodic prominence, as compared to clause-internal post-verbal positions, and (ii) (topical givenness) licenses deaccenting.

While (ii) is an extension of a claim made by Kálmán and Nádasdy (1994) and it is an instantiation of the special relation between givenness and reduced prominence in stress-accent languages in general, the proposal in (i) is new in the form presented here, and we have left the issue of its implementation open.

The degradedness of the new " given order as well as the preferential, rather than categorical, nature of this degradation are then explained in terms of the marked status of prosodic forms (namely, those associated with a new " given order) that involve a deviation from default prosody in the presence of an available syntactic alternative that licenses a different word order (namely, the given » new order) in which the same prosodic deviation is avoided. 
While such a prosodic approach successfully explains the pattern found in the experiment, it opens up certain empirical questions, as well as questions for existing theories of the Hungarian prosody-syntax interface, which are, however, beyond the scope of this paper to begin to explore, let alone conclusively settle. It may nevertheless be worth concluding by spelling out the most relevant issues in the hope that they offer worthwhile new perspectives for future research.

An outstanding empirical issue raised by our prosodic approach is whether the claim made regarding the deaccenting patterns associated with topical givenness stands up to empirical scrutiny in prosodic production (though see Genzel et al. 2015 for some relevant confirmatory evidence). An additional empirical question of immediate relevance is whether and which other types of givenness, in addition to topical givenness, have a similar ordering effect in the post-verbal field as the one that we reported here.

Two points made in Section 2 are of immediate relevance to this issue. First, the association of givenness with deaccentuation is subject to cross-linguistic variation. Second, givenness is a family of closely related yet different notions, and furthermore different types of givenness may be combined with each other. Therefore it may also be subject to variation which type of givenness a language associates with deaccenting. The only expectation in this regard is a priori: namely, if there is an implicational relation holding between two different types of givenness (or combinations thereof), then this implicational relation will be reflected in their prosodic marking, and a fortiori, in their ordering preferences in the Hungarian post-verbal field.

Another key issue concerns the status of the special prosodic prominence that is assumed to be located at the end of the clause by default. On current assumptions of prosodic phonology, this prominence must be associated with a prosodic position at the right edge of some high-level prosodic constituent aligned with the right edge of the clause. What is the nature of this constituent in terms of the prosodic hierarchy, and how is it derived in a default syntaxprosody mapping (for different views of the syntax-prosody mapping, see Vogel \& Kenesei 1987, 1990; É. Kiss 1994; Hunyadi 2002; Varga 2002; Szendrői 2003; Surányi et al. 2012)? Do sentences with given » new and new " given orders correspond to the same prosodic structure or different prosodic structures, apart from accentuation (and strictly concomitant phonological phrase formation)? At a more theoretical level, how does the assumption of a special right-edge prominence bear on models of the directionality of prosodic heads in Hungarian (Kálmán \& Nádasdy 1994; É. Kiss 1994; Varga 2002; Vogel \& Kenesei 1987; Kenesei \& Vogel 1989; Szendrői 2003), and more generally? How do they bear on the prosodic headedness of broad focus sentences (Katz \& Selkirk 2011)? All these are non-trivial issues that point to intriguing avenues for future research. 


\section{References}

Ariel, Mira. 1990. Accessing noun-phrase antecedents. London: Routledge.

Ariel, Mira. 1991. The function of accessability in a theory of grammar. Journal of Pragmatics 16(5). 443-463. https://doi.org/10.1016/0378-2166(91)90136-L

Arnold, Jennifer E. 1998. Reference form and discourse patterns. Stanford University dissertation. Asher, Nicholas. 2004. Discourse topic. Theoretical Linguistics 30(2-3). 163-201.

Bates, Douglas, Martin Mächler, Ben Bolker \& Steve Walker. 2015. Fitting linear mixed-effects models using lme4. Journal of Statistical Software 67(1). 1-48.

https://doi.org/10.18637/jss.v067.io1

Baumann, Stefan. 2006. The intonation of givenness. Evidence from German. Tübingen: Max Niemeyer Verlag. https://doi.org/10.1515/9783110921205

Baumann, Stefan \& Martine Grice. 2006. The intonation of accessibility. Journal of Pragmatics 38(10). 1636-1657. https://doi.org/10.1016/j.pragma.2005.03.017

Baumann, Stefan \& Arndt Riester. 2013. Coreference, lexical givenness and prosody in German. Lingua 136. 16-37. https://doi.org/10.1016/j.lingua.2013.07.012

Behaghel, Otto. 1932. Deutsche syntax IV. Heidelberg: Carl Winters.

Bianchi, Valentina \& Mara Frascarelli. 2010. Is topic a root phenomenon? Iberia 2. 43-88.

Bródy, Michael. 1995. Focus and checking theory. In István Kenesei (ed.), Approaches to Hungarian 5, 29-44. Szeged: JATE.

Büring, Daniel. 1997. The meaning of topic and focus: The 59th street bridge accent. London: Routledge. https://doi.org/10.4324/9780203448014

Chafe, Wallace. 1974. Language and consciousness. Language 50(1). https://doi.org/10.2307/412014

Chafe, Wallace. 1976. Givenness, contrastiveness, definiteness, subjects, topics and point of view, 25-55. Associated Press.

Clark, Herbert H. \& Eve V. Clark. 1977. Psychology and language: Introduction to psycholinguistics. New York: Harcourt Publishers Ltd.

Clark, Herbert H. \& Susan E. Haviland. 1977. Comprehension and the given-new contract. In Roy O. Freedle (ed.), Discourse production and comprehension, 1-40. Norwood, New Jersey: Ablex Publishing.

Cowles, H. Wind \& Victor S. Ferreira. 2011. The influence of topic status on written and spoken sentence production. Discourse Processes 49(1). 1-28.

https://doi.org/10.1080/0163853X.2011.635989

Cruttenden, Alan. 1997. Intonation. Cambridge: Cambridge University Press. https://doi.org/10.1017/CBO9781139166973

van Dijk, Teun. 1976. Discourse meaning and memory. Journal of Reading Behaviour 8. 89-110. https://doi.org/10.1080/10862967609547168

van Dijk, Teun. 1981. Studies in the pragmatics of discourse. The Hague: Mouton. https://doi.org/10.1515/9783110826142

É. Kiss, Katalin. 1987. Configurationality in Hungarian. Dordrecht: Reidel Publishing. https://doi.org/10.1007/978-94-009-3703-1

É. Kiss, Katalin. 1994. Sentence structure and word order. In Ferenc Kiefer \& Katalin É. Kiss (eds.), The syntactic structure of Hungarian, 1-90. New York: Academic Press.

É. Kiss, Katalin. 1995. Introduction. In Katalin É. Kiss (ed.), Discourse configurational languages, 3-28. Oxford, New York: Oxford University Press. 
É. Kiss, Katalin. 1996. Többszörös fókusz a magyar mondatszerkezetben [Multiple foci in Hungarian syntax]. In T. Mikola, L. Büky, A. Juhász \& M. Maleczki (eds.), Néprajz és nyelvtudomány (Acta Universitatis Szegediensis de Attila József Nominatae), 47-66. Szeged: JATE.

É. Kiss, Katalin. 1998. Multiple topic, one focus? Acta Linguistica Hungarica 45. 3-29. https://doi.org/10.1023/A:1009614223777

É. Kiss, Katalin. 2002. The syntax of Hungarian. Cambridge: Cambridge University Press. https://doi.org/10.1017/CBO9780511755088

É. Kiss, Katalin. 2008. Free word order, (non)configurationality, and phases. Linguistic Inquiry 39(3). 441-475. https://doi.org/10.1162/ling.2008.39.3.441

Enc, Müvet. 1991. The semantics of specificity. Linguistic Inquiry 22(1). 51-92.

Erteschik-Shir, Nomi. 2007. Information structure: The syntax-discourse interface. Oxford: Oxford Univerisity Press.

Féry, Caroline \& Shinichiro Ishihara. 2010. How focus and givenness shape prosody. In Malte Zimmermann \& Caroline Féry (eds.), Information structure: Theoretical, typological, and experimental perspectives, 36-63. Oxford: Oxford University Press.

Frascarelli, Mara \& Roland Hinterhölzl. 2007. Types of topics in German and Italian. In Susanne Winkler \& Kerstin Schwabe (eds.), On information structure, meaning and form, 87-116. Amsterdam: John Benjamins. https://doi.org/10.1075/la.100.07fra

Gécseg, Zsuzsanna \& Ferenc Kiefer. 2009. A new look at information structure in Hungarian. Natural Language \& Linguistic Theory 27(3). 583-622.

https://doi.org/10.1007/s11049-009-9071-7

Genzel, Susanne, Shinichiro Ishihara \& Balázs Surányi. 2015. The prosodic expression of focus, contrast and givenness: A production study of Hungarian. Lingua 165. 183-204. https://doi.org/10.1016/j.lingua.2014.07.010

Givón, Talmy. 1983. Topic continuity in discourse: A quantitative cross-language study. Amsterdam: John Benjamins Publishing. https://doi.org/10.1075/tsl.3

Givón, Talmy. 1990. Syntax: A functional typological introduction. Amsterdam: Benjamins.

Gundel, Jeanette K. 1988. Universals in topic-comment structure. Amsterdam: John Benjamins. https://doi.org/10.1075/tsl.17.16gun

Gundel, Jeanette K., Nancy Hedberg \& Ron Zacharski. 1993. Cognitive status and the form of referring expressions in discourse. Language 69(2). 274-307. https://doi.org/10.2307/416535

Gyuris, Beáta. 2012. The information structure of Hungarian. In Manfre Krifka \& Renate Musan (eds.), The expression of information structure, 159-186. Berlin: Mouton de Gruyter. https://doi.org/10.1515/9783110261608.159

Halliday, Michael A. K. 1967. Intonation and grammar in British English. Cambridge, MA: MIT Press. https://doi.org/10.1515/9783111357447

Heim, Irene. 1991. Artikel und Definitheit. In Arnim von Stechow \& Dieter Wunderlich (eds.), Semantik: Ein internationales Handbuch des zeitgenossischen Forschung, 487-535. Berlin: De Gruyter.

Hunyadi, László. 2002. Hungarian sentence prosody and Universal Grammar. Frankfurt: Peter Lang.

Ishihara, Shinichiro. 2003. Intonation and interface conditions. Massachusetts Institute of Technology dissertation.

Kaiser, Elsi. 2011. Focusing on pronouns: Consequences of subjecthood, pronominalisation, and contrastive focus. Language and Cognitive Processes 26(10). 1625-1666.

https://doi.org/10.1080/01690965.2010.523082 
Kálmán, László \& Ádám Nádasdy. 1994. A hangsúly [Intonation]. In Strukturális Magyar Nyelvtan 2: Fonológia., 393-467. Budapest: Akadémiai Kiadó.

Katz, Jonah \& Elisabeth Selkirk. 2011. Contrastive focus vs. discourse-new: Evidence from phonetic prominence in English. Language 87(4). 771-816.

https://doi.org/10.1353/lan.2011.0076

Kenesei, István \& Irene Vogel. 1989. Prosodic phonology in Hungarian. Acta Linguistica Hungarica 39. 149-193.

Krifka, Manfred. 2008. Basic notions of information structure. Acta Linguistica Hungarica 55(3-4). 243-276.https://doi.org/10.1556/ALing.55.2008.3-4.2

Kučerová, Ivona. 2007. The syntax of givenness. Massachusetts Institute of Technology dissertation.

Kučerová, Ivona. 2012. Grammatical marking of givenness. Natural Language Semantics 20(1). 1-30. https://doi.org/10.1007/s11050-011-9073-y

Ladd, D. Robert. 1980. The structure of intonational meaning: Evidence from English. Bloomington: Indiana University Press.

Ladd, D. Robert. 1990. Intonation: Emotion vs. Grammar. Language 66(4). 806-816. https://doi.org/10.2307/414730

Ladd, D. Robert. 2008. Intonational phonology (2nd edn). Cambridge: Cambridge University Press. https://doi.org/10.1017/CBO9780511808814

Lambrecht, Knut. 1994. Information structure and sentence form. Cambridge: Cambridge University Press. https://doi.org/10.1017/CBO9780511620607

Neeleman, Ad \& Tanya Reinhart. 1998. Scrambling and the PF interface. In Miriam Butt \& Wilhelm Geuder (eds.), The projection of arguments, 309-353. Stanford: CSLI Publications.

Neeleman, Ad \& Hans van de Koot. 2008. Dutch scrambling and the nature of discourse templates. The Journal of Comparative Germanic Linguistics 11(2). 137-189.

https://doi.org/10.1007/s10828-008-9018-0

Neeleman, Ad \& Hans van de Koot. 2016. Word order and information structure. In Caroline Féry \& Shinichiro Ishihara (eds.), The Oxford handbook of information structure, 383-401. Oxford University Press.

Prince, Ellen. 1981. Towards a taxonomy of given-new information. In Peter Cole (ed.), Radical pragmatics, 223-256. New York: Academic Press.

Prince, Ellen. 1992. The zpg letter: Subjects, definitness, and information-status. In S. Thompson \& W. Mann (eds.), Radical pragmatics, 295-325. Amsterdam: Benjamins.

Puskás, Genovéva. 2000. Word order in Hungarian: The syntax of A' positions. Amsterdam: John Benjamins. https://doi.org/10.1075/la.33

R Core Team. 2013. R: A language and environment for statistical computing. Austria: R Foundation for Statistical Computing Vienna. http://www.R-project.org/.

Reinhart, Tanya. 1981. Pragmatics and linguistics: An analysis of sentence topics. Philosophica 27(1). 53-94.

Reinhart, Tanya. 2006. Interface strategies: Optimal and costly computation. Cambridge, MA: MIT Press. https://doi.org/10.7551/mitpress/3846.001.0001

Rizzi, Luigi. 1997. On the fine structure of the le periphery. In Liliane Haegeman (ed.), Elements of grammar, 281-337. Dordrecht: Kluwer. https://doi.org/10.1007/978-94-011-5420-8_7

Rochemont, Michael. 2016. Givenness. In Caroline Féry \& Shinichiro Ishihara (eds.), The Oxford handbook of information structure, 41-62. Oxford University Press.

Selkirk, Elisabeth. 2008. Contrastive focus, givenness and the unmarked status of "discourse new". Acta Linguistica Hungarica 55(3-4). 331-346. https://doi.org/10.1556/ALing.55.2008.3-4.8 
Šimík, Radek \& Marta Wierzba. 2015. The role of givenness, presupposition, and prosody in czech word order: An experimental study. Semantics and pragmatics 8(3). 1-103. https://doi.org/10.3765/sp.8.3

Šimík, Radek \& Marta Wierzba. 2017. Expression of information structure in West Slavic: Modeling the impact of prosodic and word-order factors. Language 93(3). 671-709. https://doi.org/10.1353/lan.2017.0040

Šimík, Radek, Marta Wierzba \& Beste Kamali. 2014. Givenness and the position of the direct object in the Czech clause. In Cassandra Chapman, Olena Kit \& Ivona Kučerová (eds.), Formal approaches to slavic linguistics (FASL) 22: The McMaster Meeting 2013. 302-318. Ann Arbor: Michigan Slavic Publications.

Skopeteas, Stavros \& Gisbert Fanselow. 2009. Effects of givenness and constraints on free word order. In MalteZimmermann \& Caroline Féry (eds.), Information structure, 307-331. Oxford: Oxford University Press. https://doi.org/10.1093/acprof:oso/9780199570959.003.0013

Surányi, Balázs. 2006a. Hungarian as a Japanese-type scrambling language. In Christopher Davis, Amy Rose Deal \& Youri Zabbal (eds.), NELS 36: Proceedings of the 36th Annual Meeting of the North East Linguistic Society, 561-574. Amherst: University of Massachusetts, Graduate Linguistic Student Associaton.

Surányi, Balázs. 2006b. Scrambling in Hungarian. Acta Linguistica Hungarica 53(4). 393-432. https://doi.org/10.1556/ALing.53.2006.4.2

Surányi, Balázs. 2012. Identificational focus and the flexibility of syntax. In Ad Neeleman \& Ivona Kučerová (eds.), Information structure: Contrasts and positions, 87-101. Cambridge: Cambridge University Press. https://doi.org/10.1017/CBO9780511740084.006

Surányi, Balázs, Shinichiro Ishihara \& Fabian Schubö. 2012. Syntax-prosody mapping: Topiccomment structure and stress-focus correspondence in Hungarian. In Gorka Elordieta \& Pilar Prieto (eds.), Prosody and meaning, 35-72. Mouton de Gruyter. https://doi.org/10.1515/9783110261790.35

Szabolcsi, Anna. 1997. Strategies for scope taking. In Anna Szabolcsi (ed.), Ways of scope taking, 109-155. Dordrecht: Kluwer. https://doi.org/10.1007/978-94-011-5814-5_4

Szendröi, Kriszta. 2003. A stress-based approach to the syntax of Hungarian focus. The Linguistic Review 20(1). 37-78. https://doi.org/10.1515/tlir.2003.002

Varga, László. 1981. A topicról és a fókusz utáni elemek sorrendjéről [On the topic and the order of elements after the focus]. Magyar Nyelv 27.

Varga, László. 2002. Intonation and stress. London: Palgrave Macmillan. https://doi.org/10.1057/9780230505827

Vogel, Irene \& István Kenesei. 1987. The interface between phonology and other components of grammar: The case of Hungarian. Phonology Yearbook 4. 243-263.

https://doi.org/10.1017/S0952675700000853

Vogel, Irene \& István Kenesei. 1990. Syntax and semantics in phonology. In Dragan Zec \& Sharon Inkelas (eds.), The Phonolgy - Syntax Connection, 339-363. Chicago :University of Chicago Press.

Zubizarreta, Maria Luisa. 1998. Prosody, focus and word order. Cambridge, MA: MIT Press. 



\title{
Object agreement and locality in Hungarian
}

\section{Infinitival complement clauses, second person objects and accusative adjuncts}

\author{
Krisztina Szécsényi ${ }^{1}$ \& Tibor Szécsényi ${ }^{2}$ \\ ${ }^{1}$ Eötvös Loránd University, Budapest / ${ }^{2}$ University of Szeged
}

\begin{abstract}
The paper claims that the two types of object agreement in Hungarian, definiteness agreement and the special LAK-agreement form used for the combination of first person singular subject and second person object arguments, are the result of different syntactic operations. The argumentation is based on the different distribution of the two agreement types. To diagnose the nature of the conditions for agreement we use infinitival embedded clauses, at times with multiple embedded constructions. Six different patterns are discussed showing sensitivity to locality. Definiteness agreement turns out to be more restricted than LAK-agreement. While the condition for definiteness agreement is the availability of a position where accusative case can be checked, we claim that no such condition holds for LAK-agreement.
\end{abstract}

Keywords: object agreement, definiteness agreement, infinitives, locality

\section{Object agreement: Preliminaries}

Hungarian verbs, besides agreeing with their subjects, also agree with their objects along two properties: definiteness and person.

In the case of definiteness agreement (DEF-agree), the finite verb agrees with its object in definiteness: the presence of a definite object triggers definiteness (also called object-) agreement on the verb, while verbs taking indefinite objects and intransitive verbs appear with the indefinite (also called subject-) agreement morpheme (Table 1). ${ }^{1}$ The reflexive forms in the table show definite agreement due to the morphologically definite form of the reflexive pronoun: they behave as third person forms due to their etymology. An interesting split can be observed regarding pronouns: first and second person pronouns show indefinite agreement, whereas third person pronouns are definite.

1. For more details on object agreement in simple sentences see Bárány (2015). 
The second form of object agreement, which we call LAK-agreement in the present paper, surfaces in the form of a special verbal suffix when we have a 1sG subject and 2nd person (singular or plural) object in the sentence. ${ }^{2}$ While Bárány (2015) argues that it forms a natural part of the definite agreement paradigm, Bartos (1999) claims that it is independent of it.

If a matrix verb selects an infinitival clause, it often shows definiteness agreement with the object of its infinitival complement. To account for this, Bartos (1999) and É. Kiss (2002) argue for a long distance agreement analysis, whereas Den Dikken (2004) identifies the phenomenon as one of the clause union diagnostics. For obvious reasons, verbs that have their own objects, such as object control verbs like küld 'send' or kényszerit 'force' will be excluded from our investigation: in the presence of a local object agreement with the object of the infinitive is not possible.

One of the claims made in our paper follows Bartos in arguing that we are dealing with different syntactic processes. This argument is based on observations regarding infinitival embedding. While in the majority of cases a verb that shows definiteness agreement also shows LAK-agreement, the overlap is only partial. There are verbs that do one, but not the other, which we take as suggesting that the two types of agreement phenomena are the result of different syntactic operations.

Table 1. The Hungarian present tense object agreement paradigm

\begin{tabular}{|c|c|c|c|c|}
\hline \multirow[b]{2}{*}{ Subj } & \multirow[b]{2}{*}{$\begin{array}{l}\text { Intransitive } \\
\text { verb fut 'run' }\end{array}$} & \multicolumn{3}{|l|}{ Transitive verb: lát 'see' } \\
\hline & & $\begin{array}{l}\text { 1st person or indefinite } \\
\text { 3rd person object }\end{array}$ & $\begin{array}{l}\text { 2nd person } \\
\text { object }\end{array}$ & $\begin{array}{l}\text { 3rd person definite } \\
\text { object and reflexives }\end{array}$ \\
\hline $1 \mathrm{sg}$ & fut-ok & lát-ok & lát-lak & lát-om \\
\hline $2 \mathrm{sg}$ & fut-sz & lát-sz & lát-od (REFL.) & lát-od \\
\hline $3 \mathrm{sg}$ & fut- $\varnothing$ & lát- $\varnothing$ & lát-Ø & lát-ja \\
\hline $1 \mathrm{PL}$ & fut-unk & lát-unk & lát-unk & lát-juk \\
\hline $2 \mathrm{PL}$ & fut-tok & lát-tok & lát-játok (REFL.) & lát-játok \\
\hline $3 \mathrm{PL}$ & fut-nak & lát-nak & lát-nak & lát-ják \\
\hline
\end{tabular}

2. Though in principle it is possible to analyse the LAK morpheme as bimorphemic, we are not going to depart from traditional accounts in this paper and continue to consider them an unanalyzed unit. 


\section{The data: Six patterns of agreement}

In the following examples, we present the different possible patterns of object agreement.

\subsection{Transitive verbs with a DP object: [+DEF +LAK]}

The verb néz 'watch' is a verb that selects an accusative direct object, but it has no infinitival complement. Both definiteness agreement ( $1 \mathrm{ab})$ and LAK-agreement (1c) are attested as expected, with both agreement forms being obligatory. ${ }^{3}$

(1) $\mathrm{V}+\mathrm{DP}_{\mathrm{ACC}}$
a. Péter néz/ ${ }^{*}$ néz-i egy film-et.
Peter watch.INDEF/watch-DEF a film-ACC 'Peter is watching a film.'
b. Péter ${ }^{*}$ néz/néz-i a film-et.
Peter watch.INDEF/watch-DEF the film-ACC
'Peter is watching the film.'

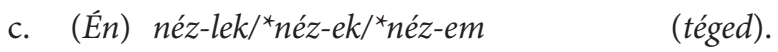
I watch-LAK/watch-INDEF/watch-DEF you.ACC
'I am watching you.'

\subsection{Intransitive verbs with an accusative adjunct: [+DEF ?LAK]}

The verb fut 'run' is an intransitive verb that selects no DP object. In spite of this, as discussed in Csirmaz (2008), it has a definite agreement paradigm as well, which surfaces when the verb fut takes a non-theta-marked definite accusative constituent. ${ }^{4}$ Due to considerations related to the meaning and the intransitivity of the verb, it is hard to draw conclusions regarding LAK-agreement. These accusative adjuncts,

3. This pattern is consistent regardless of the person and number of the subject. Thus, we use third person singular subjects throughout the work, except for the obvious cases of LAKagreement, where we need a first person singular subject.

4. The definite agreement paradigm is also needed when the verb fut 'run' appears with a perfectivizing preverb such as le lit. 'down', which actually results in a change of argument structure, transitivizing the verb. Sentence (i) would be ungrammatical without an object. In this case a second person object is also possible with the meaning 'overtake, run faster than' ((ii), we are grateful to an anonymous reviewer for the example).

(i) Le-fut-ott-ák $\quad *$ (a három kör-t $)$

PV-run-PST-3PL.DEF the three lap-ACC

'They have run the three laps (that they were supposed to).' 
which Csirmaz (2008: 169) calls situation delimiters, typically express manner and measurement. No second person pronoun is likely to appear in such a role.

(2) $\mathrm{V}+\mathrm{DP}_{\text {egyet }}^{5}$
a. Péter fut $/{ }^{*} f u t-j a$.
Peter run.INDEF/run-DEF
'Peter is running.'
b. Péter fut $/{ }^{*} f u t-j a$ egy kör-t.
Peter run.INDEF/run-DEF a lap-ACC
'Peter is running a lap.'
c. Péter ${ }^{*}$ fut/fut-ja az utolsó kör-t.
Peter run.INDEF/run-DEF the last lap-ACC
'Peter is running the last lap'
2.3 Verbs with an infinitival complement alternating with an object DP: [+DEF + LAK]

The sentences in (3) show one of the possible patterns with a verb taking an infinitival complement clause. The verb akar 'want' agrees with the accusative marked arguments of the embedded infinitival clause in exactly the same way as was seen in the sentences in (1) and (2). Both definiteness agreement and LAK-agreement (3d) are obligatory, even when the infinitive takes an accusative adjunct (3e). Finally, (3f) shows that the verb akar can take a DP object as well.

(3) $\mathrm{V}+\mathrm{V}_{\text {INF,OBJ }}\left(+\mathrm{DP}_{\mathrm{ACC}}\right)$
a. Péter akar ${ }^{*} a k a r-j a$ fut-ni.
Peter want.INDEF/want-DEF run-INF
'Peter wants to run.'
b. Péter akar/*akar-ja néz-ni egy film-et.
Peter want.INDEF/akar-DEF watch-INF a film-ACC
'Peter wants to watch a film.'

\footnotetext{
(ii) Simán le-fut-lak száz-on.

easily PV-run-LAK hundred-sUPE

'I can easily outrun you in the 100 meters.'
}

5. The $\mathrm{DP}_{\text {egyet }}$ in (2) has been chosen as the representative of this kind of adjunct. The constituent egyet literally translates into one-ACC, resulting in an aspectually slightly different meaning, something close to the English He had a run. Also, egy can appear together with manner-type modification, such as egy jó-t 'one/a good-ACC', in which case it is the adjective that carries accusative case.
(i) Fut-ott-ak egy jó-t. run-PST-3PL a good-ACC 'They had a good run.' 

c. Péter *akar/akar-ja néz-ni a film-et.
Peter want.INDEF/want-DEF watch-INF the film-ACC
'Peter wants to watch the film.'

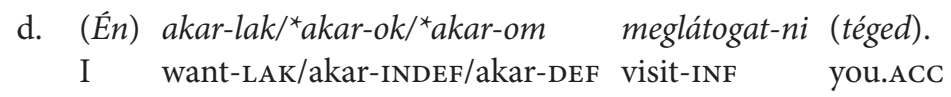
'I want to visit you.'

e. Péter *akar/akar-ja fut-ni az utolsó kör-t.

Peter want.INDEF/akar-DEF run-INF the last lap-ACC

'Peter wants to run the last lap.'

f. Péter akar egy könyv-et.

Peter want.INDEF a book-ACC

'Peter wants a book.'

The fact that these verbs need an expletive DP in the accusative case when they take a finite clause (if they do), indicates that these verbs are indeed associated with an object position (4). Variation along these lines depends on potential obviation effects and factivity among others.

(4) Péter az-t akar-ja, hogy Mari vegyen egy könyv-et.

Peter that-ACC want-DEF that mari buy.suBj a book-ACC

'Peter wants Mary to buy a book.'

Based on these data, we refer to the infinitival complements of such verbs as infinitival objects. Although some of the verbs showing this behaviour have no matching DP and/or finite clause objects, we nevertheless identify them as belonging to this group based on the fact that they show the same pattern, and we take the lack of a DP object as resulting from lexical restrictions. These verbs are very few in number, and, apart from Kenesei's (2001) auxiliaries, include verbs such as bir 'can' and mer 'dare', which are also auxiliary-like though not identified as such by Kenesei.

2.4 Verbs with a non-object infinitival complement: [-DEF \pm LAK]

Another verb, készül 'prepare' takes an infinitival agreement, but shows an unexpected pattern. It does not agree in definiteness with the object of its infinitival complement - it is the indefinite form that is used throughout. LAK-agreement, however, is optionally possible, as shown in (5c), where indefinite agreement alternates with LAK-agreement in a sentence with a first person singular subject and a second person object.

(5) $\mathrm{V}+\mathrm{V}_{\text {INF,NON-OBJ }}\left(+\mathrm{DP}_{\text {ACC }}\right)$
a. Péter készüll ${ }^{*}$ készüll-i
fut-ni.
Peter prepare.INDEF/prepare-DEF run-INF
'Peter is preparing to run.' 


\section{b. Péter készül/*készül-i néz-ni egy/a film-et. ${ }^{6}$}

Peter prepare.INDEF/prepare-DEF watch-INF a/the film-ACC

'Peter is preparing to watch a/the film.'

c. (Én) készül-lek/készül-ök/*készül-öm

I prepare-LAK/prepare-INDEF/prepare-DEF

meglátogat-ni (téged).

visit-INF you.ACC

'I am preapring to visit you.'

d. Péter készül/készül-i fut-ni az utolsó kör-t.

Peter prepare.INDEF/prepare-DEF run-INF the last lap-ACC

'Peter is preparing to run the last lap.'

e. Péter készül az eljegyzés-re

Peter prepare.INDEF the engagement-suBL

'Peter is preparing for the engagement.'

These are crucial data for the present study, indicating that definiteness agreement and LAK-agreement have different syntactic derivations. The main aim of our paper is to offer an account of this particular difference in the behaviour of the two agreement types. In order to do so, we capitalize on the difference between the selectional restrictions of the groups of verbs in question: while akar-type verbs take object DPs, készül-type verbs have no accusative arguments. Instead, they either take complements with oblique case forms, which for készül happens to be sublative (5e), or they have no complements at all. This difference shows a correlation with the availability of definiteness vs. LAK-agreement. Observationally, it can be stated that definiteness agreement is possible when the selecting verb can also take an object DP. When the selecting verb takes a complement in oblique case or is intransitive, LAK-agreement is possible for most of the speakers. This indicates that LAK-agreement is not restricted to accusative environments.

Similarly to what we saw at the end of the discussion of verbs belonging to group 3, sentences containing készül-type verbs take a finite clause introduced by

6. Bárány (2017) actually argues that these sentences are grammatical with definiteness agreement as well for some speakers. The grammaticality of the forms with definiteness agreement improves spectacularly in the presence of focus (i), for a detailed discussion see (Bárány 2017). The proposal made there seems compatible with our locality-based approach.

\section{(i) András BUDAPEST-ET készül/készül-i meglátogat-ni.}

András Budapest-ACC prepare.INDEF/prepare-DEF visit-INF

'It is Budapest that András is preparing to visit.' 
an expletive DP in the oblique case form associated with the verb in question, in this case sublative (6).

The infinitival clauses appearing in these sentences carry the non-object infinitive label in this paper.

Actually, the grammaticality judgements regarding this case are even more subtle. For a small group of speakers, definite agreement with verbs like készül 'prepare' is also possible, though, similarly to LAK-agreement, not obligatory. The really interesting cases, however, are still the patterns used by the majority of the speakers shown in (5), with definiteness agreement and LAK-agreement parting ways and behaving differently (see also fn6 for the role of focus in these constructions).

\subsection{Non-agreeing patterns with infinitival complements: [-DEF -LAK]}

Though also selecting non-object infinitives, certain verbs such as neki-lát 'begin, lit. PV-see', próbálkozik 'try'7 (7) and látszik 'seem' (8) do not show either type of agreement for the majority of the speakers. Again, for a small group of speakers, definiteness agreement and LAK-agreement are optionally possible.

(7) $\mathrm{V}+\mathrm{V}_{\text {INF,NON-OBJ }}\left(+\mathrm{DP}_{\mathrm{ACC}}\right)$
a. Péter próbál-kozik/* próbál-koz-za fut-ni. ${ }^{8}$
Peter try-KozIK.INDEF/try-KOZIK.DEF run-INF
'Peter is trying to run.'
b. Péter próbál-kozik/*próbál-koz-za néz-ni egy/a film-et. Peter try-KOZIK.INDEF/try-KOZIK-DEF watch-INF a/the film-ACC 'Peter is trying to watch a/the film.'

7. The case of próbálkozik 'try' is all the more interesting as there exists a morphologically simpler verb meaning 'try' in Hungarian: próbál. This verb behaves like akar 'want' discussed under the examples in (3) in every relevant aspect discussed in this paper, suggesting that morphological complexity also plays a role. For further details see the discussion in Section 3.3. To account for this kind of speaker variation, identified as problematic by one of our reviewers, we propose that it is the result of different processes of lexicalization. Speakers for whom there is no difference between próbál and próbálkozik lexicalize the more complex form as an unanalyzed unit, disregarding its internal morphological complexity.

8. For more details concerning the nature of the -kozik suffix, see Section 3.3. The -ik ending drops when further suffixes are added to the verb. 
c. (Én) * próbál-koz-lak/próbál-koz-om/próbál-koz-ok

I try-KOZIK-LAK/try-KOZIK-INDEF/try-KOZIK-INDEF

fölhív-ni (téged). ${ }^{9}$

call-INF you.ACC

'I am trying to call you.'

(8) a. A lányok megolda-ni látsza-nak/*látsz-szák egy/a problémá-t. the girls solve-INF seem-INDEF/seem-DEF a/the problem-ACC 'The girls seem to be solving a/the problem.'

b. (Én) fölhív-ni *látsz-ott-alak/*látsz-ott-am (téged).

I call-INF seem-PST-LAK/seem-PST-DEF/INDEF you.ACC 'I seemed to be calling you.'

2.6 Verbs with an infinitival adjunct: [-DEF - LAK]

Finally, in (9), we can see another pattern that is ungrammatical either with definiteness agreement or LAK-agreement for all the speakers of Hungarian. When the infinitival clause is an adjunct, either form of agreement is ruled out, even for those speakers who otherwise accept optional definiteness or LAK-agreement in groups 4 and 5 .

(9) $\mathrm{V}+\mathrm{V}_{\text {INF,ADJ }}\left(+\mathrm{DP}_{\mathrm{ACC}}\right)$
a. Péter leül/*leül-i
pihen-ni.
Peter sit.INDEF/sit-DEF rest-INF
'Peter sits down to rest.'

b. Péter leül/*leül-i néz-ni egy/a film-et.

Peter sit.INDEF/sit-DEF watch-INF a/the film-ACC

'Peter sits down to watch a/the film.'
c. (Én) *leül-lek/leül-ök/*leül-öm kikérdez-ni (téged).
I sit-LAK/sit-INDEF/sit-DEF ask-INF you.ACC
'I sit down to ask you.'

\subsection{Speaker variation}

Let us consider the details of speaker variation now: we have identified three groups of speakers. What they share is that definiteness agreement and LAK-agreement

9. In first person singular forms of $-i k$ verbs, the verbal suffix of indefinite agreement is the same as the definite form. Today it is rather the result of a prescriptive rule with more and more speakers actually using the regular indefinite form as well, hence the acceptability of both forms (as opposed to -LAK, which is clearly ungrammatical). We regard both forms as indefinite in these cases. 
are obligatory in the first three verb types (LAK-agreement being excluded due to independent reasons for verb type 2), but both are prohibited in infinitival adjunct clauses. We find variation in the judgement of verb types 4 and 5: there is no definiteness agreement for the majority of the speakers, with LAK-agreement possible only for verb type 4 . In the second group, LAK-agreement is also possible for type 5 verbs, but definiteness agreement is still excluded for both. For members of group 3, definiteness agreement can also optionally appear on the matrix verb as well as LAK-agreement. In general, it can be concluded that definiteness agreement is more restricted than LAK-agreement, with the exception of group 3 speakers, where the two pattern together.

Table 2 summarizes our findings, where group 1 represents the judgements of the majority of the speakers.

Table 2. Speaker variation in object agreement ('+': obligatory; '-‘: prohibited; ‘ \pm ’: optional)

\begin{tabular}{llllllll}
\hline \multirow{2}{*}{ Speaker } & Agreement & 1 & 2 & 3 & 4 & 5 & 6 \\
\cline { 2 - 7 } Group 1 & DEF & + & + & + & - & - & - \\
& LAK & + & n.a. & + & \pm & - & - \\
Group 2 & DEF & + & + & + & - & - & - \\
& LAK & + & n.a. & + & \pm & \pm & - \\
Group 3 & DEF & + & + & + & \pm & - & - \\
& LAK & + & n.a. & + & \pm & \pm & - \\
\hline
\end{tabular}

From now on, we focus on the most productive pattern, that of group 1. A natural explanation for the other variants will then fall out of our proposal as well.

\section{The proposal}

3.1 A locality-based hierarchy of verbs based on patterns of object agreement

We propose that the differences between the constructions above can be accounted for by assuming a locality-based scale. At one end of this scale we find verbs selecting an object, the most local relationship between a verb and the accusative marked constituent that it agrees with. In this case no difference between definiteness agreement and LAK-agreement can be detected potentially leading to 
the conclusion that the two result from the same syntactic processes, as claimed in Bárány (2015), who studies object agreement in simple sentences only. At the other end of the scale, we have verbs with infinitival adjuncts, where no form of agreement ever arises. Between the two ends of the scale, we find the rest of the patterns with a decreasing level in the locality of the agreement relations as described in Table 3. That definiteness agreement and LAK-agreement are not the same is shown by the verbs belonging to group 4, which do not have definiteness agreement forms, but can nevertheless show LAK-agreement.

The list of verbs taking infinitival complements in Table 3 is based on Kálmán et. al (1989), excluding object control verbs and verbs taking inflected infinitives but not showing person and number agreement themselves. The verbs marked with a star in groups 3 and 4 have no matching object or oblique DP variants.

Agreement between an intransitive verb and an accusative adjunct is still within a local domain. LAK-agreement, as pointed out in Section 2.2, is not attested for reasons to do with semantics. As we have seen, the shared property of the verbs in the third item on the scale is that they take infinitival complements that alternate with a DP object (10), or they are auxiliaries of the Hungarian language.
a. Szeretné-m
megven-ni ezt 'I would like this book.'
b. Szeretné-m ezt a könyv-et. would.like-DEF this the book-ACC 'I would like to buy this book'

ezt a könyv-et. would.like-DEF buy-INF this the book-ACC

The patterns that are in need of an explanation (which are also subject to native speaker variation indicating a degree of uncertainty in the grammars) are those that contain matrix verbs that take infinitival clauses not alternating with a DP object. These come in two groups: one with a verb taking the infinitive as a nonobject complement like készül 'prepare', showing only LAK-agreement discussed in 2.4, and the other containing verbs like látszik 'seem' and próbálkozik 'try', not showing either agreement pattern as described in 2.5. The latter are expected to behave on a par with készül-type verbs, since they share the property of not selecting an object infinitive with them. However, there is a property members of this group share as opposed to készül-type verbs: the complexity of their morphological/syntactic structure, which turns out to play a role in their syntactic behaviour.

Finally, in order to complete this part of the discussion, let us turn to type 6 verbs. To account for the lack of object agreement with objects appearing in infinitival adjunct clauses, all that needs to be pointed out is that adjunct clauses 
Table 3. The locality-based hierarchy of verbs based on patterns of object agreement

\begin{tabular}{|c|c|c|c|}
\hline \multirow[b]{2}{*}{ Verb type } & \multirow[b]{2}{*}{ Verbs belonging to the given verb type } & \multicolumn{2}{|c|}{$\begin{array}{l}\text { Agreement } \\
\text { pattern }\end{array}$} \\
\hline & & DEF & LAK \\
\hline $\begin{array}{l}\text { 1. } \mathrm{V}+\mathrm{DP}_{\mathrm{ACC}} \\
\mathrm{DP} \text { object }\end{array}$ & néz 'watch' & + & + \\
\hline $\begin{array}{l}\text { 2. } \mathrm{V}+\mathrm{DP}_{\text {egyet }} \\
\text { Intransitive verb with } \\
\text { accusative adjunct }\end{array}$ & fut 'run', alszik 'sleep' & + & $?$ \\
\hline $\begin{array}{l}\text { 3. } \mathrm{V}+\mathrm{V}_{\text {inf }}\left(+\mathrm{DP}_{\mathrm{ACC}}\right) \\
\text { Infinitival object } \\
\text { complement }\end{array}$ & $\begin{array}{l}\text { fog ' will', szokott* 'usually does', talál* 'happen to' } \\
\text { akar 'want', (meg)próbál 'try', (el)kezd 'begin', } \\
\text { bír* 'can', elfelejt 'forget', gyülöl 'hate,' imád 'adore', kíván } \\
\text { 'wish', megkísérel 'attempt', (meg)tanul 'learn', mer* } \\
\text { 'dare', óhajt 'wish', sajnál 'regret', szégyell 'be ashamed', } \\
\text { szeret 'like', szeretne 'would like', tanul 'learn', tud 'can', } \\
\text { un 'be bored', utál 'hate' }\end{array}$ & + & + \\
\hline $\begin{array}{l}\text { 4. } \mathrm{V}+\mathrm{V}_{\text {inf }}\left(+\mathrm{DP}_{\mathrm{ACC}}\right) \\
\text { Infinitival non-object } \\
\text { complement }\end{array}$ & $\begin{array}{l}\text { készül 'prepare', fél 'be afraid', habozik* 'hesitate', ADJ } \\
+ \text { lesz/volt10 'ADJ + be.FuT/be.PAST', igyekszik 'does } \\
\text { one’s best', iparkodik 'work hard', jön* '(aspectual) } \\
\text { come', kényszerül 'be compelled to', megy* (aspectual) } \\
\text { go', szándékozik* 'intend', vágyik 'desire', vonakodik } \\
\text { 'hesitate' }\end{array}$ & - & \pm \\
\hline $\begin{array}{l}\text { 5. } \mathrm{V}+\mathrm{V}_{\text {inf }}\left(+\mathrm{DP}_{\mathrm{ACC}}\right) \\
\text { Infinitival non-object } \\
\text { complement }\end{array}$ & $\begin{array}{l}\text { próbálkozik 'try (hard)', látszik 'seem', ADJ + van 'ADJ } \\
\text { + be.PREs', neki-lát 'begin, lit. PV.see, see to' (together } \\
\text { with a great number of other clitic-like preverb-verb } \\
\text { combinations meaning begin: hozzá-fog, neki-ül, etc.) }\end{array}$ & - & - \\
\hline $\begin{array}{l}\text { 6. } \mathrm{V}+\mathrm{V}_{\text {inf }}\left(+\mathrm{DP}_{\mathrm{ACC}}\right) \\
\text { Infinitival adjunct }\end{array}$ & & - & - \\
\hline
\end{tabular}

10. Interestingly, adjectives appearing with the copula show sensitivity to tense: the present form belongs to group 5 (no agreement), whereas the past and future forms show the group 4 pattern, where LAK-agreement is possible (ia). This corresponds to the observation that lexical verbs also show more willingness to bear LAK-agreement in the past tense (ib). We assume the reasons are morphological in nature: the defectivity of the verbal paradigm.

(i) a. (Én) kénytelen volta-lak/lesz-lek/*vagy-lak

I forced was-LAK/be.FUT-LAK/be.PRES-LAK

megbüntet-ni (téged).

punish-INF you.ACC

'I had/will have/have no choice but to punish you.'

b. (Én) jötte-lek/*jön-lek meglátogat-ni (téged).

I come.PAST-LAK/come.PRES-LAK visit-INF you.ACC

'I came/am coming to see you.' 
are islands; as opposed to infinitival complement clauses, they are not transparent domains, so agreement between the finite verb and the object of an infinitival adjunct clause is not possible. This is different from what we find in simple sentences containing what Csirmaz (2008) calls accusative adjuncts, where the verb and the adjunct are in the same domain making agreement possible. We focus on infinitival complement clauses in the rest of the paper, that is verb types 3-5.

Of course these verb types may turn out to need further refinement. Type 3 verbs include the three verbs that Kenesei (2001) identifies as the auxiliaries of Hungarian (fog 'will', szokott 'usually does', and talál 'happen to'). If locality is the main factor in establishing the different classes, an even closer connection between the matrix verbs and the infinitival object can be assumed, and then this group can appear as a separate category between groups 1 and 3. Similarly to this, the verbs jön 'come' and megy 'go', identified as aspectual auxiliaries when taking infinitival complements (e.g. Den Dikken 2004), may turn out to form a separate class. Responding to a reviewer's remark asking for further clarification regarding why they are different from verbs taking adjunct purpose clauses, we emphasise the semi-auxiliary status of these verbs. Under such an assumption we also account for why verbs with similar semantics but with richer content are ruled out. Whereas jön 'come' results in well-formed sentences with LAK-agreement, if a manner (siet 'hurry') or direction (vissza-jön 'come back') component is added to this verb, the result is a sharp decrease in the grammaticality judgements.

\subsection{What multiple infinitival constructions show us}

In order to be able to account for the patterns found in the infinitival constructions in verb types 3,4 and 5, we must first consider the nature of object agreement across infinitival clause boundaries. As pointed out before, simple sentences disguise some of the processes taking place in object agreement. Multiple infinitival constructions reveal some further properties of the phenomenon.

We have seen already that LAK-agreement has a different distribution from definiteness agreement: it is possible without the verb subcategorizing for an accusative argument, so it is likely to require an account different from definiteness agreement, which presupposes an argument position where accusative case can be checked. When it comes to agreement phenomena, we can choose one of the following alternatives: (i) direct one step agreement also called long distance agreement between the finite verb and the object of the infinitive; (ii) direct cyclic agreement with the definiteness features of the object recursively moving from object position to object position; (iii) indirect agreement transmitted by a constituent different from the object DP. Our underlying assumption is that, in order to account for the differences observed, different routes of agreement should be 
considered: if definiteness agreement is direct, then LAK-agreement may turn out to be indirect, and vice versa. Both patterns can be indirect if case transmission can be shown to be carried out using different means. It is these options we are going to consider in the following sections, starting with the discussion of definiteness agreement.

\subsubsection{Definiteness agreement in multiple infinitival constructions}

Szécsényi and Szécsényi $(2016,2017)$ discuss definiteness agreement in multiple infinitival constructions, concluding that definiteness agreement proceeds in a cyclic manner from clause to clause. This claim is based on the observation that a non-agreeing infinitive, such as készül 'prepare' in (11c) blocks further agreement.
a. Péter $f \circ g /{ }^{*} f \circ g$-ja
akar-ni néz-ni
egy film-et.
Peter will.INDEF/will-DEF want-INF watch-INF a film-ACC
'Peter will want to watch a film.'

b. Péter ${ }^{\star} f \circ g / f o g-j a$ akar-ni néz-ni a film-et.

Peter will.INDEF/will-DEF want-INF watch-INF the film-ACC

'Peter will want to watch the film.'

c. Péter fog/*fog-ja készül-ni néz-ni egy/a film-et.

Peter will.INDEF/will-DEF prepare-INF watch-INF a/the film-ACC

'Peter will prepare to watch a/the film.'

To explain these data Szécsényi and Szécsényi $(2016,2017)$ assume that the verbs selecting an infinitival complement do not directly agree with the accusative DP of the most embedded infinitive but by virtue of agreeing with the definiteness value of the infinitival clause directly selected by them. Definiteness then is constructed as a value that spreads from infinitival clause to infinitival clause via the transmission of the infinitival verbs in a cyclic manner. This means that the infinitive itself has a definiteness feature, and this is what the selecting verb checks. Non-agreeing verbs block definiteness agreement because they cannot check, and for this reason, cannot transmit the definiteness feature appearing on the infinitive they select (12b). What follows from this is that the infinitival clause is actually the object of the selecting verb, which needs to check a definiteness feature in a strictly local domain.
a. $\left[\mathrm{V}_{\text {fin OBJ }}\left[\mathrm{V}_{\text {inf } \cdots \text { овJ }}\left[\mathrm{V}_{\text {inf OBJ }}\left[\mathrm{V}_{\text {inf }} \mathrm{DP}_{\text {ACC }}\right] \cdots\right]\right]\right]$
b.

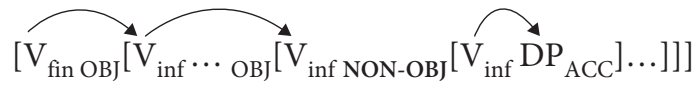




\subsubsection{LAK-agreement in multiple infinitival constructions}

Turning to LAK-agreement in multiple infinitival constructions not discussed previously, we find a more refined pattern: in a multiple infinitival construction where the most embedded verb takes an object DP as a complement, and the selecting verbs alternate with an object DP, LAK-agreement can also proceed up until it reaches the matrix finite verb. In this case, LAK-agreement is obligatory (13a). In (13b), there is an infinitival verb in the middle that can optionally LAK-agree with the object, so we find optional LAK-agreement on the finite verb. In (13c), we have a type 5 verb, which has a blocking effect on agreement, so only indefinite agreement is grammatical. ${ }^{11}$
a. (Én) fog-lak ${ }^{*}$ fog-ok ${ }^{*}$ fog-om
akar-ni meglátogat-ni
(téged).
I will-LAK/will-INDEF/will-DEF want-INF visit-INF
you.ACC
'I will want to visit you.'

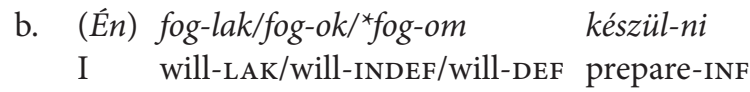
meglátogat-ni (téged).
visit-INF you.ACC
'I will prepare to visit you.'
$\begin{array}{lll}\text { c. }(E ́ n) & { }^{*} \text { fog-lak/fog-ok/ }{ }^{*} \text { fog-om próbál-koz- } n i \\ \text { I } & \text { will-LAK/will-INDEF/will-DEF try-KOZIK-INF }\end{array}$
meglátogat-ni (téged).
visit-INF you.ACC
'I will try to visit you.'

Based on these data, the following picture emerges for verb types 3, 4 and 5: when a verb taking an infinitival complement alternates with a DP object, both definiteness agreement and LAK-agreement are obligatory (type 3), and both are transmitted further onto the matrix clause. Definiteness agreement is not possible when the verb takes an infinitival complement that is not an object, but LAK-agreement is optionally possible (type 4), and the transmission of agreement takes place accordingly: LAK-agreement can, but does not have to appear on the matrix verb. For the majority of speakers, neither agreement type is possible for type 5 verbs. As (13c) indicates, even LAK-agreement is blocked by próbálkozni 'to try'.

These observations suggest that LAK-agreement is also cyclic in nature, as it is also affected by the infinitive in the middle. However, the differences between (11c) and (13b) with készül 'prepare' not showing definiteness agreement (11c),

11. Of course, the judgements of speakers who treat készül 'prepare' and próbálkozik 'tryKOZIK' on a par (speakers of group 2 and 3), are going to be as in (13b) for próbálkozik as well. 
but showing LAK-agreement (13b), indicate that we are dealing with different syntactic processes.

Now we are in the position to discuss an important difference between definiteness agreement and LAK-agreement. As we saw in (10), definiteness agreement between a matrix verb and the object of an embedded infinitive goes together with the possibility of definiteness agreement between the matrix verb and an object of its own. However, when the infinitives in type 4 sentences alternate with an oblique complement, a similar LAK-agreement between the matrix verb and the selected oblique second person complement is impossible (14b). The verb fél 'be afraid of sg' takes an ablative complement; it has no version that selects an accusative DP. ${ }^{12}$ Still, sentence (14a), showing LAK-agreement with the object of the infinitive, is grammatical. In (14c), we can see a clear contrast with (10b): an accusative complement is excluded in (14c); nevertheless, LAK-agreement is not ruled out between the finite verb and the object of its infinitival complement. One of the main questions of the present paper is how LAK-agreement can be made independent of accusative case assignment.
a.
(Én) fél-te-lek
I be.afraid
meglátogat-ni
(téged)
'I was afraid to visit you.'
b. (Én) ${ }^{\star}$ fél-te-lek/fél-t-em
töled.
I be.afraid-PAST-LAK/be.afraid-PAST-INDEF you.ABL
'I was afraid of you.'
c. (Én) ${ }^{*}$ fél-lek/^fél-ek/*fél-em
I be.afraid-LAK/be.afraid-INDEF/be.afraid-DEF you.ACC

What this indicates is that in the case of LAK-agreement the infinitive is not the object of the selecting verb, and for this reason, the matrix verb is unable to check either a definiteness or a LAK feature on the infinitive. The features of the embedded infinitival object are obviously checked in these constructions, but this checking procedure must then take place differently.

As a result, our conclusion regarding the cyclicity of LAK-agreement needs to be refined: the data show that LAK-agreement also proceeds form infinitival clause to infinitival clause. The selecting verb, however, cannot check the respective features of the infinitival clause, as it only takes an oblique complement. The agreement process therefore has to be triggered by the second person object pronoun of the embedded infinitive, and when its features end up in the same domain as the

12. The verb fél 'be afraid' used to be able to have an accusative argument, which is shown e.g. in the archaic expression fél-i az isten- $t$ 'fear God'. Its use is not productive in present day Hungarian. 
first person singular subject, the local configuration required for LAK-agreement is established (first person singular subject combining with second person object). The infinitives must have a transmitting role, as we have seen in (13); without the presence of the infinitive LAK-agreement is impossible. ${ }^{13}$ The contribution of the infinitive lies in providing the second person object to the sentence.

The pattern in (15a) shows how LAK-agreement proceeds from clause to clause. In the case of type 5 verbs, it is this kind of agreement that is blocked, as shown in (15b).

a.

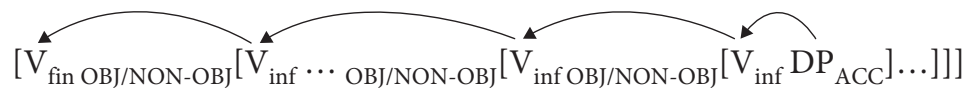

b.

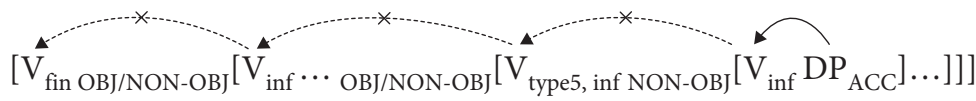

The direction of agree is spectacularly different in (12) and (15). Whereas in (12), we can see a garden variety process of Agree with a probe targeting a goal, either the DP or the infinitival object of the verb, in (15) the search begins in the lower domains.

\subsection{What is responsible for the blocking effect in type 5 verbs?}

The property shared by verbs belonging to types 4 and 5 is that they take infinitival complements that do not alternate with an accusative DP object. Type 5 verbs are morphologically more complex, and in this section, we consider the syntactic consequences of this complexity.

The verb látszik 'seem' can be identified as the unaccusative pair of the verb lát 'see', as illustrated in (16). This means that the subject of the sentence containing

13. Infinitives themselves never have a LAK-agreement form in Standard Hungarian in spite of productive inflected infinitival patterns. Data mentioned in Grétsy (2008), however, suggest an account similar to what we proposed for definiteness agreement, where the definiteness feature moves from infinitival clause to infinitival clause. What (i) shows is that LAK-agreement can optionally appear on the infinitive in very informal spoken registers. However, it is only possible in constructions where the infinitive can be otherwise inflected for the person and number properties of the infinitival subject. (For more details on inflected infinitives see Tóth 2000.)

(i) a. szólj, ha föl kell segíte-ne-lek.

call if up have.to help-INF-LAK

'Call me if I have to help you up.'

(Grétsy 2008)

b. szabad megkér-ne-lek ar-ra, hogy...?

possible ask-INF-LAK that-SUBL that $(=$ comp)

'May I ask you to...?'

(Grétsy 2008) 
látszik originates from a VP-internal position, where object agreement takes place. Since this position is occupied by the trace of Mari, LAK-agreement is blocked. The verb lát can also take an infinitival complement, but it is an object control verb with its own object DP, so it never agrees with the object of its infinitive.
a. Péter lát-ja Mari-t.
Peter see-DEF mary-ACC
'Peter sees Mary.'
a'. Mari $i_{\mathrm{i}}$ látszik $t_{i}$.
Mary seem.INDEF
'Mary can be seen.'
b. Péter lát-ja Mari-t elmen-ni.
Peter see-DEF Mary-ACC leave-INF
'Peter sees Mary leave.'
$\mathrm{b}^{\prime}$. Mari ${ }_{\mathrm{i}}$ látszik $t_{\mathrm{i}}$ elmen-ni. Mary seem.INDEF leave-INF 'Mary seems to be leaving.'

The morphological complexity of the verb látszik 'seem' reflects that látszik is derivationally related to the transitive verb lát 'see'. Out of the two arguments of lát, the internal argument is preserved, which functions as the subject of látszik. It results in the presence of two internal argument positions, a DP and an infinitival clause with the DP position occupied by the trace of the moved object $\left(16 a^{\prime}\right) .{ }^{14}$ This DP object blocks agreement with other potential candidates in the infinitival clause.

This fits into a more general pattern of intervention effects: multiple internal arguments also have a similar blocking effect elsewhere, as in dative control constructions such as (17).
(Én) segit-ek/*segite-lek
Mari-nak meggyőz-ni téged.
I help-INDEF/help-LAK Mari-DAT persuade-INF you.ACC
'I help Mary persuade you.'

As for próbál-kozik 'try-KozIK', attention can be drawn to the morphological marker shared by this verb and reflexive forms of transitive verbs. In (18), we can

14. In order to respond to a remark made by one of our reviewers, we wish to highlight the fact that Hungarian látszik 'can be seen' is not an equivalent of English seem, where we indeed have strong arguments for a subject-to-subject raising analysis. Notice that the Hungarian verb can have a structural subject without an embedded infinitive which we claim originates from an internal argument position (see 16a-a'). In English, such a construction is ruled out: ${ }^{*}$ Mary seems. The implicit claim made in (16) is that the structural subject undergoes subjectto-object-to-subject raising in the infinitival sentence. 
see two ways of expressing reflexive meanings, one using the reflexive pronoun magá- $t$ 'self-ACC', the other using the verbal reflexivizer morpheme -kozik, the same ending on the verb meaning 'try.' ${ }^{15}$
a. Péter borotvál-ja magá-t.
Peter shave-DEF self-ACC
'Peter is shaving himself.'
a'. Péter borotvál-kozik.
Peter shave-KOZIK.INDEF
'Peter is shaving himself.'
b. Péter próbál elmen-ni.
Peter try.INDEF leave-INF
'Peter is trying to leave.'
b'. Péter próbál-kozik elmen-ni.
Peter try-KOZIK.INDEF leave-INF
'Peter is trying to leave'

We argue that the reflexive morpheme leads to an intervention effect ${ }^{16}$ similar to the one we saw for látszik 'seem' above, hence object agreement is not possible. The pattern that seems to emerge for LAK-agreement is that it is always possible between a matrix verb and the object of its infinitival complement, unless it is blocked by overt or covert intervening phrase-sized constituents occupying an internal argument position.

Regarding neki-lát 'begin', (lit. 'PV-see'), and similar preverb-verb combinations typically meaning 'begin', our account capitalizes on the pronominal nature of the preverb and the fact that these verbs take arguments sharing the case form

15. This particular verb form is interesting from a cross-linguistic perspective as well. As pointed out by Medová (2009), the addition of reflexive morphemes can also result in what she calls an effort reading. The verb form próbál-kozik 'try' seems to offer further confirmation of her observations, though this use of the reflexive morpheme is clearly more productive in Czech. For more parallels between reflexivity and LAK-agreement, see Szécsényi and Szécsényi (2019).

16. One of our reviewers points out that the -kozik suffix in próbálkozik 'try' is not reflexive at all, but a tentative-frequentative one. While we agree that it is not strictly speaking reflexive, we maintain that even in this case there is a hidden reflexive/antipassive meaning, something like 'engage oneself in doing something,' and we are not dealing with a case of accidental homonymy. Differences in the argument structure of próbál 'try' taking accusative objects and próbálkozik 'try-KOZıк' taking an instrumental complement and ruling out an accusative one can also be taken as supporting such an approach. In general, we take the -kozik suffix as an indicator of an unavailable internal argument position. 
appearing on the preverb. ${ }^{17}$ In these cases, the preverb shows an argument cliticlike behaviour. In order to understand this, the reader needs to be aware that the morpheme neki appearing in our example is the same form as the dative third person pronoun in Hungarian. Having said this, let us turn to the examples in (19). (19a) shows the pattern of a simple sentence with the dative clitic preverb encoding the case form of the selected argument. Since the argument is not an accusative object, definite agreement is not an option. In (19b), we have an embedded infinitive with a definite object, but definiteness agreement is ungrammatical for the same reason: neki-lát does not take an object, so it does not agree with any. In (19c), we can see a LAK-agreement example, which is ungrammatical. Again, for those speakers who find this sentence grammatical, the verb is possibly an unanalyzed unit (see fn. 6).
a. Péter neki-lát-ott/*neki-lát-ta
a házi feladat-nak.
Peter PV-see-PST.INDEF/PV-see-PAST.DEF the home task-DAT
'Peter started the homework.'
b. Péter neki-lát-ott/*neki-lát-ta lerajzol-ni Mari-t.
Peter PV-see-PST.INDEF/PV-see-PST.DEF draw-INF Mari-ACC
'Peter started to draw Mary'.
$\begin{array}{lll}\text { c. }{ }^{*}(\hat{E} n) & \text { neki-lát-ta-lak lerajzol-ni (téged). } \\ \text { I } & \text { PV-see-PST-LAK draw-INF you.ACC }\end{array}$
'I started to draw you.'

Note that in the case of other preverb-verb combinations, we do not find the same pattern: when the matrix verb is el-kezd 'Pv(= away)-begin' LAK-agreement (20a), moreover, even definiteness agreement turns out to be fully grammatical (20b). This is actually predicted by our proposal. Notice that in these sentences, the preverb is not clitic-like; it is a pure adverbial without a pronominal use, and the verbal expression actually takes an accusative DP complement as well (20c). What this means is that the infinitive is an object infinitive, and in this case, the blocking effects do not apply, since the transitive matrix verb needs to check the respective object features on the selected infinitival object.

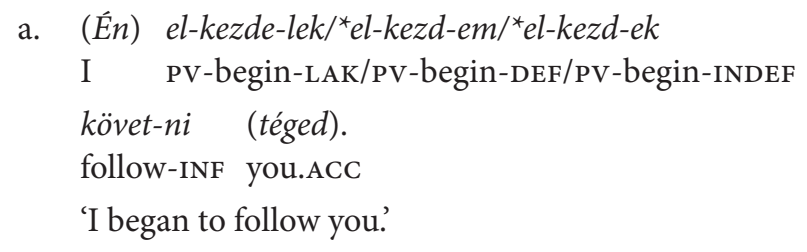

17. For more information on this construction see Kálmán and Trón (2000). 

b. Péter el-kezd-te/*el-kezd-ett
követ-ni Mari-t. Péter PV-begin-PST.DEF/PV-begin-PST.INDEF
'Peter began to follow Mary.'
follow-INF Mari-ACC
c. Péter el-kezd-te/*el-kezd-ett az iskolá-t.
Péter PV-begin-PST.DEF/PV-begin-PST.INDEF the school-ACC
'Peter started school.'

To summarize, in different ways, agreement is blocked by a matrix constituent in sentences with type 5 verbs. It is the trace of Mari in the case of látszik 'seem', the reflexive morpheme in the case of próbálkozik 'try-kozik', and the clitic-like preverb for neki-lát 'begin' (lit. 'Pv-see').

In order to account for the variation among the speakers, we propose the following: for the majority of the speakers the distinction between object and non-object arguments results in a difference between the accessible patterns of agreement. Definiteness agreement is obligatory with a local nominal or infinitival object, but it is not possible anywhere else. Optional LAK-agreement is always possible, but can be blocked by intervening phrases. Group 2 speakers, for whom every sentence with an infinitival complement is grammatical with LAK-agreement, do not show sensitivity to morphological complexity; it does not translate into syntactic complexity, and the forms are treated as lexicalized, unanalyzed units. Those speakers for whom definiteness agreement is possible whenever LAK-agreement is possible do not distinguish the two types of agreement. Definiteness agreement follows the pattern of LAK-agreement in being obligatory when LAK-agreement is obligatory, and being optional when LAK-agreement is optional.

\section{Conclusion}

The purpose of the paper has been to account for the difference between the two patterns of object agreement attested in Hungarian, definiteness agreement, and person agreement in the presence of a first person singular subject and a second person object appearing on the verb in the form of a harmonizing LAK suffix. In reaching the conclusions listed below, we used sentences with matrix verbs taking an infinitival clause with its own object, occasionally with multiple layers of embedding. The reason that such data were particularly useful is that they made it possible to identify locality-based restrictions.

We claim that, while both definiteness agreement and LAK-agreement are cyclic in nature, they are not the result of the same syntactic operations. Our data indicate that agreement is not directly between the object of the infinitive and the matrix verb, but rather the intervening infinitives also play a role and can have a 
blocking effect. Definiteness agreement is possible only across object infinitives, where the infinitive itself has been argued to be the locus of indirect cyclic agree. Non-object infinitives do not transmit definiteness, but they can transmit LAKagreement. LAK-agree is possible in every infinitival complement clause, but it can be blocked by an intervening phrase associated with an internal argument position, indicating that the object of an infinitive LAK-agrees with the matrix verb in a more local domain.

The assumptions made in the paper also make is possible to account for variation among speakers. Questions left for future research include the reasons for the sensitivity of agreement to focus and tense, why LAK-agreement is optional in the case of non-object infinitives, and the exact nature and structural description of LAK-agreement.

\section{Acknowledgements}

This research was supported by the EU-funded Hungarian grant EFOP-3.6.1-16-2016-00008, and the NKFI-6 fund through project FK128518.

\section{References}

Bárány, András. 2015. Differential object marking in Hungarian and the morphosyntax of case and agreement. $\mathrm{PhD}$ Dissertation. University of Cambridge.

Bárány, András. 2017. Budapestet készülöm meglátogatni: Issues in Hungarian long-distance agreement. Presented at 13th International Conference on the Structure of Hungarian. Budapest, 30 June 2017. http://www.nytud.hu/icsh13/

Bartos, Huba. 1999. Morfoszintaxis és interpretáció: A magyar inflexiós jelenségek szintaktikai háttere[Morphosyntax and interpretation: The syntactic background of Hungarian inflectional phenomena]. PhD Dissertation. Budapest: ELTE.

Csirmaz, Anikó. 2008. Accusative case and aspect. In Katalin É. Kiss (ed.), Event structures and the left periphery, 159-200. Dordrecht: Springer. https://doi.org/10.1007/978-1-4020-4755-8_8

Den Dikken, Marcel. 2004. Agreement and 'clause union'. In Katalin É. Kiss \& Henk van Riemsdijk (eds.), Verb clusters. A study of Hungarian, German and Dutch, 445-498. Amsterdam: John Benjamins. https://doi.org/10.1075/la.69.24dik

É. Kiss, Katalin. 2002. The syntax of Hungarian. Cambridge: Cambridge University Press. https:// doi.org/10.1017/CBO9780511755088

Grétsy, László. 2008. Anyanyelvi őrjárat. Szabad Föld Online. 1 August 2008. https://www. szabadfold.hu/cikk?12849.

Kálmán, C. György, László Kálmán, Ádám Nádasdy \& Gábor Prószéky. 1989. A magyar segédigék rendszere. In Zsigmond Telegdi \& Ferenc Kiefer (eds.), Általános Nyelvészeti Tanulmányok XVII, 49-103. Budapest: Akadémiai Kiadó.

Kálmán, László \& Viktor Trón. 2000. A magyar igekötő egyeztetése. In László Büky \& Márta Maleczki (eds.), A mai magyar nyelv leírásának újabb módszerei IV, 203-211. Szeged: SZTE. 
Kenesei, István. 2001. Criteria for auxiliaries in Hungarian. In István Kenesei (ed.) Argument structure in Hungarian, 73-106. Budapest: Akadémiai Kiadó.

Medová, Lucie. 2009. Reflexive clitics in Slavic and Romance. A comparative view from an antipassive perspective. PhD Dissertation. Princeton: Princeton University.

Szécsényi, Tibor \& Krisztina Szécsényi. 2016. A tárgyi egyeztetés és a fónévi igeneves szerkezetek. In Bence Kas (ed.), “Szavad ne feledd!” Tanulmányok Bánréti Zoltán tiszteletére, 117-127. Budapest: MTA Nyelvtudományi Intézet.

Szécsényi, Krisztina \& Tibor Szécsényi. 2017. Definiteness agreement in Hungarian multiple infinitival constructions. In Joseph Emonds \& Markéta Janebová (eds.), Language use and linguistic structure: Proceedings of the Olomouc Linguistics Colloquium 2016, 75-89. Olomouc: Palacký University.

Szécsényi, Krisztina \& Tibor Szécsényi. 2019. I agrees with you: Object agreement and permissive hagy in Hungarian. In Joseph Emonds, Markéta Janebová \& Ludmila Veselovská (eds.), Language use and linguistic structure: Proceedings of the Olomouc Linguistics Colloquium 2018, 79-97. Olomouc: Palacký University.

Tóth, Ildikó. 2000. Inflected infinitives in Hungarian. PhD Dissertation. Tilburg: University of Tilburg. 


\title{
Fixed stress as phonological redundancy:
}

\section{Effects on production and perception in Hungarian and other languages}

\author{
Irene Vogel \\ University of Delaware
}

From the perspective of word prosody, fixed stress languages such as Hungarian may seem rather uninteresting: stress, by definition, always falls on the same position in a word. This paper examines the acoustic properties of Hungarian stress based on a large, systematically collected, corpus and considers them in relation to issues of redundancy in speech production and in speech perception (stress deafness). The Hungarian findings also serve as the basis of comparison for languages with other types of stress systems, analysed with the same methods: Turkish, Arabic and Spanish. It is demonstrated that stress predictability affects both speech production and perception, and also that its effect may be mitigated by exceptions in otherwise predictable stress languages.

Keywords: stress, redundancy, stress perception, stress production, stress deafness

\section{Introduction}

In the field of prosody, fixed stress languages such as Hungarian may seem rather uninteresting since stress, by definition, always falls on the same position in a word. It turns out, however, that fixed stress in a language has interesting consequences for speakers, observable in production and perception behavior, as well as in more subtle brain activity. While fixed stress is not uncommon (e.g., initial in Finnish, Icelandic; penultimate in Polish, Quechua; final in Turkish, French), Hungarian may be distinguished from some other such languages in that it does not admit exceptions. Thus, the consistency of Hungarian stress provides a firm basis for comparing the effects of fixed stress with other types of stress systems, as well as possible secondary effects of exceptions in languages that otherwise have predictable stress.

In this paper, I examine the acoustic properties of Hungarian stress based on a large, systematically collected corpus, and consider them in relation to the broader 
issue of redundancy in speech production and in speech perception (stress deafness). The Hungarian findings are compared to those of languages with other types of stress systems, analysed with the same methods: fixed stress with exceptions (Turkish), predictable quantity-sensitive stress (Arabic), and non-predictable stress (Spanish).

Section 2 provides a brief overview of stress systems, and how predictable stress may be viewed as type of redundancy within the phonology of a language. In Section 3, the methodology for the collection and analysis of the production data is presented. The results of the Hungarian experiment are presented in Section 4, where they are compared to those of Spanish, Turkish, and Arabic. In Section 5, the effects of stress predictability on speech production and perception are discussed. The possible effects of exceptions in otherwise predictable stress languages are also considered, as are some recent brain-imaging findings. Finally, Section 6 offers some general conclusions.

\section{Stress systems and redundancy}

In this paper, "stress" is used to indicate word-level (lexical) prominence, a property most commonly identified acoustically in relation to F0, duration, intensity and vowel centralization.

\subsection{Overview of stress systems}

Languages may or may not make use of lexical stress, also referred to here just as stress, or as word stress, as distinct from broader sentential prosodic prominences. In the languages that do make use of stress, the way in which it is assigned may vary in several ways. Figure 1 schematically presents a general view of the basic types of stress system for cross-linguistic comparisons and typological considerations, although, of course, any particular language may include exceptions or other complexities. ${ }^{1}$ The languages considered here are all found on the left [+stress] branch of the tree.

1. One of the reviewers draws attention to the fact that stress and tone are not diametrically opposed types of prosody. It is thus important to note that Figure 1 is only dividing languages based on whether or not they have (lexical) stress. In the absence of stress, tone may or may not be present, but this is not relevant to the present study, which focuses on languages that do have stress. It is also possible for a language to have both tone and stress, which would require a somewhat different schematic representation; however, this is not pertinent to the present investigation since the languages examined here all, and only, have (lexical) stress. 


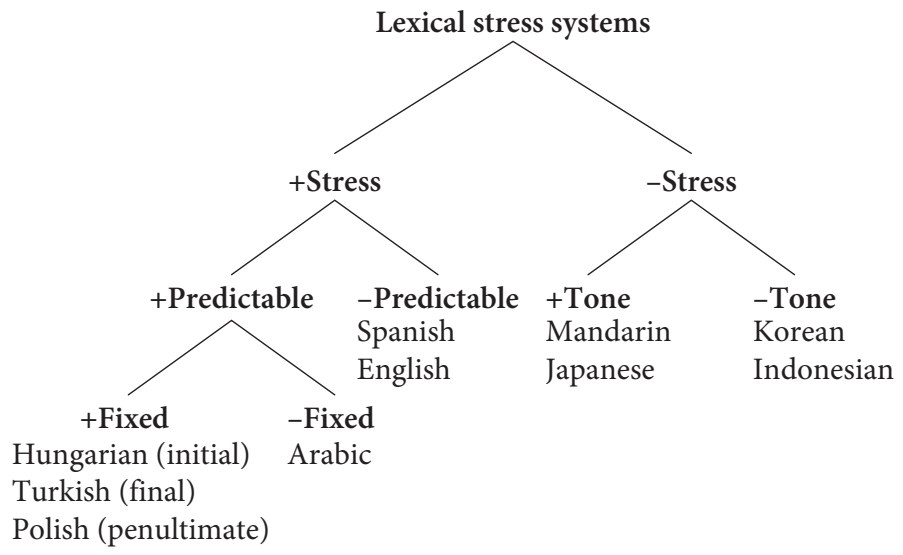

Figure 1. Overview of lexical stress systems

In fixed stress languages such as Hungarian, stress is predictably assigned to a specific position independently of the composition of the syllables (quantityinsensitive). Stress may also be predictable, but variable in position, depending on syllable weight (quantity-sensitive), as in Arabic. In both cases, since it is predictable, stress is not contrastive, or "phonemic". In other languages, however, where stress position is not consistently predictable (e.g., Spanish, English), it may be contrastive (e.g., Spanish: sábana 'sheet' vs. sabána 'savannah')2. In languages without lexical stress, tone may or may not be present (e.g., Mandarin, Japanese vs. Korean, Indonesian); however, these are not relevant to the present discussion.

Although many languages are considered to have predictable stress, it is not uncommon to also find some exceptions. For example, in Turkish, an alternate, quantity-sensitive, stress pattern, often referred to as "Sezer Stress," applies in place names and borrowings (e.g., Ánkara), although there are also exceptions to this pattern (e.g., Kabak \& Vogel 2001). Additionally, there are certain suffixes that require stress on a preceding syllable (e.g., kabá-ca 'roughly'). Hungarian stands out, however, in not exhibiting exceptional stress patterns, and thus may be taken as a type of baseline against which to compare languages not only with non-predictable stress, but also others with generally predictable stress, but also some exceptions.

2. An acute accent indicates a stressed syllable unless otherwise noted; this may or may not correspond to the orthographic conventions of a language. 


\subsection{Redundancy and predictable stress}

Redundancy appears throughout language, and in general terms, may be considered as the encoding of the same type of information in more than one way, or the presence of material that is otherwise predictable. Although this could be considered uneconomical, we also often observe a "reestablishment" of economy within a language. A simple illustration is Pro-Drop. For example, in Italian, underlying information about person and number is manifested on the surface with different verb endings for Persons 1,2 and 3, singular (e.g., parlare 'to speak': parlo, parli, parla), and plural (parliamo, parlate, parlano). Pronouns that provide the same information may thus be considered unnecessary, or redundant, and as such, they are often not used. By contrast, in French, the corresponding surface verb forms do not include redundant information: all singular (je parle, tu parles, il parle), and the third person plural (ils parlent), verb forms have the same surface phonetic manifestation ending in schwa, which may even be deleted, despite their various spellings. Thus, the pronouns must be used, since the person and number information would not otherwise be available in the speech stream. ${ }^{3}$

The situation in phonology, at first glance, appears to be the opposite. Instead of a more complete underlying structure, and more economical surface forms, redundancy as expressed by the concept of "underspecification", calls for the Underlying Representations (URs) to exclude predictable, or redundant, information. ${ }^{4}$ The additional information is then introduced in the surface forms in speech production. For example, we could consider a property such as voicing redundant for sonorants, and not part of their URs, although it is present in the speech output. In other cases, allophonic properties, by definition predictable, may be excluded from the UR, but then are introduced in actual speech, as in the case of aspiration of voiceless stops in English. Thus, generally speaking, while in syntax, the underlying representations appear richer, with redundant information removed from the output forms, in phonology, the surface forms are richer, containing predictable information that is not specified in the UR. Since speech must often be understood in "noisy" contexts, surface phonetic redundancy may

3. The Italian and French examples come from particular verb classes, -are and -er, respectively. The corresponding endings in other verb classes may differ to some extent; however, the fundamental difference between the redundancy in Italian and the lack thereof in French still holds.

4. There are different versions of underspecification, but what is crucial in all of them, and for the present point about redundancy in phonology, is that there is relatively less richness (i.e., redundant properties excluded), in underlying structure, than in the speech output, where the redundant properties are manifested. 
be viewed as favoring the listener, even if it puts a "burden" on the speaker to produce additional phonetic cues. By contrast, dropping pronouns simplifies the speaker's task, while still leaving enough information in the verb forms to be clear for the listener.

Specifically with regard to stress, fixed (or consistent quantity-sensitive) stress may be seen as involving redundancy, in the sense that there are two types of information that independently identify the position of the stressed syllable of a word: the phonological predictability of the stress position in a language, and the acoustic cues in speech that identify the appropriate syllable as the most prominent one in a word. Unlike the case of Italian pronouns, stress redundancy results in the introduction of a (stress) property in speech that was not present underlyingly. In derivational terms, predictable stress is assigned in the appropriate position by a phonological rule or process, and expressed with the requisite acoustic properties. In this sense, predictable stress appears somewhat like allophonic phenomena, where the speaker "knows" where each allophone surfaces, and produces the relevant phonetic properties when speaking. When stress is not predictable, however, it must be indicated in the UR, and then pronounced as required in the specified position, more like distinct phonemes. In fact, in languages with non-predictable stress, it is often referred to as contrastive or phonemic.

While the relationship between the underlying and surface properties of predictable stress shows the former to be reduced with respect to the latter, there is another way in which predictability may affect the manifestation of stress. The "Smooth Signal Redundancy Hypothesis" addresses the effect of predictability not in terms the representations and properties of individual words, but rather in terms of the articulation of different aspects of speech in the broader sentential or discourse context. Viewed in this way, we find that predictability does lead to somewhat simpler, or reduced, surface forms, more analogous to the dropping of pronouns when the information is retrievable in a different way. For example, it has been found that contextually predictable syllables and words have shorter durations than non-predictable ones, and predictable words have a lower pitch or F0 than non-predictable ones. In addition, predictable vowels are more centralized/reduced than non-predictable ones (e.g., Aylett \& Turk 2004; Turk 2010; Turnbull 2017; Watson et al. 2008). Such findings are particularly interesting with regard to stress, even though they involve non-phonological considerations, since they include precisely the acoustic properties that are typically associated with stress (i.e., duration, F0 and vowel centralization).

\subsection{Predictable stress: Perception and production}

While there has been considerable interest in the effects of predictable stress on perception, in particular, with respect to "stress deafness", the general inability of 
speakers of fixed stress languages to perceive stress, less attention has been paid to the possible effects of predictable stress on production. First, a brief summary of the findings of perception research is presented, followed by discussion of the implications of the nature of the stress system on production.

\subsubsection{Stress perception}

In a number of behavioral studies of stress perception, using different methodologies, it has been quite consistently found that speakers of languages with fixed stress (e.g., Hungarian, Turkish, French) are "stress deaf". That is, they cannot reliably hear stress in other languages, or experimental stimuli, while speakers of languages with non-predictable stress are able to perceive stress under similar circumstances (e.g., Dupoux et al. 1997, 2001, 2008; Peperkamp \& Dupoux 2002; Peperkamp et al. 2010; Altmann 2006).

The difference in stress perception abilities is attributed to a difference in the URs of the different types of language. In languages with predictable stress, stress is not indicated in the UR, but rather, inserted by regular phonological rules to yield the necessary output forms. By contrast, languages with nonpredictable stress include an underlying stress specification. It is proposed, furthermore, that it is the absence of an underlying stress property that makes speakers of a language like Hungarian "stress deaf". Thus, the difference may be seen as similar to the difference between contrastive underlying (phonemic) properties and predictable surface phonetic (allophonic) properties: the former are readily perceived by speakers of a language, while the latter are not. In the absence of a particular phonological category, if listeners are exposed to the relevant property, they fail recognize it since there is nothing to associate it with at the contrastive, underlying level. ${ }^{5}$

The representational difference between predictable and non-predictable stress is illustrated in Figure 1, based on proposals of Dupoux and others. A speaker of a language with fixed stress like Hungarian applies a Stress Assignment rule along with any other phonological rules (P-Rules) to arrive at the surface form. A speaker of a language with non-predictable stress like Spanish, however, simply brings the underlying stress property to the surface, as distinct from the application of other P-Rules.

5. Note that this pertains to stress perception in language tasks. When speakers must only distinguish sounds in an auditory, but not linguistic, task, they are able to respond to different acoustic properties that happen to be associated with stress (Dupoux et al.2001), as they can distinguish between many types of subtle, non-linguistic auditory stimuli. 


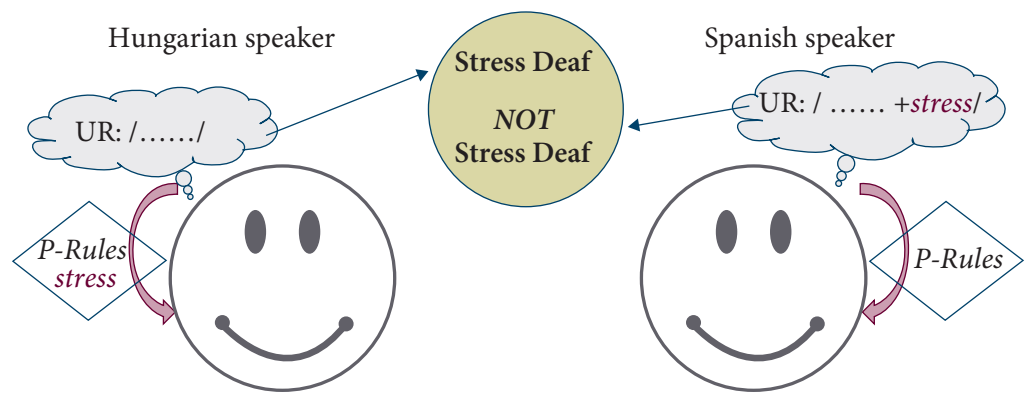

Figure 2. Stress representation in fixed and unpredictable stress systems

Additional research has shown that what is crucial for stress deafness is the predictability of stress, but it need not be fixed. Thus, Arabic speakers are stress deaf like French and Turkish speakers (Altmann 2006), although stress position is variable, assigned on the basis of syllable structure (quantity-sensitive). ${ }^{6}$ In this case, too, stress need not be present in the UR, so the left side of Figure 2 can account for Arabic as well as fixed stress languages like Hungarian.

It has been suggested that the effects of stress deafness may be somewhat mitigated by the presence of exceptions in a language. Specifically, it was noted that while Polish has predictable penultimate stress, its speakers appear to be somewhat better at perceiving stress than French speakers, but less good than Spanish speakers, a result attributed to the presence of exceptions in Polish (Peperkamp \& Dupoux 2002, Peperkamp et al. 2010). This is somewhat surprising since Turkish speakers appear to be just as stress deaf as French and Hungarian speakers; however, Turkish has considerably more stress exceptions than Polish.

More generally, the possible effect of exceptions on stress perception raises interesting questions for an interpretation of stress deafness in terms of the absence of an underlying stress property in a language. If such a property is available to affect stress perception, why does it do so only some of the time? That is, if Polish speakers do have some underlying stress category - to handle the exceptions, why do they not perceive stress as effectively as Spanish speakers? Moreover, why do the more extensive stress exceptions in Turkish not lead it speakers to be only partially stress deaf, like Polish speakers - or even more generally sensitive to stress like Spanish speakers? ${ }^{7}$

6. In most varieties, stress is assigned to the right-most heavy syllable, although for final stress, the syllable must be super-heavy (i.e., contain three moras: long vowel + consonant, or short vowel + two consonants). In the absence of a heavy (or super-heavy) syllable, stress is on the antepenultimate syllable, usually the word-initial syllable.

7. Note that the assessment of exceptional stress in Polish included final stress in monosyllabic words; however, it is not clear that such cases are really exceptions, since no other options 


\subsubsection{Production}

While the perceptual consequences of the redundancy associated with predictable stress (i.e., stress deafness) have been documented for a number of languages, despite some differences as noted, the possible effects of stress redundancy on production have received less attention. Although the "Smooth Signal Redundancy Hypothesis (SSRH)" does not explicitly consider stress predictability, we may nevertheless apply the insights to this case. That is, as suggested above, we may expect predictable stress languages to exhibit somewhat reduced cues with respect to the cues present in non-predictable stress languages. Furthermore, since the properties found to undergo reduction in the context of the SSRH (i.e., duration, F0, vowel centralization) are the main properties typically associated with stress cross-linguistically, we may expect reduction of these same properties due to the redundancy introduced by predictable stress in a language. While languages with non-predictable stress require clear acoustic stress cues since the listener cannot know otherwise which syllable of a word is stressed, languages with predictable stress may require less precision in the production of the stress cues since the listener already knows where the stressed syllable is. Figure 3 provides a schematic representation, where the less precise properties in a predictable stress language are informally referred to as "sloppy", in comparison with those in a language with non-predictable stress, referred to as "clear".

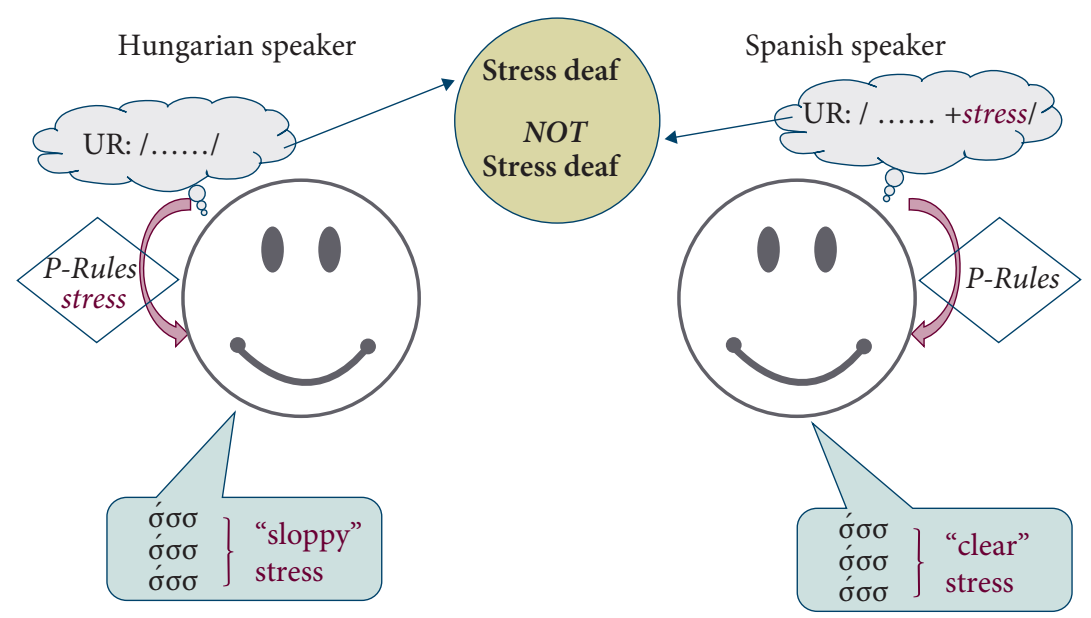

Figure 3. Stress production in predictable and unpredictable stress systems

are available. If we exclude the monosyllables, the number stress exceptions in Polish is quite small, and thus all the more surprising in comparison with Turkish, whose speakers do not show an effect of exceptions on their stress perception. 
Note that in this type of representation, a less precise, or "sloppy" manifestation of the stress cues would be expected to arise in both fixed and quantitysensitive predictable stress languages, even though in the latter (e.g., Arabic), stress appears in different positions in a word. Since this reflects the view that the crucial consideration is just whether or not stress is predictable, the grouping coincides with the distinction made with regard to stress deafness. Nevertheless, consideration of the clarity of speech production suggests that there may be an alternative account, or at least an additional consideration, of the stress deafness observed in predictable stress languages. That is, if stress cues are produced with less precision, and thus more variability, they will not provide consistent, reliable acoustic information for the listener. Thus, when faced with typical stress properties, the listener does not have a clear and consistent constellation of these properties to serve as the basis for the identification of a stress category.

\section{Experimental design: Stress production and analysis}

Hungarian, as an "exemplary" fixed stress language, with no exceptional stress patterns, provides a means of assessing the effect of predictability on the clarity of stress production. The methodology presented is that adopted in a larger crosslinguistic investigation of the acoustic properties of lexical prosody and (narrow) focus. That is, the findings of the other languages considered in relation to those of Hungarian have been collected in the same way, and thus provide a meaningful comparison.

\subsection{Experimental design}

\subsubsection{Hypotheses}

In order to investigate the role of redundancy, specifically predictability, in the production of stress, the following hypotheses are tested.

(1) Hypothesis 1: Predictable stress results in less clear stress cues than nonpredictable stress.

(2) Hypothesis 2: Fixed stress results in less clear stress cues than variable stress.

The first hypothesis predicts that languages with predictable stress, whether fixed or quantity-sensitive, will similarly exhibit weak stress cues. In the present study, this means that Hungarian, as well as Turkish and Arabic, will have a less clear distinction between stressed vs. unstressed vowels, regardless of the nature of the predictability, than Spanish. This would coincide with the grouping of 
languages associated with stress deafness. Hypothesis 2 predicts a slightly different grouping of stress production behaviors, specifically that Hungarian and Turkish will exhibit weak stress cues, but the variable position of stress, regardless of its predictability, will result in a clearer manifestation of stress in Spanish as well as in Arabic. In this case, there would be a difference in the grouping of languages based on production and perception.

Based on the claim that exceptions allow speakers of a fixed stress language to perceive stress somewhat better than speakers of a language without exceptions (Peperkamp et al. 2010), a third hypothesis tests the role of exceptions in the production of stress.

(3) Hypothesis 3: The presence of exceptions in a language with fixed stress results in increased clarity in the stress cues.

That is, while the redundancy of predictable stress generally leads to a reduction of clarity in the acoustic cues, this effect may be somewhat mitigated by the presence of exceptions. Specifically, it is predicted that the manifestation of stress in Hungarian, without any stress exceptions, will be less clear than the manifestation of stress in Turkish.

\subsubsection{Procedure}

The Hungarian corpus, like the corpora for the other languages, was collected on location, by a speaker of the same language variety as the participants, here Debrecen, Madrid, Ankara, and Amman. (See Vogel et al. 2016, 2017 for details.) In all cases, ten speakers (ideally $5 \mathrm{~F}$ ), university students or recent graduates, were recorded reading short dialogues containing the target stimuli, administered on a computer as a PowerPoint presentation. ${ }^{8}$ The target slides alternate with pictures of various objects that the speakers must name, in order to vary the prosodic patterns, and thus encourage more natural readings.

\subsection{Stimuli}

In all of the languages, the stimuli are real, three-syllable, words. Each of the target vowels / i, u, a/, as well as their long versions in Hungarian and Arabic, appeared in open syllables in 10 items in all three syllables with and without stress, where possible. Since Hungarian has fixed initial stress, the comparison was between the first syllable (bolded) with stress, and the second syllable without stress, as illustrated in (4) (cf., Vogel et al. 2015, 2016).

8. The data from one Hungarian speaker were eliminated due to recording problems. 


\section{(4) Sample Stimuli}

a. Short Stressed Vowel

kapatos 'tipsy' fizikus 'physicist' tubusok 'tubes'

b. Long Stressed Vowel ${ }^{9}$

sátoros 'tent dwelling' típusos 'type, adj' kúpokat 'cones, ACC'

Note that the /a, i, u/ in the second syllable of the items in (4a) may also be included in the analysis as tokens of unstressed target vowels. Other items provided long vowels in the second, unstressed syllable.

Each word appeared in two dialogues, one priming focus on the target (Focus Condition), and one priming focus on a subsequent word, and thus removing it from the target (Non-Focus Condition), as shown in (5) for Hungarian; focused items are bolded, and the targets are between quotation marks.

(5) Hungarian Dialogues ${ }^{10}$

a. Focus Condition

Q: Mit mondott Mária reggel?

'What did Mária say in the morning?'

A: Mária a "kapatos" szót mondta reggel.

'Maria said the word "kapatos" in the morning.'

9. In this case, the acute accents follow Hungarian orthography, and indicate long vowels.

10. A reviewer points out that the questions and answers in our dialogues could also be produced with other prosodic patterns, especially given the complexities of Hungarian topic and focus constructions. It is suggested, furthermore, that this possible use of different options may account for the "sloppiness" of the stress manifestation reported here, rather than the more general property of fixed (lexical) stress. Different interpretations are a potential problem in any data elicitation design; however, we take precautions to reduce such prosodic variability to the extent possible, not only in Hungarian, but in all of the languages. Prior to the actual experiment, the participants are given very detailed instructions, including explicit information about how to interpret the different types of questions and answers. The instructions are then followed by practice items, to ensure that the speakers are comfortable with the format and intentions of the dialogues. Since we use only two types of dialogues, it is not difficult for the participants to recognize them, and read them with the intended interpretations as they proceed through the experiment. Moreover, the participants read both the question and answer in each dialogue, to further encourage them to produce the intended interpretations, especially in the answer portions. It must also be borne in mind that the clarity or "sloppiness" of the production patterns reported for Hungarian, and the other languages, are particularly meaningful in relative terms here, since the same methods were used for all of the languages. That is, we find that the cues are weaker in Hungarian (and other fixed stress languages) than they are in languages with non-predictable stress. Thus, the Hungarian findings are consistent with a broader typological pattern, even if there were instances in which the speakers produced some inconsistent prosodic patterns among the 600 target vowels we analyzed. 


\section{b. Non-Focus Condition}

Q: Mária délután mondta azt, hogy "kapatos"?

'Did Maria say "kapatos" in the afternoon?'

A: Nem. Mária a "kapatos" szót reggel mondta, nem délután.

'No. Maria said the word "kapatos" in the morning, not in the afternoon.'

For the present investigation, only the targets in the Non-Focus Condition were considered, since this permits the examination of the properties of stress without the confounding presence of focus properties, a problem encountered in previous studies of stress in many languages.

\subsection{Analyses}

The recordings were annotated manually, and measurements of the vowels were made for duration, (mean) F0, $\Delta \mathrm{F} 0$ (F0 change from the beginning to the end of vowel, calculated as F0 at end minus F0 at beginning), intensity and centralization using Praat. The data were normalized using Z-scores to permit pooling across speakers.

Binary Logistic Regression Analyses (BLRAs) were used to statistically assess the clarity of the manifestation of stress, and the contributions of the individual acoustic properties. First, an Overall classification rate was calculated, using all of the acoustic properties to classify, or distinguish between, two categories of vowels, stressed vs. unstressed. A high Overall percentage of correct classification indicates that stressed and unstressed vowels were produced in ways that are clearly distinguishable, while a low percentage indicates that the distinction is not very clearly or consistently manifested; chance is $50 \%$. Since the initial BLRA includes an indication of which properties contributed significantly to the Overall classification, we also ran follow-up BLRAs using each significant property as the sole classifier in order to assess the strength of its contribution to the stress distinction. Again, a high classification rate means that a clear distinction is being made between stressed and unstressed vowels, indicating that the individual property tested is a strong cue for stress. A low classification rate means that the property is not very salient, and while it may be statistically significant, it is unlikely to be a cue used by a listener; again, $50 \%$ is chance. ${ }^{11}$

11. As a reviewer pointed out, there are acoustic properties other than the ones discussed here that may also contribute to stress. It would certainly be interesting to consider other properties in future research; however, for the present purposes we focus primarily on duration and $\mathrm{F} 0$, since these are the significant properties most consistently returned by the 


\section{Results: Stress properties in Hungarian, and comparison with other languages}

As Table 1 shows, the Overall success rate of the BLRA in distinguishing between stressed and unstressed vowels in Hungarian is very low (59\%). That is, using all of the acoustic measures available, the Overall classification is not much greater than chance. It can also be seen that the only properties that were significant in the classification involve F0: (mean) F0, yielding a $61 \%$ success rate when considered as the sole classifying property, and $\Delta \mathrm{F} 0$, the change in $\mathrm{F} 0$ from the beginning to the end of the vowel, yielding a result barely above chance (Vogel et al. 2016). ${ }^{12}$

Table 1: Hungarian BLRA classification: Stressed vs. unstressed vowels

Hungarian: \pm stress classification (non-focus condition)

\begin{tabular}{ll}
\hline Overall rate & Significant properties \\
\hline $59 \%$ & F0 $(61 \%), \Delta \mathrm{F} 0(56 \%)$ \\
\hline
\end{tabular}

With the Hungarian findings as the basis for comparison with languages with different types of stress systems, we present the BLRA results for the other languages in Table 2: Turkish (fixed stress with exceptions), Arabic (predictable but not fixed stress) and Spanish (non-predictable stress) (Vogel et al. 2016, 2017). (F0 = mean $\mathrm{F} 0, \Delta \mathrm{F} 0=\mathrm{F} 0$ change from beginning to end of vowel, Dur = duration, Int = Intensity, Cent $=$ centralization)

Table 2. Turkish, Arabic, and Spanish BLRA classifications: Stressed vs. unstressed vowels

\pm Stress classification (non-focus condition)

\begin{tabular}{lll}
\hline Language & Overall rate & Significant properties \\
\hline Turkish & $71 \%$ & $\Delta \mathrm{F} 0(64 \%), \mathrm{F} 0(59 \%)$, Int $(58 \%)$, Cent $(55 \%)$ \\
Arabic & $87 \%$ & $\mathrm{~F} 0(88 \%)$, Int $(66 \%), \operatorname{Dur}(59 \%)$ \\
Spanish & $86 \%$ & $\mathrm{~F} 0(82 \%), \Delta \mathrm{F} 0(76 \%)$ \\
\hline
\end{tabular}

BLRAs, not only for the languages discussed here, but also across the other languages in the larger study. These are also the properties most commonly reported to be significant in the manifestation of stress cross-linguistically.

12. See also Vogel et al. (2015) for discussion of additional findings regarding the stress and focus properties of Hungarian. 
As can be seen, there is a considerable difference between the classification rates of Hungarian, with fixed stress and no exceptions, and Spanish, with non-predictable stress: $61 \%$ and $86 \%$, respectively. The other fixed stress language, Turkish (71\%), also shows a considerably weaker stress classification than Spanish; however, it is somewhat stronger than the classification for Hungarian. Although Arabic has predictable stress, and Arabic speakers are stress deaf, our findings show that they nevertheless produce a very strong difference between stressed and unstressed syllables $(87 \%)$, placing them with the Spanish, as opposed to the Hungarian and Turkish speakers.

\section{Discussion: Effects of predictability and exceptions on the production and perception of stress}

The analysis of the production of stress in Hungarian, and the comparison with several languages with different stress systems, reveals that the redundancy of predictable stress does affect the manifestation of stress, but the effect also depends on the nature of the predictability. Thus, Hypothesis 1 is disconfirmed, in that not all of the languages with predictable stress exhibited less clear stress cues than Spanish; only languages with fixed stress (Hungarian and Turkish) had "sloppy" stress cues. This finding instead confirms Hypothesis 2. That is, only languages with fixed stress exhibited reduced clarity, showing that what is crucial for the clear production of stress is the variability of its position, whether this is predictable (quantity-sensitive) or not. Thus, we find a difference between the grouping of languages based on perception, where what matters is only the predictability of stress, and the grouping based on production, where what matters is the appearance of stress in the same position in a word.

Hypothesis 3 is also confirmed since a difference was observed between the rates of distinction between stressed and unstressed vowels in Hungarian and Turkish. That is, the presence of exceptions in Turkish, but not Hungarian, could account for the somewhat clearer stress properties in the former. The issue that remains, however, is the fact that Turkish speakers appear to be as stress deaf as speakers of Hungarian (and French), despite the presence of exceptional stress in Turkish (Altmann 2006).

Thus, with regard to production, the general picture that emerges is that stress predictability does indeed behave like other types of redundant properties, permitting a less clear or reduced manifestation of stress, but only in fixed stress languages (Hungarian and Turkish), not in quantity-sensitive languages (Arabic). A more subtle distinction also emerges among the fixed stress languages, where the presence of exceptions to the fixed stress pattern results in the lessening of the 
redundancy effects on the clarity of stress production. Thus, stress in Hungarian, which lacks exceptions, is the least clearly produced. ${ }^{13}$

Returning to the issue of the representation of a stress property in the Underlying Representations of a language, we observe that the UR appears to play a more consistent role in stress perception than it does in production. This, in turn, suggests that for perception, redundancy may indeed be viewed as economy at the underlying level, with the surface forms manifesting the full set of properties, similar to the type of analysis usually proposed for other predictable phonological properties (i.e., surface allophonic variations). The effect of redundancy on production, however, is observed as an economy (reduction) of acoustic cues, when the stress position is not only predictable, but fixed, and the listener need not rely as heavily on its acoustic properties (Hungarian, Turkish). This is consistent with the reduction of the same acoustic properties seen in a broader context, according to the SSRH. It must be noted that although stress is predictable in Arabic, it may appear on different syllables, making it crucial for listeners to be able to identify its position. Thus, imprecision in production is not permissible, as it is in Hungarian and Turkish.

Finally, let us consider further the role of exceptions in stress perception and production. As noted above, it has been claimed that despite the general predictability of stress in Polish, speakers are only partially stress deaf, since there are also words with exceptional stress in the language (Peperkamp et al. 2010). It was also pointed out, however, that this is somewhat surprising since Turkish has considerably more words with exceptional stress than Polish, yet its speakers are as stress deaf as speakers of French and Hungarian. The Turkish production data, however, offer some support for the position that exceptions may mitigate the effect of fixed stress. That is, in comparison with Hungarian, the acoustic properties of stress in Turkish are somewhat clearer, consistent with the presence of exceptions in the latter but not the former. A similar analysis of stress in Polish would be required to further test the role of fixed stress, with exceptions, in production.

13. At first glance, an alternate account of the difference between Hungarian and Turkish seems possible: the somewhat better classification in Turkish may be due to the fact that stress is word final, and thus subject to additional boundary effects (e.g., final lengthening). Such an account cannot be sustained, however, since (a) final lengthening is not observed in the Turkish stressed vowels, (b) final and (exceptional) penultimate stress are not distinguished from each other on the basis of duration, and c) the two main stress cues in Turkish are the same as those in Hungarian, with relatively similar individual classification rates (i.e., Hungarian: $\mathrm{F} 0=61 \%, \Delta \mathrm{F} 0=56 \%$; Turkish: $\Delta \mathrm{F} 0=64 \%$, F0 $=59 \%$ ). See further details in Athanasopoulou et al. (2017). 
In the meantime, additional insight may be gained from recent investigations using brain imaging techniques. While German speakers, with non-predictable stress, readily detect an incorrectly placed stress regardless of its the location in a word, French speakers do not do so (Schmidt-Kassow et al. 2011; Domahs et al. 2008; Knaus \& Domahs 2007; Knaus et al. 2009). Focusing on the role of exceptions, it was demonstrated that Turkish speakers appear to be sensitive to incorrectly placed stress, but only when the change involves exceptional stress; they do not detect alterations involving the canonical fixed stress in word-final position (Domahs et al. 2012a).

It has been claimed that Polish speakers also show a sensitivity to altered stress position when it involves an exceptional stress, but not the canonical penultimate stress (Domahs et al. 2012b). While this may, in fact, be the case, there is reason to be concerned about the naturalness of the stimuli, and thus the results, since brain imaging picks up responses that are not observable in other ways. Specifically, it is reported that the Polish stimuli were produced by a monolingual speaker of Polish (Domahs et al. 2012b), and it is questionable whether such a speaker would be able to manipulate the position of stress at will, in a natural way. ${ }^{14}$ It has also been found that (Cairene) Arabic speakers show sensitivity to incorrect stress placement in different positions; however, the results are somewhat complex when it comes to different incorrect stress positions. In some cases, it is claimed that the perception reflects foot structure, but in another case, it is suggested that frequency is the crucial consideration (Domahs et al. 2014). Another possibility may be that since the position of stress in Arabic stress is variable, speakers must able to detect its location on any syllable in order to understand a word's meaning. Moreover, as was shown above, the cues to stress in Arabic are quite clear, presumably facilitating its identification, although the sensitivity only shows up in brain imaging studies, but not behavioral studies.

A final consideration is in order with the brain imaging studies. Although they are making claims about the responses to stress, the carriers in which the stimuli they are testing place the stimuli in a position of focus. For instance, the carrier for Polish was: On powinien powiedzieć... wiele razy 'he should say ... many times.' (Domahs et al. 2012b, p. 5). Since focus is known to enhance the properties of the stressed syllable of a word, we must also ask whether stress, without

14. In addition, although F0, duration and intensity measurements are provided to show that the stress patterns in correctly and incorrectly stressed words were the same, it is not clear how accurate these measurements are. That is, different syllable structures were involved in the various items, and in many cases, the segmentations would have presented considerable challenges (e.g., with /1/ in elementarz). 
the enhancement of focus, would yield similar results. (See Athanasopoulou et al. 2017; Vogel et al. 2015, 2016, 2017 for the effects of focus on the production of stressed syllables in the four languages discussed here.)

\section{Conclusions}

The present study has investigated the concept of stress redundancy in terms of both the production (acoustic properties) and perception of stress in Hungarian, a fixed stress language with no exceptions. The Hungarian findings were used as the basis of comparison for languages with different types of stress systems. Given that different types of linguistic predictability have been found to result in somewhat reduced production of several acoustic properties that are also the ones most commonly associated with stress (i.e., F0, duration, vowel centralization), it was expected that lexical stress predictability could result in similar reductions in the manifestation of stress itself.

Indeed, it was demonstrated that the languages considered here with fixed predictable stress, Hungarian and Turkish, showed less clear stress cues than the other languages. The cues in Turkish were somewhat stronger than those in Hungarian, which may be attributed to the presence of stress exceptions in Turkish, such that the stress position is not fully predictable, as it is in Hungarian. In Arabic, although stress is predictable (i.e., quantity-sensitive), the cues were as strong as those in Spanish, with non-predictable stress. Thus, as far as stress production is concerned, it seems that the variability of the stress position is crucial in determining the manifestation of the stress properties, even if the position is predictable.

The production findings were additionally considered in relation to stress perceptibility by speakers of the same languages, in particular, their degree of stress deafness. Differently from production, it is only the predictability of stress that is crucial, whether it is fixed, or variable but quantity-sensitive. Thus, for perception, Arabic speakers behave like the Hungarian and Turkish speakers, all of whom have been found to be stress deaf. Only Spanish speakers, with non-predictable stress, are consistently able to correctly identify the location of stress. It has also been reported that the presence of stress exceptions may mitigate the effects of stress predictability, in that Polish speakers appear to be less stress deaf than French and Turkish speakers. While the potential role of exceptions may account for the difference in the clarity of the stress cues in the production of Hungarian and Turkish, as noted, the role of exceptions in perception remains somewhat unclear, since Turkish has more exceptional stress than Polish, but Turkish speakers do not similarly show an intermediate degree of stress deafness. 
Since stress perception abilities have been associated with the presence or absence of an underlying stress property, the question was raised as to how exceptions might fit into this view. That is, if exceptional stress requires an underlying stress specification, we must ask how this affects the phonological system more generally. The conundrum is that if stress must be available in the UR for some items, it would seem that it should be available for stress perception in general, and thus allow Turkish and Polish speakers to perceive stress as well as Spanish speakers.

Finally, recent brain imaging studies of stress have been considered, which seem to support both the distinction between languages with predictable and nonpredictable stress, and the role of exceptions in stress production. As expected, non-predictable stress allows (German) speakers to detect incorrect stress in any syllable position, while fixed stress results in the inability to detect stress alternations in French speakers. It has also been demonstrated that Turkish speakers respond differently to incorrect stress placement involving exceptional stress, but not the canonical final stress. A similar claim has been made with regard to the exceptional and canonical penultimate stress in Polish, but as was noted above, even if such an effect exists, the results must be questioned in this case since there is reason to believe that the stimuli used in the experiment may not have been natural-sounding. Speakers of Arabic were found to be generally sensitive to incorrect stress placement as well, although different explanations were offered for the perceptibility in different positions. A possible alternative was also suggested, that is, that the variability in stress position, whether predictable or not, is what allows speakers to be sensitive to incorrect stress placement. This would thus align with the difference in production discussed here, where both Spanish and Arabic speakers produce clear stress cues, while Turkish and Hungarian speakers produce less consistent cues. As such, it also makes a different distinction than that made by the behavioral stress deafness studies, where all that seems to matter is whether or not stress is predictable, by fixed position or quantity-sensitivity.

\section{References}

Altmann, H. 2006. The perception and production of second language stress: A cross-linguistic experimental study. PhD Dissertation. University of Delaware.

Aylett, M. \& A. Turk. 2004. The smooth signal redundancy hypothesis: A functional explanation for relationships between redundancy, prosodic prominence, and duration in spontaneous speech. Language and Speech 47(1). 31-56. https://doi.org/10.1177/00238309040470010201

Athanasopoulou, A., I. Vogel \& H. Dolatian. 2017. Acoustic properties of canonical and noncanonical stress in French, Turkish, Armenian and Brazilian Portuguese. Proceedings of Interspeech 2017. Stockholm, Sweden. https://doi.org/10.21437/Interspeech.2017-1514 
Domahs, U., R. Wiese, I. Bornkessel-Schlesewsky, \& M. Schlesewsky. 2008. The processing of German word stress: Evidence for the prosodic hierarchy. Phonology 25. 1-36. https://doi.org/10.1017/S0952675708001383

Domahs, U., S. Genc, J. Knaus, R. Wiese \& B. Kabak. 2012a. Processing (un-) predictable word stress: ERP evidence from Turkish. Language and Cognitive Processes 28(3). 335-354. https://doi.org/10.1080/01690965.2011.634590

Domahs, U., J. Knaus, P. Orzechowska \& R. Wiese. 2012b. Stress "deafness" in a language with fixed word stress: An ERP study on Polish. Frontiers in Psychology 3. 1-15. https://doi.org/10.3389/fpsyg.2012.00439

Domahs, U., J. Knaus, H. El Shanawany \& R. Wiese. 2014. The role of predictability and structure in word stress processing: An ERP study on Cairene Arabic and a cross-linguistic comparison. Frontiers in Psychology 5. 1-18. https://doi.org/10.3389/fpsyg.2014.01151

Dupoux, E., N. Sebastián-Gallés, E. Navarrete \& S. Peperkamp. 2008. Persistent stress "deafness": The case of French learners of Spanish. Cognition 106. 682-706. https://doi.org/10.1016/j.cognition.2007.04.001

Dupoux, E., S. Peperkamp, \& N. Sebastián-Galles. 2001. A robust method to study stress "deafness." The Journal of the Acoustical Society of America 110. 1606-1618. https://doi.org/10.1121/1.1380437

Dupoux, E., C. Pallier, N. Sebastian, \& J. Mehler.1997. A destressing “deafness" in French? Journal of Memory and Language 36. 406-421. https://doi.org/10.1006/jmla.1996.2500

Kabak, B., \& I. Vogel. 2001. The phonological word and stress assignment in Turkish. Phonology 18. 315-360. https://doi.org/10.1017/So952675701004201

Knaus, J., \& U. Domahs. 2009. Experimental evidence for optimal and minimal metrical structure of German word prosody. Lingua 119: 1396-1413.

https://doi.org/10.1016/j.lingua.2008.04.002

Knaus, J., R. Wiese \& U. Janssen. 2007. The processing of word stress: EEG studies on task related components. In Proceedings of the International Congress of Phonetic Sciences, 709-712. Saarbrücken.

Peperkamp, S. \& E. Dupoux. 2002. A typological study of stress “deafness”. In C. Gussenhoven \& N. Warner (eds.), Laboratory Phonology, 203-240. Berlin: de Gruyter

Peperkamp, S., I. Vendelin \& E. Dupoux. 2010. Perception of predictable stress: A cross-linguistic investigation. Journal of Phonetics 38. 422-430.

https://doi.org/10.1016/j.wocn.2010.04.001

Schmidt-Kassow, M., K. Rothermich, M. Schwartze \& S. Kotz. 2011. Did you get the beat? Late proficient French-German learners extract strong-weak patterns in tonal but not in linguistic sequences. Neuroimage 54. 568-576. https://doi.org/10.1016/j.neuroimage.2010.07.062

Turk, A. 2010. Does prosodic constituency signal relative predictability? A smooth signal redundancy hypothesis. Laboratory Phonology 1(2). 227-262. https://doi.org/10.1515/labphon.2010.012

Turnbull, R. 2017. The role of predictability in intonational variability. Language and Speech 60. 123-153. https://doi.org/10.1177/0023830916647079

Vogel, I., A. Athanasopoulou \& N. Pincus. 2015. Acoustic properties of prominence in Hungarian and the functional load hypothesis. In É. Dékány, K. É. Kiss \& B. Surányi (eds.), Approaches to Hungarian. 14, 267-292. Amsterdam: John Benjamins.

https://doi.org/10.1075/atoh.14.11vog 
Vogel, I., A. Athanasopoulou \& N. Pincus. 2016. Prominence, contrast and the functional load hypothesis: An acoustic investigation. In R. Goedemans, J. Heinz \& H. van der Hulst (eds.), Dimensions of phonological stress, 123-167. Cambridge: University Press.

https://doi.org/10.1017/9781316212745.006

Vogel, I., A. Athanasopoulou \& N. Pincus. 2017. Acoustic properties of prominence and foot structure in Arabic. In H. Ouali (ed.), Perspectives on Arabic Linguistics XXIX. Papers from the Annual Symposium on Arabic Linguistics, Milwaukee, Wisconsin, 2015, 55-88. Amsterdam: John Benjamins Publishing Company. https://doi.org/10.1075/sal.5.04vog

Watson, D., J. Arnold \& M. Tanenhaus. 2008. Tic tac toe: Effects of predictability and importance on acoustic prominence in language production. Cognition 106. 1548-1557. https://doi.org/10.1016/j.cognition.2007.06.009 


\title{
(Non-)exhaustivity in focus partitioning across languages
}

\author{
Malte Zimmermann ${ }^{1}$, Joseph P. De Veaugh-Geiss ${ }^{1}$, \\ Swantje Tönnis ${ }^{2} \&$ Edgar Onea $^{2}$ \\ ${ }^{1}$ Universität Potsdam / ${ }^{2}$ Universität Graz
}

We present novel experimental evidence on the availability and the status of exhaustivity inferences with focus partitioning in German, English, and Hungarian. Results suggest that German and English focus-background clefts and Hungarian focus share important properties, (É. Kiss 1998, 1999; Szabolcsi 1994; Percus 1997; Onea \& Beaver 2009). Those constructions are anaphoric devices triggering an existence presupposition. EXH-inferences are not obligatory in such constructions in English, German, or Hungarian, against some previous literature (Percus 1997; Büring \& Križ 2013; É. Kiss 1998), but in line with pragmatic analyses of EXH-inferences in clefts (Horn 1981, 2016; Pollard \& Yasavul 2016). The cross-linguistic differences in the distribution of EXH-inferences are attributed to properties of the Hungarian number marking system.

Keywords: clefts, definite pseudoclefts, Hungarian focus, exhaustivity, experimental evidence, semantics-pragmatics interface

\section{Focus partitioning: A cross-linguistically unified discourse phenomenon}

Well-studied examples of focus partitioning constructions include the English and German focus-background cleft (1) (Horn 1981; Percus 1997; Velleman et al. 2012; Büring \& Križ 2013, i.a.), and the Hungarian preverbal focus construction (2) (Szabolcsi 1981, 1994; Kenesei 1986, 2006; É. Kiss 1987, 1998, 1999; Brody 1990; Onea \& Beaver 2009; Horváth 2010, i.a.) (CAPs = focus accenting).

(1) a. It is MAX who mixed a cocktail.

b. Es ist MAX, der einen Cocktail gemischt hat. 'It is MAX who a cocktail mixed has'

(2) Mari PÉTERT hívta fel.

Mari PÉTER-ACC called PRT

'It was Peter that Mari called up.'

[É. Kiss 1998: 256] 
A common assumption - articulated in Szabolcsi (1981) and É. Kiss $(1998,1999)$ - is that the two construction types share important interpretive properties, irrespective of their different morphosyntactic realization, e.g., existence presuppositions $(\exists$ ) and exhaustivity (EXH) inferences (e.g., Horn 1981; Percus 1997; Kenesei 1986; Szabolcsi 1994).

The interpretive similarities raise the question of what focus partitioning constructions share across languages. Do they constitute a natural class at the level of discourse-structure, with the same (discourse) semantic properties and identical pragmatic effects? And if so, do they also share the same (underlying) morphosyntax, for instance, in the form of a structural position FocP (Brody 1990; É. Kiss 1998)? The second question has been answered affirmatively for Hungarian focus and English clefts in É. Kiss (1998) and for Russian and English clefts in Reeve (2012). In this paper, we will focus instead on the semantic and pragmatic properties of focus-background partitioning across languages. We argue that focus partitioning is a universal structural device for (optionally) expressing information-structural partitioning, but languages may differ in their choice of structural building blocks (Zimmermann 2016). This is stated as H1, with the semantic corollary (3).

H1: Focus partitioning structures form a unified discourse-semantic class of (possibly) structurally heterogeneous constructions.

(3) Focus partitioning exhibits parallel interpretive effects across languages.

H1 predicts focus partitioning structures to behave on a par across languages regarding $\exists$ - and $\mathrm{EXH}$-inferences. Conversely, systematic cross-linguistic differences in the availability of those inferences would constitute evidence against $\mathrm{H} 1$.

This paper reports on the results of a controlled cross-linguistic experimental study of EXH-inferences in focus partitioning in an incremental information retrieval paradigm. The experimental results suggest that EXH-inferences with focus partitioning are indeed parallel across languages. Moreover, our results pertain to the theoretical debate on the nature of EXH-inferences. The latter are commonly taken as a semantic property of focus partitioning; see, e.g., Percus (1997), Krifka (2008), Büring \& Križ (2013) on clefts and Szabolcsi (1981, 1994), É. Kiss (1998), i.a., on Hungarian focus. An opposing view is found in Horn (1981, 2016), Wedgwood et al. (2006), and Onea \& Beaver (2009), who all analyze EXHinferences with focus partitioning as optional pragmatic implicatures. In line with pragmatic analyses, our results suggest that EXH-inferences are neither obligatory with focus-background clefts nor with Hungarian preverbal focus.

To explain our findings, we analyze focus partitioning structures as anaphoric devices with specific discourse-semantic use conditions, which are identical across languages, following ideas in Horn (1981, 2016), Delin (1992), Onea \& 
Beaver (2009), Velleman et al. (2012), Pollard \& Yasavul (2016), De Veaugh-Geiss et al. (2017). We claim that such constructions semantically encode an $\exists$-inference, often explicitly marked by means of givenness or anaphoricity markers (deaccenting, demonstratives, definites, relative markers, etc.). The EXH-inference, by contrast, is not semantically coded, but can be systematically derived from the $\exists$-inference and preceding context depending on how the existential presupposition is resolved. In particular, the presence or absence of EXH-inferences is tied to the QUD or to the nature of the (accommodated) discourse antecedent, which can be indefinite or definite/maximal. Crucially, in our account, the EXH-inference does not involve exhaustifying over focus alternatives, as suggested, e.g., by Velleman et al. (2012).

Section 2 of the paper gives a short overview over the cross-linguistically variable morphosyntax of focus partitioning structures and their invariable discourse anaphoricity, modelled as an $\exists$-inference. Section 3 explains the experimental setup and the logic behind the experiments. Section 4 reports on the results for German and English clefts and introduces our analysis of EXH-inferencing. Section 5 reports on the results for Hungarian preverbal focus, concentrating on similarities and differences to our findings for German and English clefts. We argue that gradual differences in the availability of EXH-inferences with Hungarian preverbal focus follow from differences in the number marking system of Hungarian. Section 6 concludes with an outlook on the importance of background/anaphoricity marking in the analysis of focus-background partitioning.

\section{Focus partitioning: Morphosyntax and interpretation}

Focus partitioning constructions across languages make use of different morphological building blocks, such as pronouns, demonstratives, copulas, relative clauses, focus markers, and different syntactic configurations: some focus partitions involve bi-clausal structures, whereas others involve focus fronting, and some languages require the focus to be in a peripheral clausal position, whereas other make use of a designated focus position. According to É. Kiss (1998: 259), even the seemingly unified strategy of cleft formation in English involves different derivational histories for clefts using the complementizer that or a wh-pronoun.

At least three common strategies for the expression of focus-background partitioning can be identified. Next to focus-background clefts, as in (1a-1b) and (4a) for French, there are demonstrative èto-clefts in Slavic languages (e.g., Junghanns 1997; Kimmelman 2009; Reeve 2012), as in (5a) for Russian, and syntactic focus left dislocation, such as in Hungarian preverbal focus (2) and Akan left-peripheral focus (6a). 
(4) a. C'est $M_{A R C_{F O C}}$ [qui a préparé un cocktail $]_{\mathrm{BG}}$. It's Marc who has prepared a cocktail

b. PRON/DEM COP XP $\mathrm{FOC}_{\mathrm{REL}}\left[\mathrm{CP}_{\mathrm{REG}} \ldots\right]_{\mathrm{BG}}$

[French, Destruel \& De Veaugh-Geiss 2019: 1]

(5) a. Ėto [BORIS vypil vodku].

DEM Boris drank vodka

'It was BORIS who drank the vodka.'

b. DEM $\left[\mathrm{XP}_{\mathrm{FOC}} \cdots\right]$

[Russian, Reeve 2012: 13]

(6) a. sbaai no na me huu noi.

woman DEF FOC I sawher

b. $\left[\mathrm{XP}_{\mathrm{FOC}, \mathrm{i}}\right] \mathrm{FOC}\left[\ldots \mathrm{PRON}_{\mathrm{i}} \ldots\right]$

[Akan, Saah 1994: 102]

Despite their morphosyntactic differences, the three construction types share a number of important properties. First, their central purpose is to separate the focus constituent from the background, typically expressing given or otherwise accessible information. This division facilitates processing and information update, which makes it a (near) universal feature of natural languages.

Second, focus partitioning structures come with an existence presupposition, which is computed over the backgrounded property (Rooth 1996) and leads to discourse-anaphoric interpretation (Geurts \& van der Sandt 2004), and they are not licensed out of the blue (Delin 1992; De Veaugh-Geiss et al. 2017). (7) and (8) illustrate two standard diagnostics for existence presuppositions in clefts. (7) shows that clefts do not license negative quantifiers in focus position. This is because the asserted meaning of the cleft (nobody won) would contradict the presupposition $\exists z\left[\right.$ won $\left.^{\prime}(z)\right]$. As shown by the contrast between the infelicitous cleft in $(8 \mathrm{~A})$ and the felicitous canonical structure in $\left(8 \mathrm{~A}^{\prime}\right)$ (Rooth 1996), clefts are illicit in contexts suggesting that nobody has the backgrounded property in question:

(7) Q: Who won the football pool this week?

A: \#It's NOBODY who won it.

(8) Q: Did anyone win the football pool this week?

A: \#Probably not, because it's unlikely that it's MARY who won it, and she's the only person who ever wins.

$\mathrm{A}^{\prime}$ : Probably not, because it's unlikely that MARY won it, and she's the only person who ever wins.

Third, many scholars take EXH-inferences to be a cross-linguistic semantic characteristic of focus partitioning. In order to derive EXH-inferences from such diverse surface structures, É. Kiss (1998) postulates a designated focus projection with an interpretable feature [+exhaustive] in the underlying syntax. However, our experiments indicate that the EXH-inference may not be a cross-linguistically 
robust, systematic interpretive feature of focus. If the EXH-inference is pragmatic in nature, it need not be coded in the syntax of clefts or other focus partitioning structures. Instead, we will suggest that the EXH inference should be derived from the $\exists$-inference in certain cases.

\section{Testing for EXH-inferences in an incremental information retrieval paradigm}

\subsection{Experimental set-up}

We carried out two behavioral experiments each on the availability of the EXHinference with focus partitioning structures in German, English, and Hungarian (total of six experiments). The experiments were conducted in an incremental information retrieval paradigm. Exp. I was a verification task and tested for the existence and the status (in terms of the distinction between at-issue vs. not-atissue inferences; cf. Simons et al. 2010; Tonhauser et al. 2013; Destruel et al. 2015; De Veaugh-Geiss et al. 2015) of the EXH-inference. Exp. II was a falsification task and tested for whether the EXH-inference is semantically coded or not. The two experiments yield information about the source of the EXH-inference as semantic (conventionally-coded) or pragmatic (non-conventionally-coded), and about its robustness or systematicity within and across speakers and trials. The experiments had two measures: Early Response [continue vs. judgment] and Late Response $[ \pm \mathrm{EXH}$-inference in Exp. I and $\pm \mathrm{CAN}$ (onical)-inference in Exp. II]. The factor 'sentence type' had four levels, as illustrated in (9) for German:

(9) a. Es ist MAX\, der einen Cocktail gemischt hat.

CLEFT 'It is MAX who mixed a cocktail.'

b. Derjenige, der einen Cocktail gemischt hat, ist MAX।. DEF.PSE(udocleft) 'The one that mixed a cocktail is MAX.'

c. Nur MAX\ hat einen Cocktail gemischt. 'Only MAX mixed a cocktail.'

d. MAX\ hat einen Cocktail gemischt. 'MAX mixed a cocktail.'

EXCL(usive) prosodic FOCUS

We controlled information structure with auditory stimuli with a falling nuclear pitch accent $(\backslash)$ on the focus constituent and de-accenting on the remainder of the clause. The exhaustification domain was controlled for by making reference to the same four individuals (four roommates) across all conditions and trials. ${ }^{1}$

1. Participants' behavior in the exclusive control condition (see below) clearly shows that the exhaustification domain indeed consisted of this group of four individuals. 
Finally, the experiments aimed at an explicit comparison of the interpretation of focus clefts and definite pseudoclefts, which have been claimed to share the same underlying syntax and interpretation (Percus 1997; see also Büring \& Križ 2013). Thereby, we assumed, following the literature, that definite pseudoclefts are semantically exhaustive. The conditions EXCL(usive) and Focus were included as control conditions to check for the reliability of participants.

The participants saw the target sentences together with a visual display consisting of four covered boxes on a computer screen in a lab. The participants' task was to successively uncover boxes with the computer mouse and to judge the sentence as true or false as soon as sufficient information was available.

The experiments were programmed such that crucial information for determining whether a target sentence was true in Exp. I on its canonical interpretation (no EXH-inference) or false in Exp. II on an exhaustive interpretation always showed in the second box uncovered, irrespective of which particular box was targeted with the mouse. The information in Box 1 was always orthogonal to the question at hand, and the information in Box 3 and Box 4 made the target sentence either true or false on the remaining meaning component (canonical or exhaustive).

Consider the evaluation of the cleft sentence in (10) in Exp. I (verification) after uncovering the second box (Figure 1).

(10) Es ist MAX, der einen Cocktail gemischt hat.

'It is Max that mixed a cocktail.'

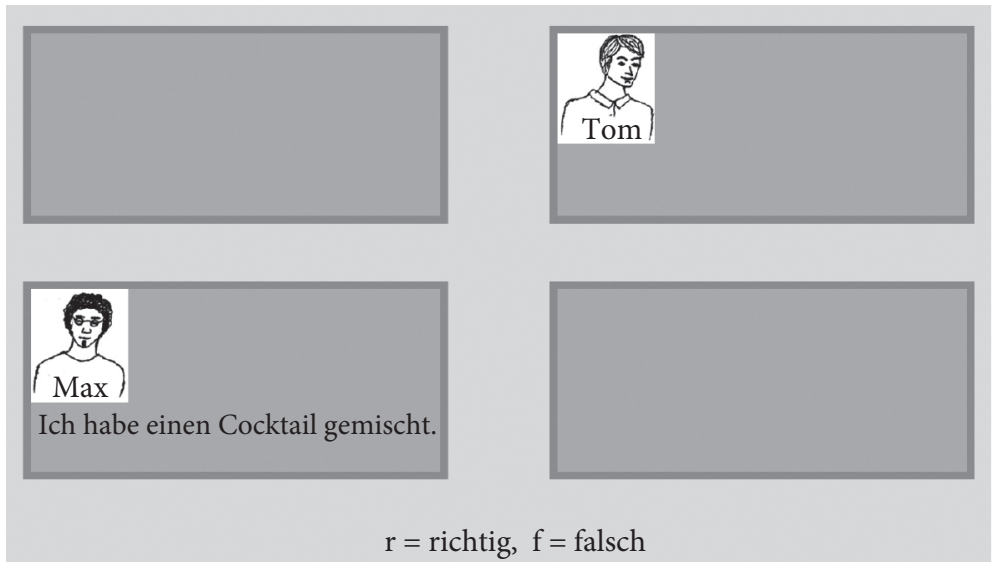

Figure 1. Verification, 2nd box matches canonical inference (Max says: 'I mixed a cocktail')

The logic of the verification experiment is as follows. Consider the canonical inference $p$ of (10), that Max mixed a cocktail, and the EXH-inference $q$, that nobody 
else mixed a cocktail. In Figure 1, $p$ is verified in Box 2, leaving two possibilities: If only $p$ is relevant for assessing the truth of (10), as is the case in the focus control condition, participants should give a true judgment at Box 2 (Early Response) and start with the next trial. However, if both $p$ and $q$ are truth-relevant, as is the case in the exclusive condition with only, participants should continue to Boxes 3 and 4 in order to check for the validity of the EXH-inference (Late Response). While the predictions are clear for the two control conditions, Exp. I aimed at investigating the effect of clefts and definite pseudoclefts.

In the falsification experiment (Exp. II), the reverse situation obtains: the information shown in Box 2 was sufficient for falsifying the EXH-inference $q$, if present. Consider again Figure 2, but with a critical difference: in Exp. II, Box 2 depicted someone other than Max saying that he mixed a cocktail. Consequently, the backgrounded property in question is attributed to a different individual than the subject of (10). The logic of Exp. II is as follows. After uncovering Box 2, participants have two options. If only the canonical inference $p$ (but not the EXH-inference $q$ ) is relevant for assessing the truth of the target sentence, as in the Focus condition, participants should continue to Boxes 3/4 to check for the validity of the CAN(onical)-inference (Late Response), namely, that Max indeed mixed a cocktail $[+\mathrm{CAN}]$; note that in half the trials the canonical meaning was violated $[-\mathrm{CAN}]$ and Max did something other than mix a cocktail at Box 3/4 (see Table 1). By contrast, if both $p$ and in particular $q$, are truth-relevant, as in the EXCL condition, participants should judge the sentence as false at Box 2 and start with the next trial (Early Response). Again, the predictions are clear for the control conditions, whereas the main interest lies in clefts and pseudoclefts.

Table 1 gives a schematic overview of the experimental set-up for Exp. I and Exp. II summing up the conditions obtaining in each box for a trial with target stimulus (10).

Table 1. Overview conditions

Exp. I (verifier) $\quad$ Exp. II (falsifier)

Box $1 \quad$ orthogonal

Jens: 'I opened a bottle.'

Box 2

(Early Response)

Box 3/Box 4

(Late Response) canonical verified

Max: 'I mixed a cocktail.'

[+EXH] exhaustivity supported

Tom/Ben: 'I fetched a straw.

[-EXH] exhaustivity violated

Tom/Ben: 'I mixed a cocktail.' exhaustivity falsified Ben: 'I mixed a cocktail.'

[+CAN] canonical supported

Max: 'I mixed a cocktail.'

[-CAN] canonical violated

Max: 'I fetched a straw'. 
3.2 Theoretical accounts and predictions for clefts and definite pseudoclefts

As indicated in Section 1, there are different theoretical analyses of clefts that differ vastly in empirical predictions when it comes to the robustness of the EXHinference with clefts and Hungarian preverbal focus as well as to the parallels with definite pseudoclefts. The available accounts sub-divide into three classes: (i) pragmatic analyses as in, e.g., Horn $(1981,2016)$ for clefts and Wedgwood et al. (2006) and Onea \& Beaver (2009) for Hungarian preverbal focus; (ii) semantic analyses treating clefts and definite descriptions alike (Percus 1997; Büring \& Križ 2013); (iii) semantic analyses treating clefts as expressing a not-at-issue maximality inference, which is unconnected to definite descriptions (Velleman et al. 2012).

On Horn's (1981) pragmatic account, the use of the structurally marked cleft It is a that BGs, with the existence presupposition (11a) and the canonical meaning $B G(a)$, triggers the pragmatic EXH-inference as a generalized conversational implicature (11b):

$$
\begin{array}{ll}
\text { a. } & \exists z[B G(z)] \\
\text { b. } & \forall x[x \neq a] \rightarrow \neg B G(x)
\end{array}
$$

The pragmatic account does not predict EXH-inferences to be consistent, robust, or systematic across speakers and trials. Moreover, clefts should behave differently from definite pseudoclefts, which - as definites - are commonly taken to trigger a maximality presupposition. ${ }^{2}$

On the semantic definite account in Percus (1997), clefts derive syntactically from definite pseudoclefts; cf. (12). The two construction types trigger a uniqueness/maximality presupposition (13a-13b). The EXH-inference follows from the identificational semantics of (13a) in combination with the maximality presupposition of discourse referent $z .^{3}$

(12) [The one/s who mixed a cocktail] is MAX.

$\Rightarrow$ It is MAX that mixed a cocktail.

(13) a. $\quad$ iz. $[z$ mixed a cocktail $]=$ Max;

b. defined iff there is a maximal $z$, such that $z$ mixed a cocktail.

Parallel analyses of Hungarian focus constructions as presupposition triggers are found in Kenesei (1986) and Szabolcsi (1994). This analysis of focus partitioning

2. But see Heim (1982) and subsequent work for alternative familiarity-based analyses of definite descriptions that do not rely on uniqueness/maximality as part of their meaning.

3. We gloss over known issues the $\iota$-operator encounters with pluralities and assume for expository purposes that $\iota$ incorporates maximality instead of strict uniqueness; cf. Szabolcsi (1994). 
structures as covert definites predicts the EXH-inference of clefts to be robust and systematic. Moreover, it predicts clefts to be semantically parallel to definite pseudoclefts; see also Büring \& Križ (2013).

Finally, the semantic analysis of Velleman et al. (2012) treats focus clefts as the semantic counterpart of exclusive operators, with the (not-)at-issue status of the MIN- and MAX-meaning components exchanged. With clefts, the MIN-inference (John mixed a cocktail) is at-issue (14i), whereas the MAX-inference (Nobody other than John mixed a cocktail) is not-at-issue (14ii). The opposite holds for sentences with exclusive only (Beaver \& Clark 2008).

(14) It is JOHN who mixed a cocktail.

i. at-issue: $\operatorname{MIN}_{\mathrm{QUD}}(\lambda s$. John mixed a cocktail in $s)$

ii. not-at-issue: $\operatorname{MAX}_{\mathrm{QUD}}(\lambda s$. Nobody other than John mixed a cocktail in s)

The MIN/MAX-analysis accounts for the fact that clefts are focus-sensitive and discourse-anaphoric: they provide a maximally informative answer to the current question (because of the MAX-operator). The analysis also predicts the EXH-inference of clefts to be robust and systematic, as long as the QUD does not change. In contrast to the semantic definite analysis, though, it makes no predictions concerning a parallel interpretation of clefts and definite pseudoclefts. Table 2 summarizes the predictions of the three major theoretical approaches to cleft exhaustivity, with 'strength' as short-hand for robustness and systematicity of the EXH-inference across experiments, speakers, and trials.

Table 2. Predictions of major theoretical approaches to cleft exhaustivity.

\begin{tabular}{lll}
\hline & \pm parallel cleft \& def. pseudocleft & \pm strength \\
\hline (a) pragmatic & - & - \\
(b) semantic definite & + & + \\
(c) semantic MIN/MAX & \pm & + \\
\hline
\end{tabular}

\subsection{Procedure}

The experiments were conducted in a lab with 32 participants included in the analysis for each experiment after exclusion of a small number of participants for not being native speakers of the respective language or erratic behavior on exclusive controls (German Exp. I: 8 male, 24 female, mean age 25.4, range 20-48; German Exp. II: 12 male, 20 female, mean age 27.8, range 19-52; Hungarian Exp. I: 9 male, 23 female, mean age 24.2, range 19-40; Hungarian Exp. II: 9 male, 23 female, mean age 30.03, range 19-55; inclusion criteria for English participants, all students at the University of Texas at Austin, were that they were native speakers of American English between the ages of 18 and 50). 
After an introduction to the four roommates constituting the discourse domain, three practice trials were followed by 64 experimental trials. All stimuli were presented auditorily. There were 32 target sentences, corresponding to 8 lexicalizations per sentences type, and 32 fillers. Given language-specific differences, lexicalizations in the stimuli sometimes differed across languages. The targets were distributed over four lists in a Latin square design, yielding a total number of 1024 data points per experiment. All target sentences contained a transitive verb as well as a proper name in subject position and an unspecified indefinite in object position (the latter to prevent unwanted interactions with definiteness). After listening to the stimulus, participants began uncovering the pictures in the boxes until giving a truth-value judgment, after which the next trial started. In order to prevent participants from uncovering all the pictures in one go, there was a built-in time delay of 2000 ms before a new box could be revealed. Participants were free to choose in which order the boxes were uncovered, but the experiments were programmed such that the picture content was presented in the same order irrespective of individual participants' choices. ${ }^{4}$

The experiments delivered two dependent measures: the Early Response (continue vs. judgment) on seeing Box 2, and the Late Response in Box 3 or Box 4 on encountering the relevant information for deciding on whether the EXH- (Exp. I) or the CAN- (Exp. II) inferences hold (i.e., the final truth-value judgment when participants had chosen to continue at Box 2). Same as for the control items, the late measure served as a sanity check for making sure that participants read and understood the sentences correctly. We found that participants were highly consistent on the late response: if they decided to continue at Box 2, they judged the trial true or false as expected based on the still missing piece of information. For this reason, we will disregard late responses in the following.

\section{EXH-inference in German and English clefts: Results and analysis}

\subsection{Results: A first look}

Sample target sentences for the German experiments were shown in (9), repeated below:

4. The procedure and the design of the German experiment are discussed in more detail in De Veaugh-Geiss et al. $(2017,2018)$. The procedure reported there is the same for English and Hungarian here. 
(15) a. Es ist MAX, der einen Cocktail gemischt hat.

CLEFT

b. Derjenige, der einen Cocktail gemischt hat, ist MAX.

DEF.PSE

c. Nur MAX hat einen Cocktail gemischt.

EXCL

d. MAX hat einen Cocktail gemischt.

FOCUS

Averaging over speakers, we obtained the early response patterns shown in Figure 2 , in which the proportions of judgments made at Box 2 are shown graphically (corresponding to 'true' in Exp. I and 'false' in Exp. II). ${ }^{5}$

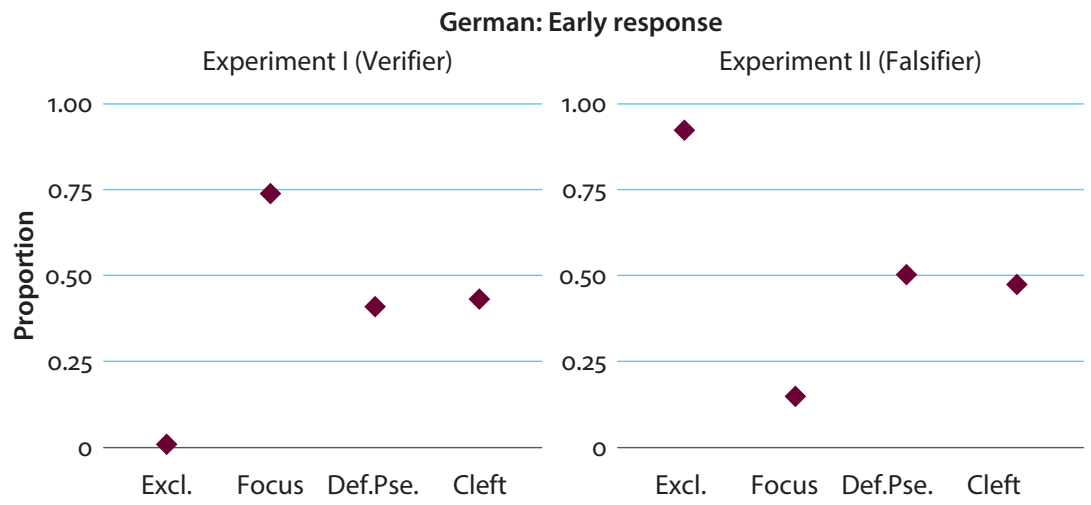

Figure 2. German early responses at Box 2 per sentence type (Exp. I: 'true', Exp. II: 'false')

Both experiments showed little difference between clefts and definite pseudoclefts in the judgments at Box 2 (Exp. I: Clefts $43 \%$ vs. Def.Pse. $41 \%$ 'true' judgments; Exp. II: Clefts $47 \%$ vs. Def.Pse. $50 \%$ 'false' judgments), in line with the semantic definite analysis. Moreover, in the verifying experiment, the exclusive condition almost always elicited 'continue' responses (Exp. I: 1\% 'true' judgments) and the focus condition generally elicited 'true' judgments (Exp. I: 74\%), in line with expectations on these control conditions. Conversely, in the falsifying experiment, the exclusive condition generally elicited 'false' judgments (Exp. II: 92\%) and the focus condition 'continue' responses (Exp. II: 15\% 'false' judgments), again as expected. What is unexpected, though, is the midway exhaustive behavior of both clefts and pseudoclefts, which is unaccounted for on any of the three approaches mentioned above.

Results for the English experiments are largely the same, as shown in Figure 3:

5. Note that occasional errors made at Box 2 ('false' for Exp. I or 'true' for Exp. II, against all logic) were removed from the analysis. Total erroneous judgments per language: German: 3; English: 4; Hungarian: 4. 


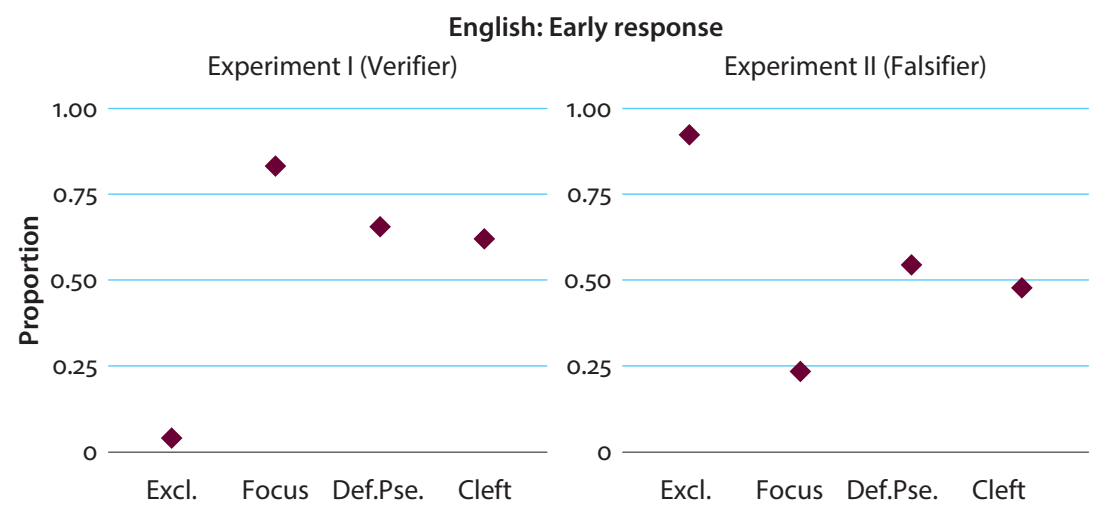

Figure 3. English early responses at Box 2 per sentence type (Exp. I: 'true', Exp. II: 'false')

Clefts and pseudoclefts again patterned alike in verification (Exp. I: Clefts 62\% vs. Def.Pse. $66 \%$ 'true' judgments) and falsification (Exp. II: Clefts $48 \%$ vs. Def. Pse. 55\% 'false' judgments), and elicited midway exhaustive behavior. And again, under verification the exclusive condition almost always elicited 'continue' responses (Exp. I: 4\% 'true' judgments) and the focus condition overall elicited 'true' judgments (Exp. I: 84\%), whereas under falsification the exclusive condition almost always elicited 'false' judgments (Exp. II: 96\%) and the focus condition generally elicited 'continue' responses (Exp. II: 23\% 'false' judgments). Clefts and definite pseudoclefts in English appear to be, at least descriptively, somewhat less exhaustive than their German counterparts, a tendency we will return to below.

\subsection{Post-hoc analysis: Different sub-groups}

A post-hoc analysis of the data reveals the observable midway exhaustivity with clefts and pseudoclefts to come about by averaging over two different participant groups. On closer scrutiny participants divide into two sub-groups, EXH and Non-EXH, where group membership is determined on the basis of participants' interpretive behavior in terms of whether or not a truth-value judgment was made in the cleft-condition in German and English. ${ }^{6}$ Note that members of the EXHgroup chose to make a truth-value judgment $40 \%$ or less times at Box 2 in the verifying experiment (instead choosing to continue a majority of the time to check that exhaustivity holds) and, moreover, they judged the target sentences as 'false'

6. Group membership was based on the number of truth-value judgments made at Box 2 (i.e., 'true' for Exp. I and 'false' for Exp. II) out of the total number of possible judgments per participant after data preparation. We refer the reader to De Veaugh-Geiss et al. (2018: 26) for details regarding German; the description there also applies to English. 
$60 \%$ or more times at Box 2 in the falsifying experiment (choosing not to continue a majority of the time, but rather make a judgment). Members in the Non-EXH group showed the opposite pattern. Note that participants who made truth-value judgments between $40-60 \%$ of the time were categorized as responding at chance. If the responses are sorted according to sub-group, a different picture emerges. As shown in Figure 4, members of the EXH-group treat clefts and pseudoclefts as more exhaustive, more or less like exclusives. Members of the Non-EXH group treat clefts and pseudoclefts as less exhaustive, more or less like prosodic focus. In short, one group shows the expected behavior on pragmatic analyses of EXHinferences, whereas the other shows the expected behavior on semantic analyses of EXH-inferences in focus clefts.

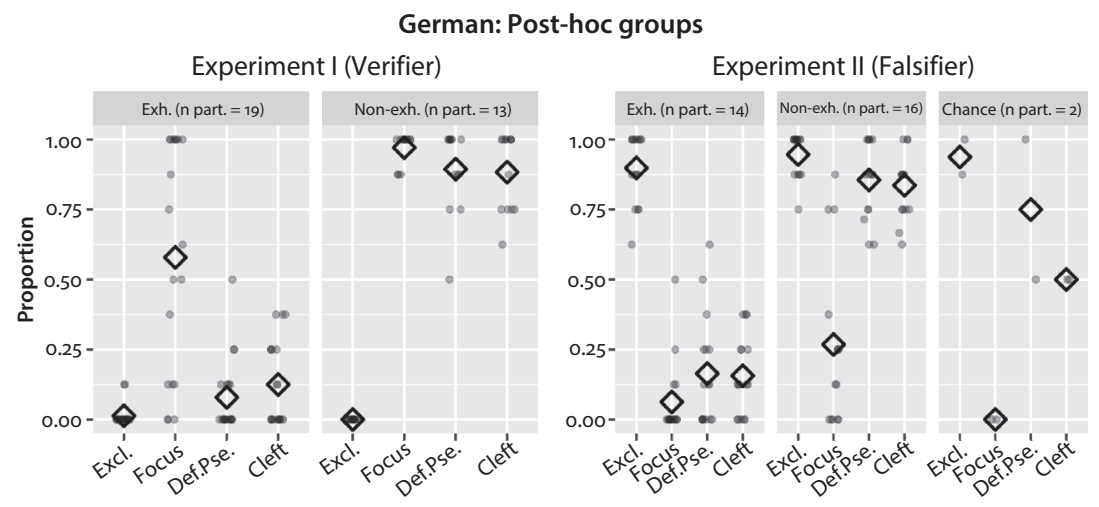

Figure 4. Split results German; large diamonds show proportions per sentence type, small jittered dots show proportions per participant

By and large the same results obtain for the English experiments, with the difference that the Non-EXH-group is larger than the EXH-group in the verifying Exp. I (20:12 as opposed to 13:19 in German). As a result, clefts and pseudoclefts come out as overall less exhaustive in the total results for Exp. I, as shown in Figure 5.

\subsection{Accommodating discourse antecedents (Pollard \& Yasavul 2016)}

Compared to the predictions of the different types of accounts discussed in Table 2, our experiments delivered unexpected results. We found that clefts are indeed parallel to definite pseudoclefts, as predicted by the semantic definite analysis. Contrasting with this analysis, however, the EXH-inference was neither robust nor systematic in either of the two constructions, suggesting a pragmatic approach. In sum, our findings are incompatible with any existing account. 


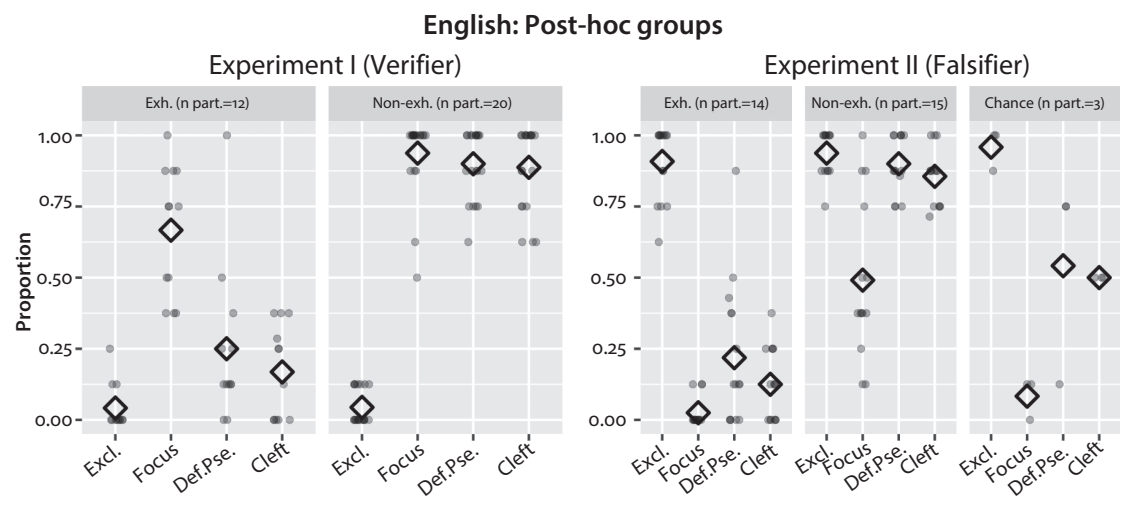

Figure 5. Split results English; large diamonds show proportions per sentence type; small jittered dots show proportions per participant

In order to account for the observations, we postulate that the group-specific variation in the interpretation of clefts and definite pseudoclefts follows from the discourse-anaphoric nature of the two constructions. Recall from Section 2 that clefts are anaphoric in triggering an $\exists$-presupposition on the preceding context, same as definite pseudoclefts. As a result, both constructions are not easily licensed in out-of-the blue utterances. Compare the infelicitous (16a-16b) with the felicitous focus clause in (16c):

(16) a. \#Hey, listen! It was the president that I shook hands with yesterday!

b. \#Hey listen! The one I shook hands with yesterday was the president!

c. Hey listen! I shook hands with the president yesterday.

For concreteness, we adopt the proposal from Pollard \& Yasavul (2016), who argue that EXH-inferences in focus clefts are optional and follow from their discourse anaphoricity. The cleft in (16a) triggers the presupposition in (17), to be satisfied by a suitable discourse antecedent in the preceding context.

(17) $\exists x[$ speaker_shook_hands_with' $(x)]$

However, target sentences in the experiments were presented without a preceding context, so participants had two options available for accommodating suitable discourse antecedents (Pollard \& Yasavul 2016): First, they could accommodate a discourse antecedent that is maximal (unique) with respect to the background property, as sketched in (18a). In a question-based discourse analysis (Roberts 2012; Beaver \& Clark 2008), the corresponding QUD would be an identification question (18b). The discourse referent $z$ can be modelled with the Russellian l-operator, and the meaning of the EXH-interpreted cleft is shown in (18c). 
(18) Option I: Maximal antecedent (DEF) $\Rightarrow \mathrm{EXH}$

a. There's a maximal $z$ that danced. It's Carla that danced.

b. QUD: Who's the (maximal) $z$ that danced?/Who danced?

c. $\quad l z[$ danced $(z)]=$ carla

Alternatively, participants could accommodate an indefinite (non-maximal) antecedent, as in (19a). The corresponding QUD would be an open complement question (19b), as suggested by Onea (2016) under the label potential questions, licensed by indefinite antecedents. ${ }^{7}$ The discourse referent can be modelled with the help of a choice function. The meaning of the non-exhaustive cleft is shown in $(19 c)$.

(19) Option II: Non-maximal antecedent (INDEF) $\Rightarrow$ non-EXH

a. Somebody danced. It's Carla that danced.

b. QUD: Who was it? / Who danced?

c. $f_{\mathrm{CH}}($ danced $)=$ carla

In sum, the EXH or non-EXH interpretation of German clefts follows from the anaphoric nature of clefts, together with different strategies for accommodating suitable antecedents. The two semantic objects $ı$ [danced $(z)]$ and $f_{C H}$ (danced) stand for two possible discourse antecedents that participants can accommodate in the absence of context. The two objects may be modelled as possible referents for the cleft pronoun it/es, if this pronoun is referential; see Reeve (2012). Depending on whether participants choose a definite/maximal or an indefinite discourse antecedent, clefts will get an EXH- or a Non-EXH-reading. The EXH-inference in clefts is a pragmatic inference (Horn 1981), but it has nothing to do with exhaustification of focus alternatives or with scalar implicatures computed over focus alternatives, pace De Veaugh-Geiss et al. (2015). Indeed, the MAX-accommodation strategy behind the EXH-inference may be what Horn (1981) had in mind with his generalized conversational implicature, which was tied to the existence presupposition of focus clefts (11a-11b); see also Onea (2019) for discussion of this point.

The analysis proposed for focus clefts carries over to definite pseudoclefts involving the morphologically complex determiner der/die/das-jen-ige thedemonstr-adj' in German and the one in English as in (20), thereby accounting for the parallel behavior of the two construction types.

(20) Diejenige, die getanzt hat, war Carla.

'The one that danced was Carla.'

7. Pollard \& Yasavul (2016) do not explicitly discuss this part, but we see no reason to give up the intuition from Velleman et al. (2012) and others that focus partitioning is a general answering device to the QUD. 
These inherently anaphoric DPs denote familiarity definites in the sense of Schwarz (2009): they refer to the unique/maximal previously mentioned individual $z$ with backgrounded property $P$ :

$$
\left[\left[\text { der/die/das-jen }{ }_{i}-\text { ige }\right]\right]^{g}=\lambda P . ı x .[P(x) \wedge x=g(i)]
$$

Familiarity definites do not refer to the globally unique/maximal individual with property $P$, but rather to the unique salient individual in a given context. In the case of accommodation to non-maximal antecedents, the unique salient individual is the discourse referent introduced by a preceding indefinite expression (Heim 1982; Kamp \& Reyle 1993). In sum, the parallel behavior of focus clefts and definite pseudoclefts does not follow from the presence of a Russelian definiteness operator (Percus 1997; Büring \& Križ 2013), but rather from their anaphoric nature as familiarity definites. Familiarity is compatible with EXH- and Non-EXH-readings alike.

\section{Hungarian preverbal focus: Results and analysis}

In order to compare the interpretive behavior of focus clefts regarding the EXHinference with that of preverbal focus constructions in Hungarian, we also conducted the above two experiments on Hungarian. The four different stimuli types are shown in (22). Sentences (22a-22b) are the closest Hungarian counterparts to focus clefts and definite pseudoclefts, respectively. What sets Hungarian apart is that there is no plain prosodic alternative to structural focusing in Hungarian, only preverbal focus as in (22d). Consequently, there is no real control structure with a clearly non-exhaustive interpretation.
a. Tamás
$a z$
$a k i$
felvett egy
pulóvert.
Tamas that REL on.put a pullover
'Tamás is the one that put on a pullover.'
(biclausal) CLEFT
b. Az, aki felvett egy pulóvert, az Tamás.
that REL on.put a pullover that Tamás
'The one that put on a pullover is Tamás.'
DEF.PSE
c. Csak Tamás vett fel egy pulóvert.
'Only Tamás put on a pullover.'
EXCLUSIVE
d. Tamás vett fel egy pulóvert.
'Tamás put on a pullover.'
(preverbal) FOCUS

Figure 6 shows the results for the verification and falsification experiments. 


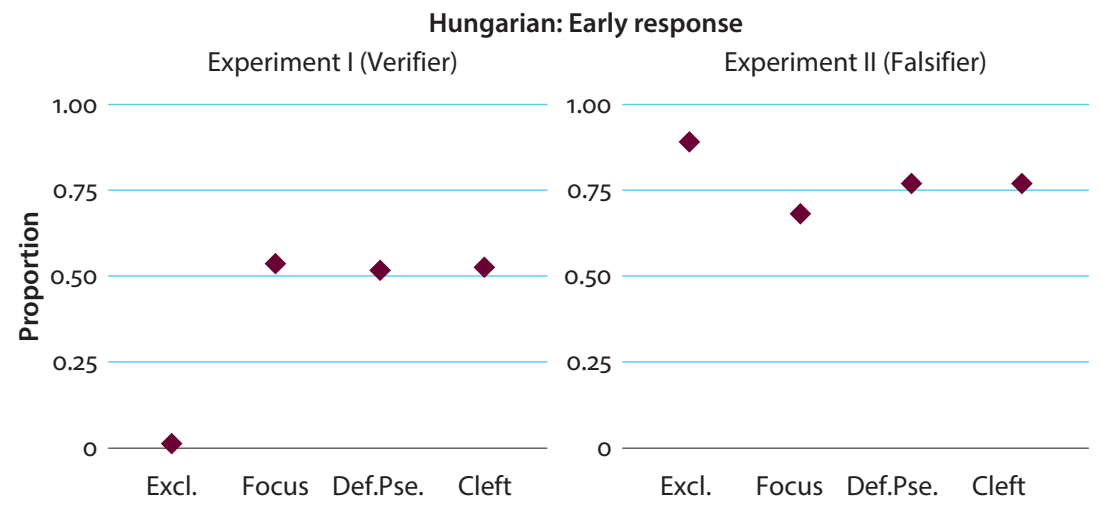

Figure 6. Hungarian early responses at Box 2 per sentence type (Exp. I: 'true', Exp. II: 'false')

The Hungarian results differ slightly from those observed for German and English. In particular, there is no clearly non-exhaustive structure eliciting a majority of 'true' judgments (Exp. I: preverbal Focus 54\%, biclausal Cleft 53\%, and Def.Pse. 52\% 'true' judgments; Exclusives 1\% 'true' judgments). Furthermore, the EXHinference is quite robust with the preverbal focus construction under falsification, generally eliciting 'false' judgments (Exp. II: preverbal Focus 68\% 'false' judgments; cf. biclausal Cleft 77\%, Def.Pse. 77\%, and Exclusive 89\% 'false' judgments). At the same time, there are parallels: the results for the exclusive condition pattern with the English and German results, and the EXH-inference with preverbal focus is available to some extent, giving rise to midway exhaustivity under verification. In line with Szabolcsi (1994), among others, preverbal focus constructions differ systematically in interpretation from sentences with exclusives. At the same time, contrasting with previous literature (see specifically Horváth 2010) but in line with our findings for German and English clefts, the EXH-inference is neither systematic nor robust across participants and experiments. This is evidenced by the results for members of EXH- and Non-EXH-group, respectively. Under verification, in Figure 7, the two groups - for Hungarian determined by participant behavior in the preverbal focus condition - are of even size (16 EXH; 16 Non$\mathrm{EXH}$ ), showing that the EXH-inference is not mandatory with Hungarian preverbal focus, at least under verification.

Summing up, Hungarian is the only language of the three with no mirror results in the two experiments. There is a rather robust EXH-inference with focus, clefts, and definites under falsification, with the Non-EXH group being rather small (6 participants). Finally, whereas Hungarian preverbal focus behaves on a par with Hungarian bi-clausal clefts (as often postulated in cross-linguistic 


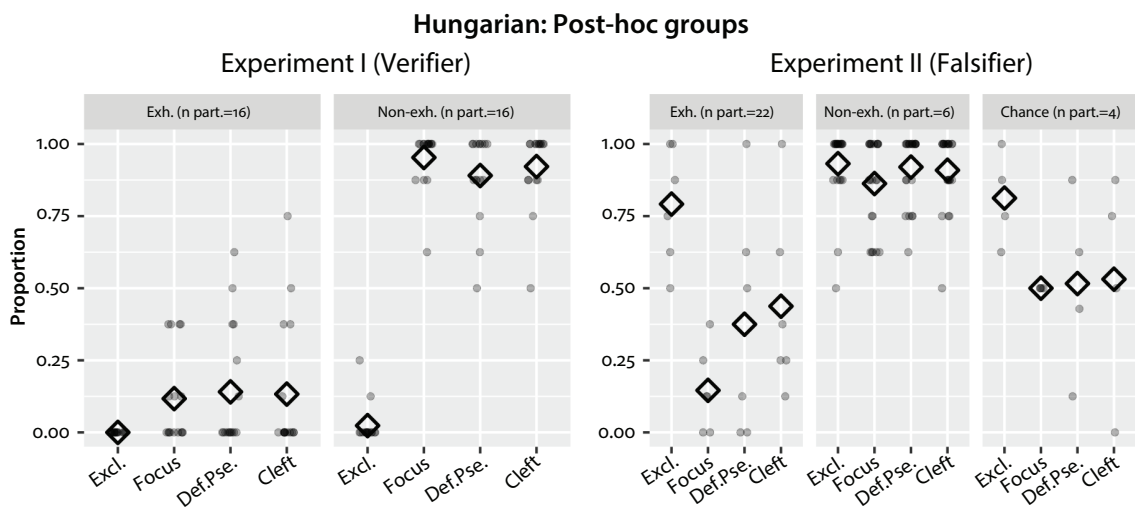

Figure 7. Split results Hungarian; large diamonds show proportions per sentence type; small jittered dots show proportions per participant

comparison; see É. Kiss 1998), it behaves slightly different from its English and German counterparts.

This leaves us with three possibilities for explaining the more robust EXH-interpretation under falsification. First, the effect may be an experimental artifact. There was no clear Non-EXH-condition in the Hungarian experiments, so participants may develop a bias for EXH-interpretations; still, this would leave open why there is a difference between verification and falsification tasks. Second, Hungarian preverbal focus might be semantically exhaustive, but at the not-at-issue layer of meaning. As a result, exhaustivity may be readily ignored in the verification task (Non-EXH = $16)$, but rarely so in the falsification task (Non-EXH =6) with a more salient EXHinference. This line of reasoning would be compatible with standard analyses of Hungarian focus (e.g., Kenesei 1986; Szabolcsi 1994). What remains open, though, is how this analysis would generalize to definites and definite pseudoclefts.

While we currently lack evidence to reject these possibilities, we would like to entertain a third possibility by pushing for a unified pragmatic analysis of EXH-inferences in focus partitioning in German, English, and Hungarian. On this analysis, focus partitioning structures are not semantically exhaustive in any of the three languages, and the EXH-inference arises by pragmatic reasoning to a maximal (unique) discourse antecedent as before. The only difference lies in the fact that Hungarian speakers preferably accommodate to maximal discourse antecedents when encountering a context-free preverbal focus. Why? Hungarian focus constructions form default answers to wh-questions (Onea \& Beaver 2009; Abrusán 2016), so speakers will try to accommodate a suitable singular QUD - or the corresponding maximal discourse antecedent. Hungarian differs from German and English in that wh-questions in the individual domain are morphologically 
marked for sG $k i / m i$ 'who/what ${ }_{\mathrm{SG}}$ ' vs. PL $k i k / m i k$ 'who/what ${ }_{\mathrm{PL}}$ ' PL-marked whquestions indicate that the backgrounded property holds of a plurality, whereas the SG variant is number-neutral in allowing both SG- and PL-answers. Related to this, the choice of a preverbal focus structure with a SG focus constituent in (23a, 24a) (or its cleft counterpart with sG aki) over the exclusive variant with csak ('only') in (23b, 24b) may trigger the accommodation of a sG wh-question with SG (= maximal) interpretation. As shown in Balogh (2009), the two focusrelated structures have different answer potentials by imposing different felicity constraints on preceding questions. Whereas sentences with csak 'only' + focus are compatible with both sG and PL $w h$-questions (23b, 24b), its plain focus counterpart can only answer SG questions; see (23a) vs. (24a)

$$
\begin{aligned}
& \mathrm{Q}: \quad \mathrm{Ki} \text { ment el Hágá-ba? } \\
& \mathrm{who}_{\mathrm{SG}} \text { went VM Hague-ILL } \\
& \text { 'Who went to The Hague?' }
\end{aligned}
$$

a. AMY ment el Hágába. 'Amy went to The Hague.'

b. Csak AMY ment el Hágába. 'Only Amy went to Hague.'

[Balogh 2009: 108] sG-expectation FOCUS PL-expect. EXCL.

$$
\begin{aligned}
& \text { Q: Kik mentek el Hágá-ba? } \\
& \text { who }_{\text {PL }} \text { went-PL VM Hague-ILL } \\
& \text { 'Who went to The Hague?' } \\
& \text { a. \#AMY ment el Hágába. } \\
& \text { b. Csak AMY ment el Hágába. }
\end{aligned}
$$

Here is a sketch of this type of the hearer's answer-based pragmatic reasoning: (i) speaker used a focus/aki-structure; (ii) focus/aki-structures must answer SG wh-questions; (iii) SG wh-questions are in principle compatible with SG or PL expectations on the answer space, i.e., the discourse antecedent to accommodate; however, (iv) if the speaker wanted to make unambiguous reference to a question with PL expectation on the answer space, she could and should have done so by using the more explicit exclusive structure, which would presuppose a plural expectation, for the maximal/definite antecedent construal. Alternatively, she could use, e.g., a focus structure with the particle többek között 'among others' for an indefinite construal. With no such discourse particles (Beaver \& Clark 2008), the hearer concludes that the preverbal focus structure constitutes the answer to a SG wh-question with a SG-expectation, Who is the SG $x$ with BG-property $P$ ? Reconstructing this QUD amounts to the accommodation of a unique discourse antecedent by way of the maximal antecedent strategy, thereby triggering EXH-inferences. 
Finally, judging from the quantitatively different speaker behavior in the verification and falsification tasks, it appears that in the verification task it is sufficient for many speakers that the accommodated maximal individual has the background property in Box 2, whereas others continue to check whether uniqueness/maximality is satisfied. In falsification, by contrast, uniqueness/maximality is violated in Box 2, leading the majority of speakers of the EXH-group to judge the sentence as 'false' due to presupposition failure. The few members of the Non-EXH-group, by contrast, make the utterance felicitous given the content of Box 2 by shifting the interpretation of the accommodated SG wh-question to a plural expectation. The accommodated indefinite antecedent is part of a plurality of individuals with the background property in question, resulting in the absence of an EXH-inference.

There are some open ends to this analysis. First, if our analysis is correct, plural preverbal focus in Hungarian should be about as (non-)exhaustive in our experimental setting as for German or English clefts. This should be tested in future research. Secondly, Hungarian definite constructions also exhibit higher exhaustivity alongside preverbal focus. This appears unexplained by our analysis. Notice, though, that a similar analysis can be produced for Hungarian definite pseudoclefts, which also have singular vs. plural marking on the relative pronoun $(k i / k i-k, a k i / a k i-k)$.

\section{Outlook: Anaphoricity vs. EXH-inferences in focus partitioning}

We have reported on offline behavioral experiments that showed cross-linguistic parallels in the interpretation of focus partitioning structures, in spite of surface morphosyntactic differences. We argued that the parallels follow if focus partitioning structures instantiate a cross-linguistically unified construction type, which is defined by discourse-anaphoricity in the form of an $\exists$-presupposition on the preceding context. We also found that EXH-inferences on the focus domain were neither robust nor systematic in our experiments, which leads us to conclude that EXH-inferences are not semantically coded interpretive properties of focus partitioning across languages. Rather, focus partitioning structures are underspecified for exhaustivity, with the EXH-inference arising when a maximal discourse antecedent is established. It follows that the formal semantic analysis of clefts or Hungarian preverbal focus should not be based on an interpretive feature [+exhaustive], pace É. Kiss (1998) or Horváth (2010). Interestingly, our experiments found the robustness/strength of the EXH-inference with clefts and Hungarian focus to be somewhere midway between exclusives (entailment) and plain focus (conversational implicature), in agreement with most speakers' pretheoretical intuitions and with the divided theoretical landscape. 
Another unifying feature of focus partitioning is that all focus partitioning structures feature formal markers of familiarity or givenness. In German and English clefts, these are the referential pronouns (es/it) and de-accenting (Schwarzschild 1999); and in definite pseudoclefts an overt definite marker. Moreover, there appears to be regular morphosyntactic marking of anaphoricity/familiarity even with Hungarian preverbal focus: there are recent claims that the obligatory verb movement with preverbal focus is indicative of backgrounding/familiarity (Onea 2007: 170; É. Kiss \& Pintér 2014; É. Kiss 2015). In (25a) from Onea (2007), the second clause with verb movement anaphorically refers back to the previously introduced event, whereas (25b) without verb movement introduces a new event.
a. Péter meg-sebesült. Tegnap sebesült meg Péter? Peter PRT.hurt yesterday hurt PRT Peter
'Peter got hurt. Did Peter get hurt YESTERDAY?' $\mathrm{e} 1=\mathrm{e} 2$
b. Péter meg-sebesült. Tegnap meg-sebesült Péter?
Peter PRT.hurt yesterday PRT hurt Peter
'Peter got hurt. Did Peter get hurt YESTERDAY (too)?'

The overall conclusion is that there has been too strong a focus on focus in the theoretical literature of clefts and preverbal focus, which often ignored backgrounding or anaphoricity effects, with the notable exception of Delin (1992). However, it seems that the information-structural category of the background plays at least as important a role in interpretation as focus.

This is in line with traditional insights from functional grammar (Sgall et al. 1986) and functionalist-cognitive approaches (Erteshik-Shir 1997), which assign an anaphoric backward-looking function to the category of background, whereas the focus domain constitutes the forward-looking at-issue core of the information conveyed. Our results are moreover in agreement with formal approaches to Hungarian focus, such as É. Kiss (2015) and É. Kiss \& Pintér (2014: 5), which stress the importance of background: "In fact, the main motivation for the formation of a focus construction can be the need of indicating that the background is presupposed"; they are compatible with the possibility of independent focus and background marking in Ngamo (Grubic 2015), Fulani, and Hausa (Güldemann 2016); and they support Büring's (2016) conceptual shift from focus-driven alternative semantics to background-based Unalternative Semantics.

To conclude: It is the background that matters for semantic interpretation of focus-background partitioning. Focus-background partitions are anaphoric devices with an existence presupposition. EXH-inferences may or may not arise, depending on how the existence presupposition is resolved. 


\section{References}

Abrusán, Márta. 2016. Presupposition cancellation: Explaining the 'soft-hard' trigger distinction. Natural Language Semantics 24. 165-202. https://doi.org/10.1007/s11050-016-9122-7

Balogh, Kata. 2009. Theme with variations. A context-based analysis of focus. $\mathrm{PhD}$ thesis. Universiteit van Amsterdam.

Beaver, David I. \& Brady Z. Clark. 2008. Sense and sensitivity. Oxford: Blackwell. https://doi.org/10.1002/9781444304176

Brody, Michael. 1990. Some remarks on the focus field in Hungarian. UCL Working Papers in Linguistics 2. 201-225.

Büring, Daniel. 2016. Unalternative semantics. In Sarah D’Antonio, Mary Moroney \& Carol Rose Little (eds.), Proceedings of Semantics and Linguistic Theory (SALT) 25. 550-575. https://dx.doi.org/10.3765/salt.v25io.3634

Büring, Daniel \& Manuel Križ. 2013. It's that, and that's it! Exhaustivity and homogeneity presuppositions in clefts (and definites). Semantics and Pragmatics 6(6). 1-29. https://doi.org/10.3765/sp.6.6

Delin, Judy. 1992. Properties of it-cleft presupposition. Journal of Semantics 9. 289-306. https://doi.org/10.1093/jos/9.4.289

Destruel, Emilie \& Joseph P. De Veaugh-Geiss. 2019. (Non-)Exhaustivity in French c'est-Clefts. In Christopher Pinon (ed.), Empirical Issues in Syntax and Semantics 12 (EISS 12). Paris: CSSP. Preview version cited.

Destruel, Emilie, Dan Velleman, Edgar Onea, Dillan Bumford, Jingyang Xue, \& David Beaver. 2015. A cross-linguistic study of the non-at-issueness of exhaustive inferences. In Florian Schwarz (ed.), Experimental perspectives on presuppositions, 135-156. Dordrecht: Springer.

De Veaugh-Geiss, Joseph P., Malte Zimmermann, Edgar Onea \& Anna-Christina Boell. 2015. Contradicting (not-)at-issueness in exclusives and clefts: An empirical study. In Sarah D’Antonio, Mary Moroney \& Carol Rose Little (eds.), Proceedings of Semantics and Linguistic Theory (SALT) 25.373-393. https://doi.org/10.3765/salt.v25io.3054

De Veaugh-Geiss, Joseph P., Swantje Tönnis, Edgar Onea \& Malte Zimmermann. 2017. An experimental investigation of (non-)exhaustivity in es-clefts. In Rob Truswell (ed.), Sinn und Bedeutung 21 (SuB 21). University of Edinburgh.

De Veaugh-Geiss, Joseph P., Swantje Tönnis, Edgar Onea \& Malte Zimmermann. 2018. That's not quite it: An experimental investigation of (non-)exhaustivity in clefts. Semantics \& Pragmatics 11(3). https://doi.org/10.3765/sp.11.3

É. Kiss, Katalin. 1987. Configurationality in Hungarian. Dordrecht: Reidel. https://doi.org/10.1007/978-94-009-3703-1

É. Kiss, Katalin. 1998. Identificational focus versus information focus. Language 74. 245-273. https://doi.org/10.1353/lan.1998.0211

É. Kiss, Katalin. 1999. The English cleft construction as a focus phrase. In Lunella Mereu (ed.), Boundaries of morphology and syntax, 217-229. Amsterdam: Benjamins. https://doi.org/10.1075/cilt.180.14kis

É. Kiss, Katalin. 2015. Grammaticalized backgrounding: Preliminary version of grammaticalized backgrounding. In Johan Brandtler, David Håkansson, Stefan Huber \& Eva Klingvall (eds.), Discourse and grammar: A Festschrift in honor of Valéria Molnár, 193-214. Lund University. 
É. Kiss, Katalin \& Lilla Pinter. 2014. Identificational focus revisited: The issue of exhaustivity. Paper presented at Chicago Linguistic Society (CLS) 50.

Erteschik-Shir, Nomi. 1997. The dynamics of focus structure. Cambridge: Cambridge University Press.

Geurts, Bart \& Rob van der Sandt. 2004. Interpreting focus. Theoretical Linguistics 30. 1-44. https://doi.org/10.1515/thli.2004.005

Grubic, Mira. 2015. Focus and alternative sensitivity in Ngamo (West Chadic). PhD thesis. Universität Potsdam.

Güldemann, Tom. 2016. Maximal backgrounding = focus without (necessary) focus encoding. Studies in Language 40(3). 551-590. https://doi.org/10.1075/sl.40.3.03gul

Heim, Irene. 1982. The semantics of definite and indefinite noun phrases. $\mathrm{PhD}$ thesis. Amherst: University of Massachusetts.

Horn, Laurence R. 1981. Exhaustiveness and the semantics of clefts. In North Eastern Linguistic Society (NELS) 11, 125-142. Amherst: University of Massachusetts.

Horn, Laurence R. 2016. Information structure and the landscape of (non-)at-issue meaning. In Caroline Féry \& Shinichiro Ishihara (eds.), The Oxford handbook of information structure, 108-127. Oxford: Oxford University Press.

Horváth, Julia. 2010. "Discourse-Features", syntactic displacement and the status of contrast. Lingua 120. 1346-1369. https://doi.org/10.1016/j.lingua.2008.07.011

Junghanns, Uwe. 1997. On the so-called èto-cleft construction. In Martina Lindseth \& Steven Franks (eds.), Proceedings of the sixth annual workshop on formal approaches to Slavic linguistics, 166-190. Stanford: CSLI Publications.

Kamp, Hans \& Uwe Reyle. 1993. From discourse to logic. Dordrecht: Kluwer.

Kenesei, István. 1986. On the logic of word order in Hungarian. In Werner Abraham \& Sjaak de Meij (eds.), Topic, focus and configurationality, 143-159. Amsterdam: John Benjamins. https://doi.org/10.1075/la.4.08ken

Kenesei, István. 2006. Focus as identification. In Valéria Molnár \& Susanne Winkler (eds.), The architecture of focus, 137-168. Berlin: Mouton de Gruyter.

https://doi.org/10.1515/9783110922011.137

Kimmelman, Vadim. 2009. On the interpretation of èto in so-called èto-clefts». In Gerhild Zybatow, Uwe Junghanns, Denisa Lenertová \& Petr Biskup (eds.), Studies in formal Slavic phonology, morphology, syntax, semantics and information structure: Proceedings of FDSL 7 , 319-329. Frankfurt: Lang.

Krifka, Manfred. 2008. Basic notions of information structure. Acta Linguistica Hungarica 55. 243-276. https://doi.org/10.1556/ALing.55.2008.3-4.2

Onea, Edgar. 2007. Exhaustivity, focus and incorporation in Hungarian. In Maria Aloni, Paul Dekker \& Floris Roelofsen (eds.), Proceedings of the Sixteenth Amsterdam Colloquium, 169-174. University of Amsterdam.

Onea, Edgar. 2016. Potential questions at the semantics-pragmatics interface. Leiden: Brill. https://doi.org/10.1163/9789004217935

Onea, Edgar. 2019. Exhaustivity in it-clefts. In Chris Cummins \& Napoleon Katsos (eds.), The Oxford handbook of experimental semantics and pragmatics. Oxford University Press.

Onea, Edgar \& David I. Beaver. 2009. Hungarian focus is not exhausted. In Ed Cormany, Satoshi Ito \& David Lutz (eds.), Proceedings of Semantics and Linguistic Theory (SALT) 19. 342-359. https://doi.org/10.3765/salt.v19io.2524 
Percus, Orin. 1997. Prying open the cleft. In Kiyomi Kusumoto (ed.), Proceedings of the North Eastern Linguistic Society (NELS) 27. 337-351.

Pollard, Carl \& Murat Yasavul. 2016. Anaphoric it-clefts: The myth of exhaustivity. Proceedings of the Chicago Linguistic Society (CLS) 50.

Reeve, Matthew. 2012. Clefts and their Relatives. Amsterdam: Benjamins. https://doi.org/10.1075/la.185

Roberts, Craige. 2012. Information structure in discourse: Towards an integrated formal theory of pragmatics. Semantics and Pragmatics 5. 1-69. https://doi.org/10.3765/sp.5.6

Rooth, Mats. 1996. Focus. In Shalom Lappin (ed.), The Handbook of Contemporary Semantic Theory, Oxford: Blackwell. 271-297.

Saah, Kofi Korankye. 1994. Studies in Akan syntax, acquisition, and sentence processing. $\mathrm{PhD}$ thesis, University of Ottawa.

Schwarz, Florian. 2009. Two types of definites in natural language. $\mathrm{PhD}$ thesis, Amherst: University of Massachusetts.

Schwarzschild, Roger. 1999. Givenness, avoidF and other constraints on the placement of accent. Natural Language Semantics 7(2). 141-177. https://doi.org/10.1023/A:1008370902407

Sgall, Petr, Eva Hajičová \& Jarmila Panevová. 1986. The meaning of the sentence in its semantic and pragmatic aspects. Edited by Jacob L. Mey. Dordrecht: Reidel - Prague: Academia.

Simons, Mandy, David Beaver, Judith Tonhauser \& Craige Roberts. 2010. What projects and why. In Nan Li \& David Lutz (eds.), Proceedings of Semantics and Linguistic Theory (SALT) 20. 309-327. https://doi.org/10.3765/salt.v20io.2584

Szabolcsi, Anna. 1981. Compositionality in focus. Folia Linguistica 15. 141-161. https://doi.org/10.1515/flin.1981.15.1-2.141

Szabolcsi, Anna. 1994. All quantifiers are not equal: The case of focus. Acta Linguistica Hungarica 42. 171-187.

Tonhauser, Judith, David Beaver, Craige Roberts \& Mandy Simons. 2013. Towards a taxonomy of projective content. Language 89(1). 66-109. https://doi.org/10.1353/lan.2013.0001

Velleman, Dan, David Beaver, Emilie Destruel, Dylan Bumford, Edgar Onea \& Elizabeth Coppock. 2012. It-clefts are IT (Inquiry Terminating) constructions. In Anca Chereches (ed.), Proceedings of Semantics and Linguistic Theory (SALT) 22. 441-460.

Wedgwood, Daniel, Gergely Peth \& Ronnie Cann. 2006. Hungarian 'focus position' and English it-clefts: The semantic underspecification of 'focus' readings. Ms., University of Edinburgh.

Zimmermann, Malte. 2016. Cross-linguistic variability (and uniformity) in focus-background partitioning. Presentation at KNAW Colloquium 'Language Variation in Action'. Amsterdam, 19 February 2016. 


\section{Index}

A

accommodation 221-222, 225

accusative

adjuncts $167-168,176$

case $165,168-169,176,179$

additive (particles) 26-28,

34-38, 42-44

agreement 165-185, 226-227

indirect agreement 176

long distance

agreement 166, 176

object agreement 165-167, 173-176, 181-182, 184

person agreement 184

ambiguity 20, 117-118

analogy 13,133

anaphor $115-117,119,122,125$, $128,130-133$

anaphoric possessor 115-117, 120, 133-134

antecedent 116-120, 122-125, 127-128, 130-131, 133-134, 139, 148-149, 209, 220-221, 224-226

Arabic 187-189, 193, 195-196, 199-204

articulatory features 56 aspectual adverbials 25, 31 auxiliary 169, 176

\section{B}

backgrounding 227

backness $48,52-55,58,60-62$, 64, 66-69, 97

Bavarian 6 binding (domain) 115-117, 119-122, 129-130, 133-134, 136 breathy (whispery) voice 49, $51,53,55-56,67$

C

cartographic approach 141, 153 center of gravity (COG) 56

clause union 166

cleft sentence 212

clitic $183-184$ coarticulation 50, 53-54, 56, 69

comparative operator $12-13,20$ complementiser $5-8,10-13$,

$15-16,18,20-21$

complex reflexive 116, 125 ,

132-134

concessive $26-27,36-40$, 42-44

continuity topic 141

contrast $74,78,81-82,85-94$

conversational

implicature 214, 221, 226

CP 7, 10, 13, 20, 115

cyclic agreement 176

Czech 49, 140-142, 152-153, 156,182

\section{D}

dative possessor 121 deaccented (deaccenting) 143-145, 156-159

dedicated possessive reflexive $117-120$

definite

article 115-120, 122-125, 127-134

object $165-166,183$

definiteness agreement $165-168,170-174,176-180$, $183-185$

degree equative $6-10,13$, 15-16, 21

discourse

anaphoricity 209, 220

configurational 76,143

discourse-related functional projections 153

doubling 9-10, 12, 20-21

DP 115-135, 167-171, 174-181, 183

duration 49, 52, 58-59, 63, 65-66, 188, 191, 194, 198-199, 201-203

E

economy 12, 14, 53, 123, 190, 201
English 6, 11, 16, 22-23, 25-26, 28-31, 36-37, 39, 41-44, 49, 76-77, 117-119, 161-162, 168, 181, 189-190, 207-209, 211, 215-221, 223-224, 226-227 equative phrase 8

éto-cleft 209 exclusive particles 39 exhaustive interpretation 29 , $78,94,212$ existence presupposition 207, 210, 214, 221, 227

\section{F}

familiarity topic 141-142, 149, $151,154,157$

focus $29-30,33-37,41-42$, 44, 73-82, 88, 92-94, 137, 142-146, 148, 152-157, 159 170, 195, 197-199, 202-203, 207-215, 217-230

double focus 145

focus partitioning 207-211, $214,221,224,226-227$

focus position 29,143 , 209-210

pre-verbal focus $74,76-82$, 87-89, 91-94, 207-209, 214, 222-224, 226-227

French 118, 187, 190, 192-193, 200-204, 209-210

fricative $47,49-51,53$, 55-57, 69

G

German 5-14, 18-21, 25, 29, 34, 38, 41-43, 202, 204, 207, 209, 211, 215-219, 221, 223-224, 226-227

Given-before-New

Generalization 137, 140

givenness 137-153, 155-160, 209, 227 givenness operator

(G-operator) 141, 151-152

gradable adjective 8 
grammaticalisation 11-13, 16,21

\section{H}

harmonic suffix 97, 99, 102, 111 harmonics to noise ratio

(HNR) 48, 55-56

Hindi $25,37,40-44,118$

\section{I}

identification $73-74,78,82,84$, $86,88,92-94,220$

Incremental Information

Retrieval Paradigm 208, 211 infinitival

adjunct 172-176;

clause $166,168,172,176-177$, 179-181, 184

complement 165-169, $176-179,181-182,184-185$

embedding 166

multiple infinitival construction $176-178$

inflected infinitive 174,180 internal argument 181-182, 185 inter-speaker variability 62,64 intervocalic 47-52, 54-56, 60-61, 63-68

intransitive verb 165,167 , 174-175

Italian 118, 141-143, 154, 190-191

J

jaw opening $67-68$

K

Kučerová 140-141, 151-153

L

label change 21

larynx 52-55, 57-58, 67-69

Latin $14-15,17,117-118$

lingual oral model 68

lip rounding 58, 68

locality 100-101, 103-104, 108, $111,165,173-176,184$

logophor $126-128$

\section{M}

marginality 26-27, 31-33, 37, 39,44

matrix clause 5, 7, 10, 19, 121, 130, 178

maximality operator 13,20
Maximize Presupposition 141, 151, 153

morphological complexity 99, $171,181,184$

\section{$\mathbf{N}$}

Nepali 25, 37, 40-44

neutral vowel 98-103, 106, 108, 111-112

noise (noisy quality) 48, $55-56,60,63,65,67$

nominalization 131

non-degree equative 5-8,

$11-13,15-17,19,21$

noun phrase $76,115-116$, 119-121, 123, 147, 152

\section{O}

oblique case $170-171$

Old Hungarian 5, 13-16, 18, 20-21, 37, 41

openness $47-48,52-55,58$, 6o-62, 64, 66-69

\section{$\mathbf{P}$}

perception 187-188, 191-194, 196, 200-204

perceptual-acoustic features 67

personal pronoun 116, 122, 124-125

phase $117,119,130-131,133-134$ phonetic process $48,66,68$

pitch-accent 47-48, 57-58, 61, $66,68,211$

place of articulation 50-51, 54,57

possessor 115-134

possessum 116, 121, 123-124, 131,133

post-pausal 47-50, 54-55, 58, 6o-61, 63, 65-67

post-verbal constituent order 143, 145, 158

domain 138, 143-144, $152-154$

focus $76,145,153-155$

topic position 154

Praat 56, 59-60, 198

preverb $167,175,182-184$

primary reflexive 116,120 ,

125-128, 132-133

pro-drop 120, 123-124, 126,

133,190 production $53-57,67-68,82$, 88, 91-92, 105, 159, 187-188, 190-192, 194-197, 200-201, 203-204

prominence $48-49,52-55,57$,

$77,140,142,156-159,188$

pronoun 116, 118, 121-122,

124-125, 127, 133, 165, 168,

179, 182-183, 190-191, 209,

221, 226-227

prosodic prominence 140,142 , 156-159

pseudoclefts 212-215, 217-222, 224, 226-227

\section{R}

ratio of the voiced part

(RVP) 55, 58

reanalysis $5,7,12-14,18-21$

reciprocal 116, 119, 122, 125,

128-131, 133-134

redundancy $20,187-188$,

190-191, 194-196, 200-201, 203

reflexive 115-121, 125-128,

$132-134,165,181-182,184$

repetitives $26,37,40-41,43$

Russian 117-118, 208-210

S

scrambling 144, 156-157

Serbo-Croatian 118-119

"Smooth Signal Redundancy

Hypothesis" 191

Spanish 118, 187-189, 192-193,

195-196, 199-200, 203-204

stress

fixed 187-189, 192-193,

195-197, 199-203

predictable 187-192,

194-196, 200, 203

quantity-sensitive 188-189,

191, 193, 195, 200, 203

unpredictable 193-194

stress deafness 187-188, 191,

193-196, 203-204

subordinate clause $7-8,11,13$, 19-20, 130

syllable onset $47-48,50,54-55$,

$57,61,65$

syntax-prosody mapping

156-159

T

Thuringian 7

tongue $52-53,55,66-69$ 
Topic position $127,143,154$

topical givenness $146,148,151$, 157-159

topicality $139-141$

transitive verb $85,166,181,216$

transparency 16, 21, 36, 97-100

turbulent

air stream 56

noise 48

Turkish 187-189, 192-196, 199-204

U

unaccusative 130,180 underspecification 190

\section{V}

vacillation $97-98$

Varga 38, 144-145, 151, 155-156

variation $3043-44,74-75,91$,

97, 99, 103, 107, 110, 112, 115,

$120-121,125-127,134,137-138$,

$142,159,169,171-174$,

$184-185,220$

verbal modifier 19,74

vocal folds $50,53,55-56,67$

voice leak 49, 63, 65-66

voiced fraction 55, 59-60, 67 voicelessness 53,56

voicing $47-56,58,60-68,190$

vowel harmony 97,110

vowel quality $48,53-54,61$,

63-64, 66-67, 103

vowel space 68

W

word order $73-77,80,84-85$, $87,89,91-92,94,137-138$, 140-143, 146-151, 153-155, $157-158$ 
This volume contains selected papers from the 13th International Conference on the Structure of Hungarian (Budapest, 2017).

The contributions address current issues in Hungarian linguistics, including comparisons with other languages (e.g., English, German, Turkish, Arabic, Spanish).

Specifically, the phonetics and phonology papers present experimental and corpus studies of $/ \mathrm{h} /$ voicing, the acoustics of Hungarian word stress, and vowel harmony in harmonically mixed stems.

The papers on syntax and semantics discuss object agreement and its locality restrictions, equative markers in German and Hungarian diachronically and synchronically, anaphoric possessor strategies and definite article distribution, and the semantics of various aspectual adverbs. Experimental studies of information structure examine the linear placement of textually given topical constituents post-verbally, exhaustivity inferences with focus partitioning in German, English and Hungarian, and contextual factors licensing Hungarian structural focus.

The broad range of topics ensures that this volume will interest scholars of Hungarian and theoretical linguists more generally.

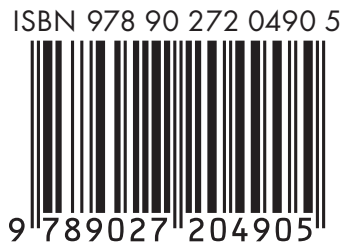

\section{John Benjamins Publishing Company}

